\title{
Identifying Temperature Breaks in the Export Cold Chain of Navel Oranges: A Western Cape Case
}

\author{
Gculisile Khumalo
}

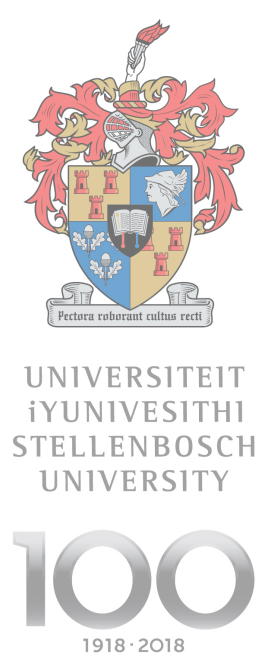

Thesis presented in fulfilment of the requirements for the degree of Master of Commerce (Logistics Management) in the

Faculty of Economics and Management Sciences at Stellenbosch University

Supervisor: Prof L.L. Goedhals-Gerber

March 2018 


\section{Declaration}

By submitting this thesis electronically, I declare that the entirety of the work contained therein is my own, original work, that I am the sole author thereof (save to the extent explicitly otherwise stated), that reproduction and publication thereof by Stellenbosch University will not infringe any third-party rights and that I have not previously in its entirety or in part submitted it for obtaining any qualification.

March 2018

Copyright (C) 2018 Stellenbosch University All rights reserved 


\section{Abstract}

The South African citrus industry contributes significantly to the exportation of fresh fruit annually. South Africa is among the top-ten citrus producing countries in the world and it is the second largest exporter after Spain. There is growing concern in the citrus industry that there are significant breaks in the temperature profiles of the export cold chain of navel oranges to the United States of America. In the citrus export cold chain, one of the most critical functions is to ensure that the quality and conditions of fruit are optimised. Each stage in the cold chain must be conducted reliably and efficiently to reduce the risk of economic losses. The critical factors of the export cold chain that the study explored are temperature protocols and fruit quality as high risks are attached to inefficiencies due to temperature breaks. The United States of America is a steri-market, meaning that navel oranges have to be exported at sub-zero temperatures for phytosanitary purposes. This procedure is known as cold sterilisation treatment. Cold sterilisation treatment commences from the time the fruit consignment has been loaded onto conventional vessels and compartments closed, with all three major temperature probes reading $-0.6^{\circ} \mathrm{C}$ until the port of destination. Steri-market protocols require that fruit be shipped at $-0.6^{\circ} \mathrm{C}$ for a period of 22 days. Steri-markets make use of cold sterilisation treatment to ensure that pests and diseases are not imported along with fruits that arrive at their ports.

Observations were made at fruit farms, pack houses, cold stores and the Port of Cape Town. The observations made clearly depicted that export cold chain protocols are to a large extent followed. To analyse the pulp and ambient temperature of navel oranges, temperature trials were conducted and data received from export organisations was analysed. The data was analysed from the point of harvest (orchard) until the port of destination. From the analysis conducted, it was clear that export cold chain processes were followed, thus, reducing the risks of temperature breaks, which in the cold sterilisation export industry translate to significant income losses due to the rejection of an exported consignment of fruit.

The study was undertaken by Stellenbosch University in conjunction with Company X to help redress the issue of breaks in the export cold chain and improve their fruit quality. The study proved to be a step in the right direction, but it should be noted that further research still needs to be conducted on the export cold chain of fruit under cold sterilisation treatment, as the low temperatures are known to be detrimental to fruit quality, as they tend to cause chilling injury.

Keywords: Citrus fruits; Cold sterilisation treatment protocols; Conventional vessels; Export cold chain; Navel oranges; Temperature breaks. 


\section{Acknowledgements}

I would like to thank the following people for their contribution towards this thesis:

Professor Leila Goedhals-Gerber, the best supervisor a student could ask for. Thank you for your support, kindness, guidance and patience. I appreciate the advice and your feedback throughout the process of completing this study. Thank you for teaching me to believe in myself and my work. Without your guidance, this study would not have been possible.

Dr P. Cronje, I would like to express my sincere gratitude for your guidance and input. Thank you for your assistance and contribution of your immense knowledge on the export cold chain of the citrus industry.

My sincere thanks also go to Professor J.J. Louw who was kind enough to assist and calm me down during my moments of panic with data analysis. Also, many thanks to Prof D Nel who played a big role during the data analysis phase. Thank you for your patience and the advice. My cousin, Dr N.B. Khanyile, thank you for acting as my unofficial supervisor and giving me a push in the right direction. My two Honours students, Amé and Savia, it was a pleasure working with the both of you. To my best friends, Brian Manda and Poloko Ntamehlo, thank you for having faith in me.

Company $\mathrm{X}$, thank you for approaching my supervisor and granting me the opportunity to conduct this research and for the help with data collection. My sincere gratitude to the export company I worked with and the farm owner in Citrusdal.

To my parents, Mr. D.C. and Mrs. S.S. Khumalo, thank you for funding my studies and for supporting me. I dedicate my work to you. Also, my utmost thanks to my siblings, Sihle, Mihla and Zitsile, for always motivating and believing in me. Your support is the most amazing gift you have blessed me with.

Likewise, thank you to the pleasure of music, for being my calm during chaos.

Lastly, to the Lord Almighty. Thank you for the strength, good health and patience you blessed me with. For reminding me, that in your hand lays power, might and infinite possibilities. 


\section{Table of contents}

Declaration i

Abstract .ii

Acknowledgements .iii

Table of contents iv

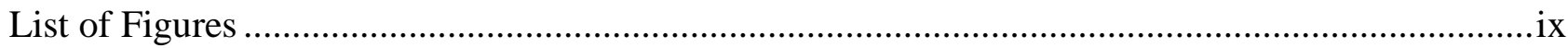

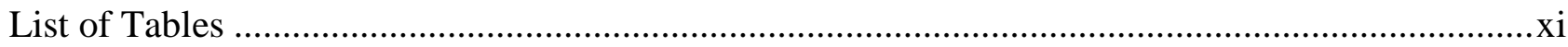

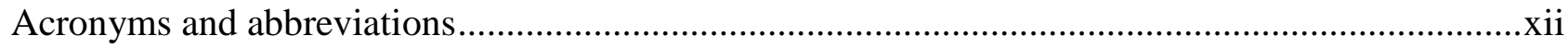

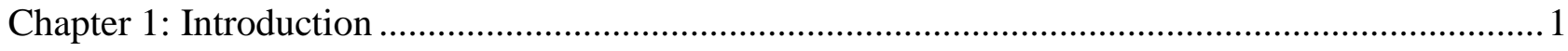

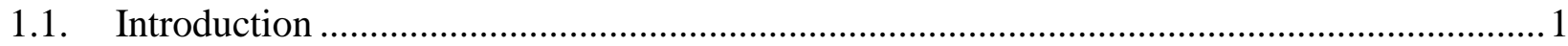

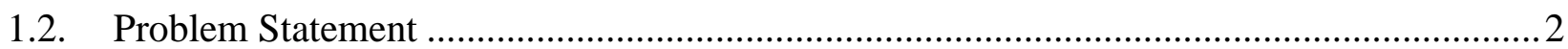

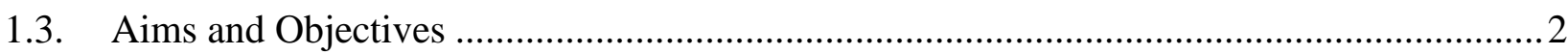

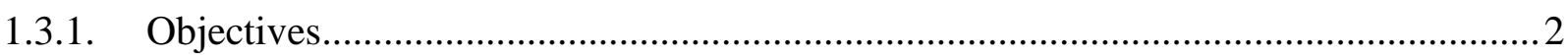

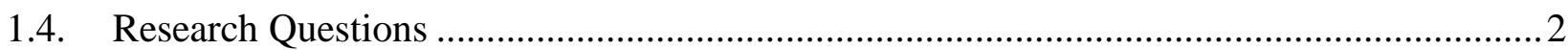

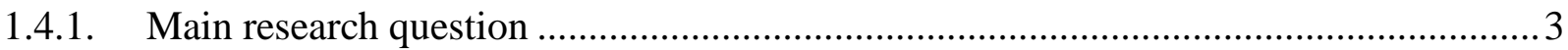

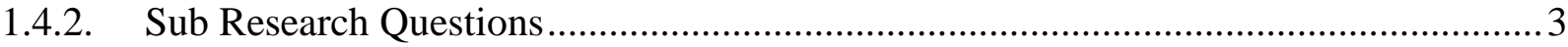

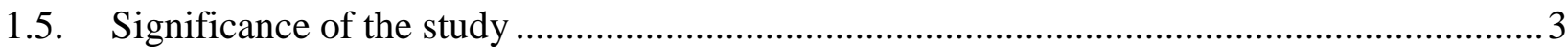

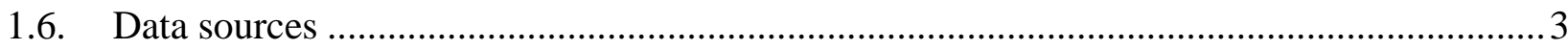

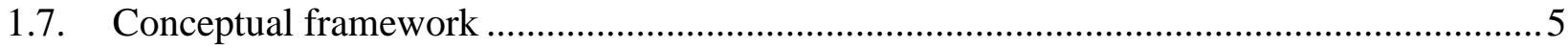

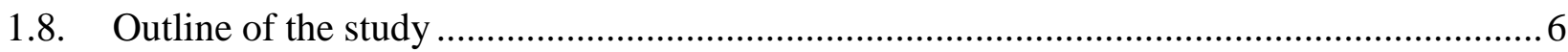

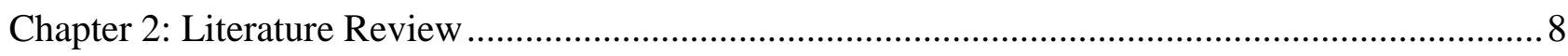

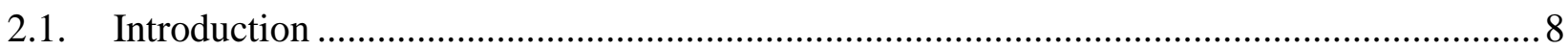

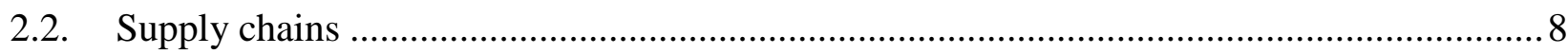

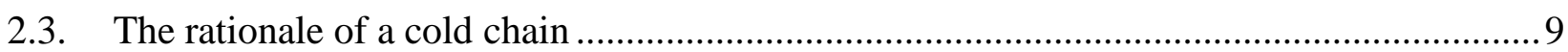

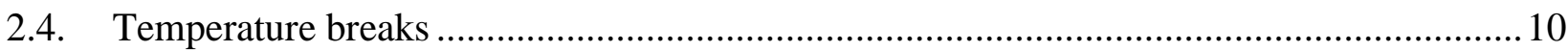

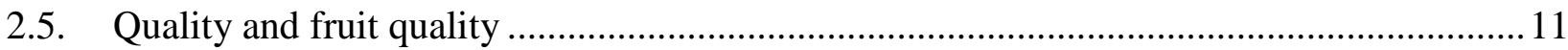




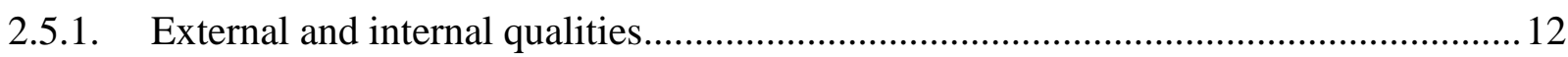

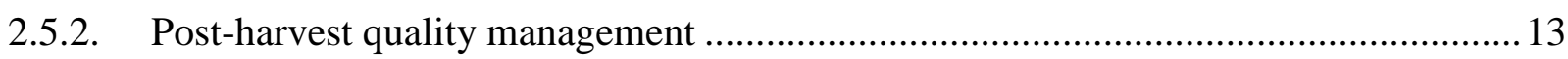

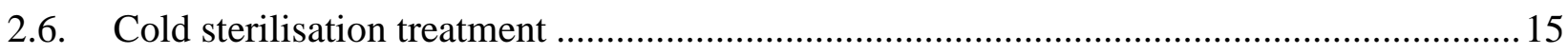

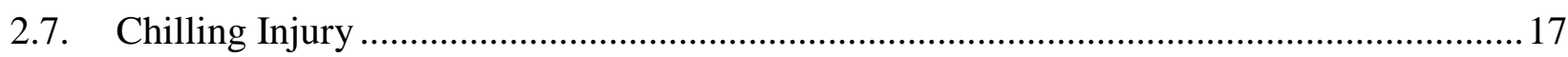

2.8. A discussion of fruit quality factors and their link to temperature .................................... 18

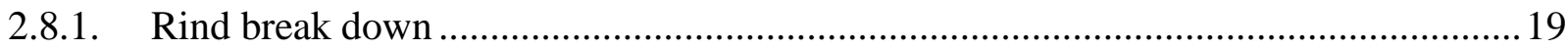

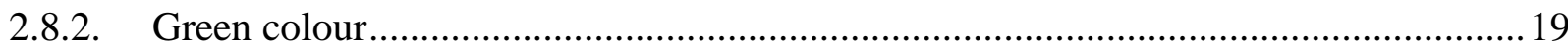

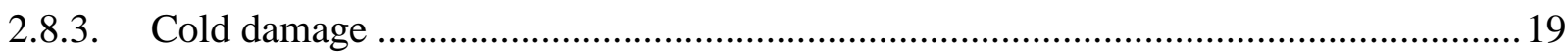

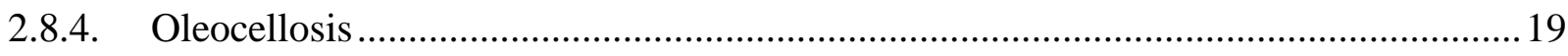

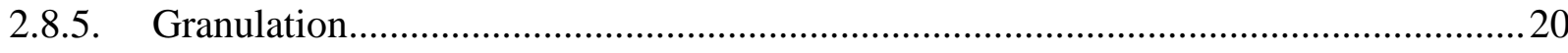

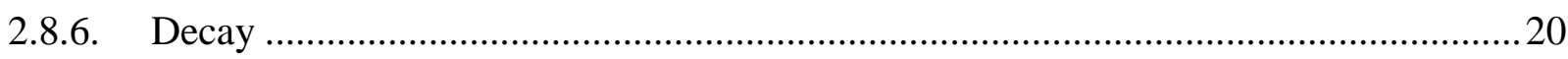

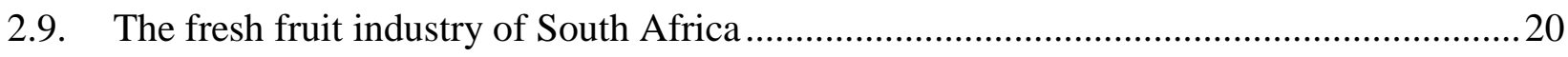

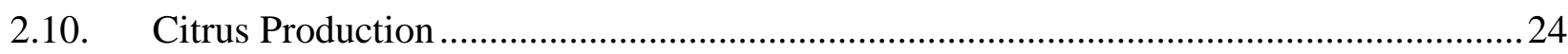

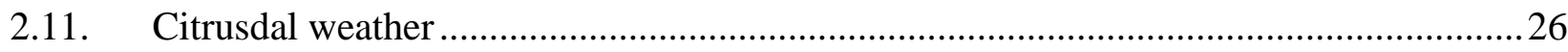

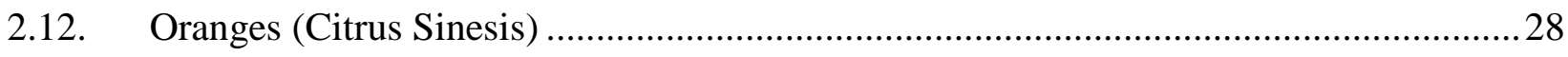

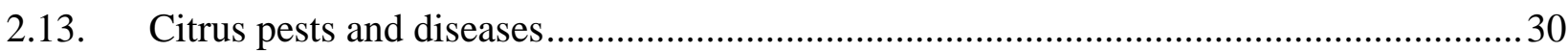

2.13.1. The Mediterranean fruit fly (Ceratitis capitata) .................................................. 31

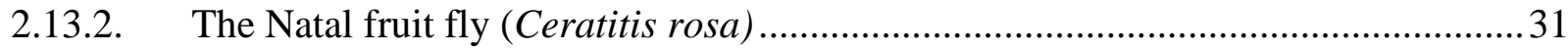

2.13.3. False Codling Moth (Thaumatotibia leucotreta) .................................................. 31

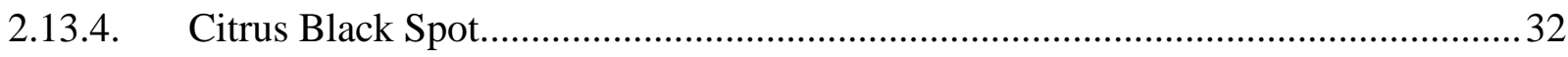

2.14. Regulatory organisations and their roles in the export cold chain............................... 33

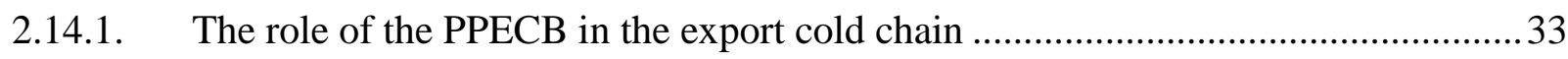

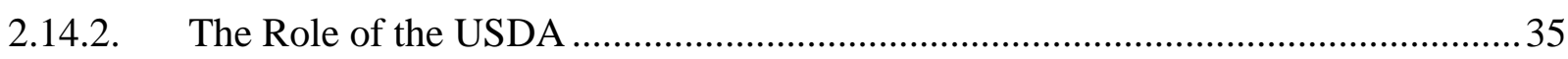

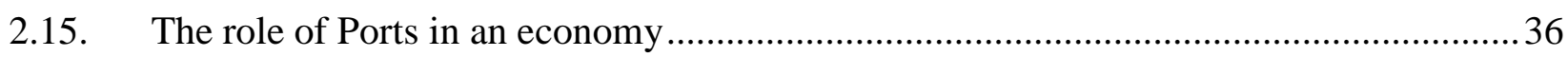

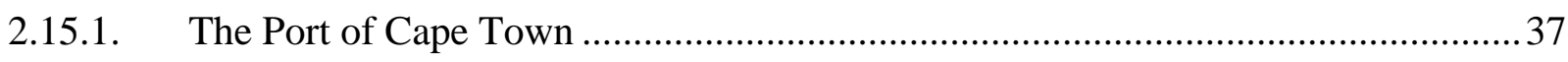

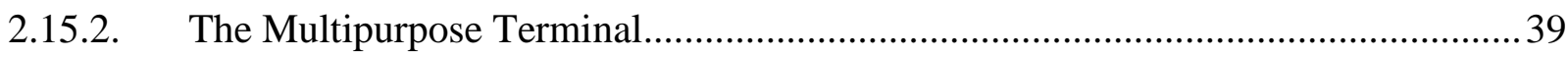

2.15.3. Factors affecting cold chain performance at the Port of Cape Town ...................... 40 
2.16. South Africa's competitiveness compared to other citrus producing and exporting nations

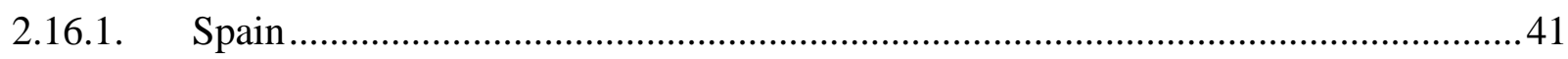

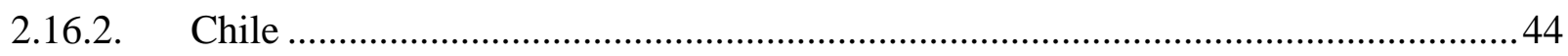

2.16.3. South Africa's competitive strengths and weaknesses......................................... 44

2.17. International cold chain best practices............................................................. 47

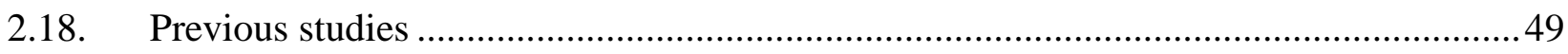

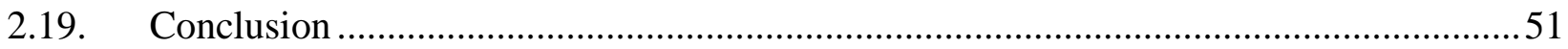

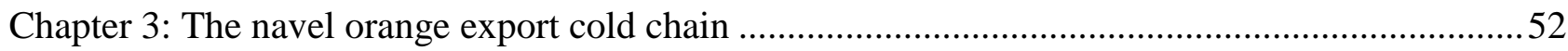

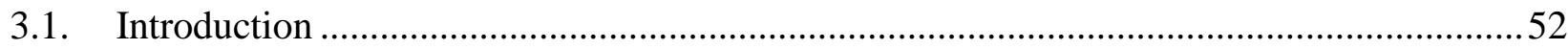

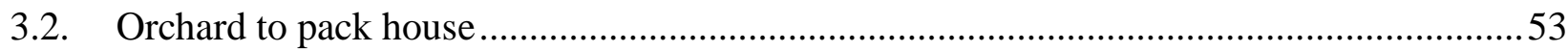

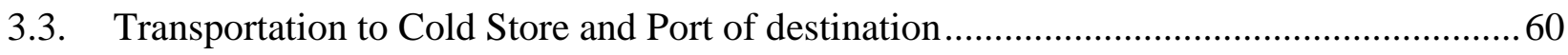

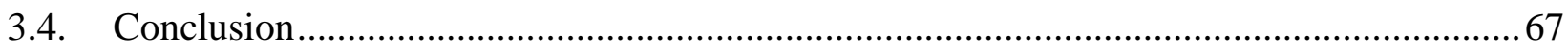

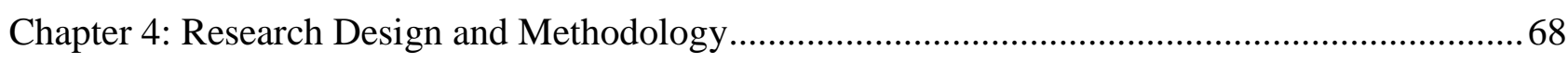

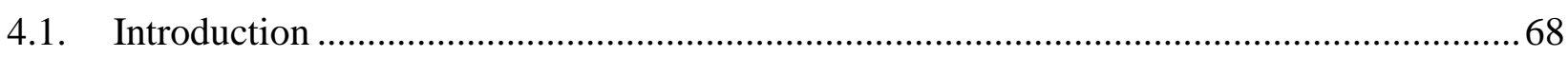

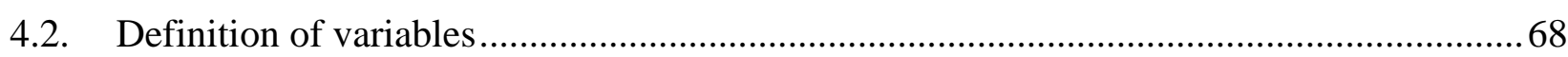

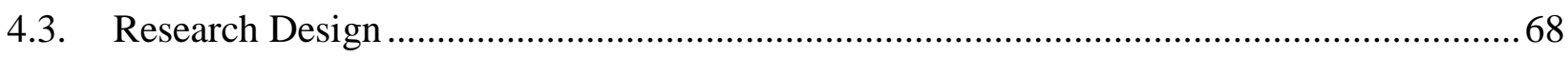

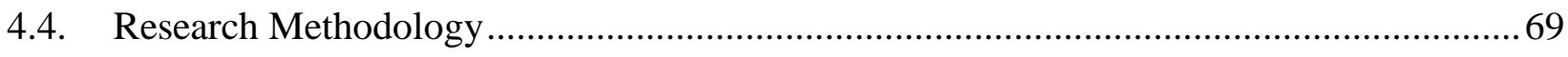

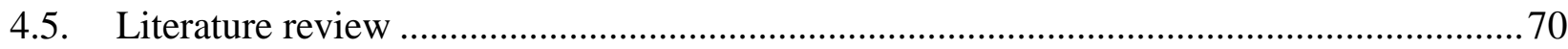

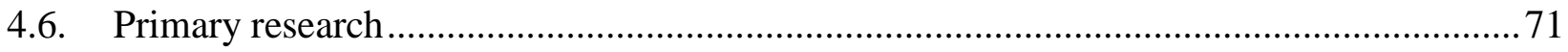

4.6.1. Observations of the navel orange export cold chain .............................................. 72

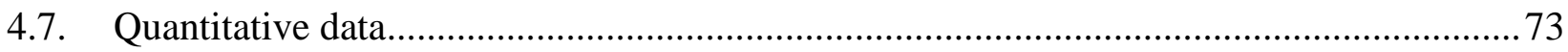

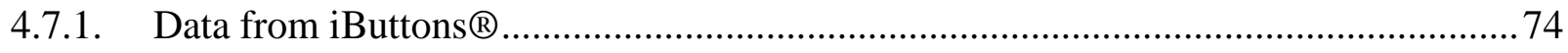

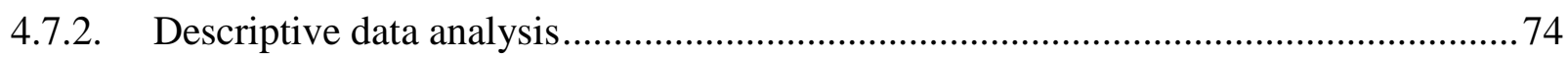

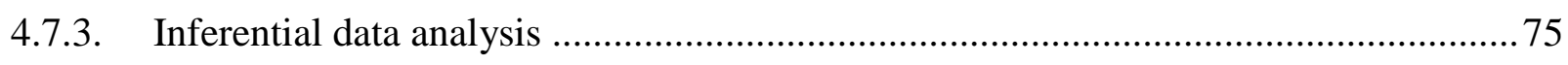

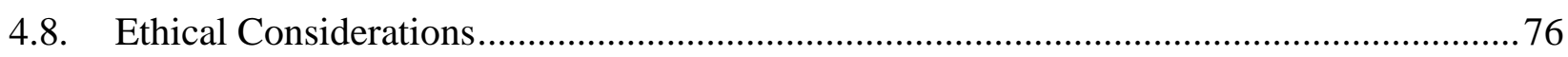

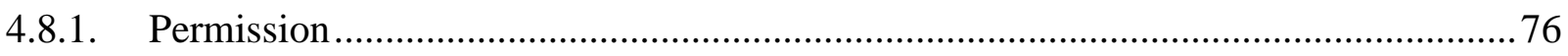




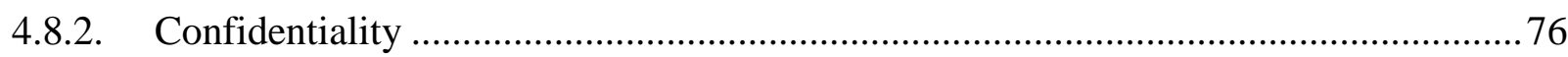

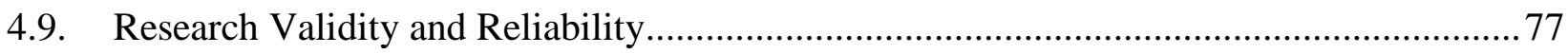

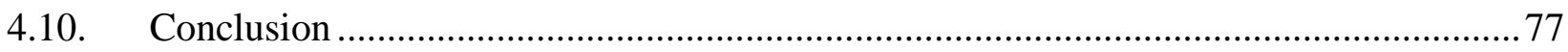

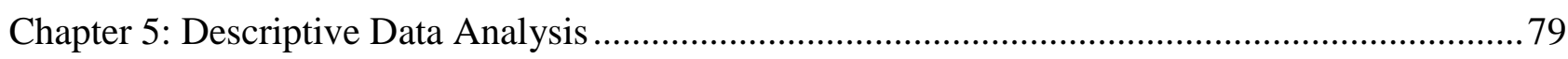

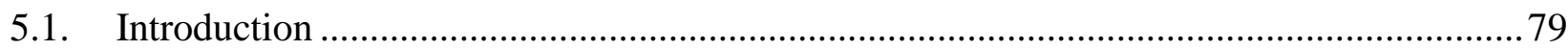

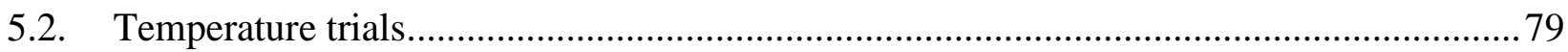

5.3. Descriptive Analysis of Santa Lucia and Regal Bay vessels ........................................ 84

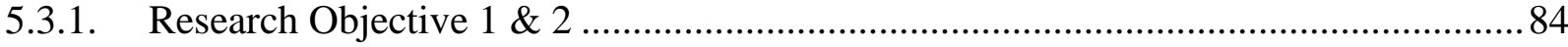

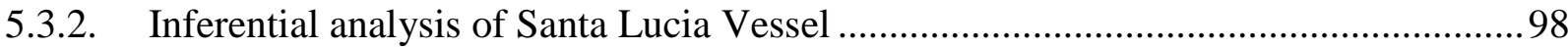

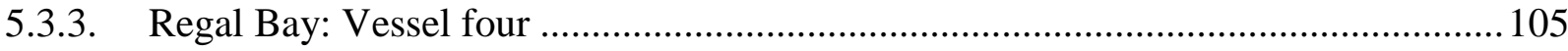

5.3.4. Inferential analysis of Regal Bay vessel ......................................................... 116

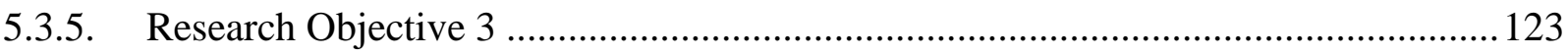

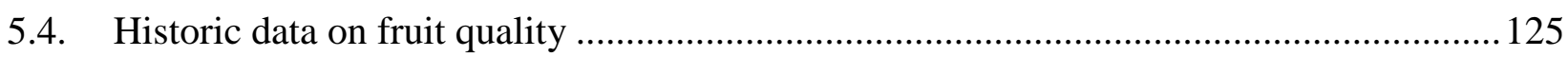

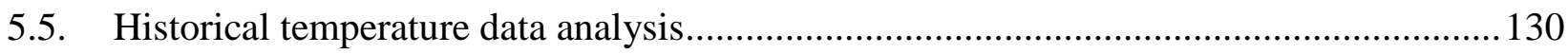

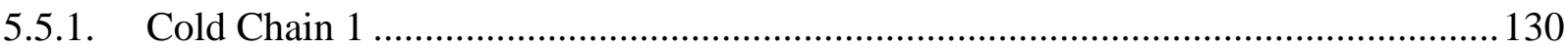

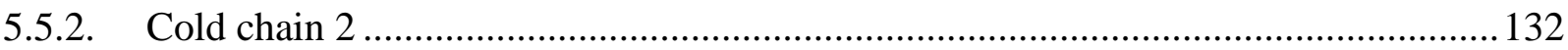

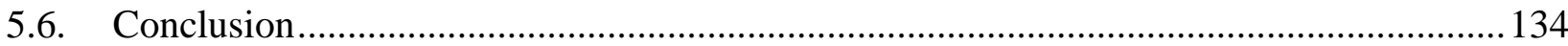

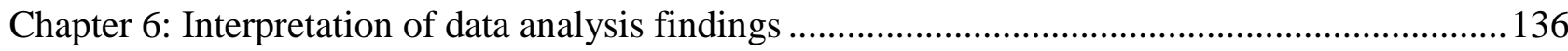

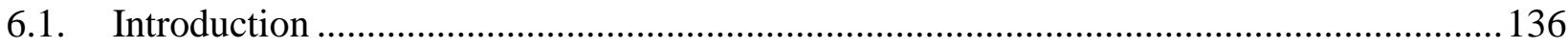

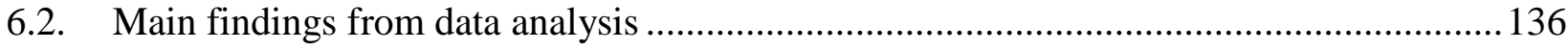

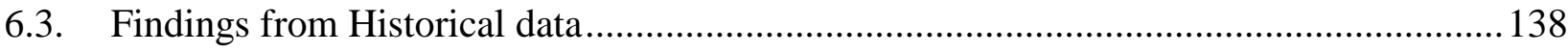

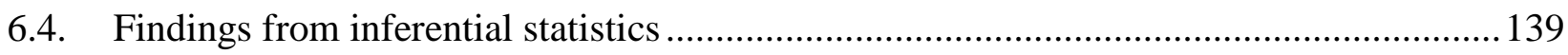

6.5. Discussion of findings for the first research hypothesis........................................... 139

6.6. Possible explanations for the origin of spikes/breaks during drenching, transportation,

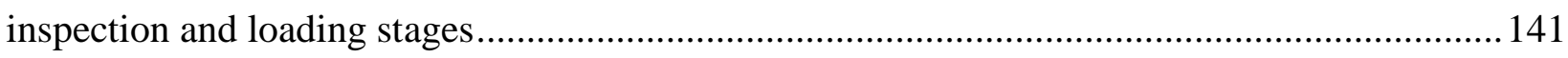

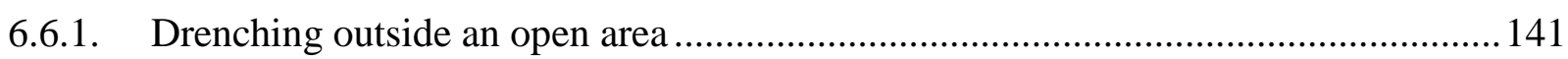

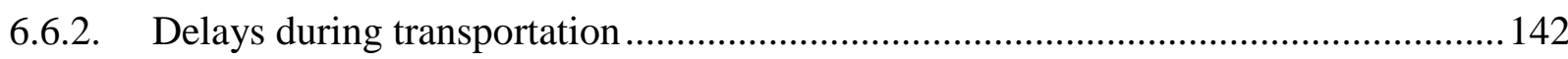




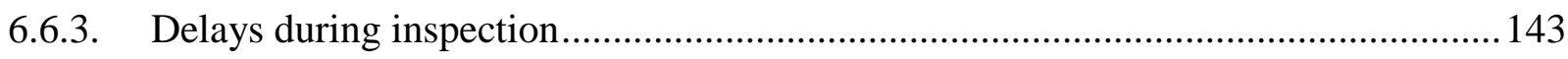

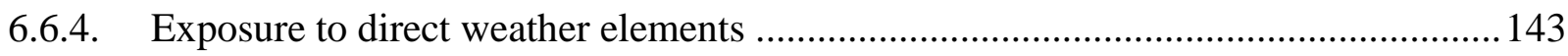

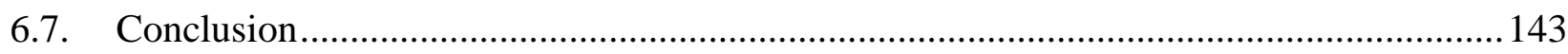

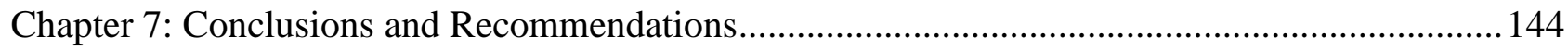

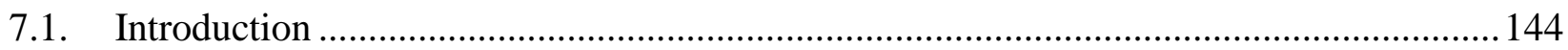

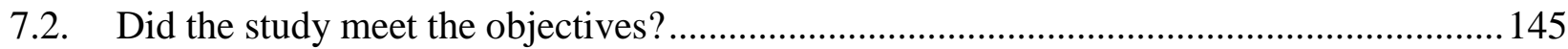

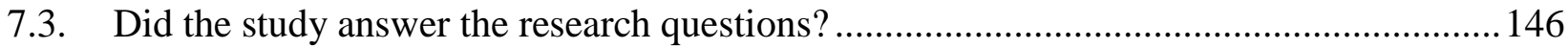

7.3.1. Exploration of good cold chain practice guides developed in previous studies ........147

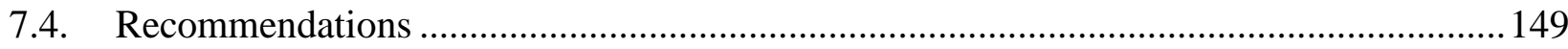

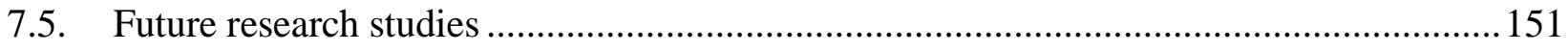

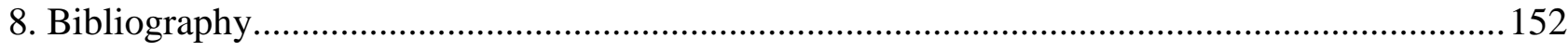

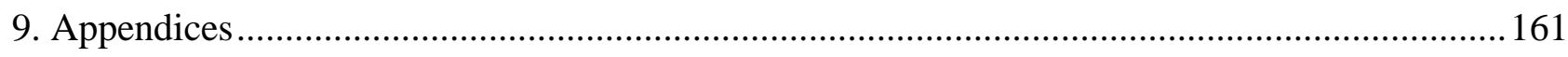




\section{List of Figures}

Figure 1: Conceptual Framework of research study ............................................................ 6

Figure 2: Illustration of where each fruit type is produced in South Africa .................................2 21

Figure 3: The harvesting season of different fruits in South Africa. .............................................2 23

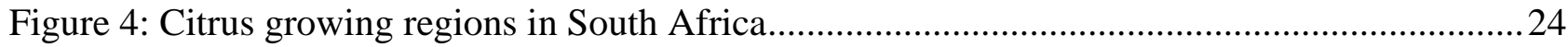

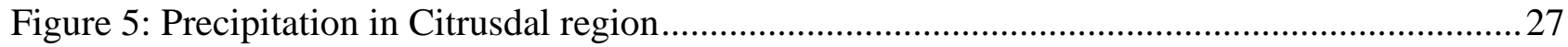

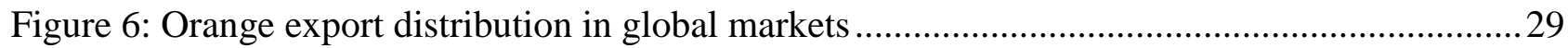

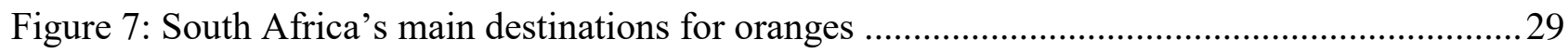

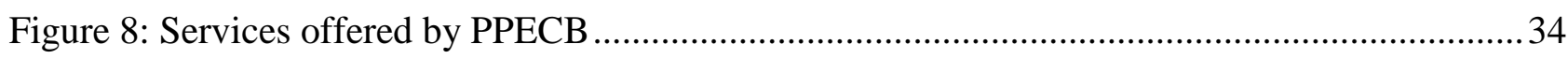

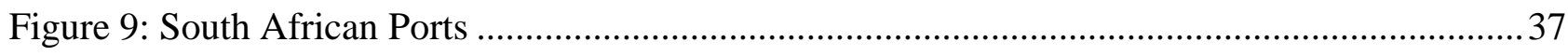

Figure 10: An aerial view of the Port of Cape Town .................................................................... 39

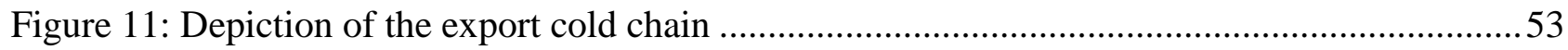

Figure 12: Fruit left for a maximum of 24 hours after drenching .................................................55

Figure 13: Degreening Chamber at Citrusdal Pack house .............................................................57

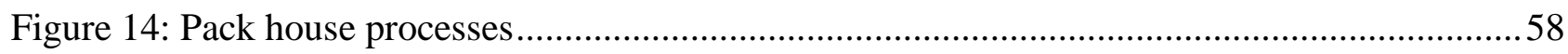

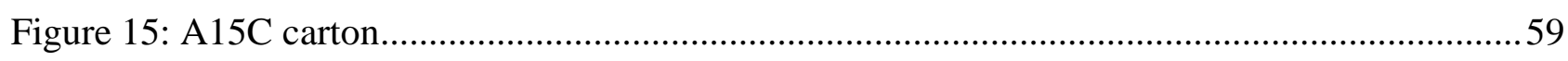

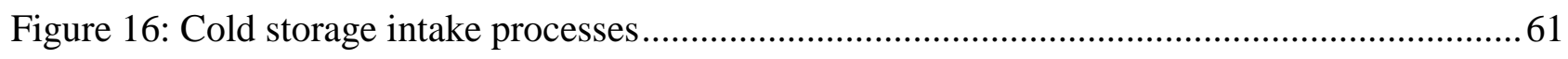

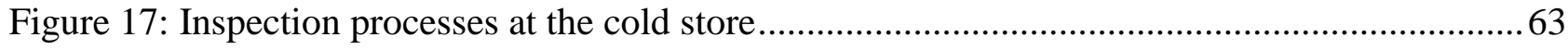

Figure 18: Depiction of cartons and pallets passed for exportation...............................................64

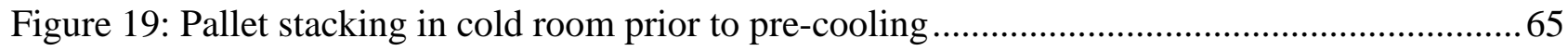

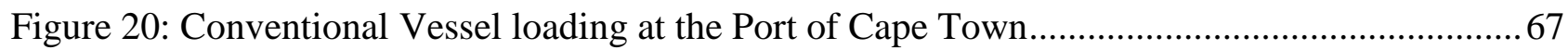

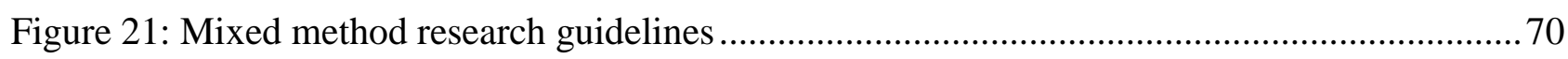

Figure 22: Illustration of iButtons ${ }^{\circledR}$ probed inside a navel orange and ambient recording iButtons ${ }^{\circledR}$

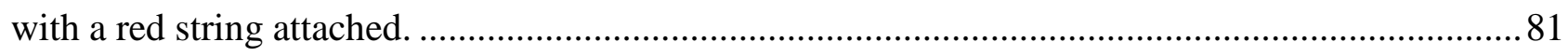

Figure 23: Pulp and ambient iButtons ${ }^{\circledR}$ in bins at the orchard................................................... 82

Figure 24: Ambient and fruit pulp iButtons ${ }^{\circledR}$ location from pack house to cold store .................... 82

Figure 25: Pulp (56 iButtons ${ }^{\circledR}$ ) and ambient temperature $\left(14\right.$ iButtons $\left.{ }^{\circledR}\right)$ of Santa Lucia in ${ }^{\circ} \mathrm{C} \ldots \ldots . . .86$ Figure 26: Ambient (14 iButtons $\left.{ }^{\circledR}\right)$ and pulp (56 iButtons $\left.{ }^{\circledR}\right)$ temperature from cold store to port of

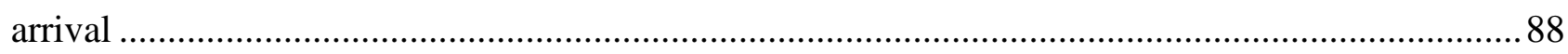

Figure 27: Pulp temperature (56 iButtons $\left.{ }^{\circledR}\right)$ of iButtons ${ }^{\circledR}$ position during shipment 90

Figure 28: Pulp temperature (56 iButtons $\left.{ }^{\circledR}\right)$ of iButtons ${ }^{\circledR}$ position during shipment of Santa Lucia vessel 


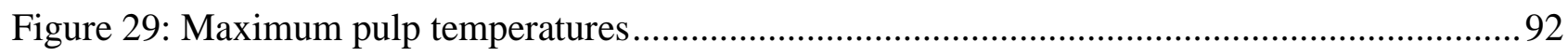

Figure 30: The difference in temperature at different positions at the transport stage ....................99

Figure 31: The difference in temperature at different positions at the cold store stage .................. 100

Figure 32: The difference in temperature at different positions at the inspection stage ................. 101

Figure 33: The difference in temperature at different positions at the cold sterilisation stage ........ 102

Figure 34: The difference in temperature at different positions at the loading stage .................... 103

Figure 35: The difference in temperature at different positions at the shipment stage.................. 104

Figure 36: Pulp (56 iButtons $\left.{ }^{\circledR}\right)$ and ambient (14 iButtons $\left.{ }^{\circledR}\right)$ temperature for Regal Bay Vessel .. 106

Figure 37: Pulp (56 iButtons ${ }^{\circledR}$ ) and ambient temperature (14 iButtons $\left.{ }^{\circledR}\right)$ of Regal Bay Vessel.... 107

Figure 38: Average pulp (56 iButtons ${ }^{\circledR}$ ) temperature of iButtons position during shipment ......... 109

Figure 39: Cartons placed in the middle position during the sea leg for the Regal Bay vessel.......110

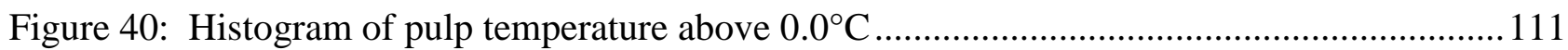

Figure 41: The difference in temperature at different positions at the transportation stage ........... 117

Figure 42: The difference in temperature at different positions at the cold store stage ................. 118

Figure 43: The difference in temperature at different positions at the inspection stage ................. 119

Figure 44: The difference in temperature at different positions at the cold sterilisation stage ........ 120

Figure 45: The difference in temperature at different positions at the shipment stage.................. 121

Figure 46: The difference in temperature at different positions at the shipment stage.................. 122

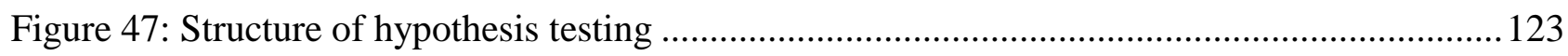

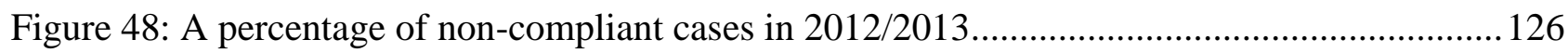

Figure 49: Factors resulting in fruit rejection in 2012/2013 ................................................. 126

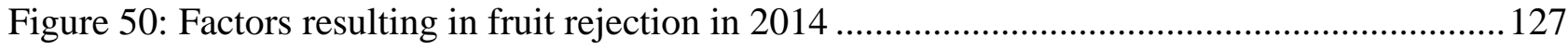

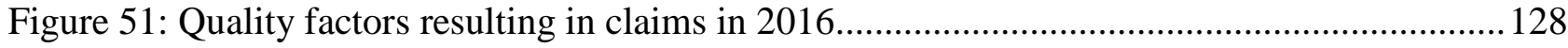

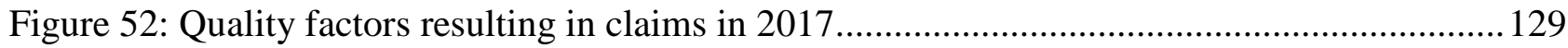

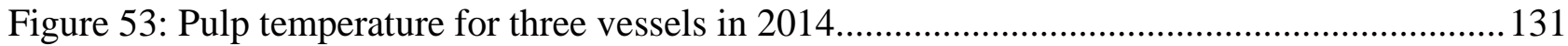

Figure 54: Pulp temperature of different decks in 2016/2017 .................................................. 132

Figure 55: Pulp temperature of one of the reefer vessels ............................................................. 133

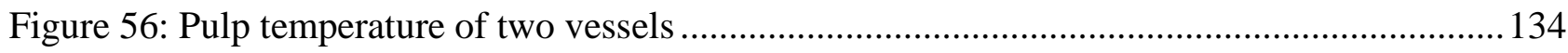




\section{List of Tables}

Table 1: Lowest safest temperatures of some fruits.............................................................. 18

Table 2: Citrus types and varieties produced in South Africa .....................................................2 25

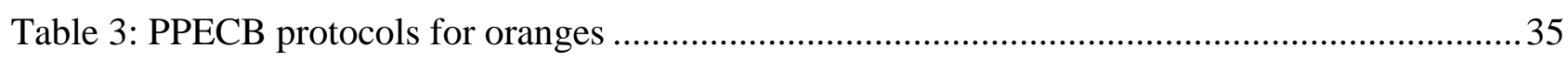

Table 4: Competitive factors between Spain and South Africa's citrus production........................ 43

Table 5: SWOT Analysis of the South African Citrus Industry .......................................................46

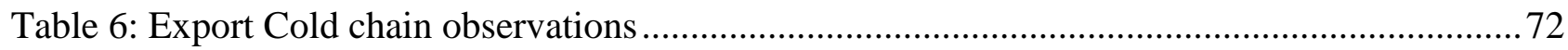

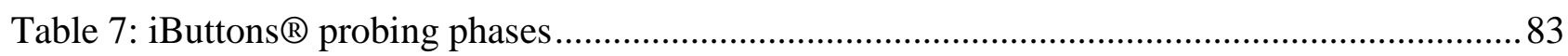

Table 8: Temperature trial process for Santa Lucia Vessel ...................................................... 85

Table 9: Descriptive statistics of harvesting stage .................................................................. 93

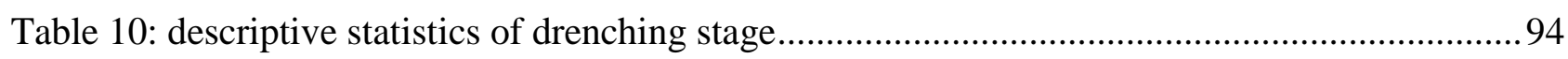

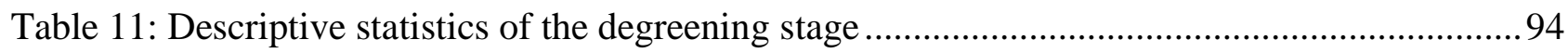

Table 12: Descriptive statistics of the pack house stage ….......................................................95

Table 13: Descriptive statistics of the transportation stage ........................................................ 95

Table 14: Descriptive statistics of the inspection stage …......................................................... 96

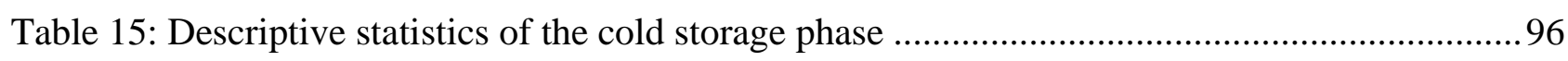

Table 16: Descriptive statistics of the vessel loading stage ......................................................... 97

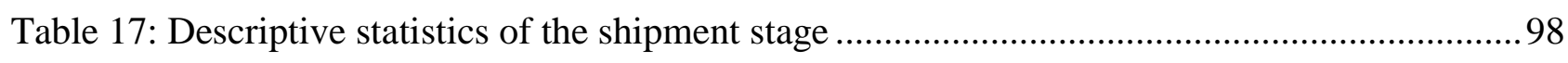

Table 18: Descriptive statistics for the different stages and position of iButtons ${ }^{\circledR}$ in the export cold

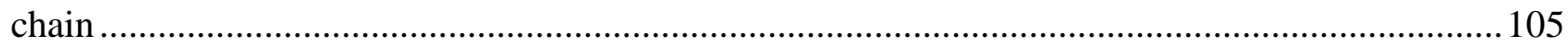

Table 19: Temperature trial process for Regal Bay Vessel ...................................................... 105

Table 20: Descriptive statistics of the harvesting stage ........................................................... 112

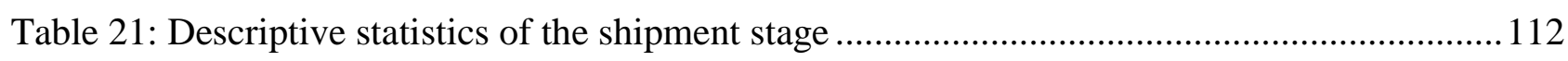

Table 22: Descriptive statistics of the pack house stage ......................................................... 113

Table 23: Descriptive statistics of the transportation stage ...................................................... 114

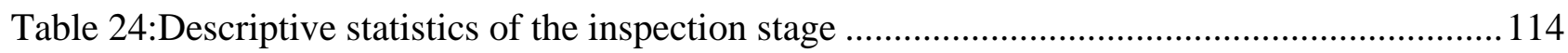

Table 25: Descriptive statistics of the cold storage stage ..................................................... 115

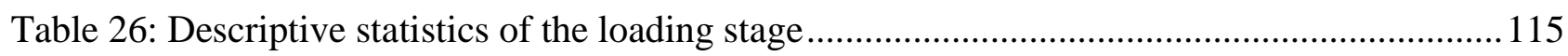

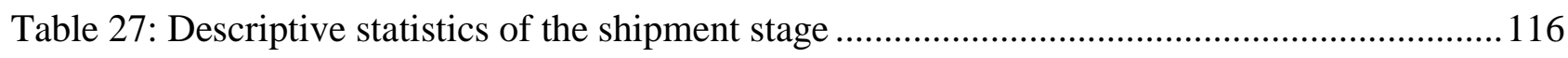

Table 28: Descriptive statistics for the different stages and position of iButtons ${ }^{\circledR}$ in the export cold chain 


\section{Acronyms and abbreviations}

ALA: $\quad$ Australian Logistics Assured

APHIS: $\quad$ United States Animal Plant Health Inspection Service

CBC: $\quad$ Citrus Black Spot

CRI: Citrus Research International

CSCMP: The Council of Supply Chain Management Professionals

DAFF: Department of Agriculture, Forestry and Fisheries

FAC: $\quad$ Forced Air Cooling

FCM: $\quad$ False Codling Moth

FPT: $\quad$ Fresh Produce Terminals

IACSC: International Association for Cold Storage Construction

IARW: International Association of Refrigerated Warehouses

IRTA: International Refrigerated Transportation Association

NCCD: National Centre for Cold Chain Development

PGI: $\quad$ Protected Geographic Indication

PPECB: $\quad$ The Perishable Products Export Control Board

PPQ: $\quad$ Plant Protection and Quarantine

TA: $\quad$ Titratable Acid

TNPA: $\quad$ Transnet National Ports Authority

TSS: $\quad$ Total Soluble Solids

USA: $\quad$ United States of America

USDA: United States Department of Agriculture

VPD: $\quad$ Vapour Pressure Deficit 


\section{Chapter 1: Introduction}

\subsection{Introduction}

The fruit industry contributes significantly to South Africa's economy with an annual turnover of approximately R24.4 billion (Liphadzi, 2015). The fruit industry's turnover consists of exports valued at R19.8 billion, local sales valued at R2.6 billion, fruit for processing valued at R1.8 billion and dried fruits to the value of R0.3 billion (Liphadzi, 2015). The industry also contributes more than 50\% to the country's agricultural products (Liphadzi, 2015). South Africa is known globally as a producer and exporter of traditional crops such as citrus, deciduous and subtropical fruits. The South African fruit industry exports approximately 2.7 million tons of fresh produce annually to 87 countries on four continents, which places it among the top 10 fruit-exporting countries in the world (GoedhalsGerber, Stander \& Van Dyk, 2017).

South Africa's citrus industry is the third largest horticultural industry after deciduous fruits and vegetables in the country (Department of Agriculture, Forestry and Fisheries, 2015). However, citrus fruits contribute the largest share annually to South Africa's total fruit exports (Potelwa, 2016; Department of Agriculture, Forestry and Fisheries, 2015). Yet, there are still a number of problems posing a threat to the industry. The main problem identified is the non-optimal management of the export cold chain resulting in temperature breaks. This problem leads to reduced fruit quality, which results in losses of revenue and sequentially could result in economic losses for South Africa (Negi \& Anand, 2015). According to Thompson, Mitchell, Rumsey, Kasmire \& Crisosto, 2008; Freiboth 2012:1, temperature is the greatest determinant of fresh produce deterioration rates and potential market life. Some of the cold chain breaks result in claims, while in other cases a reduced price is accepted.

Since the citrus industry is economically important, it is critical to ensure that the export cold chain functions at an ideal level. There is a growing concern in the citrus fruit industry that it is losing a substantial amount of money due to temperature breaks. As a result, an investigation on how to curb the loss of potential revenue through temperature maintenance was prompted by Company $\mathrm{X}$ in conjunction with Stellenbosch University. Company $\mathrm{X}$ is a supplier of fresh fruit to selected global markets and a provider of supply service solutions to international fruit trading partners. This specific study aims to help exporters of citrus redress issues of breaks in the cold chain and improve their fruit quality. The focus of this study is on the temperature profiles in the different phases of the export 
cold chain of oranges under cold sterilisation protocols, specifically navel oranges, from the Citrusdal region in South Africa to Philadelphia in the United States of America.

\subsection{Problem Statement}

There is a growing concern in the citrus industry that there are significant temperature breaks in the export cold chain of navel oranges to the United States. Temperature variability in the different phases of the cold chain leads to non-optimal temperature management and results in lower quality fruit arriving at its destination.

This study identifies whether there are breaks in temperature in the different phases of the navel orange export cold chain, which takes place under cold sterilisation treatment protocols, and if so, it provides solutions on how they can be managed. In addition, this study determines the link between temperature breaks and fruit quality. Cold sterilisation treatment protocols refer to treatment of fruit used to eradicate larvae through applying sub-zero temperatures.

\subsection{Aims and Objectives}

The aim of the study is to identify whether there are breaks in temperature at the different phases of the navel orange export cold chain from the Citrusdal region in South Africa to Philadelphia in the United States of America. In addition, the study strives to determine the link between temperature breaks and fruit quality.

\subsubsection{Objectives}

The objectives of the study are:

- $\quad$ To identify whether temperature breaks occur along the export cold chain of navel oranges from the Citrusdal region in South Africa to Philadelphia in the United States of America.

- $\quad$ To determine where along the export cold chain of navel oranges (if anywhere) temperature is not optimally maintained.

- $\quad$ To analyse the impact of temperature breaks on the quality of navel oranges.

\subsection{Research Questions}

To achieve the desired aim and objectives of the study, the main research question investigated is: 


\subsubsection{Main research question}

Where along the export cold chain of navel oranges from South Africa (Citrusdal region) to the United States of America (Philadelphia) is the temperature of oranges not optimally maintained?

The main research question was supported by the following sub research questions:

\subsubsection{Sub Research Questions}

- What causes temperature breaks in the export cold chain?

- $\quad$ How can temperature breaks in the cold chain be minimised?

- What impact do temperature breaks have on the quality of navel oranges?

- What best practises can be undertaken to ensure the effective management of temperature along the different phases of the exportation of oranges from South Africa to the United States of America?

\subsection{Significance of the study}

Temperature is an important determining factor of fruit quality decline and potential market losses (Freiboth, Goedhals-Gerber, Van Dyk \& Dodd, 2013; Freiboth, 2012; Thompson, Mitchell, Rumsey, Kasmire \& Crisosto, 2008). In order for fruit to be preserved for longer periods, the temperature profile has to be optimally maintained. According to Freiboth, et al., (2013) a significant percentage of losses in the fruit industry are due to temperature breaks in the export cold chain. Hence, this study explores various causes of temperature breaks in the export cold chain of navel oranges. In addition, this study identifies the impact of temperature breaks on the quality of navel oranges. Studies have been conducted on the export cold chain of fruit, but only a few have researched the cold chain of navel oranges. It is on this basis that the study adds value to the ongoing discourse of the export cold chain of fruit through broadening the scope of export cold chain studies, by exploring in-depth issues such as temperature variations from the point of origin to the point of consumption that influences the shelf life of navel oranges and their market value.

\subsection{Data sources}

The research design for the study is an explorative case approach analysed through a mixed method research approach. The period of the study was chosen to coincide with the export season of navel oranges. Data collection was conducted during the months of April to June 2017.

Primary qualitative information was collected through observation of processes followed at the farms, pack houses, cold stores and the Port of Cape Town. Personal interviews with farm owners, cold store 
and pack house managers were also conducted. In addition, to gain more insight on the field, the researcher contacted other key industry role players. Primary quantitative data was gathered through temperature readings taken from the orchard, degreening chamber, pack house, cold store and conventional vessels. Temperature trials were conducted using a temperature-monitoring device called an iButton ${ }^{\circledR}$. An iButton ${ }^{\circledR}$ is a coin-sized electronic device that acts as a temperature sensor and electronic memory to record temperature readings. It can measure temperature from $-30^{\circ} \mathrm{C}$ to $+85^{\circ} \mathrm{C}$ in $0.5^{\circ} \mathrm{C}$ increments. It captures the pulp and ambient temperatures at pre-set intervals for the duration of the export cold chain process. Each iButton ${ }^{\circledR}$ has a unique identification number, so that it is individually identified. Data is stored in three ways, namely, temperature loggings, histogram bins and threshold alarms. For the purpose of this study, data was recorded through temperature loggings, which are time and date stamped readings recorded at pre-set intervals. Pulp temperature monitors were probed inside fruit inside cartons stacked on pallets and ambient temperature monitors were inserted amid fruit in the carton. Pulp temperature refers to temperature of the internal flesh of refrigerated commodities and ambient temperature refers to temperature surrounding the environment (Oxford Dictionary, 2017).

To ensure a smooth process of data collection along the different phases of the export cold chain, data was collected in five phases. The five phases represent the different dates when data was collected. For phase A, seven bins were used for temperature trials, 56 fruit were probed and 14 iButtons ${ }^{\circledR}$ were placed to collect ambient temperature. Phase A represents the probing of temperature monitors into fruit at the orchard. Phase B required the use of another fifty-six iButtons ${ }^{\circledR}$ probed inside the fruit and fourteen iButtons ${ }^{\circledR}$ placed to collect ambient temperature. Phase B was conducted for the purpose of collecting temperature data in the degreening room. For phase $\mathrm{C}$ and $\mathrm{D}$, eighteen pallets were used for temperature trials. Three boxes in each pallet were probed with iButtons ${ }^{\circledR}$ and one box for placing the logger. In total, seventy temperature loggers were utilised. Phase C and D was conducted for the collection of temperature data at the pack house, after fruit had been palletized. Phase E required the use of seven bins, 55 fruits probed with iButtons ${ }^{\circledR}$ and 14 iButtons ${ }^{\circledR}$ placed to collect ambient temperature. Phase E represents the temperature collected at the drenching area. The fruit used for the trial was from same population. From this data, it is possible to identify whether breaks occur and how severe each break is (Nel, 2017; Cronje, 2017). The probed fruit were shipped through the use of conventional vessels. Initially the study had aimed to utilise four (4) conventional vessels, but in the end only three (3) conventional vessels were used for the temperature trials of the study.

Historic data received from fruit exporting organisations for past export seasons were also examined. Secondary information was gathered through the internet, books and articles on the fresh fruit industry 
in South Africa. Data was gathered from previous studies that are of a similar nature to the current research to gain insight on what has been done and areas that are still in need of improvement. Secondary research was also conducted to guide the literature review of the study.

\subsection{Conceptual framework}

The research is based on the conceptual framework illustrated in Figure 1. The figure demonstrates the flow of the research. The research is guided by Company X's concern of temperature breaks in the export cold chain of navel oranges to the United States of America. The exportation of citrus is done through the cold sterilisation treatment protocols. The problems, which are thought to influence the cold chain are depicted by the orange coloured arrows in the figure. The results of temperature breaks in cold sterilisation treatment protocols are illustrated by the dotted lines.

The framework was used to guide the researcher during the research process and aims to provide the reader with a background on how the research was conducted. The conceptual framework is used to connect all phases of the study. The research objectives and questions were derived from the research problem and the gap that exists. 


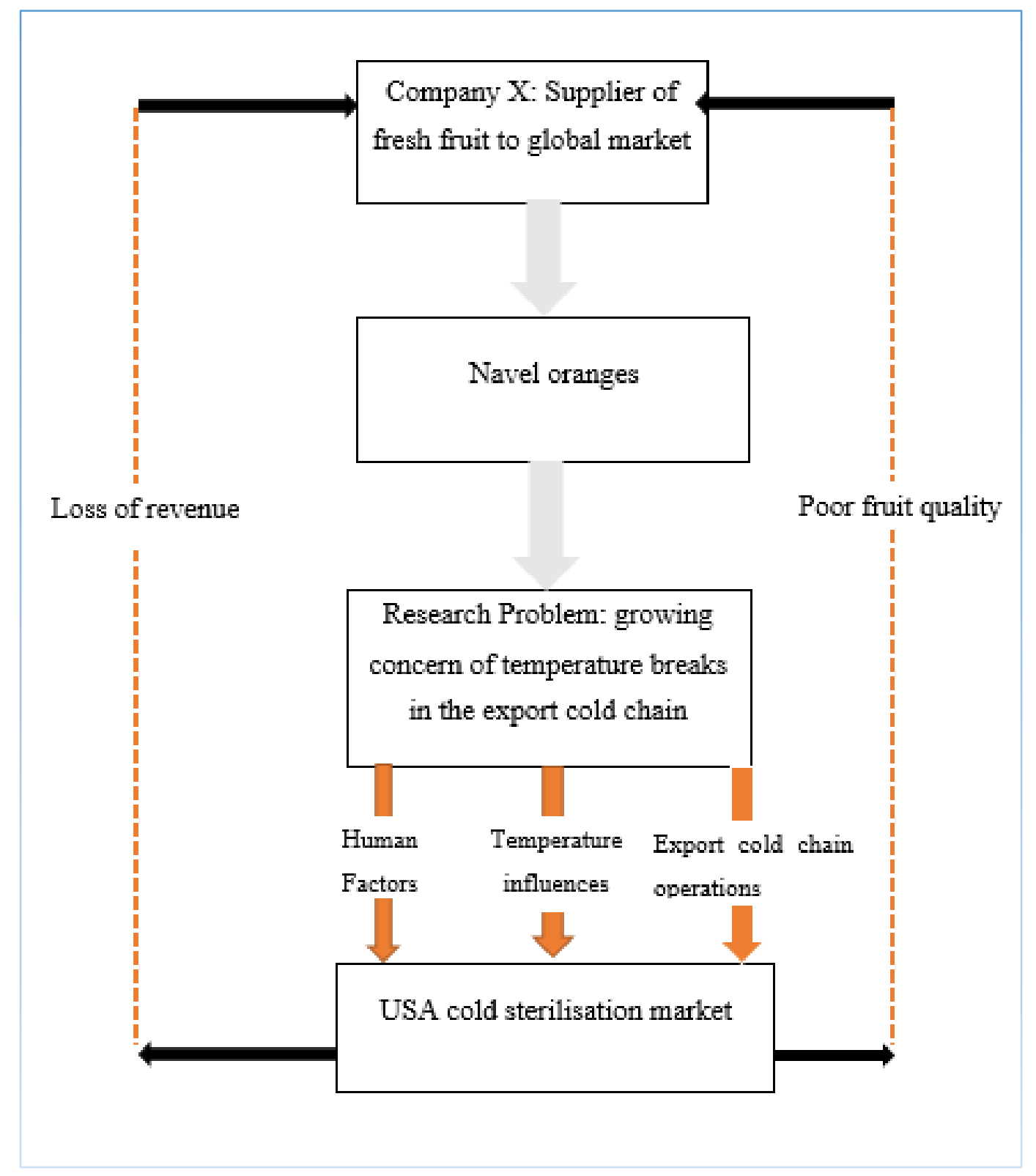

Figure 1: Conceptual Framework of research study

\subsection{Outline of the study}

The remainder of the study is divided into the following chapters:

- $\quad$ The second chapter discusses the literature review that forms the basis of the study. Firstly, it provides an overview of the supply chain from a cold chain perspective. Secondly, it discusses how temperature can be used to preserve oranges and the importance of temperature on the cold chain. Thirdly, it discusses the link between temperature and fruit quality and cold sterilisation protocols. In addition, it provides an overview on the fresh fruit industry of South Africa and the organisations involved in cold chain practices and protocols that are put in 
place as exportation requirements and guidelines. Finally, South Africa's competitiveness with other citrus producing nations and previous studies that have been conducted are highlighted.

- $\quad$ The third chapter contains a discussion on the navel oranges export cold chain. It describes theoretical and practical undertakings of the different stages of the export cold chain.

- $\quad$ The fourth chapter discusses the research design and methodology employed in the study. It examines the type of data required to analyse the cold chain and explains the processes followed.

- $\quad$ The fifth chapter contains data analysis. The results of temperature trials conducted and data gathered are discussed. Results on inferential statistics conducted are discussed. Tables and graphs depict the findings. Furthermore, the graphs and tables illustrated are interpreted.

- The sixth chapter interprets the findings of the study depicted through graphs and tables. It explains the data outcomes.

- The seventh chapter summarises the findings of the study. It examines whether all the research questions were answered and if the objectives of the study were met. It also gives recommendations for maintaining the export cold for navel oranges. It also includes challenges experienced while conducting the study and suggestions for future research. 


\section{Chapter 2: Literature Review}

\subsection{Introduction}

Research has been conducted on the export cold chain of various fruit types that are exported from South Africa to different global markets. However, few studies have focused on the export cold chain of navel oranges. Therefore, this chapter aims to provide an understanding on the export cold chain of fresh fruit, specifically navel oranges, and factors affecting cold chain performance. The chapter starts by explaining the supply chain from a cold chain perspective, and then proceeds to give detail on the fresh fruit industry of South Africa, the effects of temperature breaks and previous studies conducted on the export cold chain of fresh fruit. The role of the Port of Cape Town as a port of importance in the export cold chain is also discussed. The entire chapter is sourced as secondary research from sources including books, articles, journals and the internet.

\subsection{Supply chains}

According to Ketchen \& Hult (2006:574), by tradition supply chains have predominantly been viewed as a process for moving goods and materials from a place of low value to that of higher value. Supply chains consist of a network composed by interrelated organisations working together to ensure the flow of materials and information from suppliers to end users (Lu, Gu \& Predko, 2015:1). The supply chain is viewed as a support function that helps industries implement strategies, yet the use of a supply chain is not merely to get products where they need to be, but to enhance key outcomes that drive performance. Coordination of the supply chain allows for positive benefits to all involved role players. Goedhals-Gerber (2016) defines a supply chain as a progression or chain beginning with raw materials and ending with the sale of the finished product or service. Ketchen \& Hult (2006:573) state that a supply chain is a series of units that transform raw materials into finished products and ensures that products are delivered to the customer. Mashabela (2007:13) defines a supply chain as a network of organisations that are involved, through upstream and downstream linkages, in the different processes and activities that produce value in the form of products and services in the hands of the ultimate consumers. The Council of Supply Chain Management Professionals (CSCMP) (2017), define a supply chain as a process that starts with unprocessed raw materials and ends with the consumers using the finished product. The CSCMP also defines a supply chain as the material and informational interchanges in the logistical process stretching from acquisition of raw materials 
to delivery of finished products to the end-user. The primary similarity in the above-mentioned definitions is the ultimate provision of products and services to the end customer.

Mashabela (2007:16) states that the concept of a supply chain has been used in the logistics and manufacturing fields for many years. Supply chains can be traced back to the rise of modern logistics. Ross (1998:72) argues that, although the supply chain represents a radically new approach in the search for significant breakthroughs in products and markets, it is closely connected with logistics and is in many ways a product of changes that have taken place in logistics. Thus, the definition of a supply chain is mostly similar to that of the value chain, except the basis of supply chain is logistics (Mashabela, 2007:14).

Business logistics can be divided into materials management and physical distribution. Business logistics is an integral part of a supply chain and is defined as "the part of the supply chain process that plans, implements and controls the efficient, effective flow and storage of goods, services and related information from point of origin to the point of consumption to meet customers' requirements (CSCMP, 2017). Physical distribution provides time and place utility to the fruit as they are moved from the orchards to retail stores. The thesis focuses on the physical distribution of navel oranges from the point of harvest until port of destination, through the use of a cold chain. Therefore, logistics plays an essential part in ensuring timely and effective distribution of fruit. Citrus fruits are perishable products, meaning they are prone to decay. A temperature controlled supply chain, also known as a cold chain is used to prevent fruit from decaying.

\subsection{The rationale of a cold chain}

Rodrigue \& Notteboom (2013) state that in all processes that the supply chain is concerned with, the reliance on cold chains continues to gain prominence and is ever increasing. This is due to growth in globalisation that has allowed for a larger number of exports (Khumalo, 2006). An increase in demand for refrigerated products has resulted in an increase in goods that have to go through the export cold chain to reach the desired end destination. From a supply chain perspective, a cold chain is defined as the seamless movement of fresh, chilled or frozen products from production area to the market, through various storage and transportation mediums without any change in the optimum storage temperature and relative humidity (PPECB, 2017). Goedhals-Gerber et al., (2017:363) define a cold chain as a temperature-controlled supply chain that allows for national and trans-national trade in perishable products such as fresh fruit and vegetables. Montanari (2008:425) defines it as the processes and information management used to protect chilled and frozen foods from the point of harvest until it reaches the end customer. He further states a cold chain must be preserved from the 
point of production and processing to that of storage at the end destination. Similar to a supply chain, the basis of a cold chain is to ensure timely and good quality provision of products to end consumers. The cold chain is important as it primarily deals with perishable products, which are en-route towards markets. Perishable products have a finite lifespan and are in state of decline from the moment of harvest (Haasbroek, 2013; Freiboth, 2012). The cold chain optimises the freshness of products to be delivered to the consumer and hence the main determinant in the cold chain is optimal temperature (PPECB, 2017). Lu et al., (2015) argue that the cold chain is not only about the cooling of products but also keeping them at ideal temperatures. For navel oranges exported to the US, the cold chain serves the function of slowing down the respiration rate, preserving the internal and external quality of fruit, that is, the acid to sugar level ratio and to kill pests, which may be found on fruit. It is also associated with health issues, since proper temperature protocols reduce the likelihood of bacterial and fungal contamination (Rodrigue \& Notteboom, 2013). Therefore, the integrity of the cold chain must be preserved from the point of production and processing until the end consumer (GoedhalsGerber et al., 2017:363; Khumalo, 2006). This prolongs shelf life and maintains the quality and freshness of produce during the exportation process. A successful cold chain also offers competitiveness in markets thus improving profitability, adding to the revenue of the export industry. In addition, food waste and pollution are prevented (Lu et al., 2015:4). However, it is important to note that an efficient cold chain only preserves the quality of perishable produce; it does not improve it (Freiboth, 2012).

\subsection{Temperature breaks}

Freiboth (2012:18) states that maintaining the ideal temperature is the primary objective along the cold chain, since temperature breaks can occur when it is not optimally managed. Any temperature break in the cold chain speeds up the decaying process, resulting in loss of quality of the product. A temperature break is an interruption in a series of refrigerated production, storage and distribution activities, which maintain a desired low temperature range. In the citrus industry, there is no scientifically accepted definition of what defines a temperature break. Therefore, after consulting with industry role players and relevant literature, definitions were formulated for the two main sections of the navel orange export cold chain, for the purpose of this study. From the orchard until the export port, a temperature break (referred to hereafter as a temperature spike) is defined "as any time temperature rises along the export cold chain." The temperature has to rise by $2^{\circ} \mathrm{C}$ or more for the rise to be significant and influence the fruit quality (Goedhals-Gerber et al., 2017). From the export port until the port of destination a temperature break is defined as "a temperature deviation above 
$0.0^{\circ} \mathrm{C}$ or below $-1.5^{\circ} \mathrm{C}$ '. The latter definition takes into account steri-market protocol requirements. Steri-market protocols stipulate that pulp temperature may vary between $-0.6^{\circ} \mathrm{C}$ to $0.0^{\circ} \mathrm{C}$, but if temperatures exceed $0.0^{\circ} \mathrm{C}$, it is considered a steri-breach and the cold treatment is extended so that temperature is brought back down to $-0.6^{\circ} \mathrm{C}$. If the temperature exceeds $1.1^{\circ} \mathrm{C}$, cold sterilisation treatment is nullified (PPECB, 2012).

Citrus is more resilient to cold temperature as opposed to hot temperature, therefore, once the cold chain has been started, temperature must be maintained through a 'step-down temperature approach. (Cronje, 2017). A step-down temperature approach is whereby temperature only decreases as fruit moves along the export cold chain phases. Throughout the export cold chain, different temperatures are maintained to ensure the integrity of the cold chain. Usually, the maintained temperatures in the different stages are the same or lower than the previous stage (Rodrigue \& Notteboom, 2013). A stepdown approach constitutes a negative change in temperature, thereby enhancing fruit quality.

Cold chain management is essential for maintaining quality and safety of citrus fruits. Temperature breaks at several points of the export cold chain compromise the safety of products and quality thereby reducing profitability (Goedhals-Gerber et al., 2017:364; Jobling, 2009).

\subsection{Quality and fruit quality}

Ladaniya (2008) \& Hewett (2006) state that quality is a difficult notion to define as people differ in terms of expectations and demands for a particular product. Hewett (2006) defines quality as "the state in which a product meets the expectations of consumers." Quality is especially important for citrus fruits as the state in which the fruit meets end customers determines price in the export market. Fruit quality refers to the combination of fruit attributes or characteristics that possess significance in determining the degree of consumer acceptance. Profitability of exporters is correlated to the yield and quality of products at a given time. In simpler terms, the higher the quality of fresh fruit, the higher the rate of acceptance in the market (Ladaniya, 2008). The quality of citrus fruits can be differentiated through hidden, sensory and quantitative attributes. Sensory attributes are connected to external qualities of fruits. External qualities refer to the outer physical characteristics governed by vision and appearance, for example, rind colour, the shape and the size of the fruit. Hidden attributes are related to internal qualities, which refer to inward attributes such as juice content and flavour, which are determined by taste (Ladaniya, 2008; Hewett, 2006). Quantitative attributes relate to both external and internal qualities such as texture, rind colour, juice content, flavour of the fruit, as they both contribute to the overall fruit quality. 


\subsubsection{External and internal qualities}

External fruit quality is an important determinant in the fresh fruit market. In most instances, customers buy products based on appearance (Ehlers, 2006:5). Goedhals-Gerber et al., (2017:363) concur that product quality is the second most critical influencer of consumers interchanging between retailers. Fruit that is damaged or is affected by scars and blemishes does not usually meet quality standards and is therefore discarded (Ehlers, 2006:6). External qualities relate to the outward appearance of fruit such as fruit size, rind blemish and the colour. Rind colour is an important factor in determining the quality of citrus fruits and their market value. According to Ladaniya (2008) consumers prefer brightly coloured fruit and are willing to pay a higher price for them. Rind colour is a result of chlorophyll degradation and a change in carotenoids. For citrus fruits, rind colour happens to develop late in the harvest season (Ehlers, 2006:6). Thus, citrus fruits have to undergo a process of degreening as applying the right manipulation techniques helps in increasing the value of exported fruit in the market.

Fruit that are deemed to be of high quality are those that are free from physical damage, decay and rind disorders. The rind of fruit can be affected by pathological and physical disorders that deform the rind thus contributing to lower fruit external quality (Ehlers, 2006:7). Some rind disorders are related to low temperatures, whilst others are related to other factors such as diseases. These may be categorised as chilling and non-chilling related rind disorders. Both pathological and physical disorders can be controlled through post-harvest management, thus maintaining external fruit quality. Consumers tend to purchase on the notion that bigger is better. Fruit size is determined during growth development stages. At the fruit maturity stage, the size of a fruit is related to fruit count per tree, which helps indicate the total yield per tree. Underweight fruit is not accepted in the export market.

Ehlers (2016:8) states that any factor influencing taste is regarded as a part of internal quality. Internal quality is important for the consumption of fresh fruit. Citrus fruits' internal quality is influenced by Total Soluble Solids (TSS), Titratable Acids (TA) and the juice content. TSS refers to the palatability and flavour of citrus fruits. Citrus fruits' internal quality is also influenced by TAs, as it plays a significant role in consumer acceptability due to its contribution towards the flavour of citrus. According to Ehlers (2016:8) internal quality can be expressed as a TSS: TA ratio and for navel oranges a minimum TSS: TA ratio of $6.5: 1$ is required. In general, external quality largely influences purchasing decisions and the internal quality of fruit determines consumption and repeat purchases (Hagenmaier \& Baker, 2004:301). 
Overall, fruit quality is mainly affected and to a large extent determined by two factors, namely, preharvest and post-harvest management. Pre-harvest management takes place while the fruit is still attached to its growth medium and post-harvest management involves practices and strategies that aim to reduce post-harvest losses once the fruit has been removed from its nutrient source. The major determinant of fruit quality is pre-harvest management as the quality of fruit cannot be improved once fruit is harvested. Pre-harvest management comprises various factors including climatic conditions such as water availability, temperature and light intensity, genetics and cultivar selection and cultural practices. Since exportation of fruit only takes place after fruit have been removed from their growth medium, post-harvest management is discussed more in depth.

\subsubsection{Post-harvest quality management}

According to Matare (2012) and Barth \& Weston (1997), for the best results, post-harvest management starts with pre-harvest management, as the overall quality of fresh fruit cannot be improved after harvesting, but it can be maintained. Quality of fruit depends on the quality achieved during harvest. Post-harvest is the period between the separation of food items from the medium of immediate growth and the stages of consumption (Matare, 2012). Post-harvest management is mainly responsible for the reduction of weight loss and maintaining quality of fresh citrus. The quality of navel oranges is also influenced by various factors during post-harvest activities. These factors are discussed in detail as fruit is sold to markets after harvest and must be prepared appropriately. These factors include harvesting, maturity of produce, sorting and grading, and temperature management (Ahmad \& Siddiqui, 2015). The market values of produce depend on the growers' ability to apply the best available post-harvesting processes (Ahmad \& Siddiqui, 2015).

\subsubsection{Harvesting, maturity of produce and harvesting methods}

The maturity stage is seen as the starting point of post-harvest quality management (Ahmad \& Siddiqui, 2015). Hence, it must be ensured that fruit are mature before harvesting. Fresh fruit should be harvested once it reaches the appropriate development stage and ideal conditions, since the maturity of fruit influences quality, shelf life and market price of exported fruit. Immature fruit constitute inferior quality and results in a short post-harvest life of fruit (Ahmad \& Siddiqui, 2015). Non-climacteric fruit like navel oranges have to be harvested after attaining proper eating qualities. Being non-climacteric means fruit does not ripen any further after being removed from its nutrient source (Ahmad \& Siddiqui, 2015). In addition, fruits need to be harvested without any form of damage so as to preserve its quality and forestall deterioration. Faulty harvesting tools affect quality as they damage fruit. 


\subsubsection{2. $\quad$ Sorting and grading}

Sorting and grading is undertaken for the purposes of quality packing and removal of defective and infected produce from fruit bound for exportation. Ahmad \& Siddiqui (2015) state that sorting and grading gives assurances of quality produce. Grading of fruit may be based on colour, size and the extent of defects and sorting is mainly based on removal of defective fruit.

\subsubsection{Temperature management}

Temperature management is paramount for post-harvest management (Matare, 2012). Efficient temperature management between the period of harvesting and consumption has been identified to be the most effective solution to maintaining fruit quality as temperature is the most important environmental factor that influences the deterioration of commodities (Arah, Harrison, Kumah \& Ofori, 2015). Strano, Alteri, Admane, Genovese \& Di Renzo (2017) also concur that temperature is considered the key factor in the control of deterioration rate during post-harvest handling of citrus since it possesses a significant effect on how other internal and external qualities influence fruit. Temperature assists in preserving non-appearance quality attributes of oranges such as flavour, texture and nutrition (Ahmad \& Siddiqui, 2015). Temperature management is also important for the provision of most favourable conditions to fruit that has been harvested. Storing fruit at low temperatures reduces the rate of metabolic activities, which contribute to post-harvest life and quality. Effective temperature management plays an important role in preserving all qualities of fruit (Cronje, 2017).

Temperature has a direct effect on the rate of respiration, transpiration, ethylene, internal quality and post-harvest growth of micro-organisms (Cronje, 2017; Haasbroek, 2013; Jobling, 2009). According to Haasbroek (2013: 24) and PPECB (2013), fruit is alive and thus uses up oxygen and gives off carbon dioxide. Once fruits are harvested, they must be kept alive for long as possible. Since navel oranges are non-climacteric, they are characterised by the lack of ripening associated with an increase in respiration and ethylene production. Being non-climacteric additionally implies that they start to deteriorate after harvesting (Strano, Altieri, Admane, Genovese \& Direnze, 2017; Matare, 2012).

\subsection{Rate of Respiration}

Metabolic activity in fresh fruits continues for a period after harvest (Becker \& Fricke, 1996). The energy required to sustain this activity comes from the respiration process. Respiration is the process in which carbohydrates are broken down to constituent parts to produce energy to maintain cellular processes. Throughout the process, water, carbon dioxide and energy are released, while water is consumed (Silva, 2008). The storage life of a commodity is influenced by its respiratory activity. 
Controlling the rate of respiration is important as harvested fruit is no longer connected to its roots or parts of its plant, therefore nutrients are no longer produced. Once fruit nutrients diminish, deterioration starts (Silva, 2008).

Haasbroek (2013) states that the rate of respiration indicates the deterioration rate of fresh fruits. Temperature has a direct effect on respiration and therefore, an increase in temperature increases the rate of respiration, resulting in faster deterioration rates and lower shelf life (Haasbroek, 2013; Cronje, 2017). It should be noted that harvested fruit have different rates of respiration. Navels have a slow respiration rate meaning they are less perishable. Regardless of the rate, optimal temperatures still need to be applied to prolong produce life. By storing a commodity at low temperature, respiration is reduced and senescence is delayed, thus extending storage life (Becker \& Fricke, 1996). Therefore, it is critical to maintain low fruit pulp temperatures throughout the cold chain to keep the rate of respiration as low as possible.

\subsection{Post-harvest Micro-organisms}

According to Haasbroek (2013) micro-organisms and post-harvest rots in fruit are a problem that could be avoided through cold chain management. Temperature management provides the best solution to this problem. Haasbroek (2013) further states that fruit is susceptible to diseases caused by bacteria and fungi. Navel oranges are susceptible to citrus pests and diseases, for example, False Codling Moth (FCM), which affects citrus and its hybrids (Malan, Knoetze \& Moore, 2011). FCM causes serious phytosanitary concerns with restrictive import regulations having been imposed by importing countries (Malan et al., 2011)

The growth rate of such pests and fungi increases with an increase in temperature and can be controlled by temperature management (Haasbroek, 2013). Goedhals-Gerber et al., (2017) concur that adhering to maintaining product-specific temperature standards within the cold chain reduces the opportunity for microbial decay. Storing and transporting navel oranges in optimal temperature keeps disease and pests in the fruit at a minimum. Since post-harvest micro-organisms are a cause for concern as they are a major phytosanitary threat, regulatory procedures such as cold sterilisation treatment have been enforced by several import countries such as the USA.

\subsection{Cold sterilisation treatment}

Citrus fruits possess a natural resistance to insect infestation to a certain extent as a result of allelopathic essential oils in the flavedo region of the peel (Ladaniya, 2008). Resistance of citrus fruits to pests also depends on factors such as stage of fruit maturity, ripeness and flavedo thickness. 
However, with time, the natural resistance diminishes thus leaving fruit vulnerable to infestation. To eradicate challenges that are posed by citrus pests and diseases, quarantine measures were introduced. According to Mathaba (2012), cold sterilisation was introduced by the global fresh produce community. Under the guidance of the Food and Agricultural Organisation (FAO), the International Plant Protection Convention was introduced. The treaty was signed as an agreement on the prevention and monitoring of pests and diseases during the trade of fresh produce to international markets (Mathaba, 2012). The treaty enforces importing and exporting countries to have professional inspectors to approve and certify exportable plant material as free from pests and diseases.

Cold sterilisation, also known as cold disinfection treatment, requires that a certain core temperature has to be met for fruit that are to be exported to markets. It is designed to disinfect fruit from possible fruit-fly and FCM infestation (Ladaniya, 2008). The treatment includes several weeks of storage at sub-zero temperatures. The exportation markets, which prescribe cold treatment are known as 'sterimarkets'. Steri-markets make use of cold treatment to ensure that pests and diseases such as FCM, which is a typical pest for South Africa, are not imported along with fruits that arrive at their ports (Citrus Research International, 2014). Cold sterilisation treatment commences once conventional vessels have been loaded and its compartments shut, with all three major temperature probes recording $-0.6^{\circ} \mathrm{C}$ or below per independent deck until end destination of product (Henning, 2017; Cronje, 2017; PPECB, 2013). Cold sterilisation protocols are used to control the presence of pests and diseases, so that risk of consignment rejection is reduced.

Company $\mathrm{X}$ exports navel oranges from the Citrusdal region in the Western Cape to the Northern American Market, specifically, Philadelphia (Newark Port) in the United States of America. Navel oranges are exported from the Western Cape since Citrus Black Spot (CBS) is restricted by specific climate parameters and it has not been recorded in Mediterranean citrus producing climate like the Western Cape, meaning the area is CBS free. Fruit is exported to the USA through the Port of Cape Town.

Cold sterilisation protocols as set out by the Department of Agriculture, Forestry and Fisheries (DAFF) and United States Animal Plant Health Inspection Service (APHIS) stipulate that oranges must be shipped to the end destination at a temperature of $-0.6^{\circ} \mathrm{C}$ for a period of 22 days to eradicate larvae, which may be on the fruit. The stipulated temperature and time is fixed as research proves that exposing larvae to a temperature of $-0.6^{\circ} \mathrm{C}$ for 22 days induces stress leading to its death (Cronje, 2017). If the phytosanitary cold sterilisation protocols are not met, fruit designated to USA is rejected. Although South Africa uses cold sterilisation treatment to eliminate pests and diseases, the local 
treatment conditions meted out are not the same as prescribed by other countries. Many countries have their own protocols that govern the handling of fruit exported to them. For example, the Republic of Japan demands that citrus be exported at $-0.6^{\circ} \mathrm{C}$ for 12 days or temperatures be subsequently kept below $-0.6^{\circ} \mathrm{C}$ for 12 days.

Even though cold sterilisation protocol is used to kill larvae on fruit, it is known to cause chilling injury, which is detrimental to fruit quality (Hordijk, 2013).

\subsection{Chilling Injury}

Citrus fruit quality is based on internal as well as external elements (Hordijk, 2013; Mabatha, 2012). Low temperatures possess the ability to maintain internal quality as it reduces metabolic processes such as respiration, water loss and oleocellosis. In addition, low temperatures can be applied to sterilise larvae of pests in citrus during shipment to international markets (Hordijk, 2013). However, the external quality may decline due to physiological disorders that may occur as a result of chilling injury, thus leading to economic losses. Chilling injury is a flavedo (peel) disorder, which occurs from sunken lesion and discolouration due to permanent damage to plant cells as a result of exposure to temperatures below critical threshold temperatures (Mathaba, 2012). Hordjik, (2013) and Jackman, Yada, Marangoni, Parkin \& Stanley (1998) define chilling injury as a physiological damage that occurs in fruit as a result of exposure to low, but non-freezing temperatures.

The South African citrus industry is mandated to treat citrus fruit for fruit flies, FCM and other pests and diseases, to be able to export to profitable markets such as the USA (Mabatha, 2012). Cold treatments have been proven to eradicate larvae or eggs of pests when exposed to sub-zero temperatures (Mabatha, 2012; Ladaniya, 2008). The temperature prescribed for cold disinfection treatments is for the sterilisation of insects, thus is regulatory as strict inspection of fruit is enforced after harvest before it reaches final destination. Due to its low temperatures, cold sterilisation treatment has been known to cause chilling injury (Hordjik, 2013; Mabatha, 2012; Ladaniya, 2008). Different citrus fruit varieties have different tolerance limits to low temperatures. Hordijk (2013) states that various factors influence the susceptibility of navel oranges to chilling injury, for instance, fruit size, rind colour, and cultivar. According to Mabatha (2012) plant tissue exposed to chilling temperatures undergoes physical cell membrane phase transition from a normal flexible and liquid crystalline to a solid gel structure. Continuous exposure to chilling temperatures causes membrane lipids to solidify leading to a contraction of the membrane, subsequently causing cracks and results in increased cell permeability, thus leading to chilling injury symptoms on the fruit. 
Citrus fruits are subtropical in origin and are therefore highly susceptible when exposed to cold temperatures. Ladaniya (2008) states that for cold sterilisation treatment to be practical, citrus has to tolerate low temperatures without an unfavourable effect on both internal and external quality. A study conducted by McGlasson, Scott \& Mendoza in 1979 stipulated the approximate lowest temperatures that citrus fruit could endure without developing chilling injury. The results of the research are shown in Table 1.

Table 1: Lowest safest temperatures of some fruits

\begin{tabular}{|c|cl|}
\hline Produce & $\begin{array}{c}\text { Approximate } \\
\text { lowest safe } \\
\text { temperature }\left({ }^{\circ} \mathbf{C}\right)\end{array}$ & \multicolumn{1}{c|}{ Symptoms } \\
\hline Avocado & 11 & Pitting, browning of pulp and vascular strands \\
\hline West Indian other varieties & 5 & Vascular strand \\
\hline Banana & 12 & Browning streaking to blackening of skin \\
\hline Citrus & $5-10$ & Pitting of flavedo, pitted areas turn brown \\
\hline Lanzone & $10-12$ & Browning of skin \\
\hline Litchi & $2-5$ & Loss of red colour \\
\hline Mango & 5 & Dull skin, brown patches, abnormal ripening \\
\hline Papaya & 6 & Pitting of skin water soaking of flesh, \\
& & abnormal ripening \\
\hline
\end{tabular}

Source: McGlasson et al., 1979.

The temperatures stipulated for cold disinfection treatment are below the lowest safest temperatures suggested, and as a result chilling injury has been known to develop (Mditshwa, 2012). This in turn leads to post-harvest losses, which result in economic losses for the citrus export industry. Alternative methods, which could be used during cold sterilisation treatments to reduce chilling injury, are discussed in the last chapter.

\subsection{A discussion of fruit quality factors and their link to temperature}

To determine whether navel oranges are of an acceptable quality standard, quality tolerances are stipulated by the country of import. These tolerances suggest that there are limitations which fruit are not to surpass to be accepted in the export market. This section explores the link between temperature and the quality factors, which possibly contribute to the rejection of fruit. The quality factors that are explored can be differentiated between chilling-related disorders and non-chilling related disorders. 
Chilling-related disorders are those that occur during storage at low temperatures, whilst non-chilling related disorders may develop at low, sub-optimal temperatures, but low temperature is not required for their development (Ehlers, 2016: 7).

\subsubsection{Rind break down}

Rind breakdown is a post-harvest disorder that involves the collapse and darkening of epidermal tissues around the stem end of the fruit (Magwaza, Opara, Cronje \& Nicolai, 2013). Rind breakdown leads to reduced external fruit quality as it is affected by the loss of water. Rind breakdown is a nonchilling related disorder meaning that low temperatures are not required for its occurrence. Therefore, temperature breaks cannot be determined as the cause for the occurrence of rind breakdown as it usually occurs pre-harvest and becomes evident once exportation processes have begun (Magwaza, et al., 2016).

\subsubsection{Green colour}

The shipment of fruit in low sub-optimal temperatures results in poor rind colour development. The effects of cold sterilisation temperatures lead to poor rind colour due the stalling of carotenoid degradation. When low temperatures, such as those used for cold sterilisation are applied, the degradation in carotenoid, which contributes to rind colour is slowed down (Van Wyk, 2004). Low temperatures can be proven to destroy the colour development of navel oranges, more especially because of the non-climacteric nature. However, temperature breaks could have the opposite effect on the colour development of fruit. Since temperature breaks mean there is an increase from the set temperature, they could positively contribute to the development of navel oranges' rind colour (Van Wyk, 2004).

\subsubsection{Cold damage}

Cold damage, also known as chilling injury, is an external quality defect caused by the application of low temperatures to fruits. The temperatures applied for cold sterilisation protocols are known to cause chilling injury to the flavedo of navel oranges (Hordjik, 2013). This means there is a contribution to the disorder by the low temperatures applied during exportation of the fruit. However, like the case of green colour quality, temperature breaks are seen to have the opposite effect on chilling injury, as they slow down the rate of occurrence.

\subsubsection{Oleocellosis}

Oleocellosis is the unsightly damage to the rind of citrus fruits, which is caused by the accidental release of oil from damaged oil glands (Cronje, 2017). Oleocellosis, also known as oil spotting, is a 
phytotoxic reaction that occurs when the glandular cells in the rind are injured. It tends to occur more when fruit is picked wet as the oil glands are easily ruptured by finger and impact pressure due to high turgor pressure. Oleocellosis is more noticeable in degreened citrus fruits. Oleocellosis also tends to occur if turgid fruit are suddenly exposed to low temperatures, however, low temperatures have not been proven to be the main cause of oleocellosis (Dreistadt, 2012).

\subsubsection{Granulation}

Granulation in navel oranges occurs when the juice sacs become hard, dry and are filled with little fruit juice. Factors that are known to cause granulation include delayed harvesting, frequent irrigation and higher application rates of fertilisers (Sinha, 2017).

\subsubsection{Decay}

Low temperatures are known to slow down the rate of decay in fruit, therefore, extending the shelf life of fruit in the market. Low temperatures slow down the rate of reaction enzymes and further prevents growth and reproduction. Low temperatures also slow the rate of post-harvest microorganisms and the rate of respiration. Fruit is alive and thus uses up oxygen and gives off carbon dioxide. Once fruits are harvested, they must be kept alive for long as possible. With citrus fruits being non-climacteric, it means they start to decay after harvesting (Strano, Altieri, Admane, Genovese \& Direnze, 2017; Matare, 2012). Thus, low temperatures assist in preserving fruit for longer periods by reducing the rate of decay. Temperature breaks could in turn affect the quality of fruit, as it would lead to a rise in the incidences associated with fruit decay.

These mentioned fruit qualities contribute significantly to the market value of navel oranges. Low temperatures applied play a role in the development of some of these qualities, especially if fruit is shipped over long distances.

\subsection{The fresh fruit industry of South Africa}

The development of the fresh fruit industry dates back to the era of Jan Van Riebeeck when he discovered the Cape's potential as a fruit producing area. In 1652, he planted the first fruit trees in Cape Town. Fruit production was mainly aimed at supplying passing ships as well as for local consumption. By the mid-19th century, fruit exportation to Australia was attempted proving unsuccessful due lack of refrigeration technology and the long duration of the voyage. A breakthrough in refrigeration technology by Frigorifique in 1877, created the possibility of exporting perishable products over distances previously unimaginable (Freiboth, 2012). The introduction in refrigerated mechanics opened up a new range of destinations for South Africa's fruit production. In 1886, fruit 
export attempts to England were undertaken and proved successful. Over the years, many factors have influenced the fruit industry, for example, the establishment of commodity control boards after the Second World War, the establishment and disbanding of fruit boards, global market conditions, breakthroughs in refrigeration technology, weather conditions etc. (Haasbroek, 2013). The success of the South African fresh fruit industry is attributed to its climate and topography.

The climate is ideally suited for fruit production and therefore, a wide range of fruit is grown in all provinces across South Africa with a constant flow available for exportation (Fundira, 2004). The fruit industry is sub-divided into three divisions, namely: citrus, deciduous and subtropical fruit (National Agricultural Marketing Council, 2014; Fundira, 2004; Ortmann, 2005). Figure 2 illustrates a map of where each fruit type is produced in South Africa. The focus is on the citrus industry, in the Citrusdal region, Western Cape, as it is the basis of the study.

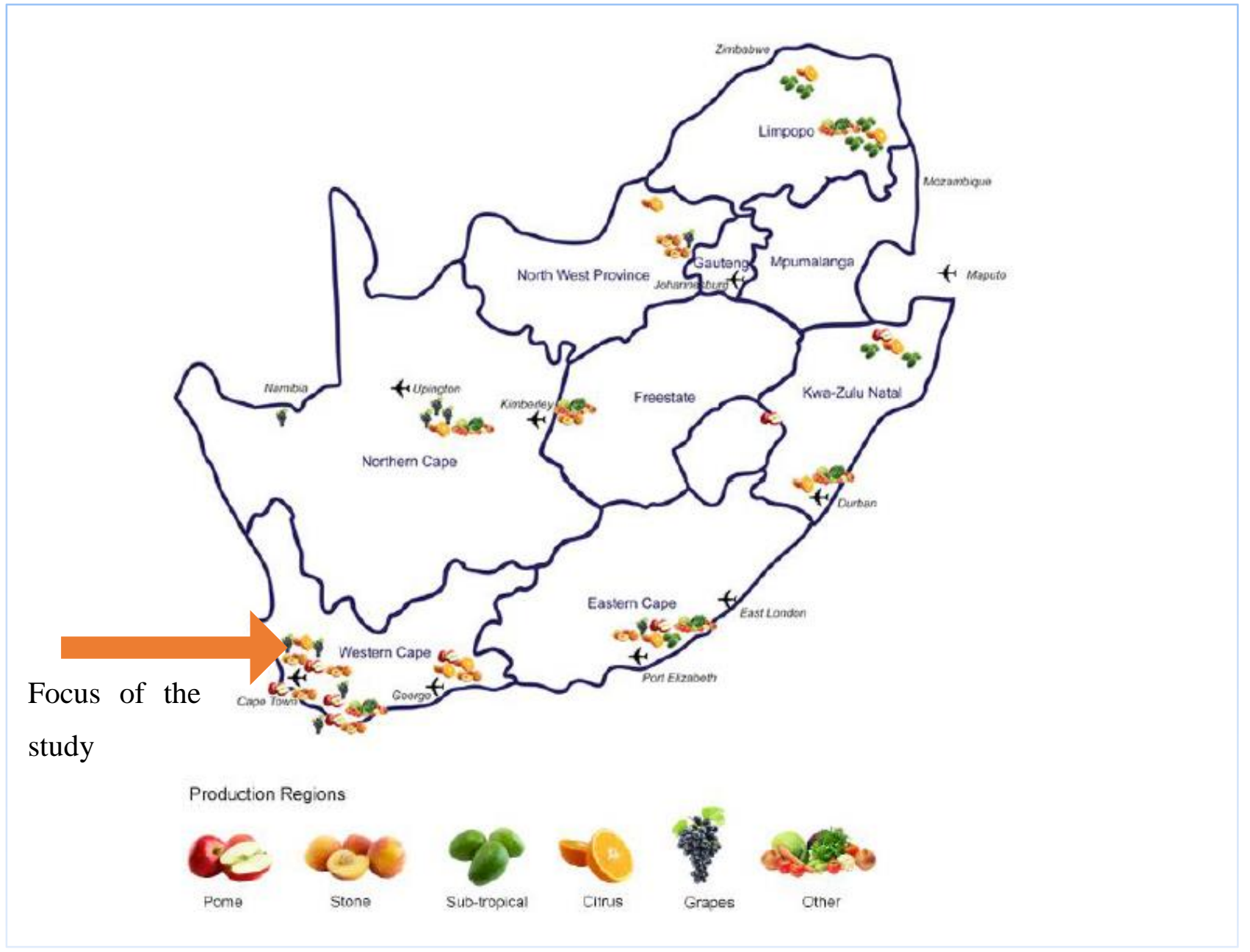

Figure 2: Illustration of where each fruit type is produced in South Africa 
The South African fresh fruit industry employs approximately 179000 people, which only includes personnel employed directly on farms and pack houses (Liphadzi, 2017). Approximately 8000 people are employed to provide services to the fruit industry and 109000 people are employed in downstream service (Liphadzi, 2017). South Africa produces a large volume of fruit each year, more than what is consumed by the country's entire population (Haasbroek, 2013). Fruit production has gradually been increasing since 1997 due to various factors, for example, improvement in cold chain and transportation systems, new emerging markets and the rise of export opportunities.

Fruit exports accounted for $50 \%$ of all agricultural exports in South Africa, with an export value of approximately R19.8 billion during 2013 (Goedhals-Gerber, Haasbroek, Freiboth \& van Dyk, 2015). The export market is an important factor for the South African fruit industry as a whole. Figure 3 depicts the harvesting season of the different fruit types produced for export in South Africa. 


\section{South Africa: Abridged seasonal fresh produce calendar}

\begin{tabular}{|c|c|c|c|c|c|c|c|c|c|c|c|c|}
\hline DECIDUOUS FRUIT & Oct & Nov & Dec & Jan & Feb & Mar & Apr & May & Jun & Jul & Aug & Sep \\
\hline \multicolumn{13}{|l|}{ Apricots } \\
\hline \multicolumn{13}{|l|}{ Peaches } \\
\hline \multicolumn{13}{|l|}{ Nectarines } \\
\hline \multicolumn{13}{|l|}{ Plums } \\
\hline \multicolumn{13}{|l|}{ Table Grapes } \\
\hline \multicolumn{13}{|l|}{ Pears } \\
\hline \multicolumn{13}{|c|}{$\Theta^{\Phi}$} \\
\hline \multicolumn{13}{|c|}{$0=0=0=$} \\
\hline \multicolumn{13}{|l|}{ Cherries } \\
\hline CITRUS FRUIT & Oct & Nov & Dec & Jan & Feb & Mar & Apr & May & Jun & Jul & Aug & Sep \\
\hline \multicolumn{13}{|c|}{ Easy Peelers \& Mandarins } \\
\hline \multicolumn{13}{|l|}{ Lemons } \\
\hline \multicolumn{13}{|l|}{ Oranges } \\
\hline \multicolumn{13}{|l|}{ Grapefruit } \\
\hline SUB-TROPICAL FRUIT & Oct & Nov & Dec & Jan & Feb & Mar & Apr & May & Jun & Jul & Aug & Sep \\
\hline \multicolumn{13}{|l|}{ Avocados } \\
\hline \multicolumn{13}{|l|}{ Litchi's } \\
\hline \multicolumn{13}{|l|}{ Mangoes } \\
\hline \multicolumn{13}{|l|}{ Pineapples } \\
\hline \multicolumn{13}{|l|}{ Passion Fruit } \\
\hline EXOTIC FRUIT & Oct & Nov & Dec & Jan & Feb & Mar & Apr & May & Jun & Jul & Aug & Sep \\
\hline \multicolumn{13}{|l|}{ Raspberries } \\
\hline Blueberries & & 98 & 98 & 98 & $9 \%$ & 98 & & & & & & \\
\hline \multicolumn{13}{|c|}{ ¿QQ } \\
\hline \multicolumn{13}{|l|}{ Strawberries } \\
\hline \multicolumn{13}{|c|}{$\theta 0$} \\
\hline Pomegranates & & & & & & & & $d y$ & & & & \\
\hline
\end{tabular}

Figure 3: The harvesting season of different fruits in South Africa.

Source: Fresh Food Trade SA, 2017

The focus of this thesis is on citrus production, which is discussed in the following section. 


\subsection{Citrus Production}

According to Fundira (2004), the citrus industry in South Africa has always been internationally imperative and by the 1960s, South Africa had been supplying the southern hemisphere with fresh citrus. By the mid-1990s, citrus exportation represented one third of the total local and export value of South African fresh fruit production (Ortmann, 2005). Ndou (2012) states that South Africa is ranked in the top-ten countries in terms of world citrus production and has been the second largest exporter of fresh citrus fruits globally since 2006. There are a number of citrus growing regions in Southern Africa, allowing for the production of a wide variety of export citrus fruits, for a large portion of the year (Chadwick, 2009). In South Africa, these regions include Limpopo, the Eastern Cape, Mpumalanga, the Western Cape, KwaZulu-Natal and the Northern Cape. In addition, citrus fruits are also grown in the neighbouring Swaziland. Citrus growing regions are shown in Figure 4. It is important to note that different provinces cater for different varieties and cultivars of citrus fruit, because of their climatic conditions. For example, soft citrus, navel oranges and lemons are widely grown in the Eastern and Western Cape provinces (Ndou, 2012).

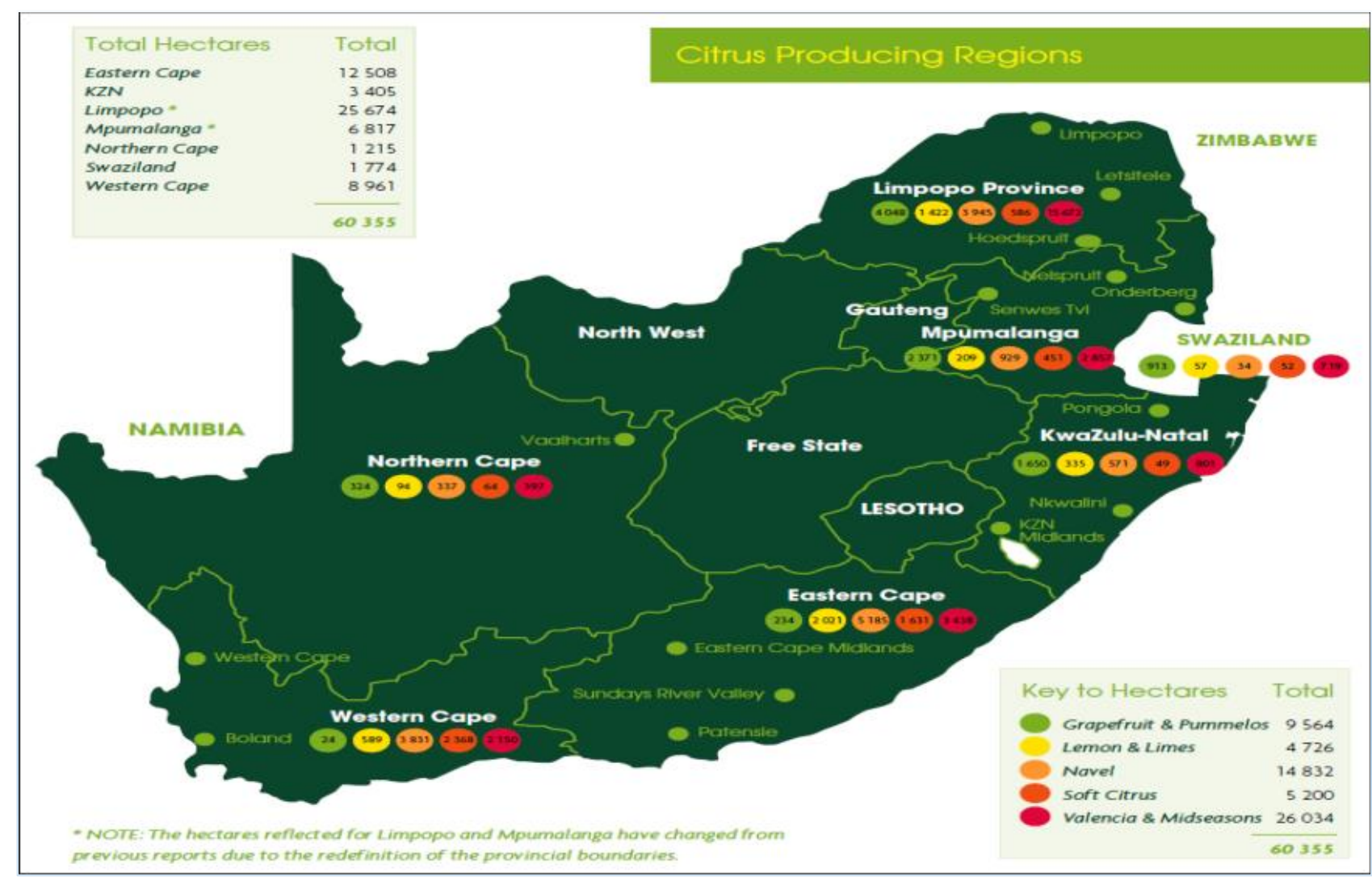

Figure 4: Citrus growing regions in South Africa

Source: Department of Agriculture, Forestry and Fisheries, 2015 
The citrus types grown in South Africa are depicted in Table 2.

Table 2: Citrus types and varieties produced in South Africa

\begin{tabular}{|l|l|}
\hline Citrus Type & Variety \\
\hline Oranges (Citrus Sinensis) & $\begin{array}{l}\text { Valencias, Navels, Deltas, Midknights, Delta Seedless, } \\
\text { Navelates, Benny Valencia, Proteas, Tomangoes, } \\
\text { Juvalles, Late Navels, Salustiana, Seville, Sanguienellis } \\
\text { Soft Citrus, Kumquats, Bella Fruita Orange, Valentines, } \\
\text { Moros's, (Shamoutis), Maltaise }\end{array}$ \\
\hline Easy Peelers (Citrus Reticulata) & $\begin{array}{l}\text { Clementines, Satsuma (Imamura, Kuno, Owari), Nules, } \\
\text { Novas, Marisol, Clemvilla Soft Citrus, Minneolas, } \\
\text { Shamoutis, Exe Soft Citrus, Torro Clementines, Naartjies, } \\
\text { Nouvelle, Valley Gold Soft Citrus, Sanguinellis Soft } \\
\text { Citrus, Tangerines, Page Mandarin }\end{array}$ \\
\hline Grapefruit (Citrus paradis) & $\begin{array}{l}\text { Star Ruby, Marsh, Rose, Ruby Red Pomelos, Pomelos, } \\
\text { Shadock Grapefruit, Oroblanco, Melow Gold Pomelos }\end{array}$ \\
\hline Lemons and Limes (Citrus Limon \& Citrus & \begin{tabular}{l} 
Eureka, Fino, Genoa, Limoneire, Libon, Verna \\
\hline auratifolia)
\end{tabular} \\
\hline
\end{tabular}

Source: Ortmann, 2005

The cooler climatic conditions of the Western and Eastern Cape have allowed for the production of easy peelers like clementines, which are in demand in the overseas markets. The Western and Eastern Cape account for $74 \%$ of total soft citrus production in South Africa, i.e. $41 \%$ and $33 \%$ respectively. Oranges (specifically navels) are concentrated in the Cape provinces and grapefruits, easy peelers and mandarins are concentrated in the Northern districts like Limpopo (Ndou, 2012). The Limpopo province is responsible for $59 \%$ of the Valencia oranges grown in South Africa. Grapefruits also do well in Limpopo (50\%) as well as Mpumalanga (22\%) and KwaZulu-Natal (12\%) provinces. Citrus from the Western Cape to USA is exported from the Citrusdal region, which has favourable climatic conditions suiting different varieties of citrus.

The citrus industry is an important foreign exchange earner for South Africa as it is export-driven. Since the local and regional market cannot sustain the quantities produced, citrus is mainly aimed at exportation to various global market destinations, while the remainder is sold locally and/or processed into fruit juice. Of the total citrus exports, $70 \%$ is oranges, $16 \%$ grapefruit, $8 \%$ lemons and mandarins account for $6 \%$ (Ndou, 2012). The major markets for citrus are the European Union, Middle East, Asia, Russian Federation, United Kingdom, and North America with a market share of 33.27\%, 
$20.38 \%, 18.04 \%, 10.78 \%, 9.70 \%$ and $6.58 \%$ respectively. In the $2013 / 2014$ season, the total gross value of citrus fruits in South Africa amounted to R9.69 billion (Department of Agriculture, Forestry and Fisheries, 2015). Citrus fruit exports amounted to 8.9 million tons, in the 2015/2016 season with an equivalent of $11 \%$ of the world's total citrus production (Department of Agriculture, Forestry and Fisheries, 2015). There has been a decline in citrus production due to various factors, for example, the occurrence of drought and declining production volumes for oranges, lemons and limes. Citrus production declined from 82.2 million tons in the 2010/2011 season to 81.1 million in the 2015/16 season (National Agricultural Marketing Council, 2015). Even though there has been a decline in the production of citrus, export trends portrayed a 10\% increase between the 2008/09 to 2012/13 seasons. The value of citrus exportation by South Africa increased from R 659 million between 1996 to over R 9.3 billion in the year 2013, due to improved supply chains and post-harvest handling techniques (National Agricultural Marketing Council, 2015).

The National Agricultural Marketing Council (2014) and Department of Agriculture, Forestry and Fisheries (2015), state that citrus fruits contribute the largest share to South Africa's total fruit exports, in terms of both value and quantity. Therefore, citrus's share of total exports indicates a strong comparative advantage in terms of exportation. In the citrus group, oranges dominate the largest share of citrus production and exportation.

\subsection{Citrusdal weather}

The diverse weather and favourable climatic conditions in South Africa allows the country to produce a variety of citrus fruits (Department of Agriculture, Forestry and Fisheries, 2015). Citrus is subtropical in origin, but it also grows in Mediterranean climates such as the Western Cape. The Western Cape region is the third largest producer of citrus, accounting for $16 \%$ of nationwide citrus production (Department of Agriculture, Forestry and Fisheries, 2015). Citrusdal is an agricultural town situated near Cederberg Mountains in the Western Cape region. It is synonymous with citrus fruit farming and production. All citrus types and varieties are produced. Resident farmers also grow rooibos tea, buchu, and vegetables, produce honey and keep livestock.

The Western Cape climate has warm, dry summers and low rainfall winter seasons. The average annual temperature is $24.4^{\circ} \mathrm{C}$, with January being the hottest month and July being the coldest. According to Goble (2009) citrus does well in areas where temperatures are between $10^{\circ} \mathrm{C}$ to $30^{\circ} \mathrm{C}$, with optimum temperatures being between $20^{\circ} \mathrm{C}$ to $28^{\circ} \mathrm{C}$. Owing to its Mediterranean type of climate, the weather in Citrusdal is described as suitable for the citrus season. There is little rainfall throughout the year. Approximately $315 \mathrm{~mm}$ precipitation falls annually. Figure 5 depicts the precipitation that 
falls annually. Citrus production requires large amounts of water especially during fruit setting stage. In Citrusdal, the lack of enough rainfall is substituted by irrigation systems.

\section{CLIMATE GRAPH CITRUSDAL}

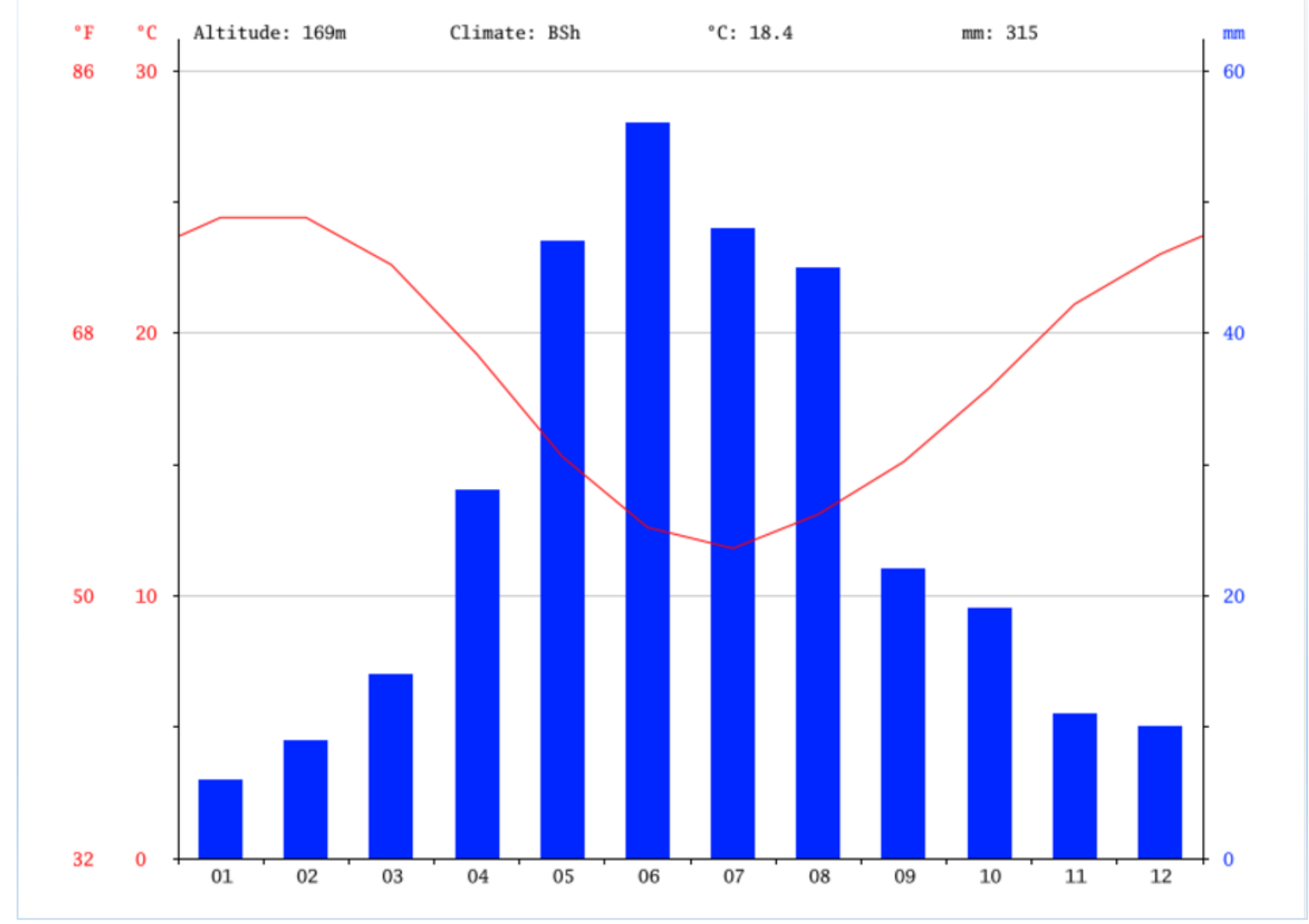

Figure 5: Precipitation in Citrusdal region

Source: Sa-Venues, 2017

Citrus production thrives in mild and almost frost-free areas where temperatures rarely drop below $2{ }^{\circ} \mathrm{C}$ (Goble, 2009). However, it is worth noting that citrus susceptibility to frost depends on the characteristics of individual cultivars and the intensity and duration of the cold (Geisel \& Unruh, 2003). Some citrus varieties are cold-hardy, meaning they have the ability to withstand frost for a certain period of time. For instance, navel oranges, sweet oranges, kumquats, grapefruits and satsumas are described as cold-hardy citrus (Geisel \& Unruh, 2003).

It is important to note that due to changing global climatic patterns, abnormal weather patterns were experienced during the 2017 citrus season (Marais, 2017). Navel oranges in the Citrusdal region were subjected to fruit splitting and dropping due to unfavourable climatic conditions encountered during 
different fruit development phases. According to Stander (2013), fruit splitting is caused by pressure resulting from the expansion of the pulp of fruit on the rind, which eventually causes a fissure leading to the fruit rind splitting. Fruit splitting is influenced by environmental factors such as irregular water supply, high temperatures, and relative humidity and high winds. It can occur in three stages, namely the cell division, increase in fruit volume and ripening stages (Stander, 2013). Six of the nine provinces in South Africa, including the Western Cape were declared as drought stricken areas, which contributed largely to the fruit split. Due to environmental changes, the Western Cape also experienced unusual excessive autumn heat, which also contributed to the fruit splitting occurrence (South African Fruit Exporters, 2017). Navel oranges and their cultivars are prone to fruit splitting (Stander, 2013). Approximately 40\% of the 2017 season's navel oranges were lost due to fruit splitting and dropping off the trees, meaning that there was an inevitable drop in exportation volumes as a split in fruit increases the chances of rind infections leading to fruit not being considered for exportation (Van Aardt, 2017). Citrusdal was the third worst affected region by the mentioned occurrence.

\subsection{Oranges (Citrus Sinesis)}

Oranges are the most produced citrus variety in South Africa (National Agricultural Marketing Council, 2015; Department of Agriculture, Forestry and Fisheries, 2015; Citrus Academy, n.d). Oranges accounted for a production average share of $81 \%$ in the 2008/09 to 2012/13 seasons, while during the 2015/2016 season they accounted for 63\%. Oranges' annual production value was estimated at R 71.2 million for 2016. Oranges had a $46 \%$ share of the citrus exports during the 2015/2016 season. The substantial decline in production and exports was due to a decrease in production volumes, because of hot weather conditions and lack of rainfall linked to the drought.

South Africa is the second largest exporter of oranges worldwide and accounts for a quarter of international exported oranges, with an average share of 25\% during the 2015/2016 season (National Agricultural Marketing Council, 2015). Figure 6 depicts orange export distribution since 2007-2016. Oranges fetch higher returns in export markets (Department of Agriculture, Forestry and Fisheries, 2015). Approximately 1138400 tons of oranges, with a net worth of R 6.4 billion, were exported by South Africa to different end destinations in 2014 (Department of Agriculture, Forestry and Fisheries, 2015). The majority of South Africa's export markets for oranges are the European Union, Middle East and Asian markets. Figure 7 depicts the main destinations for oranges. 


\section{ORANGE EXPORTS}

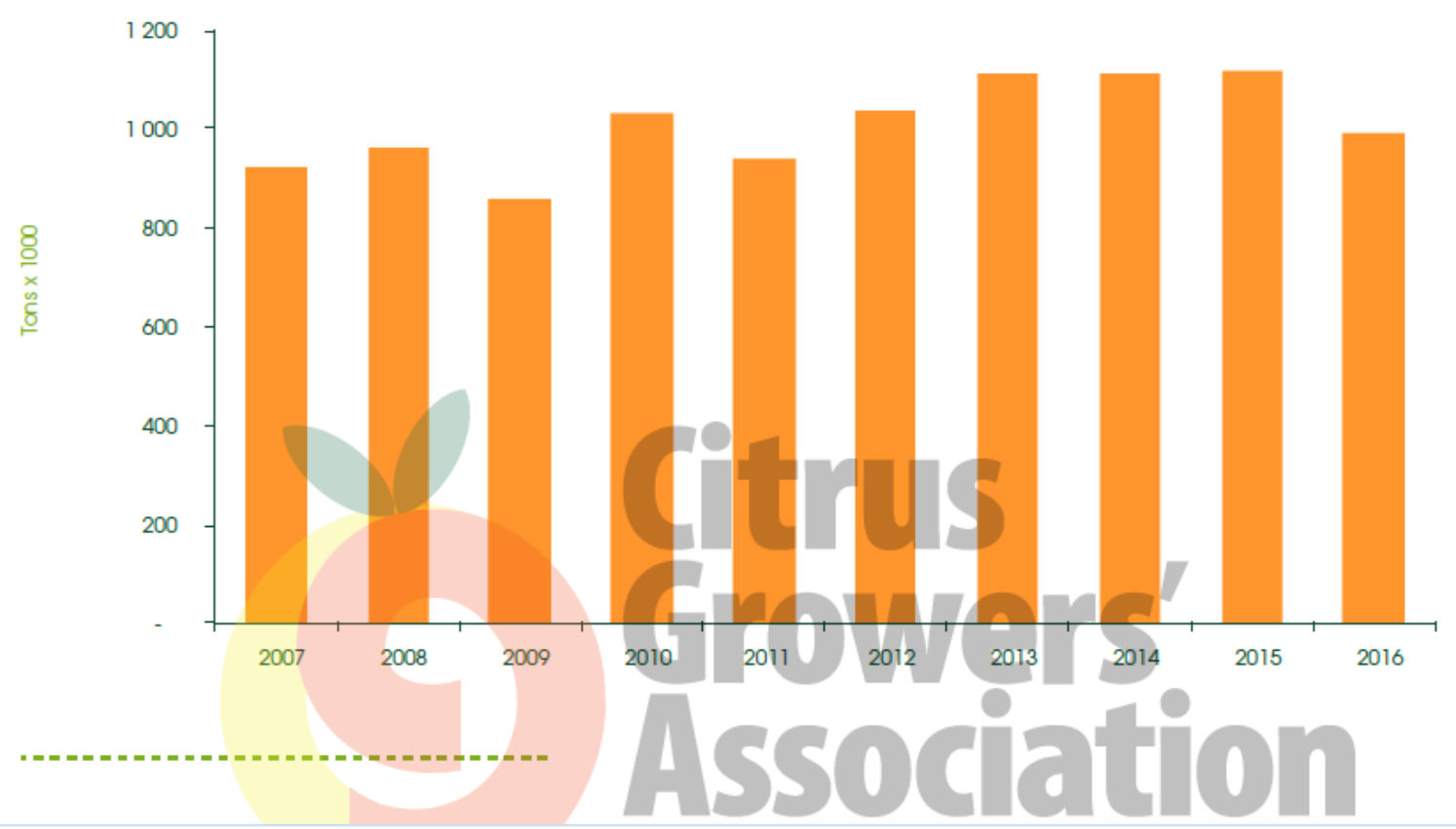

Figure 6: Orange export distribution in global markets

Source: Citrus Growers Association, 2016

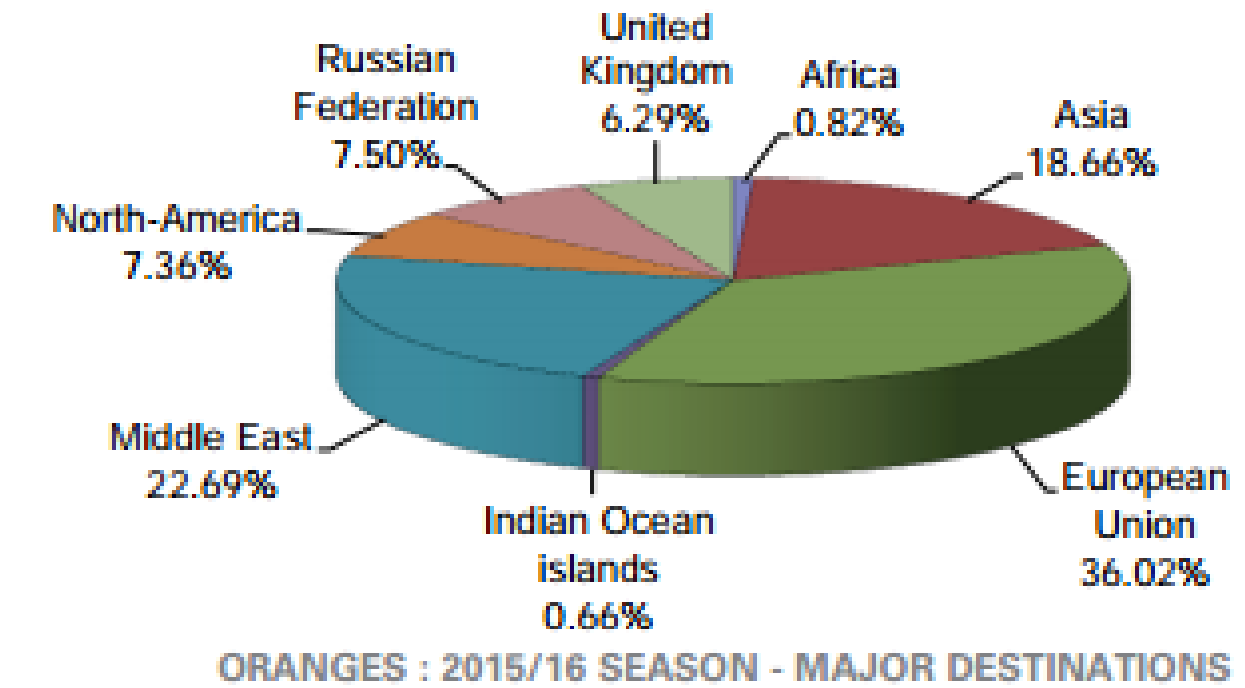

Figure 7: South Africa's main destinations for oranges

Source: Fresh Fruit Trade SA, 2017

Every citrus type and variety has different cultivars. The selection of different cultivars makes it possible for the production of fruit of superior quality throughout the season (Lee, 2016). Cultivars 
are a group of cultivated plants with distinct characteristics (Lee, 2016). For example, palmer orange, navelina orange, bahianinha orange are from the navel cultivar. Navels are the earliest maturing variety of oranges and produce seedless fruit, which is larger than other varieties. Navels have a deep orange, easy to peel rinds and a sweet flavour (Saunt, 2000). They are perceived as an excellent variety for consumption. They are one of the most popular varieties planted in South Africa. Navels are an important group in the orange variety due to their excellent quality (Ladaniya, 2008). In 2015, navels were the second largest variety planted (15 930 ha). The Eastern Cape Province is the leading grower of navel oranges with $41 \%$ production area, followed by Limpopo at $26 \%$ and the Western Cape at $25 \%$. Navels grow best and produce superior fruit quality where the climate is Mediterranean. South Africa is the biggest exporter of navel oranges in the Southern Hemisphere (Anon, 2017). As much as South Africa exports large volumes of oranges to end destinations, pests and diseases have been identified as one of the major limiting factors to production and exportation.

\subsection{Citrus pests and diseases}

There are different pests and diseases that affect citrus in South Africa. Citrus diseases are fungal and bacterial infections that affect citrus plants and fruit, whilst citrus pests are insects, which cause damage and illness to fruit plants. Pests fall into a number of different categories, namely, cosmetic pests, production pests and phytosanitary pests. The most common are phytosanitary pests, which are endemic to a production area. They are pests, which export markets do not want to allow in their countries, for example, citrus fruit flies and false codling moths. They are best described as international quarantine pests (Ladaniya, 2008). Pests and diseases are known to contribute to citrus decline as some play a major role in reducing fruit yields, limiting access to potential fruit export markets due to quarantine restrictions imposed by an importing country. South Africa is home to a number of species of the citrus fruit flies, two of which are of economic significance owing to their ability to disrupt fruit production and cause export restrictions (Ladaniya, 2008). The two species are the Mediterranean fly (Ceratitis Capitata) and the Natal fruit fly (Ceratitis Rosa). It is estimated that crop losses and pests resulting from fruit flies amount to more than R20 million per year in the Western Cape alone (Ladaniya, 2008).

A female fruit fly lays its eggs just underneath the fruit skin. Immediately after hatching, the larvae begin to feed and burrow into the pulp of the host. There are three larval instars inside the fruit. Pupariating larvae then pops out of the fruit and jump along the ground to suitable pupation sites in the soil. Soon after adult emergence, the individual starts foraging for food. Adult flies require a variety of nutrients to survive and reproduce. Natural food for adult flies include fruit juices, 
homopteran honeydew, bird droppings, nectar, plant sap exuding from the trunks of trees, stem, leaf or fruit injuries and glandular plant secretions.

\subsubsection{The Mediterranean fruit fly (Ceratitis capitata)}

The Mediterranean fruit fly (Medfly) is considered one of the most invasive insect species (Terblanche, Addison, Nyamukondiwa \& Manrakhan, 2012). It has been recorded on close to 400 plant species worldwide. Several aspects of biology, that is, polygaphy, short generation times and rapid behavioural and physiological adaptation to new environments, have facilitated the Mediterranean fly's invasion and establishment success (Terblanche, Addison, Nyamukondiwa \& Manrakhan, 2012). It is one of the most destructive fruit pests, as it possesses the ability to tolerate cooler climates better than other species of the fruit flies. Mediterranean fruit flies measure approximately $6 \mathrm{~mm}$ in length and they lay their eggs within mature fruit. The emerging larvae then feeds on the pulp of host fruits, eventually reducing it to an inedible mass (Umeh, Olaniyan, Ker \& Andir, 2004). The Mediterranean fly is mostly attracted to mandarins, lemons, clementines, and navels.

\subsubsection{The Natal fruit fly (Ceratitis rosa)}

The Natal fruit fly, which ranks second to the Mediterranean fly, is also considered a major pest of a number of commercial fruits and has similar environmental requirements. It has been recorded in more than 100 plant species in Africa and on Indian Ocean islands. The Natal fly succeeds in cooler, wetter environmental conditions. Its appearance looks similar to that of the Mediterranean fruit fly, but it is larger in size. The Natal fruit fly is recognised by its characteristic pattern of brown wing bands and the three black areas in the apical half of the scutellum (Terblanche, Addison, Nyamukondiwa \& Manrakhan, 2012).

\subsubsection{False Codling Moth (Thaumatotibia leucotreta)}

False Codling Moth (FCM) is another pest, which causes serious concern in the citrus industry. It is an indigenous pest of citrus in Southern Africa and it is a typical pest. It has a broad host range and has been recorded in over 80 different species of trees, for instance stone fruit, pome, avocados and citrus (Gobler, 2009). The adult female lays its eggs on the host plant, then the larvae will penetrate into the fruit within minutes of hatching. Infestation causes fruit to drop off the plant. FCM attacks fruit at any stage and larvae can even develop in hard green fruit. Fruit damaged by FCM becomes vulnerable to secondary pests such as fungal organisms and scavengers. FCM is an internal feeder, therefore few symptoms are displayed by the larvae (USDA, 2011). Brown spots on fruit and dark 
brown residue are visible signs of infestation. FCM causes the rind of the fruit to turn yellowish-bown as tissue decays and collapses. Infested fruit also develops spots and mold and premature ripening can occur (USDA, 2011). FCM infects most citrus types, with navels being the most prone to attacks. Whilst there are other pests that affect citrus, FCM, the Mediterranean fruit fly and the Natal fruit fly are the three major pests that cause most phytosanitary concern. FCM causes a high phytosanitary import threat particularly in the USA, because vast areas in the south western states in USA are under agricultural production and they have the same climatic characteristics as South Africa (Gobler, 2009).

\subsubsection{Citrus Black Spot}

Citrus Black Spot (CBS) is a foliar disease caused by a fungal pathogen called guinardia citricarpa, affecting citrus plants causing a reduction in fruit quality and quantity. Guinardia citricarpa occurs for a large part of its life cycle in an entophytic state. The pathogen causes unsightly lesions on the rind, spoiling the appeal of the fruit with navels, valencias, lemons and grapefruit being the most sensitive (Hattingh, le Roux, Schutte, 2000). All citrus is susceptible to CBS with the exception of sour oranges and its cultivars, rough lemons and acid limes that are insensitive to the pathogen (Truter, 2010). Black spot occurs in several forms called hard spots, cracked spots, false melanose and virulent spots. Each of the spots has different symptoms. The most common and diagnostic symptom is the hard spot. The lesions on the rind are small, round, sunken with grey centres and brick-red margins. The disease is widespread and occurs in countries like Kenya, Ghana, India, Swaziland, South Africa, USA, Australia and Taiwan (Truter, 2012). However, the disease is restricted by specific climatic parameters, with cold and wet conditions during winter as indicated as the main restrictive condition parameters. The Western Cape has been recorded as CBS free, which is why citrus can be exported to North America (Stotter, 2009).

Economic losses that are attributed to CBS include premature fruit drop, lower market value of symptomatic fruit and higher production costs due to extensive control programmes (Truter, 2010). CBS may also cause total loss of the marketable crop in some areas as asymptomatic export fruit may develop CBS symptoms while in transit and may be rejected upon arrival. Whole consignments of fruit may be rejected at pack houses or ports if, during inspection, they are found to contain affected fruit. Consequently, CBS has a great impact on the global trade of citrus.

Citrus diseases and pests have a profound impact on citrus production and quality by increasing production costs, large losses of harvestable and/or marketable fruit (Truter, 2010). Since CBS and the citrus fruit flies can be transported from one part of the world to another in a matter of hours, they 
are classified as quarantine diseases, resulting in barriers to trade. Programmes have been developed to help combat pests and diseases. Several methods used for control of pests and diseases are male annihilation technique, bait spraying, sterile insect technique and cold sterilisation. The most common method that is applied is cold sterilisation.

\subsection{Regulatory organisations and their roles in the export cold chain}

Regulations and protocols are outlined by several regulatory bodies and are a prerequisite for exportation of citrus to global markets. These organisations stipulate certain standards that must be met for the exportation process to be facilitated. Organisations that play a major role in the exportation of citrus to the US are the Perishable Products Export Control Board (PPECB) and the United States Department of Agriculture (USDA).

2.14.1. The role of the PPECB in the export cold chain

The PPECB is an independent South African service provider of quality certification and cold chain management services for producers and exporters of perishable products appointed by the Department of Agriculture to act on their behalf (PPECB, 2017). The inception of the PPECB came about in 1926 when a provision was released by parliament that all farming spheres had to be represented by a new board. The board was formed to take over responsibilities for the shipping of perishable export products, collection of growers' estimates and the allocation of pre-cooling and refrigerated shipping space and regulate exportation of all perishable produce (De Beer, Paterson, \& Olivier, 2003). Today, the PPECB controls all perishable products exported from South Africa, which has a value of approximately R20 billion per year (Department of Agriculture, Forestry and Fisheries, 2017).

The company employs more than 300 people, who deal with more than 200 products and 500 varieties. There are 50 service types, over 30 offices in eleven production areas, at more than 1500 locations (Department of Agriculture, Forestry and Fisheries, 2017). The PPECB plays a critical role in the South African fruit industry by ensuring that all perishable products that are destined for export satisfy internationally accepted quality levels (Freiboth, 2012). Figure 8 depicts the services provided by the PPECB. 


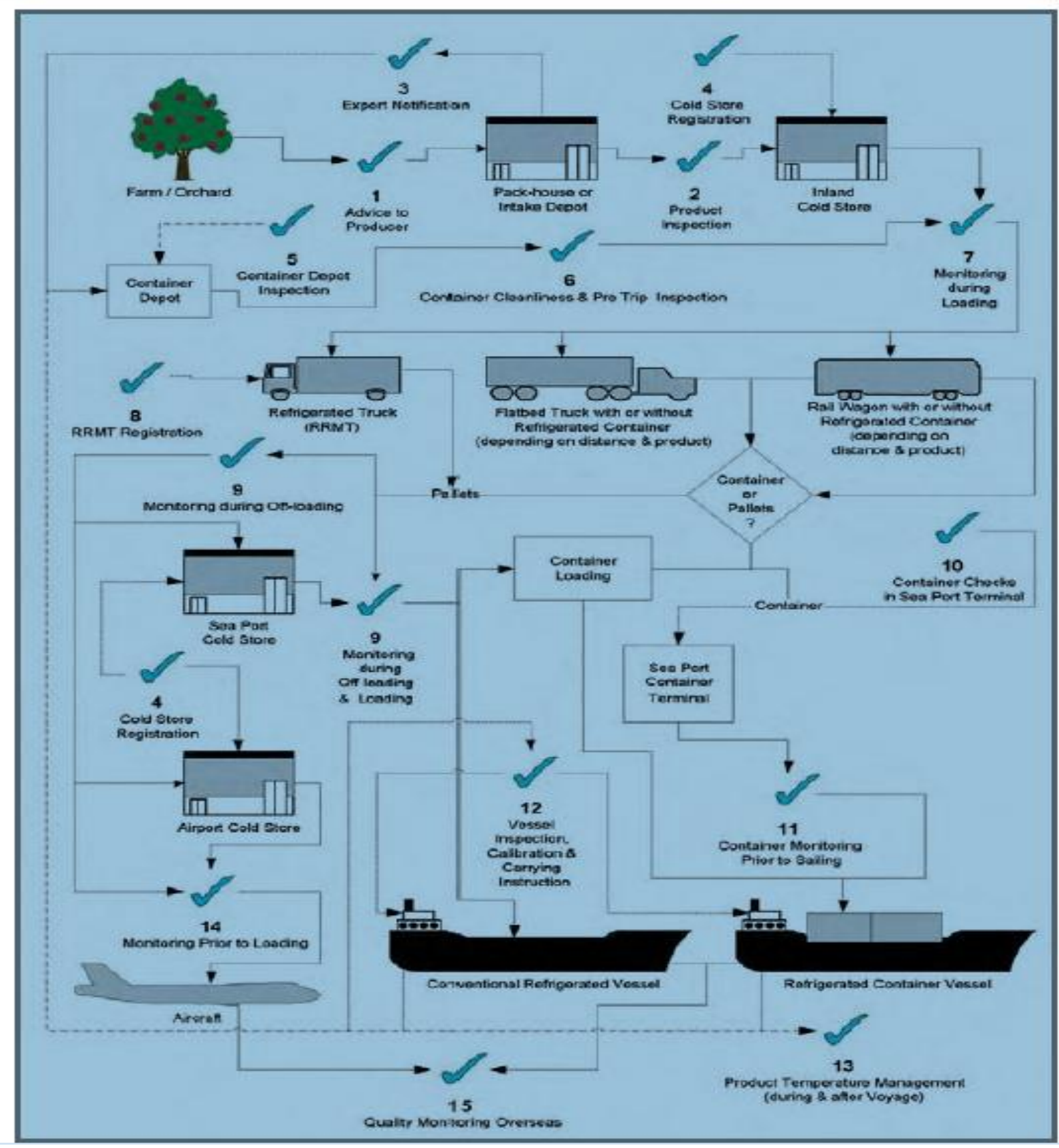

Figure 8: Services offered by PPECB

Source: PPECB, 2013

One of the main services provided to the fruit industry by the PPECB is the inspection of fruit destined for export and cold management services. Inspectors are stationed across South Africa and trained to inspect over 200 product types (PPECB, 2017). In the fruit industry, inspections are conducted in pack houses, cold stores and at loading depots.

Products that are inspected for export by the PPECB are checked according to product standards. The purpose of the standards is to provide for a disciplined export and minimum quality platform (Heilbron, 2016). Export standards are updated annually with input from various industry bodies, the 
Department of Agriculture, Forestry and Fisheries and PPECB. Updates also include international developments (Heilbron, 2016). Standards prescribe requirements for quality, food safety, traceability, containers, packaging and sampling. The standards also prescribe methods according to which products must be evaluated, as well as tolerances allowing for maximum permissible deviations from quality defects on export products (Heilbron, 2016). The main type of product inspected by the PPECB is citrus, with approximately 117 million cartons inspected in the 2015/2016 season (PPECB, 2017).

The provision of various services to the export cold chain by the PPECB results in high standards of quality assurance, reduced risks and claims. For example, after the degreening and pack house processes are completed and navel oranges are awaiting loading, the PPECB checks fruit for defects and if they meet export standards. If not, fruit is rejected before exportation. This reduces the risk of fruit being rejected on arrival at the destination, saving clients substantial sums of money. The PPECB also checks for pallet standards, carton requirements, pallet markings, optimum storage temperature, amongst other things. The checks are conducted to ensure that all role players in the export cold chain adhere to set out handling standards and protocols. These standards and protocols are published annually by the PPECB in their Blue Book. For oranges, the standards and protocols are depicted in Table 3.

Table 3: PPECB protocols for oranges

\begin{tabular}{|l|l|}
\hline BASIC PPECB PROTOCOLS & ORANGES (NA VELS) \\
\hline $\begin{array}{l}\text { Optimal temperature (False Codling } \\
\text { Moth) }\end{array}$ & $-0.6^{\circ} \mathrm{C}$ (minus $31^{\circ} \mathrm{F}$ ) \\
\hline Exposure Period & 22 days \\
\hline Storage Life & $2-3$ weeks \\
\hline
\end{tabular}

Source: PPECB, 2013

\subsubsection{The Role of the USDA}

The USDA, also known as the agricultural department, is responsible for executing laws related to farming, agriculture and food. It aims to promote agricultural trade and production. The Animal and Plant Health Inspection Service division (APHIS), through certain programs, is responsible for 
ensuring that navel oranges exported to the end market are safe, correctly labelled and administered with the correct temperatures. The Plant Protection and Quarantine (PPQ) program regulates the importation of products to safeguard US agriculture from risks associated with entry of invasive pests and diseases that are known to be economically and environmentally detrimental (USDA, 2017). The USDA works together with DAFF to ensure cold sterilisation protocols are met. Inspectors from the USDA are stationed at two stages of the export cold chain of oranges, i.e. at cold stores and the port. Upon passing inspection at the cold store, navel oranges are placed in forced air-cooling prior to being transported to the end destination. If cold sterilisation protocols are not met, inspectors from USDA either reject the fruit pallets or prolong the days that navel oranges have to stand in cold rooms until the correct temperatures are met (Roxburgh, 2017).

\subsection{The role of Ports in an economy}

According to Dwarakish \& Salim (2005), a port is a location on a coast or shore containing one or more harbours where ships can dock and transfer people or cargo to or from land. Ports constitute an important economic activity. Goedhals (2003) states that trade in countries, even those that are landlocked, are dependent on seaports. Ports are also important for the support of economic activities inland since they act as a crucial connection between sea and land transportation. Ports are one of the primary components of the general transportation sector and are linked to expanding the world economy (Dwarakish \& Salim, 2015). They serve as means of integration into the global economic system. Within a port, a wide range of services are performed, these include, cargo handling, mooring, towage and container loading. Ports have two main advantages; they perform roles as important links of hinterlands to overseas markets and are cheaper than other transportation modes (Dwarakish \& Salim, 2015).

Ports are a key component of the logistics cold chain and therefore, their operation has a direct effect on relevant economic variables such as export competitiveness, import prices thus affecting economic development (Dwarakish \& Salim, 2015). Goedhals (2003) concurs that the efficiency of ports serving a country affects the health of its economic activities.

The results of a study conducted by Dwarakish \& Salim (2005) concluded that ports are a vital part of a country's economy. Growth of ports unerringly boosts the country's economy. They lead to greater trade activity, increased supply and greater foreign reserves.

South Africa's ports serve as conduits for trade between the country and its trading partners in the Southern African region (South African Maritime Safety Authority, 2014). Ninety-five percent (95\%) 
of all trade to the Southern African region passes through South African ports (Haasbroek, 2013). South Africa has eight commercial ports, namely, Richards's Bay, Durban, East London, Ngqura, Port Elizabeth, Mossel Bay, Cape Town and Saldanha Bay (Transnet National Ports Authority, 2017). Figure 9 shows a map of South African Ports. The port system in South Africa comprises of multipurpose, container, specialised-bulk ports and a transhipment cargo port.

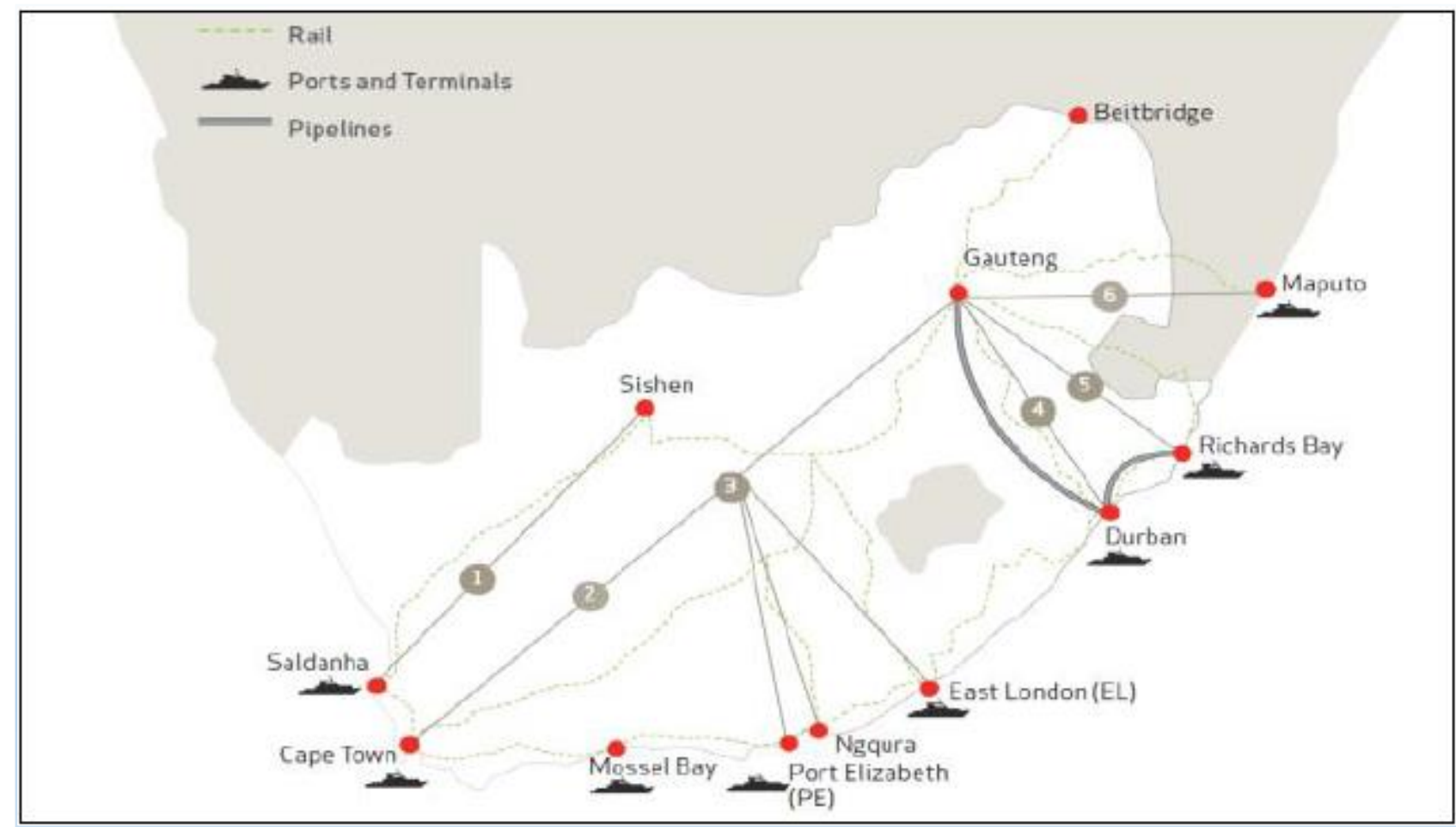

Figure 9: South African Ports

Source: South African Maritime Safety Authority, 2014

Transnet National Ports Authority (TNPA) controls and manages the country's ports and provides port services, with limited private sector competition (South African Maritime Safety Authority, 2014).

The Port of Cape Town is the focus of the study as navel oranges produced in the Western Cape are exported through the Multipurpose Terminal at the Port of Cape Town.

\subsubsection{The Port of Cape Town}

The history of the Port of Cape Town dates back to 1652 when Jan Van Riebeeck established a victualing station. The first harbour constructed was a harbour built in 1654. Today, the Port of Cape Town is enormously valuable to South Africa's economy (Goedhals, 2003). The Port of Cape Town is one of the most well-known ports worldwide (Stander, 2014). The port is situated on one of the most important international trade routes and it is one of the busiest ports in the country. It serves 
cargo moving between Europe, the Western hemisphere, Middle East and Australia. It has direct access to South Africa's road network as well as rail infrastructure connecting to all the country's major cities (Transnet National Ports Authority, 2017). Due to its position on one of the world's busiest routes, it has led to it being a major repair and transhipment hub for the West African oil and Asian fishing industries (Stander, 2014).

The port serves a critical node in the export cold chain of fruit mainly because of the fact that the distance from Cape Town to Europe and America is shorter than from the Port of Durban. Fruit is consigned via the port from places like Swaziland, Mpumalanga and Limpopo (Haasbroek, 2013). The port also serves a role as primary and general cargo port for the Western Cape region, making it a critical node in the export cold chain of fresh fruit.

The Port of Cape Town provides container handling, bulk and general cargo handling services. In addition, ship repair, cruise liners, storage services are also provided (Transnet, 2014). The port has two major docks: The Ben Schoeman and the Duncan Dock. The Ben Schoeman Dock is home to the container terminal and the Duncan Dock is used for general cargo services. The Port of Cape Town operates 24 hours a day, seven days per week (Transnet, 2014).

The port is the second largest container port in South Africa after the Port of Durban and handles large volumes of fresh fruit. The Port handled 853399 TEU's during the 2012/2013 fiscal year (Stander, 2014). The port recently completed the expansion of its container terminal to handle larger vessels and increase throughout (Transnet, 2014). The expansion was undertaken as part of a fiveyear expansion programme, which started in 2008. The goal of the expansion programme was to transform the container terminal facilities into a modern class facility, which would be capable to handle double of its cargo capacity (Transnet, 2014). Figure 10 depicts an aerial view of the port. 


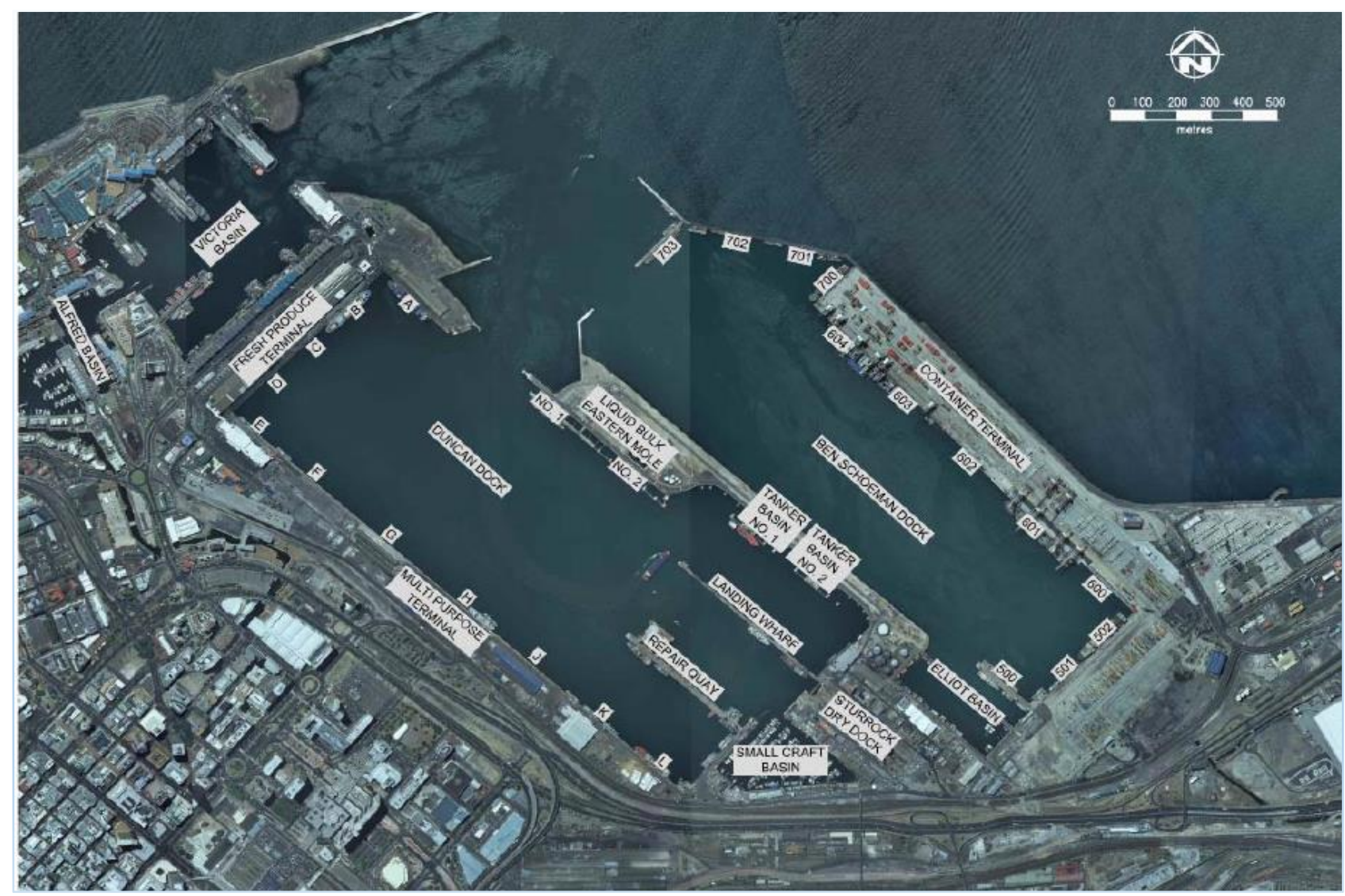

Figure 10: An aerial view of the Port of Cape Town

Source: Transnet, 2014

\subsubsection{The Multipurpose Terminal}

The Cape Town multipurpose terminal is situated at the Duncan Dock area. It handles a variety of breakbulk and bulk cargoes including fruit, agricultural products, maize, barley, steel, metal, fish, copper, soda ash, fertilizer and timber. The terminal operates within an area with a quayside length of almost 1.8 kilometres (Transnet Port Terminals, 2017). The terminal operates across seven berths each handling bulk or breakbulk cargo and is serviced with harbour cranes or ships own gear. The multipurpose terminal also houses the Fresh Produce Terminal (FPT), which handles the cold treatment (sterilisation) conventional programme of fruits destined to the United States of America and direct conventional shipments to Russia (Van Niekerk, 2017). Navel oranges destined for the USA market are shipped via conventional vessels, also known as reefer vessels, through the Fresh Produce Terminal.

The Fresh Produce Terminal utilises a data management system called WMS for the support of its logistical operations. However, the multipurpose terminal utilises the NAVIS Synchronous Planning and Real-time control system. This system is a web-based terminal operating system that provides 
terminals with tools needed to optimise operational performance (Transnet Port Terminals, 2017). The system enables the monitoring of cargo along land transport routes and during shipment loading. The system offers cargo related information from the point of entry at the terminal up to the loading of vessels. Clients can interact with the system through a customer access portal, which enhances visibility for each link in the chain (Transnet Port Terminals, 2017). The benefits of the system include electronic functionality, availability of real-time tracking and increased efficiency (Haasbroek, 2013). The NAVIS system improves overall efficiency of the entire export cold chain.

\subsubsection{Factors affecting cold chain performance at the Port of Cape Town}

A number of factors hinder efficient port operations. These factors are most prone in the Container Terminal, but they also tend to affect the operations of the multipurpose terminal.

\subsubsection{Delays upon entering the port}

The majority of goods are transported to the port via trucks. According to Stander (2014), the terminal gate is one of the major sources of congestion. During peak season, there are a large number of trucks waiting to enter the port at the same time. The Duncan road located within the port, which leads to the port's terminals, is occasionally congested, especially during fruit peak season. In some instances, trucks queue for hours to enter through the port gate. Such delays lead to breaks in the cold chain as trucks carrying palletised fruit from the pack house where fruit are pre-cooled prior to the transportation leg pick up heat during the journey.

Stander (2014) and Haasbroek (2013) state that there is still room for improvement. For instance, the Port of Ngqura has an overhead scanning facility to scan trucks information and container content and automatically directs the driver to an allocated stacking area (Haasbroek, 2013).

\subsubsection{Faulty paperwork}

Faulty paperwork is also a source of delays at the port. If consignment notes that are handed to the intake clerk are incorrect, the process of receiving goods takes a much longer time than necessary.

\subsubsection{Inept personnel and breakdown of equipment}

Incompetency in getting the job done by port personnel is yet another source of delays. Employees can have an impact on port processes including security personnel, crane operators and everyone involved in the shipping process. Another source of delays is breaking down of important equipment. Equipment and machinery maintenance is of utmost important as it possibly prevents breakdowns as far as possible (Haasbroek, 2013). 


\subsubsection{Wind delays}

Wind is one of the major causes of delays at the Port of Cape Town. According to Haasbroek (2013), the industry that is mostly affected by wind delays is that of perishable products. Cape Town is prone to high speed winds. Wind delays mostly occur during loading and offloading of cargo. Navel oranges destined to the USA are only ferried through the Port of Cape Town, which impacts negatively on the fruit as vessels may be obliged to call for export despite wind conditions. The speeding up of vessels to counter the time lost with delays is a costly project, which is invested in once in a while (Haasbroek, 2013). This could mean fruit arriving at their end destination at a later date than expected.

\subsubsection{Delays during offloading}

Stander (2014) and Haasbroek (2013) state that the Port of Cape Town, especially the container terminal, does not have sufficient equipment to handle the large number of palletised fruits and containers entering the port during peak times. This in turn causes delays as trucks have to queue in order to be offloaded.

\subsection{South Africa's competitiveness compared to other citrus producing and exporting nations}

According to Matare (2012), South Africa has been the second largest exporter of fresh citrus since 2006. Countries that are also renowned as leading producers and exporters of citrus include: Spain, the United States of America, Brazil, India, China, Egypt, Turkey and Mexico (Spreen, 2010). In this section, the competitiveness of South Africa's citrus industry is compared to that of Spain, as it is the leading producer and exporter of citrus in the world and Chile, whose biggest competitor is the Republic of South Africa.

\subsubsection{Spain}

Spain is the leading producer and exporter of citrus globally. The production of fresh products is estimated at 18 million tonnes, of which 11,112,427 tonnes are destined for foreign markets (King, 2014). Exports of fresh fruit account for approximately half of the industry turnover, with a total value of $€ 9.641$ million in 2012. The country is also forecast to experience a growth of twenty percent annually in production compared to 2015 (King, 2014). In addition to being the largest producer of citrus, it is also the primary orange producer in the European Union. The leading varieties that are grown are navels, salustines, valencias, navelates and sanguinelios (King, 2014). Exports represent the highest share, with almost $50 \%$ of citrus produced destined for international markets. The country 
is the main exporter of oranges to markets such as the European Union, China, Brazil, United Arab Emirates, Saudi Arabia and until recently, Russia (King, 2014).

The Spanish citrus industry stands out mainly because of large diversity of production areas, an extensive commercialisation calendar that covers the entire year, great innovation capability and close integration of production and commercialisation at the point of origin (King, 2014).

Compared to the citrus industry of South Africa, Spain has the upper hand in terms of the country's production scale; export overland due to shorter market distances, production technology and government policies. The country has a large diversity of production areas meaning the production volume of citrus compared to that of South Africa is much more vast, for instance, a total area of 64 510 hectares was under citrus production in South Africa in 2014 (Department of Agriculture, Forestry and Fisheries, 2015), whereas a total area of 146700 hectares was under production in Spain (Valverde, 2016). The majority of Spain's citrus exports remain with the European Union, which means there is close access and shorter distance to the market. Citrus is exported overland, using cold trucks and low volumes are exported via water transportation (Cronje, 2017). Since a lower percentage of Spain's citrus products, for example, oranges, are exported to the United States of America, less money is spent on cold sterilisation protocols. For South Africa, significant sums of money are spent on cold sterilisation protocols for shipments to the US, thus increasing production costs. This may also be attributed to the fact that the Northern American market has potential for growth hence South Africa's continual exportation to the continent. Another advantage that Spain has over South Africa is governmental policies and support. According to the United States International Trade Commission (2006), Spain's citrus industry is supported by the European Union's longstanding production programs and related agricultural policies. For citrus growers and producers, the primary support mechanisms include compensation for withdrawals, which are funds paid to remove the product from the market place in an effort to stabilise prices. Other support mechanisms include export refunds, compensation to encourage fruit processing and co-financing of operational funds for producer organisations. Such policies can be considered to provide a competitive advantage to Spain's citrus production (United States International Trade Commission, 2006). Other competitive factors between the two countries are shown in Table 4. 
Table 4: Competitive factors between Spain and South Africa's citrus production

\begin{tabular}{|c|c|c|}
\hline $\begin{array}{l}\text { COMPETITIVE } \\
\text { FACTORS }\end{array}$ & SPAIN & SOUTH AFRICA \\
\hline Natural Endowments & $\begin{array}{l}\text { Spain's Mediterranean climate is } \\
\text { optimal for growing citrus, variable } \\
\text { rainfall and periods of drought can } \\
\text { negatively affect production. Soil } \\
\text { quality in Spain can be very poor, } \\
\text { characterized by low fertility and low } \\
\text { nutrient levels. This raises the cost of } \\
\text { growing citrus. }\end{array}$ & $\begin{array}{l}\text { Many areas of major citrus production } \\
\text { are frost free, and frost prevention is } \\
\text { not of concern to growers. The } \\
\text { Limpopo and Mpumalanga states } \\
\text { within the region have some of the } \\
\text { most fertile lands in the world under } \\
\text { citrus production. However, water in } \\
\text { South Africa is extremely scarce in } \\
\text { most regions. }\end{array}$ \\
\hline Water Issues & $\begin{array}{l}\text { Spain's inconsistent supply of fresh } \\
\text { water is the key factor limiting its } \\
\text { competitiveness in the citrus market. } \\
\text { However, Citrus producing regions } \\
\text { tend to have higher percentages of } \\
\text { irrigated land. Under the EU's rural } \\
\text { development program, citrus farms } \\
\text { have been provided funding to switch } \\
\text { to more efficient drip irrigation } \\
\text { systems. }\end{array}$ & $\begin{array}{l}\text { The importance of water rights is } \\
\text { reflected in land values. Water is } \\
\text { rationed through a transferrable quota } \\
\text { that can take over one year to obtain if } \\
\text { not purchased with the entitled land. }\end{array}$ \\
\hline Pests and Diseases & $\begin{array}{l}\text { Spain has significant problems with } \\
\text { tristeza and medfly. Numerous } \\
\text { programs are implemented to help } \\
\text { combat these pest and disease } \\
\text { conditions. }\end{array}$ & $\begin{array}{l}\text { South Africa has a wide range of pests } \\
\text { and diseases. The three main concerns } \\
\text { to South African producers relate to } \\
\text { export restrictions due to the presence } \\
\text { of 1) citrus blackspot, 2) false coddling } \\
\text { moth and 3) fruit flies. This has made } \\
\text { cold storage become an important and } \\
\text { necessary part of exports to protocol } \\
\text { markets like the US. }\end{array}$ \\
\hline Seasonality & $\begin{array}{l}\text { Spain's citrus varieties enable its } \\
\text { growing season to extend almost year- } \\
\text { round }\end{array}$ & $\begin{array}{l}\text { South African citrus season is counter- } \\
\text { seasonal to that of the northern } \\
\text { hemisphere. The season generally runs } \\
\text { from the end of March to the beginning } \\
\text { of October }\end{array}$ \\
\hline
\end{tabular}




\section{Government policies}

Supported by EU's long-standing
production programs.

Government assistance to the South African citrus industry is minimal. The government established an industry financed levy on citrus production to fund the CGA. Other government activities are limited to such areas as phytosanitary regulations and trade negotiations.

Source: United States International Trade Commission, 2006

\subsubsection{Chile}

Chile is a producer and exporter of fruit; however, its role in the international citrus market is relatively minor. Chile accounts for a small share of global citrus production and exports. Although it accounts for a relatively small share, production of oranges has been increasing substantially. Chile grows several varieties of citrus fruits. The main types grown are navel oranges, lemons, clementines and mandarins. Lemons are the primary citrus fruit produced and exported, followed closely by oranges (Mandarins). The bulk of the country's output is marketed domestically, but there has been an increase in exportation. Chile's exportation market includes the United States of America, Japan, South Korea and the Netherlands. A majority of the country's exportation is to the US (Freshplaza, 2017). According to Freshplaza (2017), the biggest competitor for Chilean citrus is South Africa.

Chile's main challenges are its market base as new entrants such as Uruguay, Argentina and Peru are emerging. The country's citrus industry strength lies in its investments. Investments are contributed towards improving the quality of fruit as well as expanding the market base. Another advantage that Chile has over South Africa is the fact that the country's dry climate contributes to relatively low incidences of pests and diseases that affect citrus production. In addition, cold storage is not a major competitive factor affecting the Chilean citrus industry, as most fruits destined for exportation are shipped soon after harvest.

\subsubsection{South Africa's competitive strengths and weaknesses}

South Africa's citrus industry is among the top ten countries that dominate the citrus fruit export market, especially in the Southern Hemisphere (Ndou, 2012). The industry has maintained its competitive advantage in several markets. The industry has diverse opportunities to enhance its performance in export markets, which form part of the industry's strengths. Some of South Africa's citrus industry's strengths include, efficient export infrastructure that exist making markets easier to access. The industry is renowned for its excellent overall quality of fruit, high level of investment in 
current technology within pack houses and cold chain facilities and traceability systems are put in place as required by accreditation protocols (Department of Agriculture, Forestry and Fisheries, 2015). The industry is also supported by different structures. A number of entities provide help to producers and growers, for example, the Citrus Growers Association, which provides support to growers through research, production, marketing and market access. Some of the key organisations supporting the citrus industry are learning institutions, Fresh Produce Exporters Forum (FPEF), Citrus Research International (CRI), Agricultural Research Council (ARC), the Citrus Academy, Perishable Products Exporters Control Board (PPECB) and the National Department of Agriculture (NDA). These support structures play a major role in promoting the performance of the citrus industry in the market.

In terms of infrastructure, South Africa possesses world class infrastructure, including air transportation, road networks, water ports, which are all readily available, as well as well-developed cold chain facilities (Ndou, 2012). The wide range of climatic conditions furthermore provides an advantage of producing a wide range of cultivars that meet different consumer needs in different markets. The climatic conditions also help control pests and diseases, as some diseases and pests are more prevalent in certain climatic conditions than others are (Ndou, 2012). South Africa has a counter-season to its major northern hemisphere rivals, especially Europe. The advantage of a counter-season is that competition based on volumes exported to international markets may be lessened. According to Department of Agriculture, Forestry and Fisheries (2015), the citrus industry has seen an increase in demand due to consumers' demand for healthy diets.

The country's industry weaknesses are largely influenced by climatic conditions which production is dependent on. Drought and heatwave seasons increase the cost of production as irrigation systems have to be installed and maintained. Drought and heatwave seasons also mean challenging and unpredictable exportation volumes. For example, the PPECB inspected 112 million cartons of citrus destined for exportation in the 2016/2017 season as opposed to 117 million cartons during the previous season. Citrus markets also tend to be saturated and there is heavy reliance on the European Union market, which is also the main market for South Africa's competitors. The increased competition from Southern hemisphere counterparts like Chile and Brazil pose a threat to the industry (Department of Agriculture, Forestry and Fisheries, 2015). The export cold chain of citrus is also perceived as quite a lengthy chain, especially the processes beyond the pack house. Market prices also tend to be volatile especially in tough financial conditions such as the plummeting of the local currency. A study conducted by Ndou (2012) on the competitiveness of the South African citrus industry deemed government to have a negative impact on the export performance of the country's 
citrus. The study found that the education and environmental policy plus the tax system on investments and risk have been found to have a slightly above average impact on the competitiveness of the South African citrus industry. Table 4 summarises the SWOT analysis of the South African citrus industry.

Table 5: SWOT Analysis of the South African Citrus Industry

\begin{tabular}{|c|c|}
\hline Strengths & Weaknesses \\
\hline $\begin{array}{l}\text { The South African citrus fruit is } \\
\text { perceived as of high quality. } \\
\text { South Africa also possesses a } \\
\text { strong, positive trade reputation in } \\
\text { addition to similar transport time } \\
\text { and freight rates with other } \\
\text { Southern hemisphere suppliers. } \\
\text { Sound communication mechanisms } \\
\text { to majority of industrial participants }\end{array}$ & $\begin{array}{l}\text { The changing exchange rates } \\
\text { impact negatively on the price } \\
\text { competitiveness. } \\
\text { Lack of unique or differentiated } \\
\text { products } \\
\text { Relatively high input and capital } \\
\text { costs. } \\
\text { An element of fragmentation in the } \\
\text { industry. } \\
\text { Lengthy supply chain beyond the } \\
\text { pack house. } \\
\text { Lack of industry control on } \\
\text { efficiency and productivity in } \\
\text { supply chain beyond farm gate and } \\
\text { pack house door. } \\
\text { Poor skills and knowledge of the } \\
\text { new entrants }\end{array}$ \\
\hline Opportunities & Threats \\
\hline $\begin{array}{l}\text { Market access initiatives to the } \\
\text { Middle East, Asia (India, } \\
\text { Indonesia) and China. }\end{array}$ & $\begin{array}{l}\text { Increased price and quality } \\
\text { competition from Chile and } \\
\text { Argentina. }\end{array}$ \\
\hline
\end{tabular}




\begin{tabular}{|c|c|}
\hline $\begin{array}{l}\text { - Increasing demand due to the } \\
\text { consumers' demand for healthy } \\
\text { diets. } \\
\text { Increasing product awareness and } \\
\text { differentiation amongst urban based } \\
\text { consumers. } \\
\text { Potential to identify and target } \\
\text { higher priced supply windows or } \\
\text { market niches. } \\
\text { Strong potential to build brand } \\
\text { awareness for South African } \\
\text { products. }\end{array}$ & $\begin{array}{l}\text { Declining exchange rate } \\
\text { competitiveness versus other } \\
\text { southern hemisphere producers. } \\
\text { Oversupply of fruit into established } \\
\text { export markets. } \\
\text { Availability and cost of irrigation } \\
\text { water. } \\
\text { Impact of climate change especially } \\
\text { in the Western Cape. } \\
\text { Inflation rate with regard to cost of } \\
\text { labour and farming and also } \\
\text { packing prerequisites. } \\
\text { Currency variability, which is } \\
\text { influenced by the exchange rate. } \\
\text { Increased protectionism by the EU } \\
\text { and other established markets. } \\
\text { Citrus fruit diseases. }\end{array}$ \\
\hline
\end{tabular}

Source: Adapted from Department of Agriculture, Forestry and Fisheries (2015) \& Ndou (2012)

In spite of the challenges that the country's citrus industry faces, it has managed to cope with competition and challenges. There is a need for continuous research and innovation on how to capitalise on new opportunities as the industry is already a force to be reckoned with on the international market front.

\subsection{International cold chain best practices}

To develop the South African fruit export cold chain, it is important to examine international cold chain best practices. Best practices include training programs, guidelines, regulations, several initiatives and protocols aimed at improving agricultural and food industries in terms of food safety and quality, traceability along the supply chain and assuring sustainability for the export cold chain industry (Freiboth, 2012).

Spain is the leading producer of citrus, with leading producing regions such as Valencia, Andalusia and Catalonia. With Valencia as the leading citrus producing region, the Protected Geographic Indication (PGI) Citricios Valencios was created with the objective of protecting citrus fruits grown 
in the region of Valencia. The PGI is part of three schemes that were formed by the European Union to promote and protect the names of quality agricultural and food products. The PGI certification provides a quality guarantee that attests to fruit treatment throughout their cultivating, harvest and sale. Harvest fruit that is certified with the PGI citricos valencianos seal must meet high standards in terms of characteristics and appearance and can only be picked from certain areas of the tree where it obtains optimal ripening (United States International Trade Commission, 2006).

The National Centre for Cold Chain Development (NCCD) was established in India in 2012. The centre was established as an autonomous centre to work in close collaboration with the export cold chain industry and other stakeholders to promote and develop an integrated cold chain for agricultural perishables. The main objectives of NCCD are to recommend standards and protocols for cold chain infrastructure, suggest guidelines for human development and to recommend an appropriate policy framework for development of the cold chain. The centre also undertakes periodic revision to keep pace with technological advancements. In addition, it undertakes consultancy work, certification of cold storages and their ratings as well as advising government on issues relating to the development of integrated cold chain infrastructure in India. The aim is to help reduce post-harvest losses of perishable farm produce and the availability of farm fresh produce.

Citrus Research International (CRI), South Africa, in conjunction with the academic sector, is conducting a study on ambient loading (warm loading) of fruit. The study explores the promising cold chain protocol as an alternative to the commonly used Forced Air Cooling (FAC) of citrus prior to shipping. Ambient loading implies that fruit is loaded warm into refrigerated containers for cooling during long-haul transportation. As opposed to FAC, field heat is removed from inside the container. The practice is perceived as beneficial as it brings forth advantages such as logistical and economical savings, relieving the pressure on available precooling facilities needed for the cold disinfection treatment, reducing time and handling costs of pre-cooling pallets and early start of the cold chain, which could help in mitigating post-harvest losses. The practice is currently used for Valencia oranges and grapefruits; it is presently unknown how it will perform for fruits such as mandarins or navel oranges (Defraeye, Nicolai, Kirkman, Moore,van Niekerk, Verboven \& Cronje, 2016; Defraeye, Cronje, Verboven Nicolai, 2015).

The Asia Cold Centre in 2008 extended its coverages to providing information, expertise and experience on new post-harvest technologies. The centre also provides on-site validation of producing areas, more training for producers and growers and traceability throughout the supply chain. In addition, the centre is involved in ongoing research and development for the improvement of fresh 
produce to raise the benchmark for higher quality and extended shelf life. The Asian Cold Centre was initially formed to focus and assist Asian organisations to attain their Australian Logistics Assured Accreditation (ALA).

The Global Cold Chain Alliance was formed in 2007 as an umbrella organisation that represents all major industries involved in temperature-controlled logistics. The alliance is made up of organisations that provide cold chain services. The organisations include the International Association of Refrigerated Warehouses (IARW), the International Refrigerated Transportation Association (IRTA) and the International Association for Cold Storage Construction (IACSC). The alliance is by the World Food Logistics Organisation, which develops education and research for the cold chain industry and provides services enhancing the global cold chain.

\subsection{Previous studies}

A recent study conducted by Goedhals-Gerber et al., (2017) revealed that $81 \%$ of temperature breaks in fruit reefer containers originate in the Port of Cape Town Container Terminal. The breaks are a result of operational concerns that have not been addressed such as training of port personnel, improved scheduling for arrival at the terminal and the use of gensets during the promised plug-in within 40 minutes of entering the port gate. The purpose of the study was to identify the length and incidence of temperature breaks that reefer containers experience within the Container Terminal leg of the export chain until the point of vessel loading.

A study conducted by the Global Cold Chain Alliance in collaboration with the Kenyan Department of Commerce in 2016 in Kenya revealed that, based on observations (in Kenya), temperature breaks are more likely to occur in the transportation and warehousing link of the cold chain. In developing countries, this is especially due to transportation infrastructure, lack of new technologies and a general lack of knowledge and capacity around the industry. The study concludes that failure to keep products at the correct temperatures can result in a variety of negative attributes such as textual degradation, discolouring, bruising and microbial growth.

A study by Freiboth, Goedhals-Gerber, Van Dyk \& Dodd (2013) suggests that any break in the cold chain results in the ripening process of fruit resuming, therefore resulting in a loss of quality or total loss of the product. Any temperature above product appropriate temperature point results in lowering the quality of products.

In their study, Freiboth et al., (2013) use table grapes, summer pears and apples as an example. In order to identify potential temperature break causes, temperature and duration of the various stages 
of the export cold chain were analysed, paying particular attention to the start point of refrigeration. The first stage of analysis included examination of the initial transport leg from the cold store to the port. The second stage involved examining the time fruit spent in the port until vessel loading to determine the average length of time that a container spends in a port. The temperatures taken from the two stages were then analysed to determine any considerable temperature breaks. In addition, historic data was analysed. Of the four supply chains investigated during this study, $65 \%$ of the containers experienced a break during the port segment, while only $8 \%$ of the containers experienced a break during the transport segment. Results also revealed that a quarter of the breaks occurred between 12:00 and 15:00 in the afternoon, which is the hottest time of the day. The results highlighted important issues that needed to be addressed such as the variation in ambient temperatures inside the container, which could have a negative effect on the quality of fruit. In addition, another issue that was identified was the difference between ambient and fruit pulp temperature.

A similar study by Haasbroek (2013) which focused on summer fruit found that the majority of temperature breaks originated in the truck and reefer stack segments. The data analysed in the study indicated that $46 \%$ of the temperature breaks originated in the truck segment and $33 \%$ started in the reefer stack segment. This suggested that at the truck transportation leg, breaks occurred from the time when fruit pallets were removed from the cold store until they were loaded into a container. Breaks also occurred during the warmest part of the day (12:00 to 16:00 p.m). The possible reasons stated for the breaks originating at the two segments were fruit loaded into a container with higher pulp temperatures than optimum, loading areas situated outside in direct sunlight, and delays at the port entrance.

In 2012, Matare conducted a study on post-harvest losses and changes in the physio-chemical nature of fruit. The study concentrated on peaches, pears and citrus. In his study of temperature breaks, Matare found that the main problem linked to the fruit investigated was storage above recommended ambient temperature.

A study conducted in 2004 by Burger on post-harvest factors affecting shrivelling and discolouration of pears concluded that the maintenance of the export cold chain is of utmost importance to ensure high quality. Burger found that once the temperature of the cold chain was above $0^{\circ} \mathrm{C}$, transpiration and respiration rates were high, resulting in weight loss of the fruit, which leads to shrivelled fruit (Burger, 2004). By minimizing the rates of weight loss through an effectively maintained cold chain, the occurrence of shrivelling of pears during post-harvest activities can be lessened resulting in higher fruit quality and longer shelf life (Burger, 2004). 


\subsection{Conclusion}

The literature review depicts that the fruit industry is a vital contributor to the South Africa's economy. The export cold chain plays a significant role in ensuring delivery of high quality fresh produce to end customers. In order for continuous success of the export cold chain industry, it is important that temperatures are maintained at optimum levels to meet cold sterilisation protocol requirements thus minimising chances of consignment rejection and extending shelf life. The literature review also highlighted the importance of PPECB and USDA as providers of services of cold chain management. Emphasis was placed on the importance of the Port of Cape Town and South Africa's competitiveness compared to world leading citrus producing countries. Lastly, international best practices which apply in other countries were discussed and previous studies were explored to emphasize why this particular study adds value to the ongoing discourse of the export cold chain of navel oranges. 


\section{Chapter 3: The navel orange export cold chain}

\subsection{Introduction}

An effective and efficient cold chain contributes significantly in worldwide food supply chains as temperature control in the fresh fruit industry is required. Freiboth (2012:26) states that cold chain management involves the control of the temperature of a product as it journeys along the supply chain, in effort to maintain the quality of a product. Freiboth (2012:26) further states that the important part involves coordinating the different role players in the cold chain such as farmers, suppliers, logistics providers and consumers. Failure to coordinate the intermediaries in the cold chain leads to an imperfect chain. Imperfection of the cold chain results in poor product quality, which could translate to customer dissatisfaction and income losses ( $\mathrm{Lu}, \mathrm{Gu}$ et al., 2015: 5). The imperfection of the cold chain stems from handling, transportation and cold store management meaning at some point during exportation, one of these stages become a weak link. A weak link in the cold chain refers to a stage which is unreliable or the weakest link in the network (Lu et al., 2015:5). Freiboth (2012:26) concurs that a chain is only as strong as its weakest link. Since the cold chain enforces the links between stages of the export chain, non-optimal management or lack of coordination of any stage could lead to temperature breaks.

Montanari (2008) states that among all factors that potentially affect cold chain performance, temperature control significantly influences the shelf life of a product. Temperature control is highly connected with maintaining the product's physical qualities and chemical components. Therefore, optimal temperature management is paramount to an unbroken cold chain (Montanari, 2008). There are several areas in the export cold chain where breaks may occur. The areas where breaks were expected to occur were identified through the observation of the export cold chain of navel oranges and through interviews conducted with industry role players and people working in the different links of the export cold chain. Since the study required that the researcher gain good knowledge on the different stages of the navel orange export cold chain, farms, pack houses and cold stores were visited to gain more insight on the cold chain processes. This allowed for comparison of what happens in theory as opposed to what happens in practice. The generic cold chain of navel oranges to the USA, under cold sterilisation protocols is approximately 52 days in total. Figure 11 provides a generic depiction of the cold chain of navel oranges. 


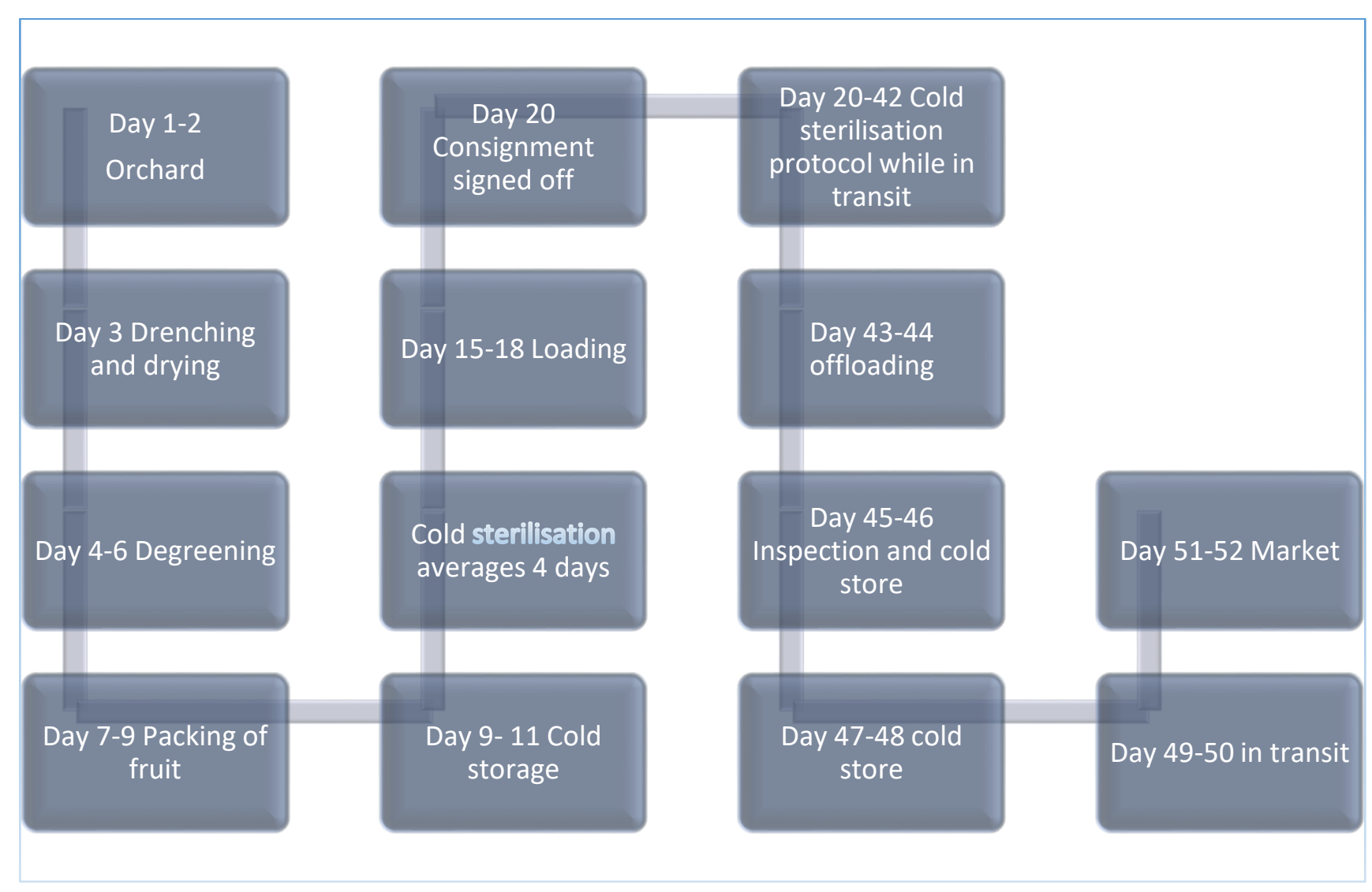

Figure 11: Depiction of the export cold chain

Source: Compiled by researcher

\subsection{Orchard to pack house}

The export cold chain begins at the orchard during harvesting. Harvesting of citrus takes into consideration factors such as the weather, expected yield, market condition and fruit quality. Fruit is harvested once it reaches peak maturity and when external and internal qualities meet market requirements. Fruit maturity refers to fruit that has completed its growth phase (Citrus academy, n.d). Maturity is determined through a tool called a maturity index, which is a process of monitoring the physiological development of fruit as it ripens. According to Marques, Falivene, Creek \& Spohr (2015), fruit must meet minimum regulatory standards for juice, peel colour and sugar to acid ratio before being harvested. However, before harvesting, a plan needs to be drawn up detailing the sections of the orchard that will be harvested and how the harvesting process will proceed. The harvest plan helps determine the volume of fruit to be harvested, transportation to pack house without damages, number of pickers available and harvesting equipment and ensuring that harvesting procedures are adhered to. 
The commercial value of citrus is directly proportional to its external quality, with more emphasis placed on colour development, along with the lack of any lesions due to physiological or physical breakdowns (Joubert, 2016). Internal quality is also a key determinant of value as it contributes to repeated sales and increase in consumption. Therefore, taking into consideration these two qualities before harvesting plays a key role.

Different parameters are used to distinguish fruit quality between markets. These parameters include the proposed use of fruit in the market (Ehlers, 2016). Navel oranges are exported to the USA mainly for consumption as fresh fruit due to their large size, high sugar to acid ratio, juicy and seedless nature. Navel oranges in Citrusdal are harvested between May and September. During visits to the orchard, the researcher observed that harvesting of navel oranges did not occur in the early hours of morning, but was rather done mid-morning. Navel oranges tend to get wet because of dew as a result of low early morning temperatures. Harvesting should take place when the fruit is dry, with temperatures ranging between $13^{\circ} \mathrm{C}$ to $30^{\circ} \mathrm{C}$ and relative humidity lower than $70 \%$ (AGRISETA, 2006). Harvesting was done once it was determined that the citrus trees and fruit are dry. This is done to prevent the occurrence of skin injury due to rupture of the oil glands because of pressure in the air, which is scientifically known as oleocellosis or oil spotting. The greatest risk of the occurrence of oleocellosis is in the early morning as dew may still be on the fruit. Time is also allowed for turgor pressure to decrease. By picking oranges mid-morning exporters reduce the risk of financial losses (AGRISETA, 2006).

A section of the farm was chosen for harvest during visitation by the farm director. Picking is done by skilled workers who handpick the fruit and place them into picking bags and then into plastic bins. Either plastic or wooden bins are used, but they are checked for splinters, screws or anything that could cause injury to the fruit. Bin liners are used for plastic bins to reduce the risk of oleocellosis which could be caused by pressure injury. Bins are kept in the orchard under shade until they are transported to the wash area by a tractor. During the first observation, the researcher noted that navel oranges were left in an open area, fairly shaded by trees while waiting for tractors to transport bins to the drench area. Bins were left to stand for approximately 30 minutes. During the second visit, it was observed that navel oranges were not left standing in the shade for too long as tractors would frequently transport bins to the drench area. However, on both days of observation at the orchard, the researcher observed that fruit were put into plastic bins without any bin liners. 
It is of utmost importance that fruit be removed from the orchard immediately to avoid fruit dehydration, which could lead to incidences of physiological disorders as fruit moves along the export cold chain (Cronje, 2017).

Bins of fruit are then transported to a drench area near the orchard. The fruit is taken through a wash system and left to stand in an open area for 24 hours to allow for the evaporation of water, which may be trapped between the fruit. Navel oranges are drenched to assist with disease control, lower the chances of oleocellosis occurrence, to allow for degreening to take place properly and to remove field heat to prevent moisture loss from the fruit rind (Muller, 2016; Cronje, 2017). Figure 12 illustrates the area in which fruit are left to dry after drenching. During observations, it was clear to the researcher that cold chain protocols were followed. Bins with fruit were left to stand for not more than 24 hours before being moved to the pack house for degreening.

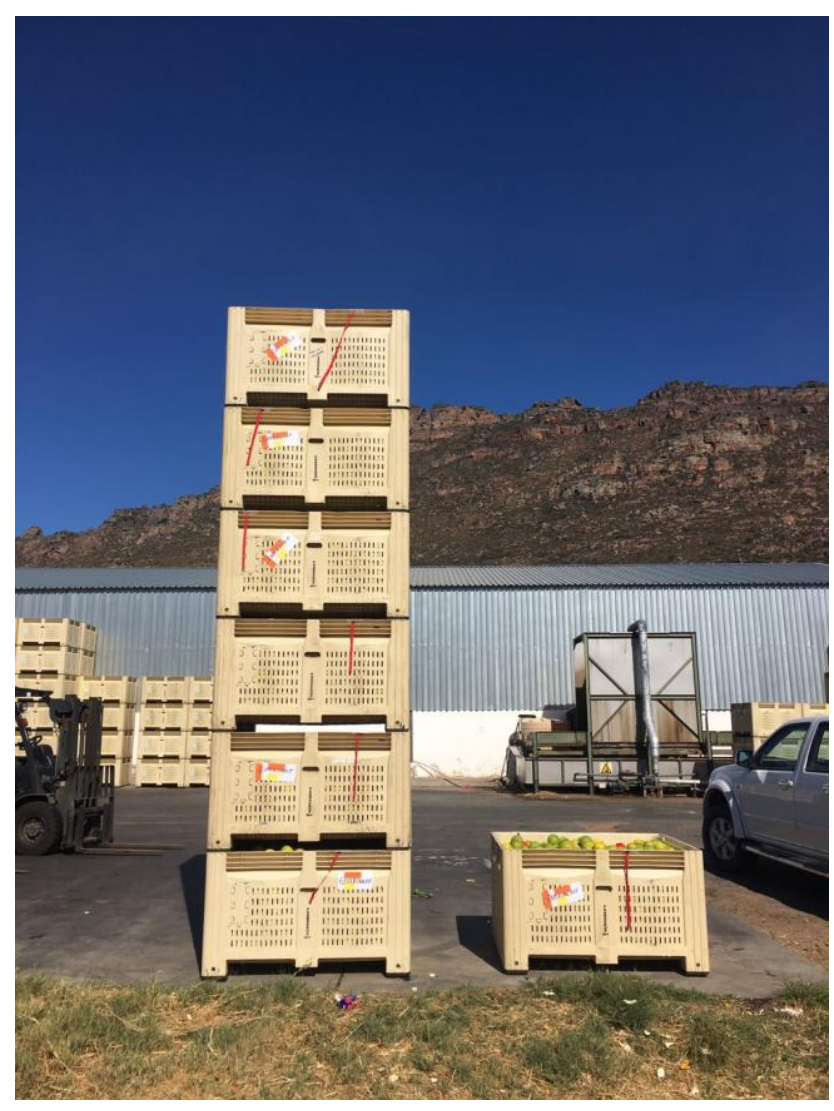

Figure 12: Fruit left for a maximum of 24 hours after drenching

Source: Photo taken by researcher

Once fruit has been moved to the pack house, it first has to undergo the process of degreening. Degreening is the process of accelerating colour change in fruit through the use of a ripening hormone (Cronje, 2017; Arpaia, 2015). As mentioned, in most cases, the pulp of citrus usually reaches maturity while the peel is still green in colour (Porat, 2008). Therefore, the degreening process is necessary. 
In order for the process to be successful, fruit needs to be picked once chloroform pigments start breaking down. Navel oranges are non-climacteric. Once they are harvested, they do not continue to increase in sweetness, colour or ripen. This means that the only change that follows post separation from tree is decay. Degreening promotes the breakdown of chloroform pigments and accumulation of orange carotene, thus rendering citrus more acceptable for markets and extending the marketing season. The process is promoted by using a plant ripening hormone called ethylene. Exposure to ethylene enhances peel colour break (Mayuoni, Tietel, Patil \& Porat, 2011). A study conducted by Porat (2008) proposed that citrus fruit be degreened under temperatures of $20-25^{\circ} \mathrm{C}$, high relative humidity and enough air circulation. Degreening is limited to three days as exposure to ethylene has the ability to enhance respiration rates, especially after 24 hours (Mayuoni et al., 2011). It also has an effect on the rate of senescence and decay development, which could result in the appearance of various peel disorders. Observations were made at the degreening room. The degreening room is fitted with air cooling systems, which are fans that are situated at the bottom of the room to allow for air to blow through the whole chamber. The cooling system used is similar to the forced air cooling system. Bins which contain fruit are designed and stacked in such a way that allows ventilation to flow through. Every bin in the chamber is clearly marked, stating the orchard origin as well as the colour of the fruit before degreening. Figure 13 depicts the degreening room used at a pack house in Citrusdal. Ambient temperature taken during the study at degreening chambers during all the different phases of temperature trials and observations confirmed that the temperature ranged between 20 to $25^{\circ} \mathrm{C}$ and was not kept for more than three days. 


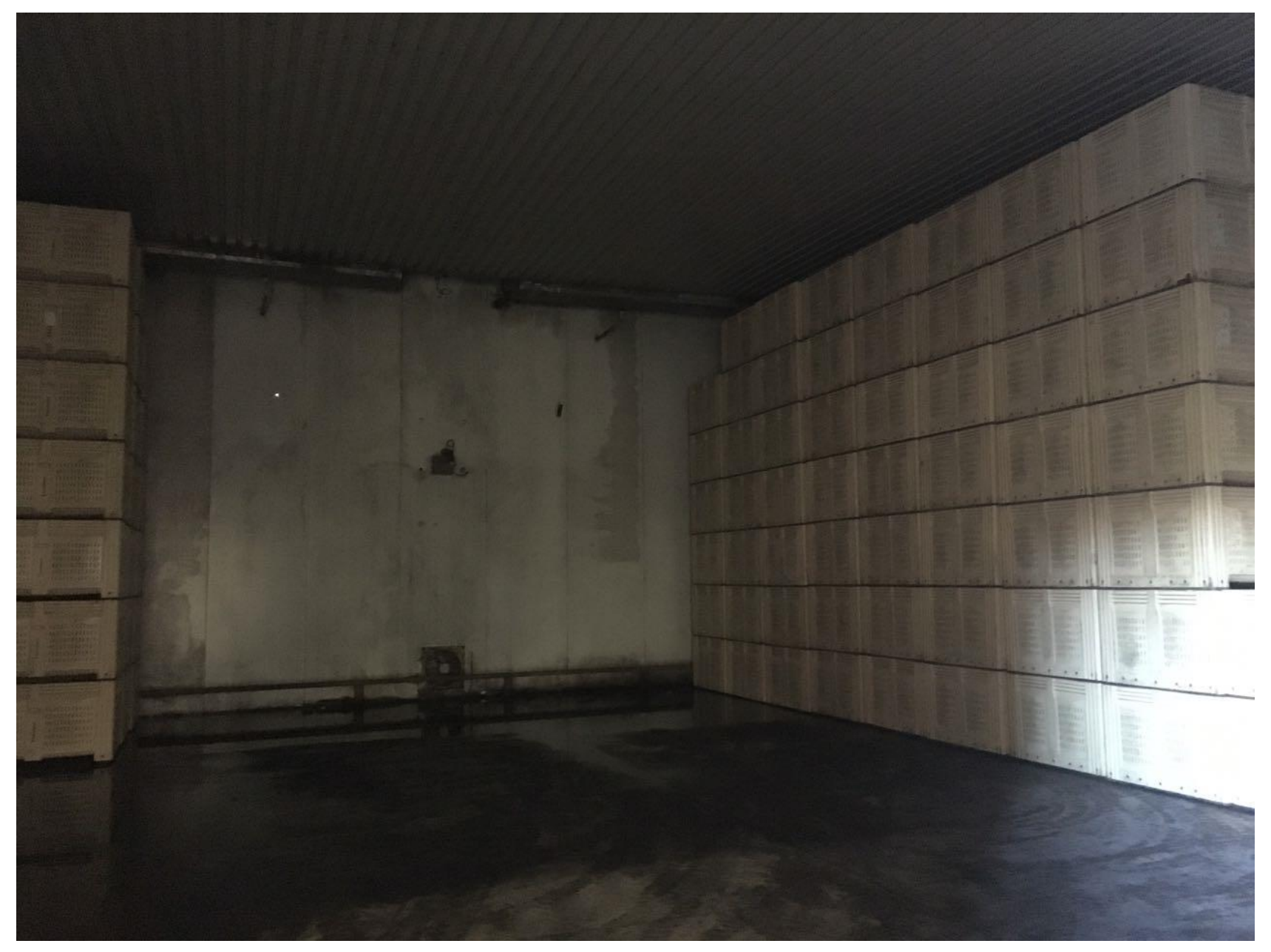

Figure 13: Degreening Chamber at Citrusdal Pack house.

Source: Photo taken by researcher

Fruit is taken out of the degreening chamber three days later and then moved into the pack house for further pack house processes. The pack house consists of different operations. An example of a pack house and its processes are depicted in Figure 14. 


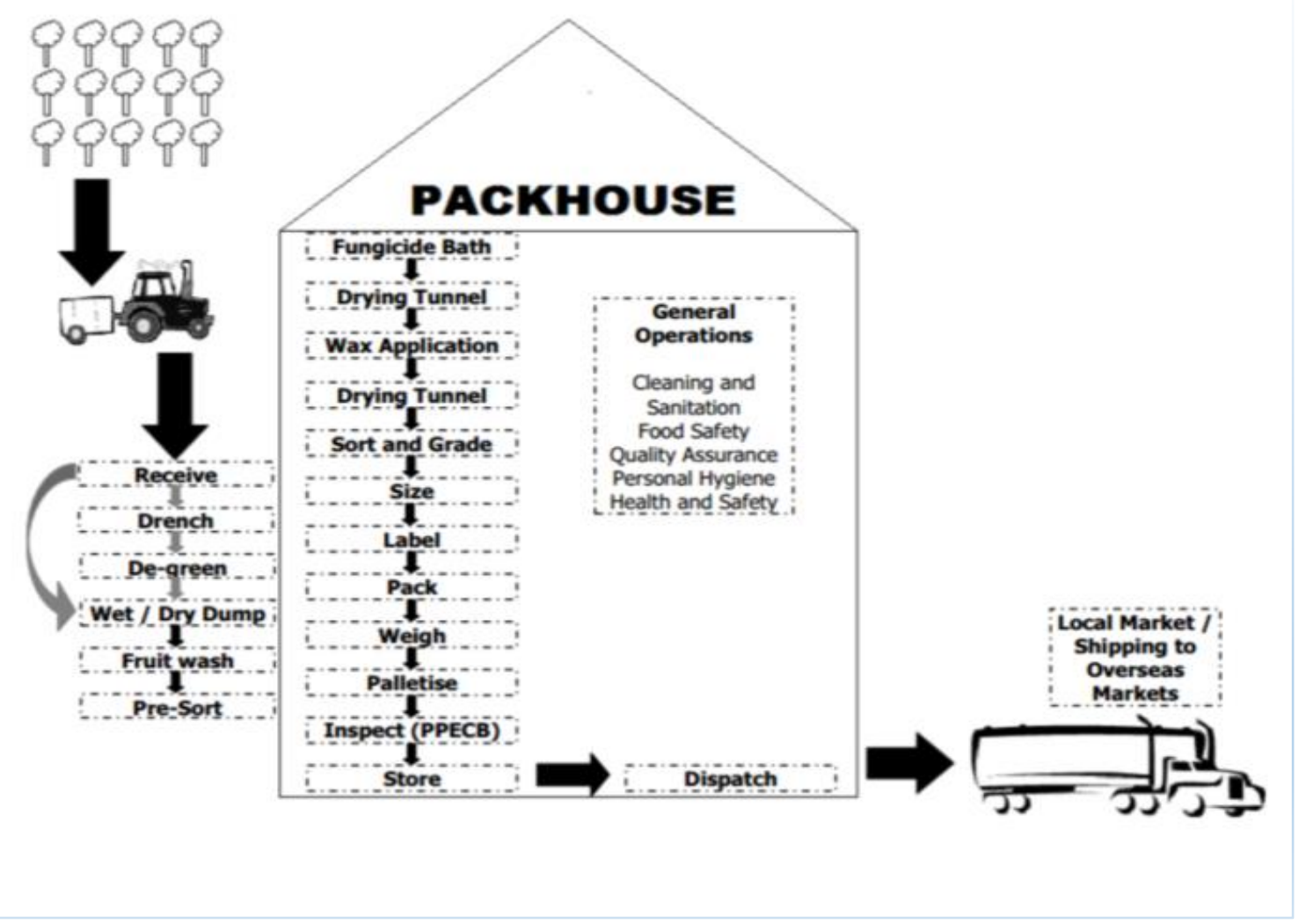

Figure 14: Pack house processes

Source: Lesar, 2017

Beukes (2011) states that citrus pack lines consist of a typical sequence of operations, which include fungicide baths, waxing, pre-sorting, pre-sizing, palletisation and inspection. Fruit is brought into the pack house and is received through dumping, which is the dropping of fruit into the packing line by tippers or personnel. The fruit is then pre-sorted according to quality and colour. The pre-sorting phase is important for the removal of non-marketable oranges such as those with damages and undesirable rind colour. Fruit is pre-sized mechanically by the use of a pre-sizer to determine which fruit are suitable for the export market. Navel oranges travel along each of the pack house processes. Each step along the pack house is meant to improve the quality and increase the marketability of navel oranges destined for the export market (Beukes, 2011). Pack houses should be maintained at a temperature below $25^{\circ} \mathrm{C}$ (Haasbroek, 2013; Roxburgh, 2017).

Palletisation is the final and one of the most important pack house operations. Cartons of fruit are stacked onto pallets. It is important to ensure that all cartons utilised for the packing of oranges and pallets comply with specifications. For instance, oranges are packed into A15C cartons. The cartons are designed to have open displays with additional ventilation holes to ensure acceptable levels of 
airflow to maximise the cold store's cooling ability. Seventy-two boxes of A15C cartons can be stacked per pallet. Figure 15 shows an example of an A15C carton.

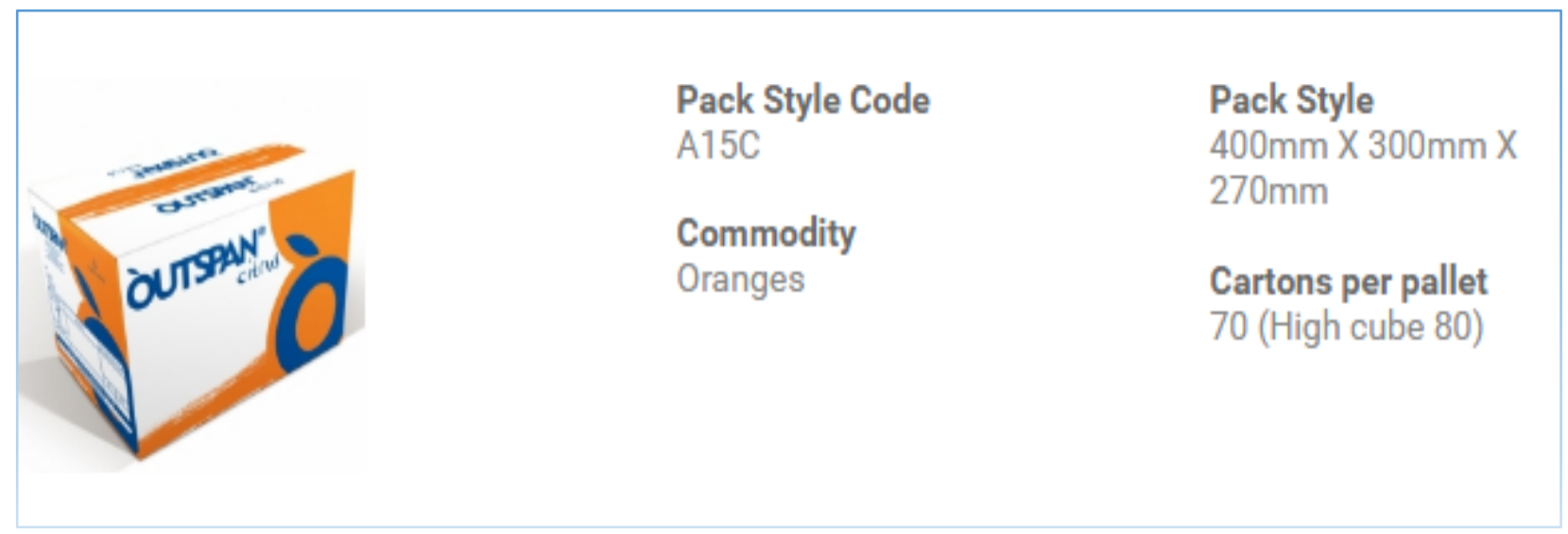

Figure 15: A15C carton

Source: Capespan, 2017

Pallet specifications are published annually by Citrus Research International. Part of these specifications highlight the type, size, components, materials, fasteners and sawn lumber defects. It is of utmost importance that pallets are smooth, with no wood splinters or nails that can damage cartons or fruit. Pallets should also have the ISPM 15 stamp on. The stamp shows that pallets have been treated and approved for use (McGlashan, Cronje \& Defraeye, 2017). Treatment of pallets using heat or methyl bromide is for phytosanitary purposes. After checking all pallet specifications, packed cartons are stabilised on the pallet using paper corner pieces and horizontal straps and pallet marking is done. Pallet marking helps track pallets on every link of the export cold chain.

During observation, it was noted that pallets are stacked up to seven rows high, with each column containing three boxes. Before pallets are loaded into trucks, inspection by PPECB representatives must be conducted. Samples are drawn from packaged fruit for inspection by the PPECB. The PPECB physically inspects and approves products before exportation of fruit is authorised. Inspections are conducted to ensure the quality of the product. In citrus, the PPECB inspectors look at the internal quality of citrus products, with regards to the juice content, the brix as well as the sugar to acid ratio of the fruit (Heilbron, 2016). The external qualities inspected for are colour and blemishes, which are determined using charts per market segment and per season. The charts used also allow for defects permissible on the outside surfaces of the fruit. If the sample carton passes the inspection, the whole pallet is approved for exportation. Citrus fruits that are approved for exportation are marked with a 'passed for export' stamp. Navel oranges are then transported to the cold store. 


\subsection{Transportation to Cold Store and Port of destination}

Navel oranges are transported from the pack house in Citrusdal to a cold store situated at the Port of Cape Town via road transportation. Navel oranges are transported using non-refrigerated trucks. According to the PPECB (2013) non-refrigerated transportation is utilised for citrus fruit to delay cooling and allow for colour maturation. Cronje (2017) concurs that it is not necessary to use refrigerated trucks for the transportation of navel oranges to the cold store since navel oranges are only pre-cooled upon arrival. Therefore, the use of a curtained truck, also known as tautliners, is sufficient. Tautliners are utilised to minimise airflow and the influence of temperature on the fruit during the transportation leg. The journey from the pack house to cold store takes approximately two and a half hours.

Many processes take place at the cold store. The processes start with the arrival of trucks at the cold store. The procedure of receiving cargo at intake is depicted in Figure 16. Cold stores have to comply with prescribed South African regulations and must possess a valid PPECB certificate (PPECB,2017). 


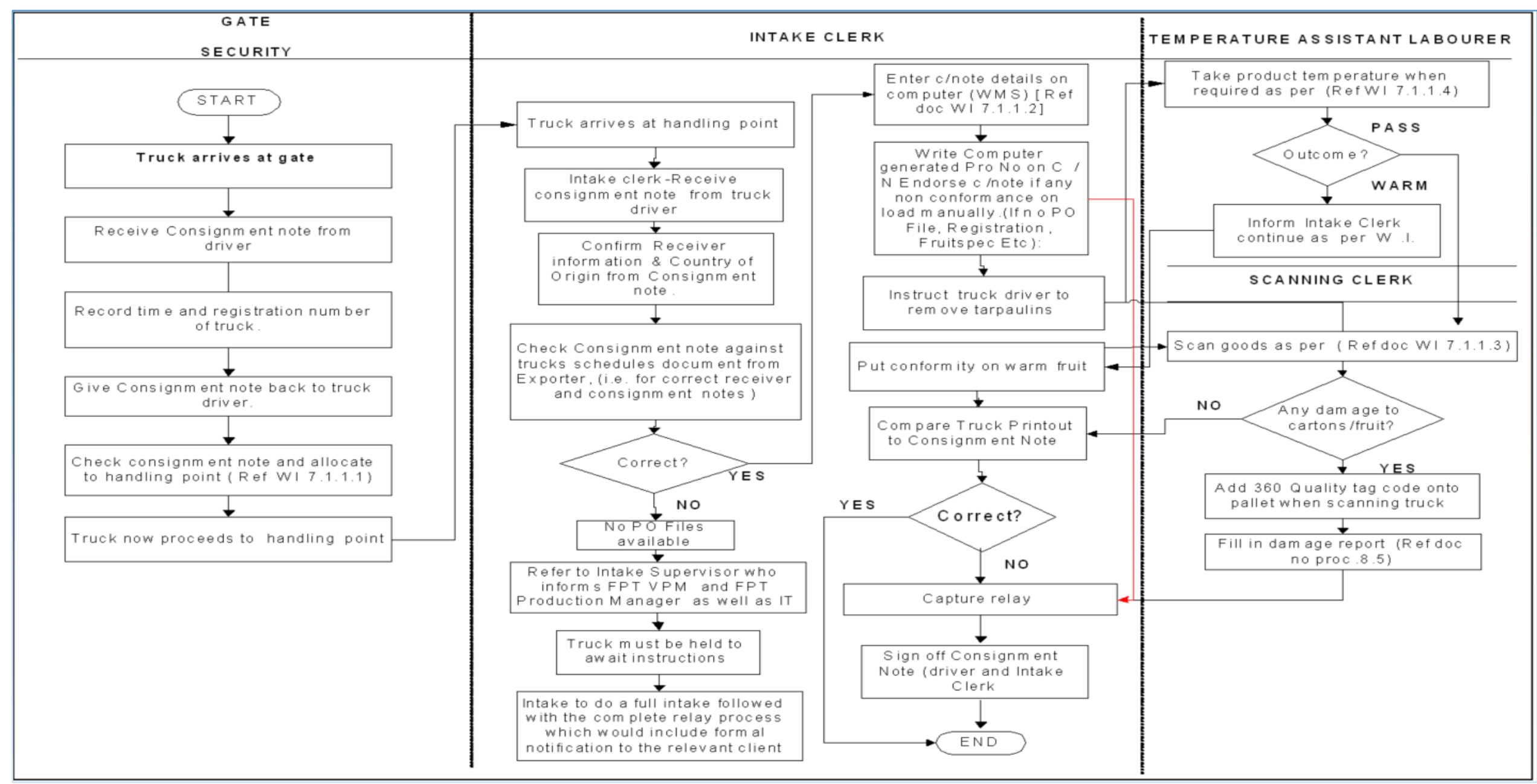

Figure 16: Cold storage intake processes

Source: FPT, 2017 
The time that trucks spend upon arrival at the cold store before fruit pallets are offloaded depends on a number of factors including the flow of traffic and correct documentation. A consignment is received once it is ensured that all consignment details are correct. After which, palletised navel oranges are then placed in a cold room, which is brought down to an optimum temperature of $4^{\circ} \mathrm{C}$ prior to inspection. This is done to remove heat that might have accumulated on the fruit during transportation. The time that the consignment spends at the cold room depends on the rate of inspection by officials. Methods that are used to cool down fruit are Forced Air-Cooling (FAC) and Room Cooling (RC). FAC, which is the most commonly used method, involves fruit being placed in cooling chambers where fans are used to blow cold air (at a temperature of minus $1{ }^{\circ} \mathrm{C}$ for navel oranges, which have an optimum temperature of minus $0.6^{\circ} \mathrm{C}$ ). FAC is achieved by exposing fruit to higher pressure on one side. The pressure forces the cool air through pallets and cartons, where it picks up heat, greatly increasing the rate of heat transfer. FAC plays a vital role in cooling down fruit to target temperature within a short period of time. The benefits of FAC include decreasing the time fruits remain at elevated temperatures, reduced deterioration, shorter cooling times and larger volumes of fruit can be cooled (Boyette, Wilson \& Estes, 2014). On the other hand, RC involves slow processes of heat removal. The fruit near the outside of the container is cooled much more rapidly than other fruit. Unfortunately, RC is not efficient in rapid removal of heat (Boyette et al., 2014).

Fruit is taken out of the cold room for phytosanitary inspection by USDA officials and for quality by officials from the Department of Agriculture, Forestry and Fisheries. Inspection of fruit follows a seven-step process. These steps consist of planned transfer, transfer intake, offloading bays, sampling process, inspection, inspection results and pallets stowage. Figure 17 depicts the inspection process at the cold store. 


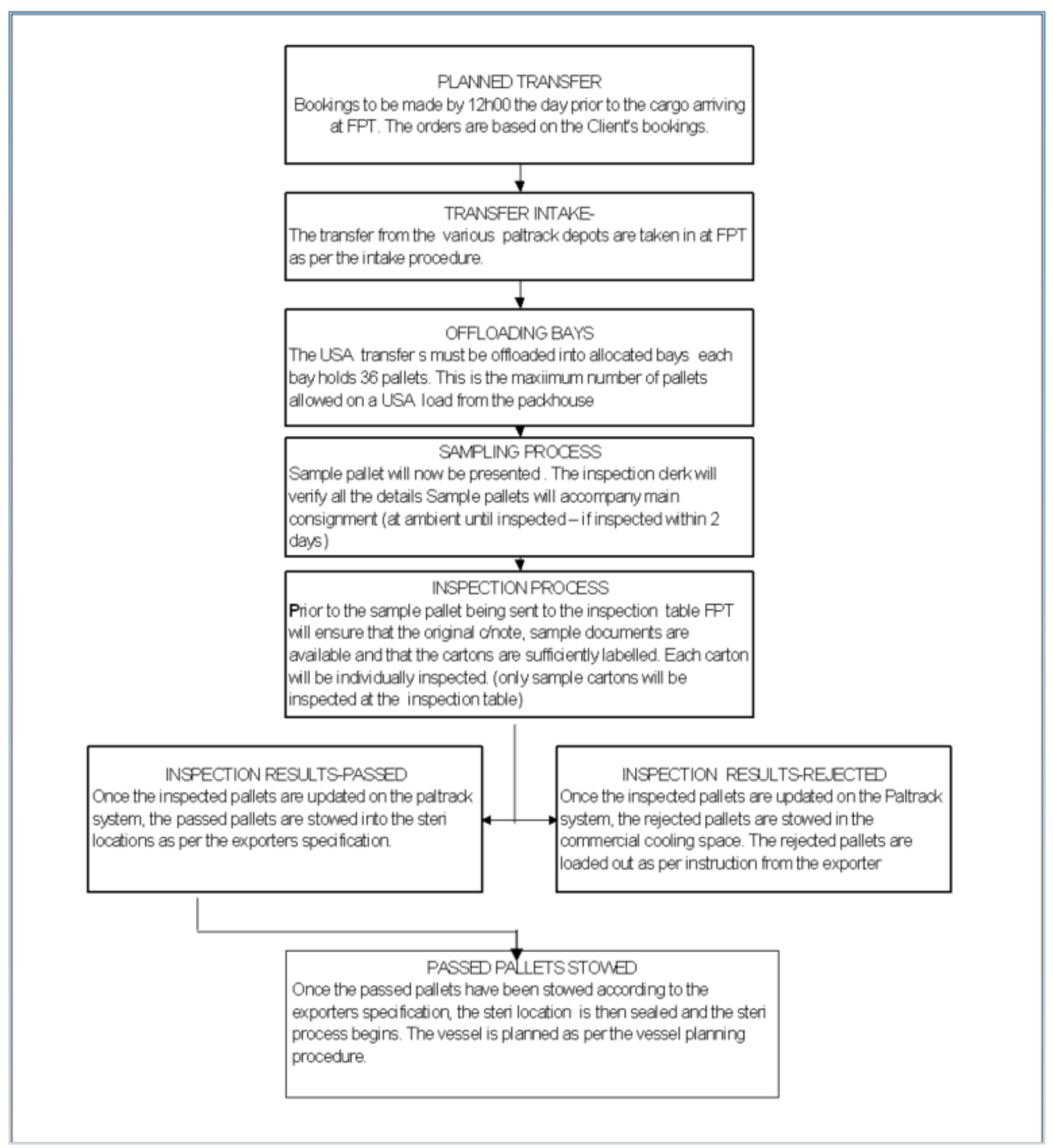

Figure 17: Inspection processes at the cold store

Source: FPT, 2017

From the consignment received, samples of pallets are chosen for inspection. USDA officials check for pests and insects of phytosanitary concern, while DAFF inspectors check for internal and external fruit quality. If cartons tested are found to be free from pest and of high quality standard, they are noted with a stamp and pallets are stowed according to export specifications. Thereafter, palletised fruit is taken to cold chambers situated at the ground floor of the cold store. Once the location is sealed, cold disinfection procedure begins. Pallets are pre-cooled for a period of 72 hours prior to loading into reefer vessels. For the last 24 hours pull down of temperature, the fruit needs to maintain 
a stipulated temperature of $-0.6^{\circ} \mathrm{C}$ as stipulated by the PPECB (Van Niekerk, 2017). If there is a deviation, the cold treatment cycle starts all over again for additional days.
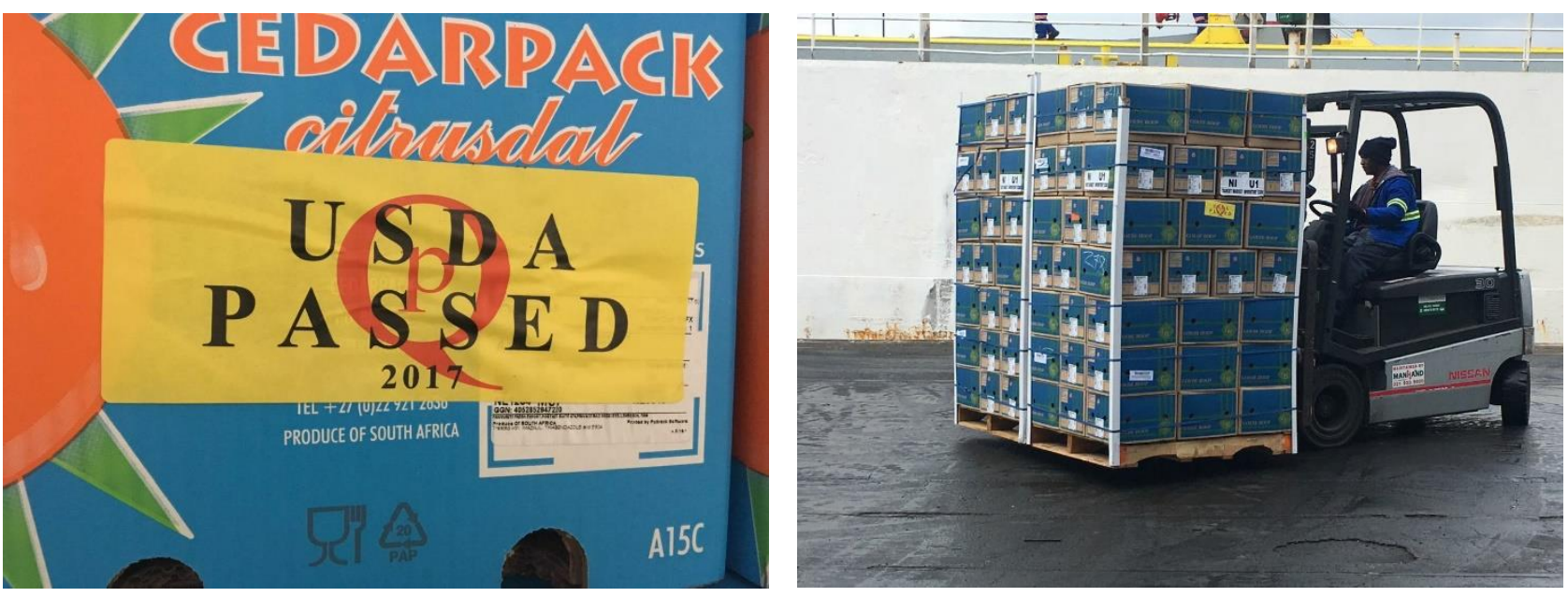

Figure 18: Depiction of cartons and pallets passed for exportation

Source: Photo taken by researcher

Pallets inside the cold room and cold sterilisation location should be lined up in a direction that maximises the airflow within the room (Haasbroek, 2013). Doors of cold stores also need to be kept tightly shut and only opened when necessary. Pallets in the cold store are stacked tightly against each other to prevent air from circulating in an unintended way. Assembling pallets together forces air to go through the fruit cartons. The spaces between pallets are also covered using insulation tape (depicted by orange arrows in Figure 19) to seal in airflow. It allows air to flow through the carton holes, rather than spaces that result because of pallet holders. Since FAC is utilised, it is important to stack pallets in an arrangement supporting effective airflow through FAC tunnels. In order for the cooling process to be effective, all tunnels in the cold room must be completely filled (Haasbroek, 2013). 


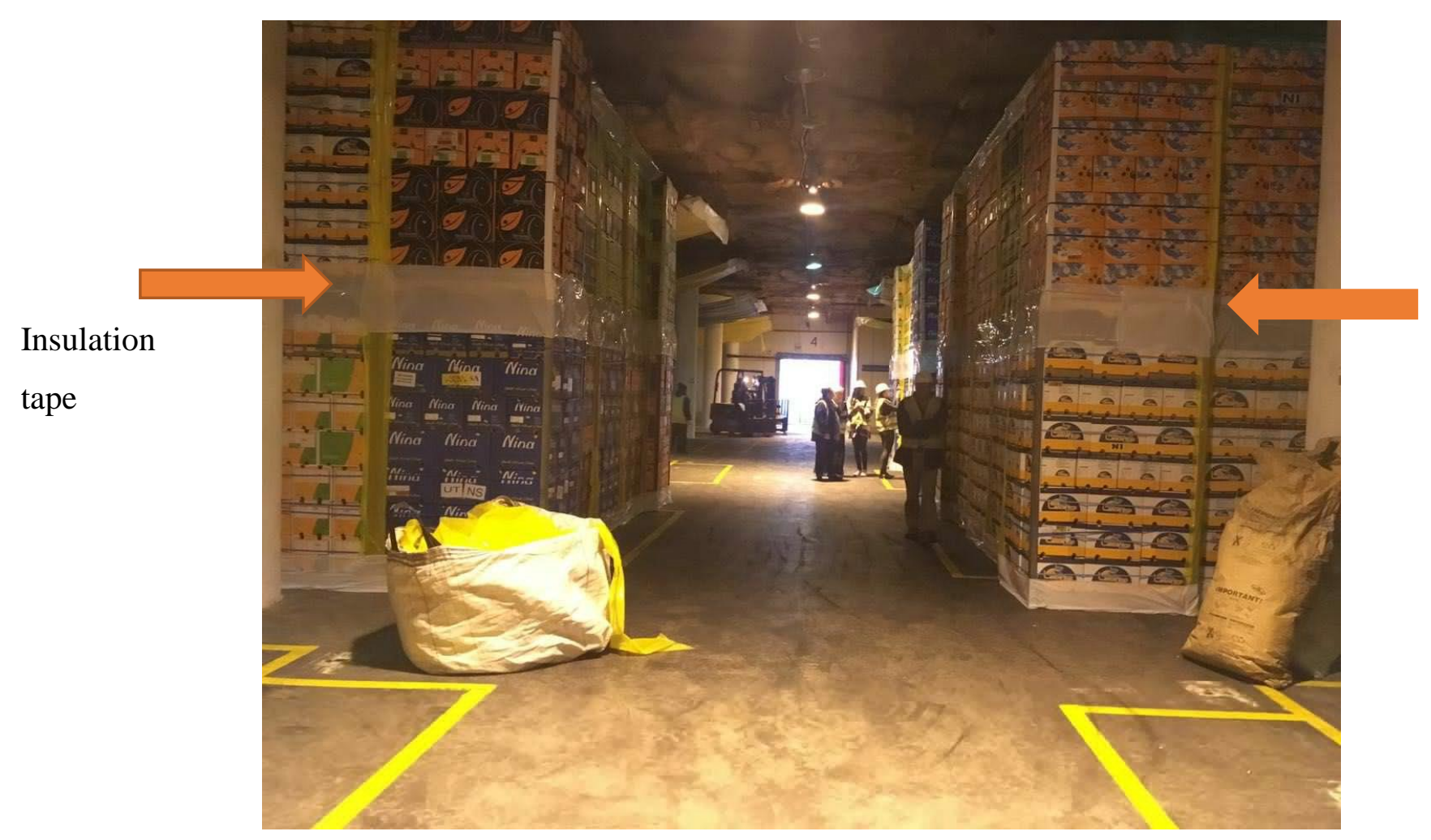

Figure 19: Pallet stacking in cold room prior to pre-cooling

Source: Photo taken by researcher

Once the consignment is ready for transportation, it is brought out of the cold store to be loaded onto vessels. Navel oranges are transported on conventional vessels. However, there has been a consistent decrease in the number and use of conventional vessels compared to container vessels. Conventional vessels have decreased to more or less 10 vessels per shipping year (Henning, 2017). Container vessels, also known as reefer containers have gained prominence due to advancement in technology and their size, which has resulted in improved efficiency and performance. Reefer containers are (currently) able to transport a larger number of products. Despite the decrease in conventional vessels, they are still seen as beneficial compared to reefer containers for citrus fruits exported to the USA. This is due to the fact that they can hold cargo in compartments and still transport containers on decks. In addition, compartments in conventional vessels are operated individually compared to reefer containers where the seal has to be broken open for the whole container, which would almost certainly guarantee its rejection by the USDA officials (Simpson, 2017). Individual operation of decks in conventional vessels allows for spot checks to be done without the shipment being rejected.

Loading of vessels commences once the PPECB has given authorisation after certain conditions are met. For example, temperature monitors are checked whether they are working to satisfactory requirements and also within stated time-temperature tolerances. In addition, shipping compartments 
are checked if they have been pre-cooled for at least 48 hours with a constant temperature of $-0.6^{\circ} \mathrm{C}$ maintained for at least 24 hours. During loading, PPECB officials also have to ensure that commodities that are susceptible to cross tainting are not loaded on the same or common deck and also measure fruit temperature as frequently as possible to ensure that stipulated temperatures are not exceeded. Fruit destined for the US market is not mixed with other fruit destined for a different country in the same compartment (PPECB, 2012). Once the stated conditions have been met and approved, loading begins. Conventional vessels vary in sizes, with a typical vessel carrying approximately 4500 to 6000 pallets at a time (Goedhals, 2003). Conventional vessels are built to maintain product temperature and they also transport a number of containers on the deck. Multiple pallets are loaded per crane using a stevedore cages hooked to cranes and the temperature of fruit is monitored throughout. If pulp temperature of fruit rises above the stipulated temperature, loading is halted and fruit is sent back in for cold sterilisation procedure (Goedhals, 2003). Cranes are used to load cartons of navel oranges into the compartment of the vessel where they are stacked next and on top of each other. In order to avoid damage to the fruit during loading, walking boards are used. The boards are placed on top of the pallets to allow for loading personnel to move around the decks without causing damage. It was observed during visitation to the port that sometimes personnel do not pay attention to the use of walking boards and step directly onto the cartons. According to the Goedhals (2003) it is of utmost importance that pallets are packed close together to avoid pallets shifting during the journey. Inflatable dunnage bags are placed in between the spaces of pallets to keep them in position. The process of loading a vessel can take up to three days, depending on other factors that can influence the rate of loading such as the weather, and flow rate of incoming fruit (Goedhals, 2003). 

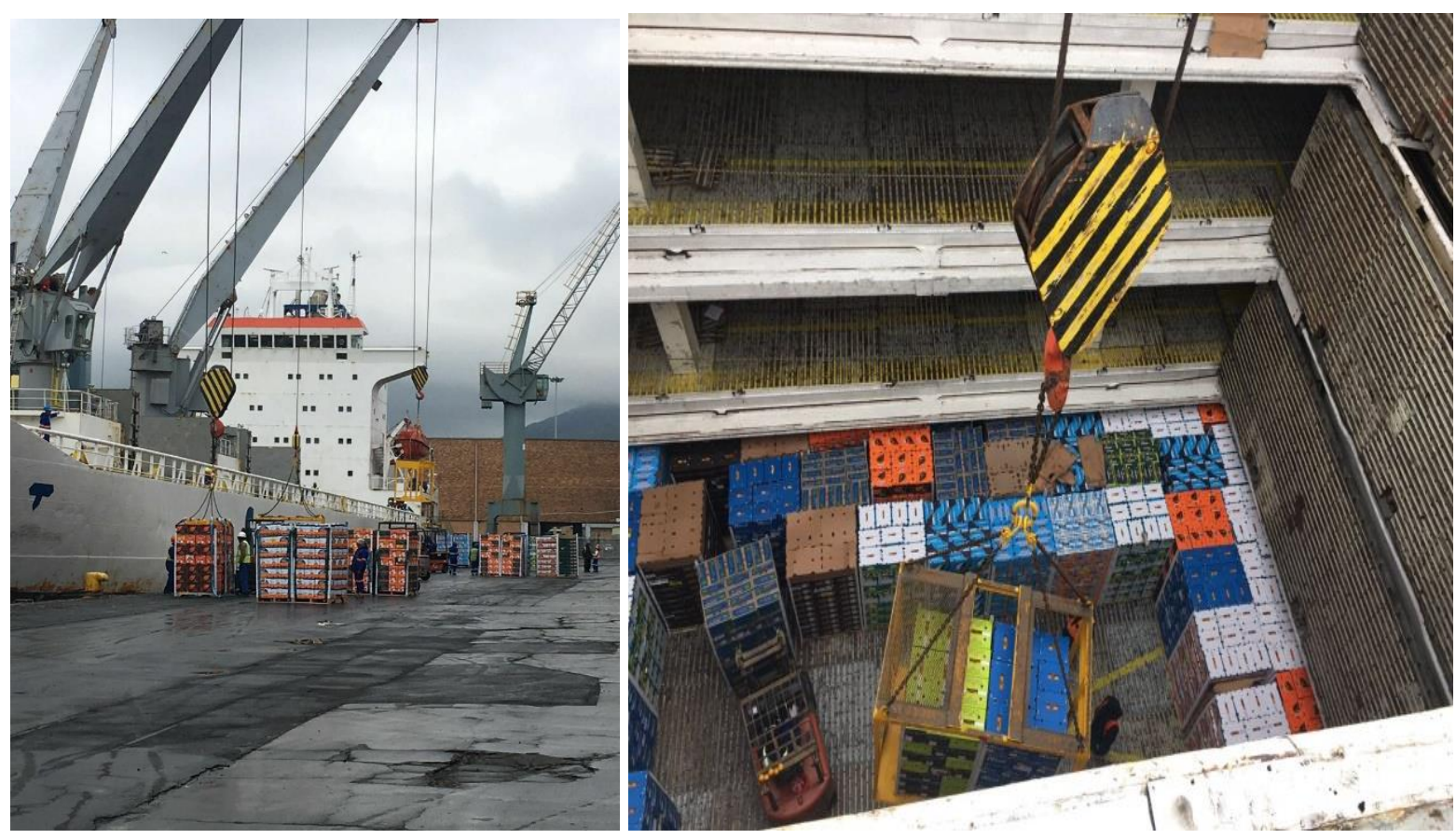

Figure 20: Conventional Vessel loading at the Port of Cape Town

Source: Photo taken by researcher

The typical holding storage of conventional vessels is four decks, with fifteen holds and a maximum of eight temperature regimes that can be set (Goedhals, 2003). The desired temperature for cold sterilisation protocol is set and has to be maintained according to PPECB and USDA regulations. All decks have an individually controlled refrigeration system; therefore, if temperature breaks occur in one deck, the consignment from that deck will be rejected but all other unaffected fruit pallets from different decks will be accepted for the market.

The cold sterilisation protocol prescribes a mandatory exposure of $-0.6^{\circ} \mathrm{C}$ for 22 days on-board a vessel. After the mandatory 22 days, the consignment is offloaded upon arrival and is sent for inspection. Upon passing inspection, the fruit is sent to a cold store for further cooling at a temperature of $4{ }^{\circ} \mathrm{C}$ before transportation to the final market. The export cold chain processes are depicted in Appendix 1.

\subsection{Conclusion}

From the discussion of the observations that were made, it is clear that protocols for the cold chain of navel oranges are mostly followed by cold chain personnel. However, there are a number of opportunities for improvement in the export cold chain of navel oranges to further ensure that temperature breaks do not occur. 


\section{Chapter 4: Research Design and Methodology}

\subsection{Introduction}

This chapter discusses the research design and methodology undertaken in the study. To articulate the data required and methods of collection used in this study, a research design was formulated. The study focuses on the export cold chain of navel oranges, from the point of harvest until the port of destination. It specifically focuses on temperature profiles along the different stages of the export cold chain. The data variables explored in this study are temperature, date, time and the different stages of the export cold chain.

\subsection{Definition of variables}

Temperature: defined as the physical quantity that expresses the subjective perceptions of the degree of hotness and cold (Oxford Dictionary, 2017). Temperature is measured through the use of thermometers. Temperature scales that are commonly used are degree Celsius, Fahrenheit and Kelvin. Temperature in this study is denoted in degree Celsius $\left({ }^{\circ} \mathrm{C}\right)$.

Date: defined as a day(s) of the month or year as specified by a number, appointment or engagement (Oxford Dictionary, 2017).

Time: defined as an observed phenomenon or a measurable period during which a process or condition exists (Oxford Dictionary, 2017). Time can be denoted in seconds, minutes, hours, days, months, years or centuries.

Export cold chain stages: the various steps or phases along the export cold chain that influence the link of the cold chain. These steps are the orchard, drenching, pack houses processes (pack house processes include degreening, the pack line segment, palletization), transportation, cold store processes, loading and shipping.

\subsection{Research Design}

The research design was a case approach, which was exploratory in nature. Using a case approach for this thesis was deemed suitable to achieve the research objectives and address the research problem stated in Section 1.1 of Chapter 1. A case approach involves the in-depth analysis of a specific case, which may be an organization, person or a community (Bryman, Bell, Hirschsohn, dos Santos, du Toit \& Masenge, 2014). The study focused on a specific case, which is the export cold chain of navel 
oranges, under cold sterilization treatment from the Citrusdal region, Western Cape to the USA. The case approach also involved conducting the research over multiple stages of the supply chain. Thus, also making the approach cross-sectional. A cross-sectional approach entails the collection of data on more than one case and at a single point in time in order to collect quantitative data related variables (Bryman \& Bell, 2015). This means that data on the variables of interest were collected at more or less the same period. Primary quantitative data was collected over a two-month period, across two cases. Therefore, a case approach was deemed the most suitable research design for this study. Furthermore, the objective of this thesis included identifying whether temperature breaks occurred along the export cold chain of navel oranges to the USA. The objective is set in an organizational setting and business environment, hence the case approach used includes a detailed analysis of the organization, which is Company $\mathrm{X}$.

The case approach was exploratory in nature. Exploratory research involves the undertaking of a study in a new area that is being investigated when little is known about a particular area of interest (Polit, Beck \& Hungler, 2001). Exploratory research suited the research problem as Company X is concerned about temperature breaks in the export cold chain, however, the company is uncertain of the existence of these temperature breaks. Therefore, the exploratory research design was used to gain familiarity with the basic details of the export cold chain as well as establish an understanding on how best to proceed in solving the research problem. Moreover, there is a need for the investigation of the research problem due to the lack of previous research in the export cold chain of navel oranges.

\subsection{Research Methodology}

A research methodology defines the kind of problems that are worth investigating and how to frame a problem in a way that it can be investigated using a set of designs and procedures. It provides a guideline on how to select and develop appropriate means of collecting data (Kothari, 2004). The study utilised a mixed research approach. It is a type of method in which a researcher applies a qualitative research paradigm for one phase of the study and a quantitative paradigm for another phase. The researcher followed the steps in Figure 21 when conducting the mixed methods approach. Qualitative research involved the observation of the export cold chain, interviews with personnel involved in the cold chain and reviewing of academic literature, while quantitative research included the conducting of temperature trials. 


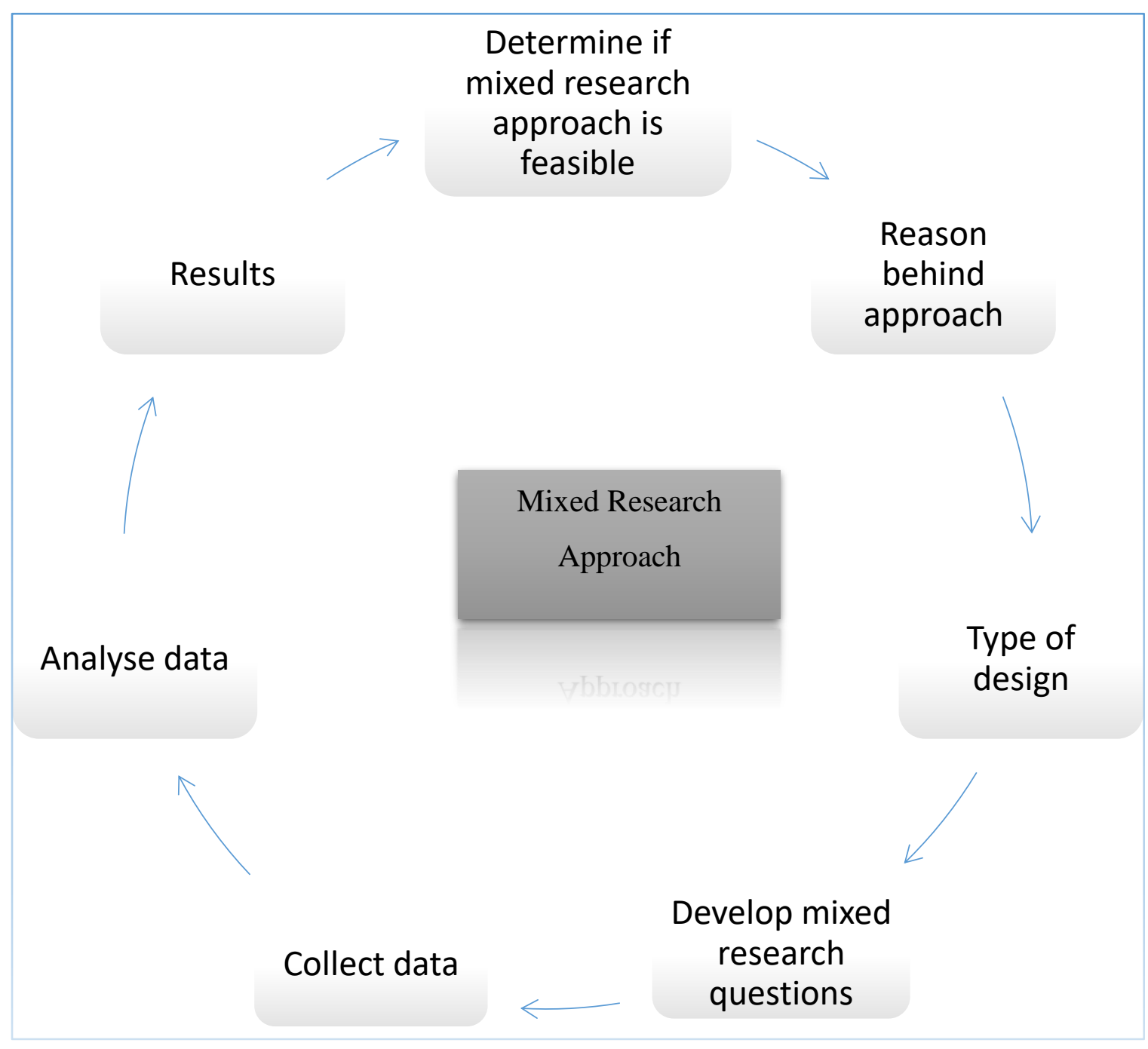

Figure 21: Mixed method research guidelines

Source: Adapted from Cannon, 2004

The remainder of this chapter is divided into two sections. The first section discusses the academic literature, also known as literature review, used to outline the scope of the study and the motivation behind the problem statement. The second section focuses on self-conducted primary research carried out through observations and temperature trials utilised to respond to the research questions and fulfil the research objectives.

\subsection{Literature review}

The literature chapters introduce and discuss the different concepts that are important to understanding the study. These concepts aided in validating the significance of the study and understanding its results. Hence, the literature reviewed by the researcher provided a theoretical framework for the study and assisted in providing scientific explanations for the research questions 
and identified what research had previously been carried out. The literature chapters are divided into two different chapters.

The first literature chapter, presented in Chapter 2, includes an overview of the supply chain and how the cold chain is an important aspect of an efficient perishable products supply chain. It also provides an explanation and definition of temperature breaks and their effect on the quality of fruit. Concepts such as cold sterilisation, chilling injury and fruit quality factors are introduced. In addition, a background on the South African fruit industry is presented. The roles played by key organisations in the seamless export cold chain are discussed as well as the importance of the Port of Cape Town in exportation of fresh fruit. The primary purpose of the first literature chapter is to explain the importance of all factors that affect and impact the export cold chain. The chapter leads to the next literature chapter on the export cold chain of navel oranges.

The second literature chapter presented in Chapter 3 centres its discussion on the export cold chain of navel oranges. The chapter emphasises the importance of efficient and effective management of each stage of the export cold chain of navel oranges. It aims to present the knowledge that the researcher gained on the export cold chain of navel oranges and highlight what actually happens in practice compared to what happens in theory.

The literature reviewed for both chapters were gathered through secondary research. Sources of information used included journal articles, books and the internet. In addition, key industry role players were consulted. The literature reviewed aided in the researcher gaining knowledge on the terminology used in the fruit export industry, basic flow of the export cold chain of fresh fruit and South Africa's strengths and weaknesses in the exportation of citrus compared to other citrus producing nations.

\subsection{Primary research}

Primary research was required for the study as the academic literature reviewed proved to be insufficient in providing answers relating to the research problem. In addition, data pertaining to temperature breaks could only be acquired through the probing of fruit while journeying the different phases of the export cold chain. Primary qualitative research included observations at the different stages of the export cold chain and primary quantitative data involved self-conducted temperature trials. 


\subsubsection{Observations of the navel orange export cold chain}

Primary qualitative research was conducted through observations at the different stages of the export cold chain. Observations were made at fruit farms, pack houses, cold stores and the Multipurpose Terminal at the Port of Cape Town. The study observed the different stages of the export cold chain to gain an understanding and allow a comparison to be made on what actually happens (in practice) and what is meant to happen (as per knowledge gained from the literature review and consultation of industry role players).

Table 6 summaries the visits made at farms, pack houses, cold stores and the Port of Cape Town.

Table 6: Export Cold chain observations

\begin{tabular}{|c|c|c|c|}
\hline Date & Site Visit & Fruit involved & Reason for visit \\
\hline 20 April & $\begin{array}{c}\text { Farm and Pack houses } \\
\text { in Citrusdal }\end{array}$ & Navel Oranges & Observation \\
\hline 03 May 2017 & $\begin{array}{c}\text { Pack house in } \\
\text { Citrusdal }\end{array}$ & Navel Oranges & Probing of fruit \\
\hline 10 May 2017 & $\begin{array}{c}\text { Orchard and Drench } \\
\text { area }\end{array}$ & Navel Oranges & Probing of fruit \\
\hline 19 May 2017 & Pack house & Navel Oranges & Probing of fruit \\
\hline 24 May 2017 & $\begin{array}{c}\text { Cold store in Cape } \\
\text { Town }\end{array}$ & Navel Oranges & $\begin{array}{c}\text { Fruit loading into } \\
\text { container/ cold } \\
\text { sterilisation protocol }\end{array}$ \\
\hline 24 May 2017 & Port of Cape Town & Navel Oranges & $\begin{array}{c}\text { Observation of } \\
\text { conventional vessel } \\
\text { loading. }\end{array}$ \\
\hline 31 May 2017 & Orchard in Citrusdal & Navel Oranges & Probing of fruit \\
\hline 9 June 2017 & Pack house & Navel Oranges & Probing of fruit \\
\hline 14 June 2017 & Wash area at farm & Navel Oranges & Probing of fruit \\
\hline 22 June 2017 & Pack house & Navel Oranges & Probing of fruit \\
\hline
\end{tabular}




\subsubsection{1. $\quad$ Farm visits}

Farms (orchards) serve as the starting point of the export cold chain as it where fruits are harvested. As soon as navels are harvested, the cold chain process begins. The researcher observed the picking process of navel oranges.

During these visits to the orchard, pulp and ambient temperatures were collected. The measurements taken resulted in primary quantitative data. In addition, interviews were conducted with farmers, packers, PPECB personal and truck drivers. Interviews allowed the researcher to acquire more information pertaining to the research problem.

\subsubsection{2. $\quad$ Pack house and cold store}

Navel oranges are transported to the pack house, which is situated near the orchard using tractors. Once the fruit journeys through all the pack house processes, it is transported to the cold store. Observations were made by the researcher at the pack house and cold store. In addition, temperature monitors were inserted inside fruit and amongst fruits packed in cartons and staged on pallets. The temperature monitors measured pulp and ambient temperature. The temperature measurements gathered resulted in primary quantitative data. Also, interviews were also conducted with the cold store managers and personnel.

\subsubsection{Port of Cape Town}

The researcher undertook a site visit to the Multipurpose Terminal at the Port of Cape Town. The visit enabled the researcher to observe the flow of traffic back and forth; from the period it enters the port until loading of conventional vessels. The researcher was able to witness conventional vessel configuration. Even though each deck on the vessel is individually operated, temperature is set to $0.6^{\circ} \mathrm{C}$ for all decks. The visit enabled the researcher to develop an understanding of port operations.

\subsection{Quantitative data}

The majority of the research study's quantitative data consists of readings from temperature monitors, whilst the rest is data provided by Company X, Fresh Produce Terminals and the PPECB.

A sample size of how many temperature monitors per data collection phase were required was chosen with the help of a statistical expert through the use of a power analysis. The chosen sample size was 55 temperature monitors per temperature trial. Temperature readings were recorded with the help of a temperature monitoring device known as an iButton ${ }^{\circledR}$ at 30-minute intervals, starting from the point of harvest until the arrival port. It would have been ideal to monitor the fruit from the initial growth 
(pre-harvest) as that would broaden the scope of the thesis and account for all factors that influence temperature breaks, but due to financial and time constraints, it was not possible. Temperature measurements taken by the iButtons ${ }^{\circledR}$ are in degrees Celsius. In addition, the time when each measurement was taken was recorded. Measurements were recorded using software called ColdChain Thermo Dynamics. iButtons ${ }^{\circledR}$ are logged into the software prior to insertion in the fruit and fruit cartons and set to take readings at certain time intervals and then readings are then recorded through the temperature monitor and downloaded using the software.

\subsubsection{Data from iButtons ${ }^{\circledR}$}

The iButtons ${ }^{\circledR}$ were personally inserted into the fruit by the researcher. Temperature monitors were inserted into 72 pallets for the whole data collection period from May to June 2017. Two hundred and eighty iButtons ${ }^{\circledR}$ were utilised with 216 iButtons ${ }^{\circledR}$ used for pulp temperature readings and 64 used for ambient temperature. iButtons ${ }^{\circledR}$ were probed in fruit stacked on pallets. Each pallet is stacked with cartons up to seven rows high. Three cartons are placed lengthwise on the long side of the pallet, with another three next to them; four cartons are then placed crosswise to complete the first stacking layer. iButtons ${ }^{\circledR}$ were probed on the first, fourth and seventh row and the fruit cartons in which iButtons ${ }^{\circledR}$ were placed into were chosen at random. iButtons ${ }^{\circledR}$ probed inside fruit were used to measure the pulp temperature and those placed in the carton were used to measure ambient temperature. Upon fruit arrival at the port of destination, temperature monitoring devices were retrieved and sent back for data retrieval. Unfortunately, due to miscommunication between the exporter and USDA officials not all iButtons ${ }^{\circledR}$ were sent back to the researcher. Some got lost during the retrieving process, even though all experiment fruit was marked using coloured tape, ambient loggers were marked with a red string and all pallets utilised for data collection purposes were clearly marked. Three conventional vessels containing shipments were utilised during the exportation process, with vessel one containing two shipments. Out of the $280 \mathrm{iButtons} 囚$ used for data collection, only 136 temperature probes were sent back by USDA officials for downloading of data. This means a total of 144 iButtons ${ }^{\circledR}$ were lost.

\subsubsection{Descriptive data analysis}

Descriptive and inferential data analysis were used to analyse the study's quantitative data. According to Zikmund \& Babin, (2010), descriptive analysis is part of the simplest analytical techniques that may be utilised in research. It helps transform data in a way that best describes the basic characteristics of the data within the framework of the study (Zikmund \& Babin, 2010:516). The descriptive data analysis focused on identifying temperature breaks and where along the cold chain they occurred. 
Both graphical and numerical statistics were used. Graphical descriptive statistics refer to graphs, tables and figures; while numerical descriptive statistics refer to statistical measures which describe the central tendency, distribution and variability of the data (Potgieter, 2016:110). For numerical descriptive statistics, the central tendency of data was determined through the mean, median and the standard deviation. The mean was calculated by summing up all observations and dividing by the number of total observations (Wegner, 2012). The median denotes data observations that fall in the middle of a data set after being arranged in ascending or descending order (Wegner, 2012). The mean can be influenced by the number of observations used, therefore it can be affected by outliers. The median is not influenced by outliers as the value is an actual observation. Both the mean and median were chosen as measures of central tendency for the study. The measures are also important to the study as they can be used to determine the shape of data sets and the spread of observations. The measures of central tendency were also used to compare temperature profiles of the different stages in the export cold chain.

The graphical and numerical statistics were computed through Microsoft Excel, Statistica and Tableau. The results of the descriptive and inferential statistics analysis are discussed in Chapter 6.

\subsubsection{Inferential data analysis}

Inferential data analysis was used to analyse the relationship between temperature breaks and fruit quality as well as to determine whether there are differences in temperature at different positions at each stage in the export cold chain (these stages exclude the harvest, drenching and degreening stages). Inferential statistics were used in the study to test two hypotheses. The two hypotheses are:

- $\quad H_{0}:$ There are no differences in temperature at different positions at each stage of the export cold chain stages.

- $\quad H_{0}$ : There is no relation between temperature breaks and fruit quality.

For the first hypothesis, each stage refers to the various phases of the export cold chain, which in this case is from the transportation phase until the port of destination. The harvesting, drenching degreening and pack house stages were excluded as iButtons ${ }^{\circledR}$ had not been probed into fruit according to the different positions. During these mentioned stages iButtons ${ }^{\circledR}$ were probed randomly into fruit, which were stored in bins. The different positions refer to the different placement of iButtons ${ }^{\circledR}$ in cartons that were stacked onto pallets. The difference in temperature and the positions at each stage of the export cold chain are tested for in the hypothesis since a comparison had to be made between the two different datasets analysed for each vessel. In addition, once pre-cooling 
commences it is assumed that the different carton positions will have similar temperature profiles since cold air is delivered horizontally (Cronje, 2017). The hypothesis was also done to test which of the different positions is likely to contribute more to the occurrences of temperature breaks at each stage. For the first hypothesis, a nonparametric Friedman test was used. The Friedman test was used as the hypothesis tests three variable measures, which were measured at the same time. The variables tested showed dependence among them. The Friedman test also proved suitable as it can be used to test for differences amongst related samples and finding differences in treatments or across multiple attempts. The rejection of the null hypothesis is determined using the p-value. If the calculated pvalue is low (P less than the selected significance level, $\alpha=0.05$ ) the null-hypothesis is rejected and it can be concluded that at least two of the variables are significantly different from each other.

A non-parametric ANOVA test was also used to test the second hypothesis. The Kruskal-Wallis test was employed. According to McDonald (2009), the Kruskal-Wallis test is best used if there is one measurement variable and one nominal variable. The test does not assume that the measurement variable is normally distributed. The measurement variable tested in the research claim was temperature breaks, whilst quality was the nominal variable. The Kruskal-Wallis test was conducted using the Statistical Package for Social Sciences (SPSS). The p-value of the test is used as an indicator (P less than the selected significance level, $\alpha=0.05$ ) if the researcher should reject or fail to reject the null hypothesis in favour of the alternative hypothesis.

\subsection{Ethical Considerations}

Given the rules and regulations of the University regarding research conducted, which involves human subjects and organisations, the following considerations were taken into account:

\subsubsection{Permission}

Permission to conduct the study was obtained from Company X. Permission was obtained to access temperature data and historic data from farm owners, the cold store and reefer vessels utilised by the company during their exportation process. For participants involved in interviews, the principle of voluntary involvement was verbally explained and participants were informed of their right to withdraw from the study at any time.

\subsubsection{Confidentiality}

Information concerning the company was handled in a confidential manner. Confidentiality was maintained for the protection of the company that initiated the study as well as to guard the privacy of historic data received from export companies and the cold store. 


\subsection{Research Validity and Reliability}

The most prominent criteria for the evaluation of research are validity and reliability (Bryman \&Bell, 2015). A researcher has to demonstrate that the research methods utilised in a study ensure validity and reliability of the findings.

According to Bryman \& Bell (2015), validity is concerned with the integrity of the conclusions that are generated from a study. It involves the data that was utilised and the methods of how data was obtained. Research reliability refers to the stability of research results when the same study is simulated under similar methodology (Bryman \& Bell, 2015; Golafshani, 2003). The reliability of a research study can further be determined through applying and responding to the questions of whether the measures in the study will yield the same results in other occasions, if similar observations would be reached by other observers and if there is transparency with regards to data collection. The research objectives of the study aimed to identify whether temperature breaks occurred, where along the export cold chain they occurred and determine the link between temperature breaks and fruit quality. The research methodology followed in the study involved the conducting of temperature trials, which meant that to measure the pulp and ambient temperature of fruit, navel oranges had to be probed with temperature monitors. The research methodology was adapted from previous studies conducted on the export cold chain of various fruit types to international markets. To further ensure validity and reliability of the study, temperature data was not only collected by the researcher, but by other organisations involved in the export cold chain using the same process. Following the right methodology and research design ensured the validity and reliability of the study.

\subsection{Conclusion}

The sources of data utilised for the study were observations of the export cold chain and readings from temperature monitors. Literature review and historic data from companies were used as secondary data. The historic data was utilised for the primary purposes of identifying any similarities or differences in temperature data collected in previous years compared to that collected by the researcher.

Analysing qualitative and quantitative data for a mixed research approach involved the data going through several stages. These stages included; data reduction, data display, data transformation, data correlation, data consolidation, data comparison and data integration. Data reduction involved filtering out or rather cleaning out data. Quantitative data was provided by readings from iButtons®, which can record up to 8000 readings per iButton ${ }^{\circledR}$ in half an hour intervals. This means that a 
significant amount of data was collected. Therefore, filtering the data to obtain the data needed for analysis was necessary. Data reduction included reducing datasets to only those that would generate the needed outcome. Since data was divided into two sections; namely, orchard to port gate and cold store to port of destination, the segments of the export cold chain which were not examined were filtered.

Data display involved visual description using tables and graphs, this was done through employing the use of descriptive and inferential data analysis. Data transformation involved converting qualitative or quantitative data into either narrative or numerical codes that can be represented statistically, which was also done through descriptive and inferential statistics. Data correlation and consolidation involved combining both data sets to create either new or consolidated variables, whilst data comparison involved the comparison of data from qualitative and quantitative data sources. Lastly, data integration involved combining temperature data generated from different sources and presenting it in a manner that the reader could understand. 


\section{Chapter 5: Descriptive Data Analysis}

\subsection{Introduction}

The purpose of the study was to identify whether there are temperature breaks in the different phases of the export cold chain. In addition, the study strived to determine the link between temperature breaks and fruit quality. The assumption that Company $\mathrm{X}$ was concerned about temperature breaks in the export cold chain of navel oranges, as mentioned in the study's problem statement, guided the research study. Based on the company's concern, the study aimed to investigate the different variables related to temperature breaks and how they could be optimally managed as a solution to reduce the incidences of quality claims and income losses.

The study investigated temperature breaks through a literature review, which focused on the factors affecting the export cold chain, the fresh fruit industry of South Africa, cold sterilisation, the role of key organisations in the cold sterilisation treatment protocols and the export cold chain of navel oranges. In addition, temperature data was collected along the different phases of the cold chain. Temperature data of navel oranges shipped in previous seasons (2012-2017) were received from export companies. Reports on the quality of fruit, which had undergone steri-protocols in past seasons were also received from Company X. Both these datasets serve as the study's historic data.

The statistical analysis techniques that were employed in the study were descriptive and inferential analysis. The numerical descriptive statistics employed in this chapter were computed using Microsoft Excel. In addition, inferential statistics were utilised to test two hypotheses.

This chapter presents the data collected and analysed for the study. The data analysed is presented per research objective. Initially, the study had aimed to utilise four reefer vessels, in which probed fruit would be shipped in, but due to circumstances beyond the researcher's control only three vessels were utilised and viable data was only received from two vessels.

\subsection{Temperature trials}

For the purposes of the study, temperature trials refer to the gathering of data through the insertion of temperature monitors inside the pulp of fruit, inside fruit cartons, thus allowing the monitoring of fruit throughout the export cold chain of navel oranges. Temperature monitors utilised measured both pulp and ambient temperature of the fruit inside the carton. Temperature monitors were provided by Company X. For the rest of this chapter, temperature monitors are referred to as iButtons ${ }^{\circledR}$. The data 
set recorded by iButtons ${ }^{\circledR}$ was divided into two, namely, the first phase and the second phase of the cold chain. The first phase is from the orchard (point of harvest) until cold storage, before fruit were accepted for cold storage processes. The latter phase is from the cold store until the port of destination. This means that for the first phase, temperature spikes are analysed and for the second phase, temperature breaks are analysed.

Temperature spikes were analysed from the orchard to cold store since the cold sterilisation treatment starts from the point when conventional vessel compartments are closed with all three major temperature probes reading $-0.6^{\circ} \mathrm{C}$ until end destination. Temperature spikes were analysed as each stage of the cold chain influences the next. For the purpose of this thesis a temperature spike was defined as "any time temperature rises along the export cold chain". The temperature has to rise by $2^{\circ} \mathrm{C}$ or more for the rise to be significant and influence the fruit quality (Goedhals-Gerber et al., 2017). Temperature breaks were analysed from the cold store until the port of destination and temperature breaks were defined as "a temperature deviation above $0.0^{\circ} \mathrm{C}$ or below $-1.5^{\circ} \mathrm{C}$ ". Monitoring of fruit from the point of harvest until port of destination was deemed ideal as it accounts for the different factors influencing the occurrence of temperature spikes or breaks along the export cold chain as well as the final quality of the product.

To determine what qualifies as a temperature break for the steri-market section of the export cold chain, an upper pulp temperature limit had to be chosen. PPECB steri-market protocols stipulate that pulp temperature may vary between $-0.6^{\circ} \mathrm{C}$ to $0.0^{\circ} \mathrm{C}$, but if temperatures exceed $0.0^{\circ} \mathrm{C}$, it is considered a steri-breach and the cold treatment is extended so that temperature is brought back down to $-0.6^{\circ} \mathrm{C}$. If the temperature exceeds $1.1^{\circ} \mathrm{C}$, cold sterilisation treatment is nullified (PPECB, 2012). Therefore, for the purpose of this study's data analysis, a temperature break for steri-protocols occurs when the pulp temperature of the navel oranges rises above $1.1^{\circ} \mathrm{C}$.

It is worth noting that regardless of the researcher inserting iButtons ${ }^{\circledR}$ into the pulp of fruit for the measurement of temperature, protocols are validated on special probes inserted into the fruit by the PPECB. These probes record temperature on a system on the vessel, which is then verified by USDA. Each probe must show that the temperature was kept below the stipulated specification for the required duration. For conventional vessels, 62 temperature probes are inserted into fruit per deck by PPECB and if any of these probes record a temperature beyond $1.1^{\circ} \mathrm{C}$, the temperature is nullified.

In the orchard, drenching and degreening stages iButtons ${ }^{\circledR}$ were randomly placed into bins. From the pack house to the cold store, iButtons ${ }^{\circledR}$ were placed in the first (bottom), fourth (middle) and seventh (top) cartons that were staged on pallets, but were not placed somewhere specific in the reefer vessel. 
iButtons ${ }^{\circledR}$ were set to record at 30-minute intervals. A program called ColdChain Thermo Dynamics was used to record the readings from iButtons ${ }^{\circledR}$. Figures 22, 23 and 24 depict the locations of iButtons ${ }^{\circledR}$ in fruit bins and fruit cartons on pallets. Figure 22 illustrates iButtons ${ }^{\circledR}$ used for the study and how they were probed inside fruit. Figure 23 illustrates the location where iButtons ${ }^{\circledR}$ were inserted in fruit bins from the orchard to pack house, and Figure 24 illustrates the location of iButtons ${ }^{\circledR}$ in fruit cartons on pallets from pack house to the cold store. Since data was collected in different phases, the same locations for iButtons ${ }^{\circledR}$ were utilised in all collection phases.
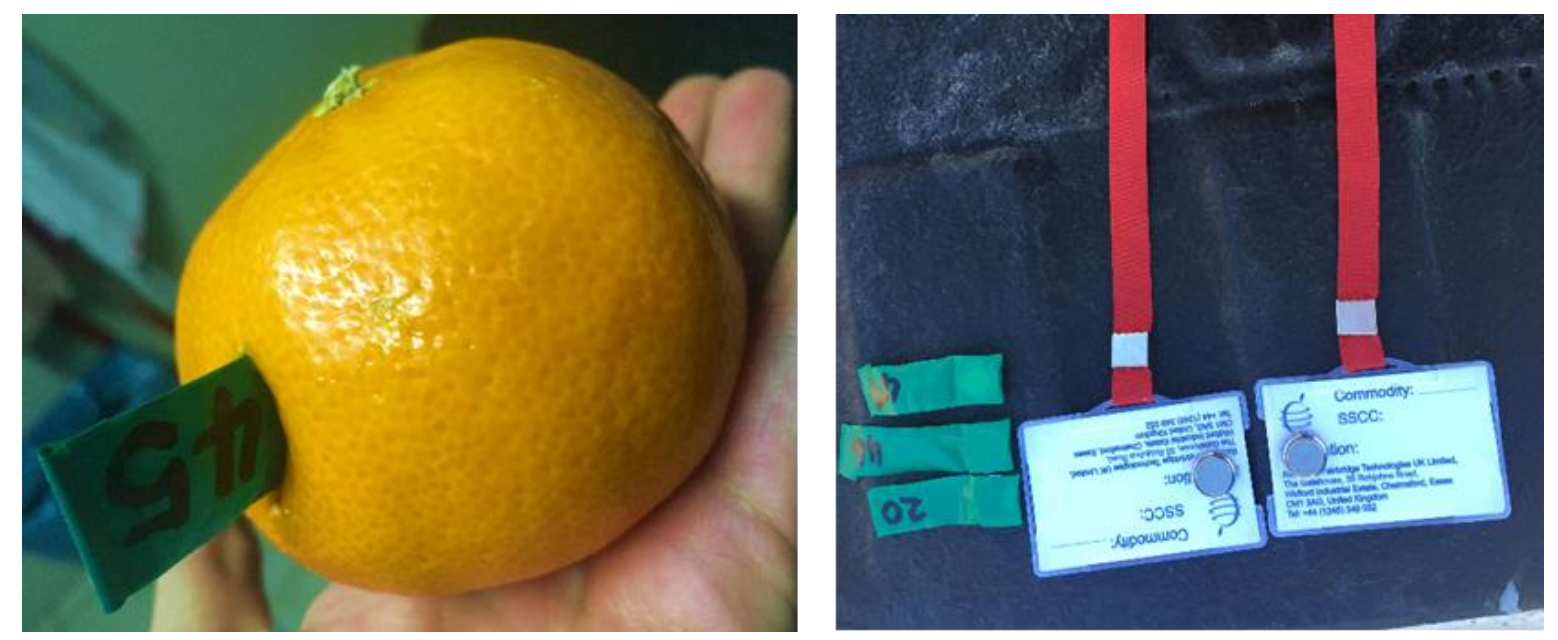

Figure 22: Illustration of iButtons ${ }^{\circledR}$ probed inside a navel orange and ambient recording iButtons ${ }^{\circledR}$ with a red string attached.

Source: Photo taken by researcher 


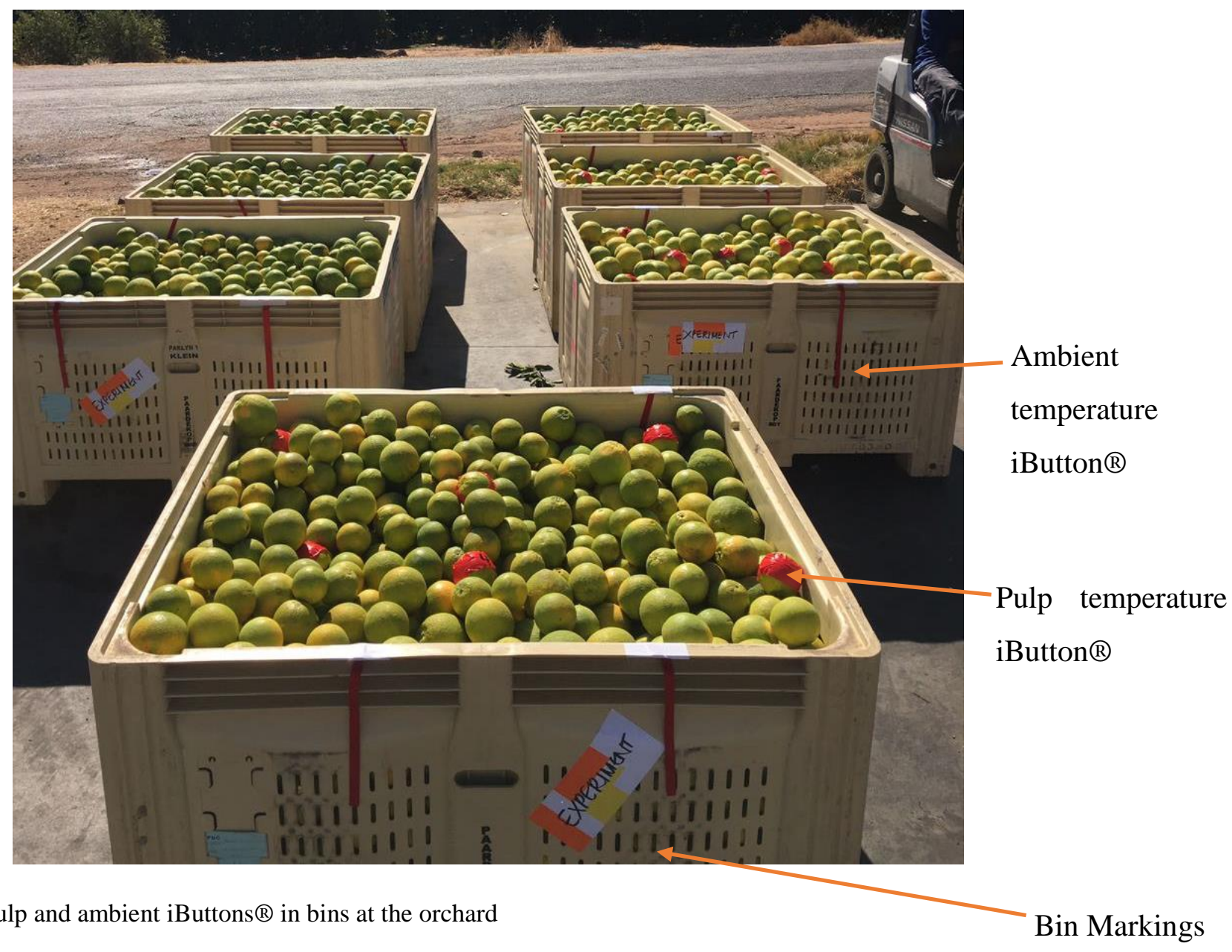

Figure 23: Pulp and ambient iButtons ${ }^{\circledR}$ in bins at the orchard

Bin Markings

Source: Photo taken by researcher

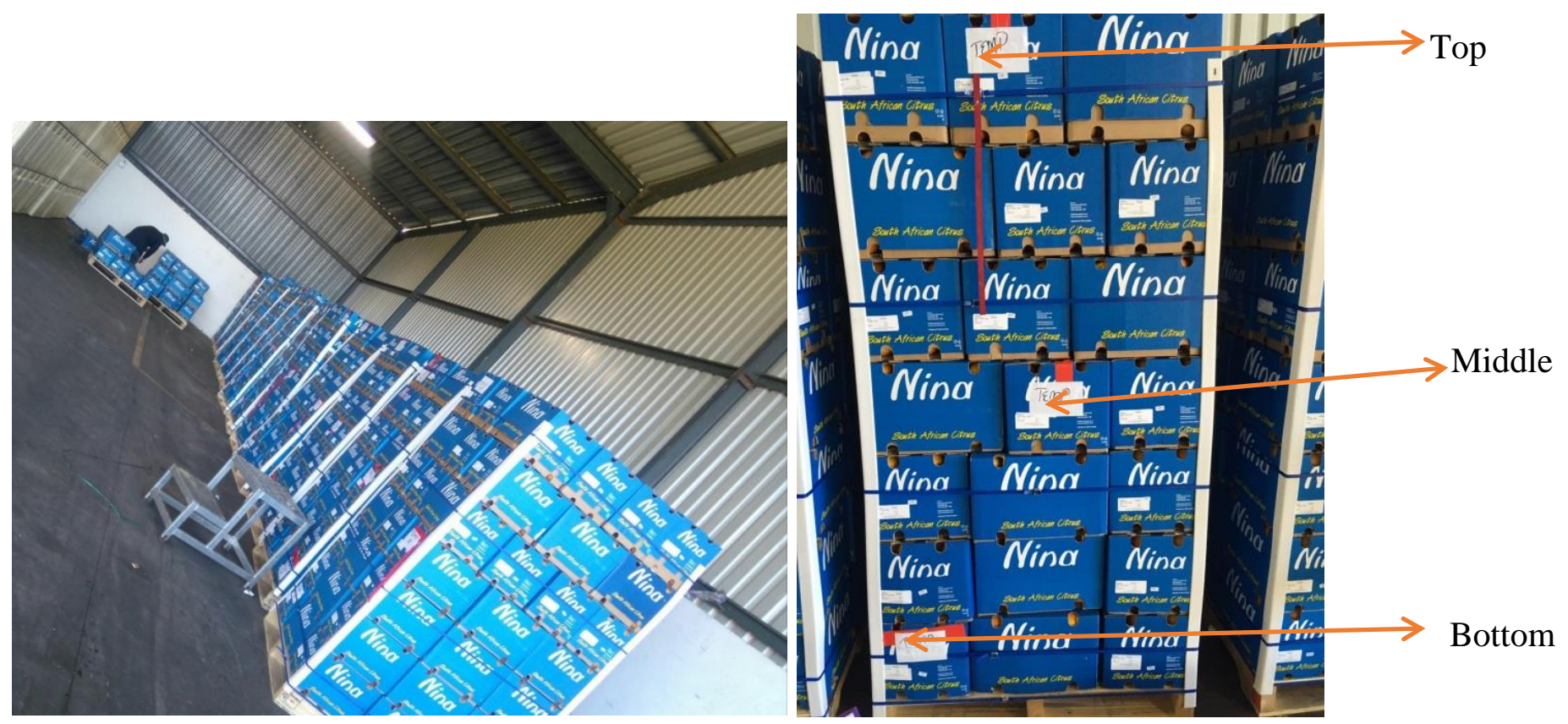

Figure 24: Ambient and fruit pulp iButtons ${ }^{\circledR}$ location from pack house to cold store

Source: Photo taken by researcher 
iButtons ${ }^{\circledR}$ were inserted immediately after navel oranges were harvested from the tree until the pack house and were removed after the degreening process was completed. iButtons ${ }^{\circledR}$ were removed before fruit journeyed through the pack line, because of the perishable nature of fruit and to avoid major losses of iButtons ${ }^{\circledR}$. Pack lines involve a lot of tossing and turning, especially during washing, drying, fungicide application and waxing. A slit was cut open on the rind of the navel oranges for insertion of the iButtons ${ }^{\circledR}$ and wrapped around with insulation tape to keep it secure. Even though the fruit were secured by insulation tape, it does not prevent the iButtons ${ }^{\circledR}$ from falling out. Therefore, the pack house managers and the researcher decided that to avoid the loss of iButtons ${ }^{\circledR}$, re-probing would take place after pack line processes were complete. Fruit was re-probed with iButtons ${ }^{\circledR}$ whilst inside fruit cartons before transportation to the cold store. All temperature trials were conducted in the Citrusdal region at Farm $\mathrm{X}$ and Pack house $\mathrm{X}$.

Temperature was monitored throughout the export cold chain phases until arrival at the port of destination. iButtons ${ }^{\circledR}$ were manually removed from inside the fruit and fruit cartons by USDA officials and were sent back to the researcher for the data to be downloaded and analysed. Unfortunately, out of the 280 iButtons ${ }^{\circledR}$ used for data collection for the study, only $49 \%$ were retrieved.

Table 7 displays iButtons ${ }^{\circledR}$ probing information during the different data collection phases. It is important to note that iButtons ${ }^{\circledR}$ were re-used during the phases where fruit was re-probed, rather than inserting new temperature monitors. For instance, iButtons ${ }^{\circledR}$ used on 19 May had been removed and re-probed from fruit that was used on 10 May.

Table 7: iButtons ${ }^{\circledR}$ probing phases

\begin{tabular}{|c|c|c|c|c|c|}
\hline Fruit Type & $\begin{array}{l}\text { Date of } \\
\text { Probe }\end{array}$ & $\begin{array}{c}\text { iButtons }{ }^{\circledR} \\
\text { Inserted }\end{array}$ & Location & Probe usage & Vessel \\
\hline Navel orange & 03 May 2017 & 70 & $\begin{array}{c}\text { Bins at pack } \\
\text { house }\end{array}$ & $\begin{array}{c}56 \text { pulp \& } 14 \\
\text { ambient }\end{array}$ & Santa Lucia \\
\hline Navel orange & 10 May 2017 & 70 & $\begin{array}{c}\text { Plastic bins at } \\
\text { drenching } \\
\text { area }\end{array}$ & $\begin{array}{c}56 \text { pulp \& } 14 \\
\text { ambient }\end{array}$ & Santa Lucia \\
\hline
\end{tabular}




\begin{tabular}{|c|c|c|c|c|c|}
\hline Navel orange & 19 May 2017 & 70 & $\begin{array}{l}\text { Pallets: top, } \\
\text { middle and } \\
\text { bottom carton }\end{array}$ & $\begin{array}{c}56 \text { pulp \& } 14 \\
\text { ambient }\end{array}$ & Santa Lucia \\
\hline Navel orange & 31 May 2017 & 70 & $\begin{array}{c}\text { Bins at drench } \\
\text { area }\end{array}$ & $\begin{array}{c}56 \text { pulp \&14 } \\
\text { ambient }\end{array}$ & Regal Bay \\
\hline Navel orange & 9 June 207 & 70 & $\begin{array}{l}\text { Pallets: top, } \\
\text { middle and } \\
\text { bottom carton }\end{array}$ & $\begin{array}{c}56 \text { pulp \& } 14 \\
\text { ambient }\end{array}$ & Regal Bay \\
\hline Navel orange & 14 June 2017 & 70 & $\begin{array}{c}\text { Bins at drench } \\
\text { area }\end{array}$ & $\begin{array}{c}56 \text { pulp \& } 14 \\
\text { ambient }\end{array}$ & Regal Bay \\
\hline Navel orange & 22 June 2017 & 70 & $\begin{array}{l}\text { Pallets: top, } \\
\text { middle and } \\
\text { bottom carton }\end{array}$ & $\begin{array}{c}56 \text { pulp \& } 14 \\
\text { ambient }\end{array}$ & Regal Bay \\
\hline
\end{tabular}

\subsection{Descriptive Analysis of Santa Lucia and Regal Bay vessels}

\subsubsection{Research Objective $1 \& 2$}

To identify whether temperature breaks occur along the export cold chain and determine where along the export cold chain of navel oranges temperature is not optimally maintained.

The descriptive analysis of objective 1 and 2 is based on primary data collected during the course of the study. The data is analysed using graphical and numerical statistics. The graphical statistics depict the time series of temperature data measured in ${ }^{\circ} \mathrm{C}$ and the numerical statistics determine central tendency.

The different phases of the export cold chain have temperature boundaries that should not be surpassed as it contributes to temperature breaks, which in turn could affect fruit quality. The main objective of the study was to identify whether breaks occur along the export cold chain. To address the study's objectives, the researcher collected data in the first and second phases of the export cold chain, excluding the pack line segment. The first phases of the supply chain were analysed for temperature spikes. To analyse any anomalies in the first vessel, called Santa Lucia, a general time frame for cold chain processes of the fruit consignment shipped is used as a point of reference. Temperature trials for the vessel were conducted in May 2017. 
Table 8 depicts the dates and days on which processes occurred until the port of destination. This was used as a basis for the analysis.

Table 8: Temperature trial process for Santa Lucia Vessel

\begin{tabular}{|c|c|c|}
\hline Export chain process & Date of process & Days \\
\hline Harvesting & 10 May & 1 \\
\hline Drenching & 10 May & 1 \\
\hline Degreening & 11 May & $3-4$ \\
\hline Packing & 14 May & 4 \\
\hline Palletisation and & 17 May & 2 \\
\hline transportation & 19 May & 3 \\
\hline Cold store & 22 May & 3 \\
\hline Cold sterilisation & & 22 \\
\hline location & 24 May & 3 \\
\hline Loading & May & 3 \\
\hline
\end{tabular}

Figure 25 illustrates the time series of the pulp and ambient temperature of navel oranges from the orchard until the Port of Cape Town before pre-cooling procedures commenced. 


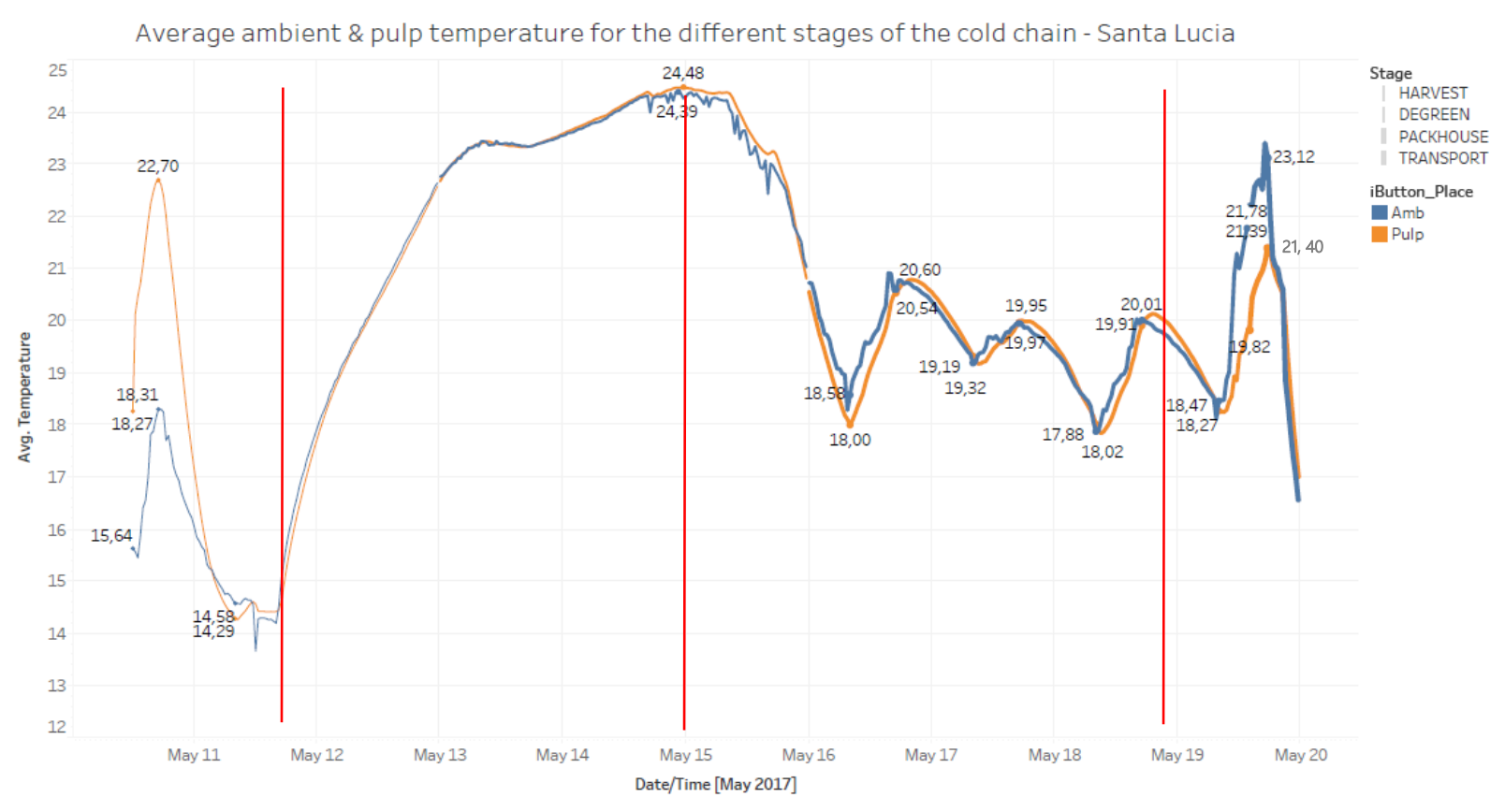

Figure 25: Pulp (56 iButtons $\left.{ }^{\circledR}\right)$ and ambient temperature $\left(14\right.$ iButtons $\left.{ }^{\circledR}\right)$ of Santa Lucia in ${ }^{\circ} \mathrm{C}$

Figure 25 depicts a temperature spike at the start of the export process, after the navel oranges were harvested. Navel oranges are harvested and thereafter go through a drenching process. After drenching, the fruit is left to stand out in the open to dry for a period of 24 hours. It is notable that the temperature spike recorded at the start of the chain is because of heat absorbed by fruit while left to dry. The pulp temperature of the navel oranges increased gradually from $18.3^{\circ} \mathrm{C}$ to a spike of $22.7^{\circ} \mathrm{C}$. The ambient temperature also increased from $15.7^{\circ} \mathrm{C}$ to $18.3^{\circ} \mathrm{C}$. Both ambient and pulp temperature of the navel oranges may have increased as a result of weather conditions on the day of harvest.

Fruit was placed into a degreening chamber, which is depicted by the gradual rise in temperature from 12 May until 15 May. Temperature increased gradually within the recommended temperature range for a navel orange degreening chamber, which is between $20-25^{\circ} \mathrm{C}$. Once the fruit is removed from the degreening chamber, it gets stored in the pack house until it can go over the pack line. The fruit probed with iButtons $®$ was kept aside, in the same conditions as the fruit would have been in if the pack house processes continued uninterrupted, until the researcher went back to re-probe the fruit. The iButtons® were removed from the fruit (the fruit had already gone off and was mouldy) and the researcher re-probed new fruit already packed in cartons and staged on pallets. The pulp and ambient temperature were relatively similar over this period. Therefore, temperature spikes depicted in the graph between 16 and 19 May are a result of fruit taking on daily temperatures. 
The researcher went back to the pack house on 19 May to re-probe fruit. A temperature spike is observed for both pulp $\left(20.01^{\circ} \mathrm{C}\right)$ and ambient $\left(19.91^{\circ} \mathrm{C}\right)$ temperature on 19 May. This is due to the handling of the 70 iButtons ${ }^{\circledR}$ when re-probing of which 56 were to collect pulp temperature and 14 were used to collect ambient temperature.

Fruit was transported to a cold store at the Port of Cape Town on the same day after re-probing. During the transportation phase, there is a continuous rise in temperature, with pulp temperature rising to $21.40^{\circ} \mathrm{C}$. The temperature eventually starts gradually decreasing once fruit pallets are placed in the cold store, after inspection by USDA officials has taken place.

To identify the implications of temperature breaks in the second phase of the export cold chain, it was crucial to identify whether breaks occurred and whether they occurred when navel oranges were placed in cold storage or once the cold sterilisation treatment protocols had begun. Cold sterilisation protocols commence once the compartments of the reefer vessel have been sealed shut and all three fruit probes recording a temperature of $-0.6^{\circ} \mathrm{C}$. The fruit arrived at the cold store on 19 May and underwent inspection on 21 May-22 May in the mid-morning.

The pulp (56 iButtons $\left.{ }^{\circledR}\right)$ and ambient (14 iButtons $\left.{ }^{\circledR}\right)$ temperature was compared to identify whether there were occurrences of temperature breaks. This is illustrated by Figure 26. 


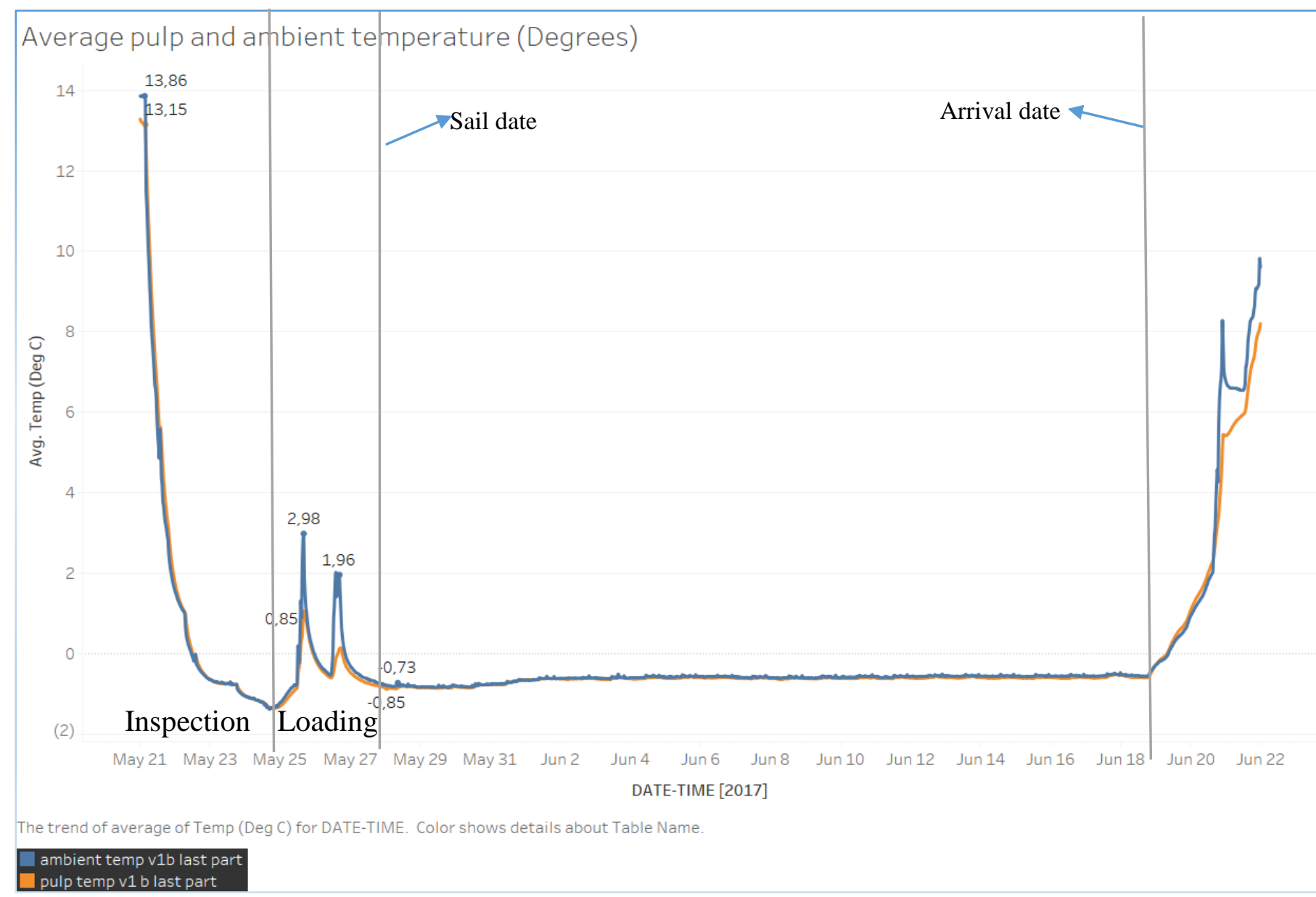

Figure 26: Ambient (14 iButtons $\left.{ }^{\circledR}\right)$ and pulp (56 iButtons $\left.®\right)$ temperature from cold store to port of arrival

Figure 26 depicts a steady decrease in temperature as the fruit is brought into pre-cooling in the cold room, after inspection by USDA officials. This means that while cartons staged on pallets are still standing outside for inspection, pulp and ambient temperature are still high. The pulp temperature of fruit during inspection was at $13.15^{\circ} \mathrm{C}$, whilst the ambient temperature was at $13.86^{\circ} \mathrm{C}$. During the last 24 hours prior to loading, navel oranges are brought down to the protocol temperature of $-0.6^{\circ} \mathrm{C}$. Navel oranges are meant to maintain the set temperature during loading. However, in the course of loading, on 25 May, a break in temperature is observed. The pulp temperature increased to $0.85^{\circ} \mathrm{C}$, which constitutes a temperature break. Ambient temperature increased to $2.98^{\circ} \mathrm{C}$. Another rise in temperature of $1.96{ }^{\circ} \mathrm{C}$ is observed in the ambient temperature on the 26 May. The breaks last for approximately two hours before temperature decreases again. The temperature breaks could be due to outside temperature influences during loading. The temperature breaks occurred during loading of navel oranges onto the reefer vessel. Once on the reefer vessel, the temperature is maintained within cold sterilisation protocols, meaning there was no temperature break in the steri-protocols. Both 
ambient and pulp temperature are maintained below $0.0{ }^{\circ} \mathrm{C}$, depicted by temperatures of $-0.85^{\circ} \mathrm{C}$ and $-0.73^{\circ} \mathrm{C}$ on sail date, which was 28 May.

To further address the research objectives, the researcher had to also analyse which of the positions where iButtons ${ }^{\circledR}$ were placed in cartons staged on pallets, were prone to more temperature breaks, i.e., spatial variations in temperature as depicted by Figure 27. The analysis for which positions where iButtons ${ }^{\circledR}$ were placed was conducted for the last stages of the export cold chain (from the cold store to the port of destination). iButtons ${ }^{\circledR}$ were probed into fruit in different positions from the pack house (before transportation to the cold store) until the port of destination. Hence, the analysis of the last stages. In addition, the PPECB requires that for the last 24 hours before loading, fruit must be cooled to a temperature of $-0.6^{\circ} \mathrm{C}$, and must remain at that temperature for 22 days while on-board the vessel. If temperature deviates above $0.0^{\circ} \mathrm{C}$ during that period, fruit is sent back for additional cooling. Therefore, analysing data from the cold store to the port of destination deemed suitable, as these phases would better depict if the PPECB requirements were met. The position where iButtons $®$ for pulp temperature were placed in pallets are the top, middle and bottom cartons.

iButtons ${ }^{\circledR}$ which were placed in the top carton are seen to be the most prone to temperature breaks during the loading stage. The graph illustrated below depicts the first temperature break that occurs during loading (shown by the black arrow). The pulp temperature depicted by the green line on the graph rises to $4.1^{\circ} \mathrm{C}$. The rise in temperature lasts for approximately 8 hours before temperatures start decreasing. The second arrow shows another temperature break which occurs on 26 May. The pulp temperature increases to $2.8^{\circ} \mathrm{C}$ for the top positioned carton. The rise in temperature lasts for approximately 6 hours before both temperatures start stabilising and decreasing to acceptable temperature range. 
All Groups

Plot of selected variables (series)

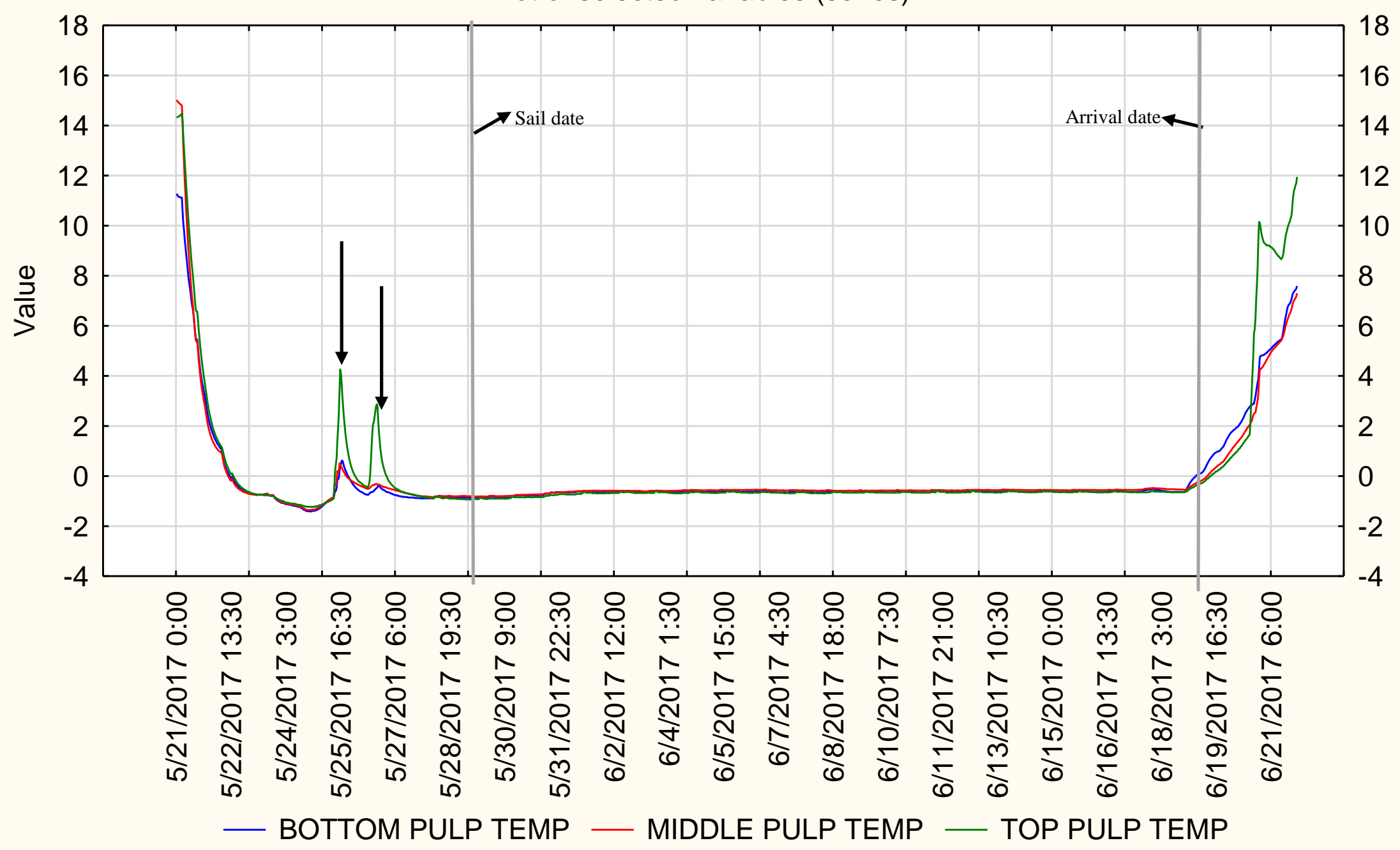


However, during the sailing of the vessel, the middle positioned cartons are seen the most likely to experience temperature breaks. Once the vessel has been loaded and stabilised and shipment takes place, the middle positioned cartons show a significant rise in temperature. This may be due to the fact that the cooling system utilised in conventional vessels delivers cold air from the bottom and the top, hence middle positioned cartons possibly trap the warm air due to insufficient airflow in the middle (as air follows the shortest and easiest airflow route, also known as the route of least resistance). Figure 28 shows the different positions of cartons staged on pallets during shipment.

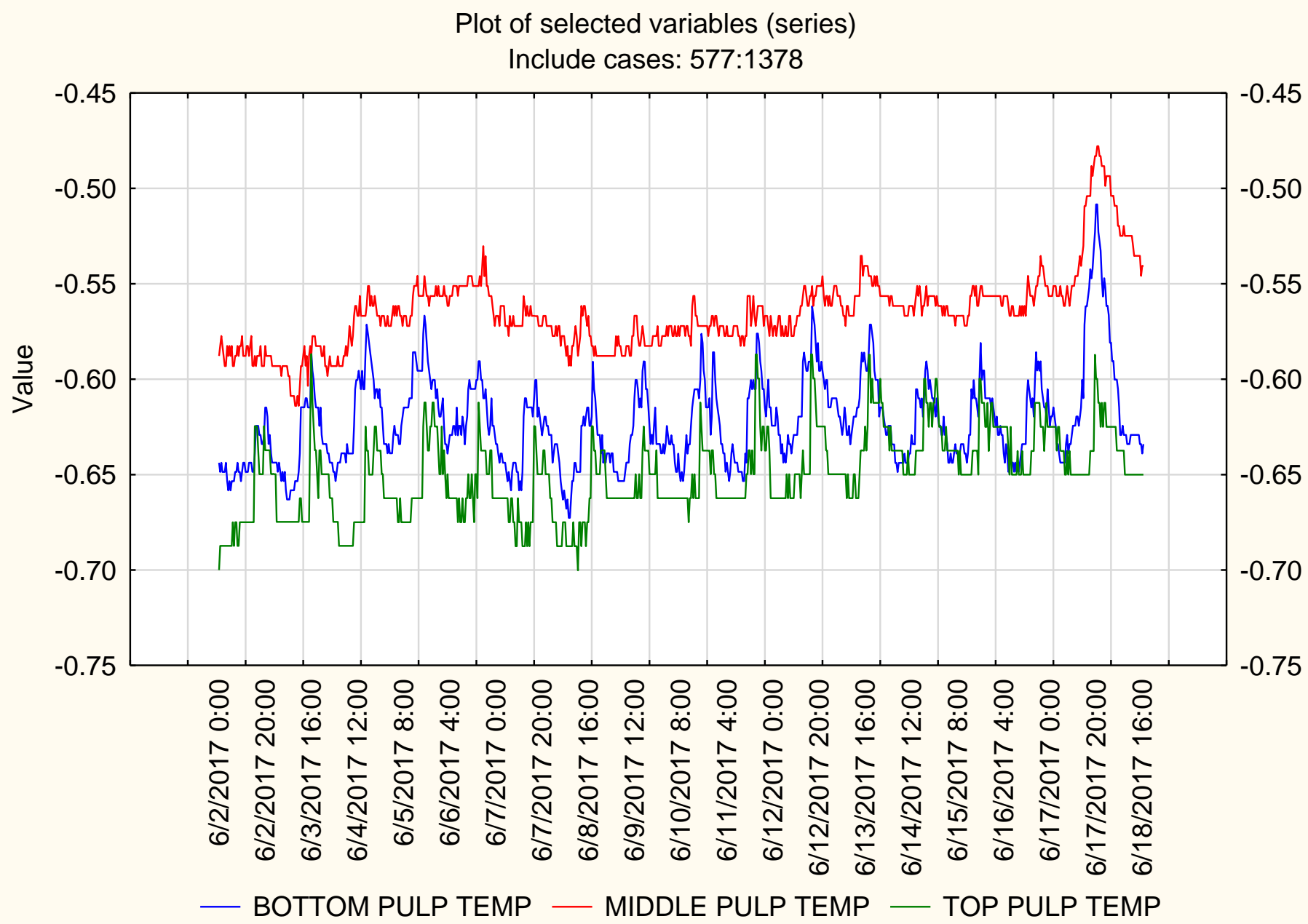

Figure 28: Pulp temperature (56 iButtons $\left.{ }^{\circledR}\right)$ of iButtons ${ }^{\circledR}$ position during shipment of Santa Lucia vessel

Figure 28 shows that cartons placed in the middle position during the sea leg have higher temperatures than the bottom and the top position cartons. The temperatures of the middle positioned cartons do not surpass the stipulated cold sterilisation treatment protocols, but the temperatures appear to be higher than the top and bottom positioned cartons. Although, no fruit consignments were reported to be rejected upon arrival of the navel oranges at the port of destination, navel oranges that are packed into cartons placed on top and middle of the pallet are most likely to experience a steri-breach. Navel 
oranges packed at the top positions are more likely to experience temperature breaks during loading and those positioned in the middle are more likely to experience temperature breaks during the sea leg. This would mean that the cold sterilisation treatment protocol has to be prolonged by additional days, depending on how long the breach occurred. A steri-breach is when the pulp temperature of fruit surpasses $0.0^{\circ} \mathrm{C}$ once cold sterilisation protocols start. This means that temperature has to be brought back down to $-0.6^{\circ} \mathrm{C}$ for additional days during shipment.

Figure 29 depicts the maximum pulp temperatures of navel oranges between the cold store and the sea leg. The highest temperature was recorded at $8^{\circ} \mathrm{C}$ during the loading of fruit and in the sea leg a temperature of $0.08^{\circ} \mathrm{C}$ is the maximum temperature reached.

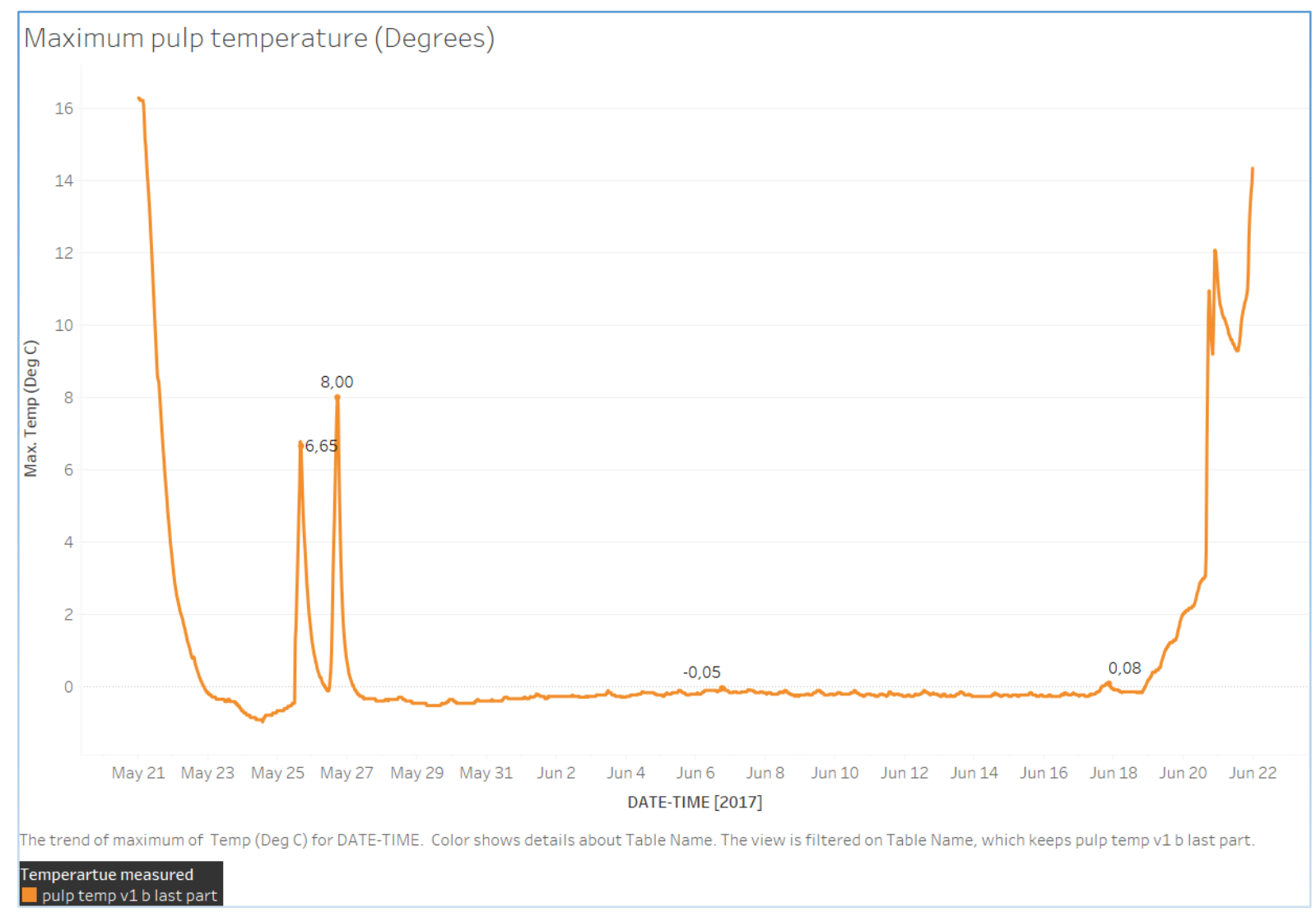

Figure 29: Maximum pulp temperatures

The graphs depicted in the graphical descriptive analysis of the Santa Lucia vessel trial show that there are temperature breaks that occur and the temperature of navel oranges is not optimally managed during the transportation, inspection and loading phase of the export cold chain. Temperatures during these phases increased to a pulp temperature of $21.4^{\circ} \mathrm{C}$ during transportation and $4.1^{\circ} \mathrm{C}$ during loading. All these breaks occur for a period of more than two hours before temperatures start decreasing. Analysis done on the last stages of the export cold chain proved that the top and middle cartons are the most likely to be affected. 
Descriptive numerical statistics were conducted on the pulp and ambient temperature for the different stages of Santa Lucia Vessel. The measures of central tendency are discussed more in detail for each individual stage. Descriptive numerical statistics were undertaken for the purposes of summarising data, which assisted in describing the relationship between the variables investigated. In turn, the descriptive numerical analysis conducted aided in validating the hypothesis of whether differences in the temperature profiles of the different stages of the export cold chain exists.

\subsubsection{Harvesting}

Table 9 presents the numerical descriptive statistics of the harvesting stage of the Santa Lucia vessel's temperature trial. According to Table 9, the pulp temperature during harvesting was $18.78^{\circ} \mathrm{C}$. The ambient temperature was $15.59^{\circ} \mathrm{C}$. The median is relatively similar, for pulp temperature the median is $18.40^{\circ} \mathrm{C}$ and for ambient temperature the median is $15.38^{\circ} \mathrm{C}$. Therefore, it is possible to conclude that the data is relatively evenly spread with no significant outliers. The standard deviation for both pulp and ambient temperature is $2.48^{\circ} \mathrm{C}$ and $1.61^{\circ} \mathrm{C}$ respectively. This means that the temperature is close to the average. The descriptive numerical statistics show that the pulp temperature during harvesting is higher than the ambient temperature. This means that during the harvesting phase, the pulp of navel oranges is likely to record higher temperatures, which may be caused by exposure to evening weather temperatures.

Table 9: Descriptive statistics of harvesting stage

\begin{tabular}{|c|c|c|c|c|c|c|c|}
\hline Variable & Mean & Median & $\begin{array}{l}\text { Standard } \\
\text { deviation }\end{array}$ & Maximum & Minimum & $\begin{array}{l}\text { Coefficient } \\
\text { of variation }\end{array}$ & $\begin{array}{c}\text { Number of } \\
\text { Observations }\end{array}$ \\
\hline $\begin{array}{l}\text { Pulp } \\
\text { Temperature } \\
\left.\text { (56 iButtons }{ }^{\circledR}\right)\end{array}$ & 18.78197 & 18.402 & 2.478939 & 24.668 & 14.715 & 6.14514 & 39 \\
\hline $\begin{array}{l}\text { Ambient } \\
\text { Temperature } \\
\text { ( } 14 \\
\left.\text { iButtons }{ }^{\circ}\right)\end{array}$ & 15.58836 & 15.378 & 1.607705 & 18.968 & 13.199 & 2.584716 & 39 \\
\hline
\end{tabular}

\subsubsection{Drenching}

Table 10 illustrates a summary of the statistics of data collected during the drenching stage. According to Table 10, the pulp and ambient temperature during drenching was approximately $21.87^{\circ} \mathrm{C}$ and $16.30^{\circ} \mathrm{C}$ respectively. The median is $21.18^{\circ} \mathrm{C}$ and $16.04^{\circ} \mathrm{C}$, suggesting that the data is evenly spread. 
The standard deviation for both pulp and ambient temperature is $2.44^{\circ} \mathrm{C}$ and $1.60^{\circ} \mathrm{C}$ respectively. This means that the temperature is close to the average. Both the pulp and ambient temperature means suggest that the pulp temperature of navel oranges increases during the drenching phase. The increase in temperature may be due to overnight temperature influences. This shows that the drenching of navel oranges is necessary to remove field heat, which is absorbed by the pulp of fruit.

Table 10: descriptive statistics of drenching stage

\begin{tabular}{|c|c|c|c|c|c|c|c|}
\hline Variable & Mean & Median & $\begin{array}{l}\text { Standard } \\
\text { deviation }\end{array}$ & Maximum & Minimum & $\begin{array}{c}\text { Coefficient of } \\
\text { variation }\end{array}$ & $\begin{array}{c}\text { Number of } \\
\text { Observations }\end{array}$ \\
\hline $\begin{array}{l}\text { Pulp } \\
\text { Temperature } \\
\text { (56 iButtons }{ }^{\circledR} \text { ) }\end{array}$ & 21.87018766 & 21.182 & 2.444832682 & 30.642 & 17.78 & 5.977206844 & 389 \\
\hline $\begin{array}{l}\text { Ambient } \\
\text { Temperature } \\
\text { (14 iButtons } ®)\end{array}$ & 16.295125 & 1.60385 & 16.0385 & 22.38 & 13.638 & 2.749495979 & 389 \\
\hline
\end{tabular}

\subsubsection{Degreening}

Table 11 illustrates the statistical summary of data collected at the degreening stage. From the descriptive statistics, it is possible to conclude that the pulp and ambient temperature are $23.63^{\circ} \mathrm{C}$ and $23.55^{\circ} \mathrm{C}$ respectively. The median for pulp temperature is $23.61^{\circ} \mathrm{C}$ and for ambient temperature, it is $23.53^{\circ} \mathrm{C}$. According to the mean and median pulp and ambient temperatures, both are kept within the acceptable temperature ranges required for the degreening of navel oranges.

Table 11: Descriptive statistics of the degreening stage

\begin{tabular}{|c|c|c|c|c|c|c|c|}
\hline Variable & Mean & Median & $\begin{array}{l}\text { Standard } \\
\text { deviation }\end{array}$ & Maximum & Minimum & $\begin{array}{c}\text { Coefficient of } \\
\text { variation }\end{array}$ & $\begin{array}{c}\text { Number of } \\
\text { Observations }\end{array}$ \\
\hline $\begin{array}{l}\text { Pulp } \\
\text { Temperature } \\
\left.\text { (56 iButtons }{ }^{\circledR}\right)\end{array}$ & 23.63 & 23.607 & 0.7044 & 24.70 & 20.266 & 0.496 & 148 \\
\hline $\begin{array}{l}\text { Ambient } \\
\text { Temperature } \\
\text { (14 iButtons®) }\end{array}$ & 23.55 & 23.527 & 0.678 & 24.64 & 21.66 & 0.4560 & 148 \\
\hline
\end{tabular}




\subsubsection{Pack house}

Table 12 presents the descriptive statistics of the pack house. According to the Table 12, the pulp temperature is $19.47^{\circ} \mathrm{C}$ and the ambient temperature is $19.58^{\circ} \mathrm{C}$. This is relatively similar to the median of $19.18^{\circ} \mathrm{C}$ and $19.54^{\circ} \mathrm{C}$ respectively, which suggests that the data is evenly spread without any significant outliers. The mean pulp and ambient temperature prove that the temperature in the pack house is kept within acceptable temperature range, which is between $18-25^{\circ} \mathrm{C}$. The median pulp and ambient temperatures are also within the acceptable temperature ranges, which further proves that the pack house temperature is maintained at an ideal level.

Table 12: Descriptive statistics of the pack house stage

\begin{tabular}{|l|c|c|c|c|c|c|c|}
\hline \multicolumn{1}{|c|}{ Variable } & Mean & Median & $\begin{array}{c}\text { Standard } \\
\text { deviation }\end{array}$ & Maximum & Minimum & $\begin{array}{c}\text { Coefficient of } \\
\text { variation }\end{array}$ & $\begin{array}{c}\text { Number of } \\
\text { Observations }\end{array}$ \\
\hline $\begin{array}{l}\text { Pulp } \\
\text { Temperature }\end{array}$ & 19.47 & 19.182 & 0.7664 & 20.742 & 17.84 & 0.58772068 & 180 \\
\hline $\mathbf{5 6}$ iButtons@) & & & & & & & \\
\hline $\begin{array}{l}\text { Ambient } \\
\text { Temperature }\end{array}$ & 19.58 & 19.5385 & 0.748 & 21.38 & 17.63 & 0.5595979 & 180 \\
\hline $\mathbf{1 4}$ iButtons@) & & & & & & \\
\hline
\end{tabular}

\subsubsection{Transportation}

The descriptive statistics of the transport stage are presented in Table 13. The mean of both the pulp and ambient temperature at this stage is $20.07^{\circ} \mathrm{C}$ and $20.80^{\circ} \mathrm{C}$ respectively. The mean is relatively similar to the median pulp and ambient temperature of $20.66{ }^{\circ} \mathrm{C}$ and $21.25^{\circ} \mathrm{C}$ respectively, meaning the data is evenly spread. The mean pulp temperature during transportation is slightly lower than the ambient temperature. The median pulp temperature is also lower than the median ambient temperature. This may be a result of the tautliner truck used during transportation, which helps minimise the influence of outside temperatures on the pulp of navel oranges.

Table 13: Descriptive statistics of the transportation stage

\begin{tabular}{|l|c|c|c|c|c|c|c|}
\hline \multicolumn{1}{|c|}{ Variable } & Mean & Median & $\begin{array}{c}\text { Standard } \\
\text { deviation }\end{array}$ & Maximum & Minimum & $\begin{array}{c}\text { Coefficient of } \\
\text { variation }\end{array}$ & $\begin{array}{c}\text { Number of } \\
\text { Observations }\end{array}$ \\
\hline $\begin{array}{l}\text { Pulp } \\
\text { Temperature }\end{array}$ & 20.07 & 20.66 & 1.3264 & 21.393 & 17.042 & 1.78768 & 35 \\
$\mathbf{( 5 6 \text { iButtons } ( )}$ & & & & & & & \\
\hline
\end{tabular}




\begin{tabular}{|l|l|l|l|l|l|l|l|}
\hline $\begin{array}{l}\text { Ambient } \\
\text { Temperature }\end{array}$ & 20.80 & 21.25 & 2.218 & 23.487 & 16.568 & 4.885979 & 35 \\
\hline$(14$ iButtons () & & & & & & & \\
\hline
\end{tabular}

\subsubsection{Inspection}

The descriptive statistics of the inspection stage are presented in Table 14. The mean of both the pulp and ambient temperature at this stage is $13.18^{\circ} \mathrm{C}$ and $12.49^{\circ} \mathrm{C}$ respectively. The mean is relatively similar to the median pulp and ambient temperature of $13.52^{\circ} \mathrm{C}$ and $12.96^{\circ} \mathrm{C}$ respectively, meaning the data is evenly spread. The mean pulp and ambient temperature show a decrease during the inspection phase. However, the pulp temperature is slightly higher than the ambient temperature, which is depicted by both the mean and the median. The ambient temperature may be lower due to set temperatures in the inspection room.

Table 14: Descriptive statistics of the inspection stage

\begin{tabular}{|c|c|c|c|c|c|c|c|}
\hline Variable & Mean & Median & $\begin{array}{l}\text { Standard } \\
\text { deviation }\end{array}$ & Maximum & Minimum & $\begin{array}{c}\text { Coefficient of } \\
\text { variation }\end{array}$ & $\begin{array}{c}\text { Number of } \\
\text { Observations }\end{array}$ \\
\hline $\begin{array}{l}\text { Pulp } \\
\text { Temperature } \\
\text { (56 iButtons } ® \text { ) }\end{array}$ & 13.17728 & 13.515 & 1.938383 & 16.271 & 10.713 & 3.75733 & 145 \\
\hline $\begin{array}{l}\text { Ambient } \\
\text { Temperature } \\
\left.\text { (14 iButtons }{ }^{\circledR}\right)\end{array}$ & 12.49177 & 12.958 & 2.757355 & 16.455 & 5.455 & 7.603009 & 145 \\
\hline
\end{tabular}

\subsubsection{Cold storage}

The descriptive statistics of the cold storage stage are presented in Table 15. The mean of both the pulp and ambient temperature at this stage is $-0.74^{\circ} \mathrm{C}$ and $-0.63^{\circ} \mathrm{C}$ respectively. The mean is relatively similar to the median pulp and ambient temperature of $-0.71^{\circ} \mathrm{C}$ and $-0.65^{\circ} \mathrm{C}$ respectively, meaning the data is evenly spread. Both the mean pulp and ambient temperature depict that the temperature at the cold store is kept below $-0.6^{\circ} \mathrm{C}$, which is the stipulated cold sterilisation treatment protocol temperature.

Table 15: Descriptive statistics of the cold storage phase

\begin{tabular}{|l|l|l|l|l|l|c|c|}
\hline Variable & Mean & Median & $\begin{array}{c}\text { Standard } \\
\text { deviation }\end{array}$ & Maximum & Minimum & $\begin{array}{c}\text { Coefficient of } \\
\text { variation }\end{array}$ & $\begin{array}{c}\text { Number of } \\
\text { Observations }\end{array}$ \\
\hline
\end{tabular}




\begin{tabular}{|l|l|l|l|l|l|l|l|}
\hline $\begin{array}{l}\text { Pulp } \\
\text { Temperature }\end{array}$ & -0.74344 & -0.708 & 0.480816 & 1.593 & -1.507 & 0.231184 & 2402 \\
\hline $\mathbf{5 6}$ iButtons@) & & & & & & & \\
\hline $\begin{array}{l}\text { Ambient } \\
\text { Temperature }\end{array}$ & -0.62523 & -0.648 & 1.286823 & 13.017 & -1.986 & 1.655913 & 2402 \\
$(\mathbf{1 4}$ iButtons () & & & & & & \\
\end{tabular}

\subsubsection{8. $\quad$ Loading}

The descriptive statistics of the loading stage are presented in Table 16. The mean of both the pulp and ambient temperature at this stage is $0.63^{\circ} \mathrm{C}$ and $0.45^{\circ} \mathrm{C}$ respectively. The mean is relatively similar to the median pulp and ambient temperature of $0.83^{\circ} \mathrm{C}$ and $0.69^{\circ} \mathrm{C}$ respectively, meaning the data is evenly spread. The mean and median pulp temperatures show that during the loading stage, there is a rise in temperature. Therefore, the statistics show that a temperature break is likely to occur as temperature rises from the set temperature prior to loading.

Table 16: Descriptive statistics of the vessel loading stage

\begin{tabular}{|c|c|c|c|c|c|c|c|}
\hline Variable & Mean & Median & $\begin{array}{l}\text { Standard } \\
\text { deviation }\end{array}$ & Maximum & Minimum & $\begin{array}{c}\text { Coefficient of } \\
\text { variation }\end{array}$ & $\begin{array}{l}\text { Number of } \\
\text { Observations }\end{array}$ \\
\hline $\begin{array}{l}\text { Pulp } \\
\text { Temperature } \\
\text { (56 iButtons } ®)\end{array}$ & 0.63456 & 0.831 & 0.873563 & 7.995 & -1.507 & 0.231184 & 2402 \\
\hline $\begin{array}{l}\text { Ambient } \\
\text { Temperature } \\
\text { (14 iButtons } ®)\end{array}$ & 0.4452 & 0.693 & 1.286823 & 13.017 & -2.134 & 0.763113 & 2402 \\
\hline
\end{tabular}

\subsubsection{Shipment}

The descriptive statistics of the shipment stage are presented in Table 17. The mean of both the pulp and ambient temperature at this stage is $-0.50^{\circ} \mathrm{C}$ and $-0.51^{\circ} \mathrm{C}$ respectively. The mean is relatively similar to the median pulp and ambient temperature of $-0.51{ }^{\circ} \mathrm{C}$ and $-0.31^{\circ} \mathrm{C}$ respectively, meaning the data is evenly spread. The descriptive numerical statistics show that the temperature is kept below the stipulated protocol temperature range. The median pulp and ambient temperature also range within the required cold sterilisation treatment protocols. 
Table 17: Descriptive statistics of the shipment stage

\begin{tabular}{|c|c|c|c|c|c|c|c|}
\hline Variable & Mean & Median & $\begin{array}{l}\text { Standard } \\
\text { deviation }\end{array}$ & Maximum & Minimum & $\begin{array}{c}\text { Coefficient of } \\
\text { variation }\end{array}$ & $\begin{array}{c}\text { Number of } \\
\text { Observations }\end{array}$ \\
\hline $\begin{array}{l}\text { Pulp } \\
\text { Temperature } \\
\left.\text { (56 iButtons }{ }^{\circledR}\right)\end{array}$ & -0.49912 & -0.505 & 0.202476 & -0.11 & -1.194 & 0.040996 & 8246 \\
\hline $\begin{array}{l}\text { Ambient } \\
\text { Temperature } \\
\left.\text { (14 iButtons }{ }^{\circledR}\right)\end{array}$ & -0.5061 & -0.308 & 2.923895 & 16.565 & -0.94 & 8.549164 & 8246 \\
\hline
\end{tabular}

\subsubsection{Inferential analysis of Santa Lucia Vessel}

As mentioned in Chapter 4, Section 4.7.3 each stage refers to the various phases of the export cold chain. The harvesting, drenching, degreening and pack house phases were excluded for this analysis. iButtons ${ }^{\circledR}$ were probed into cartons staged on pallets according to different positions after the pack house processes had been completed. During the harvesting, drenching and degreening stages, iButtons ${ }^{\circledR}$ were randomly probed into fruit and not according to position. Hence, for the testing of the following hypothesis, the first four stages were excluded.

The descriptive analysis conducted aided in validating the hypothesis tested by the study. Inferential statistics were conducted to test the following hypothesis.

The hypothesis states:

$H_{0}:$ There are no differences in temperature at different positions at each stage of the export cold chain.

$H_{1}$ : There are differences in temperature at different positions at each stage of the export cold chain.

The different positions refer to the placement of iButtons ${ }^{\circledR}$ in cartons that were staged on pallets. A comparison was made between iButtons ${ }^{\circledR}$ placed on the top, middle and bottom cartons in each of the pallets utilised during data collection. Differences in temperature at different positions of the export cold chain were tested using the non-parametric Friedman test. The rejection of the null hypothesis is determined using the p-value. If the calculated p-value is low (P less than the selected significance level, $\alpha=0.05$ ) the null-hypothesis is rejected. The results are presented per export cold 
chain stage. Figure 30 shows the differences in temperature at the different positions at the transportation stage.

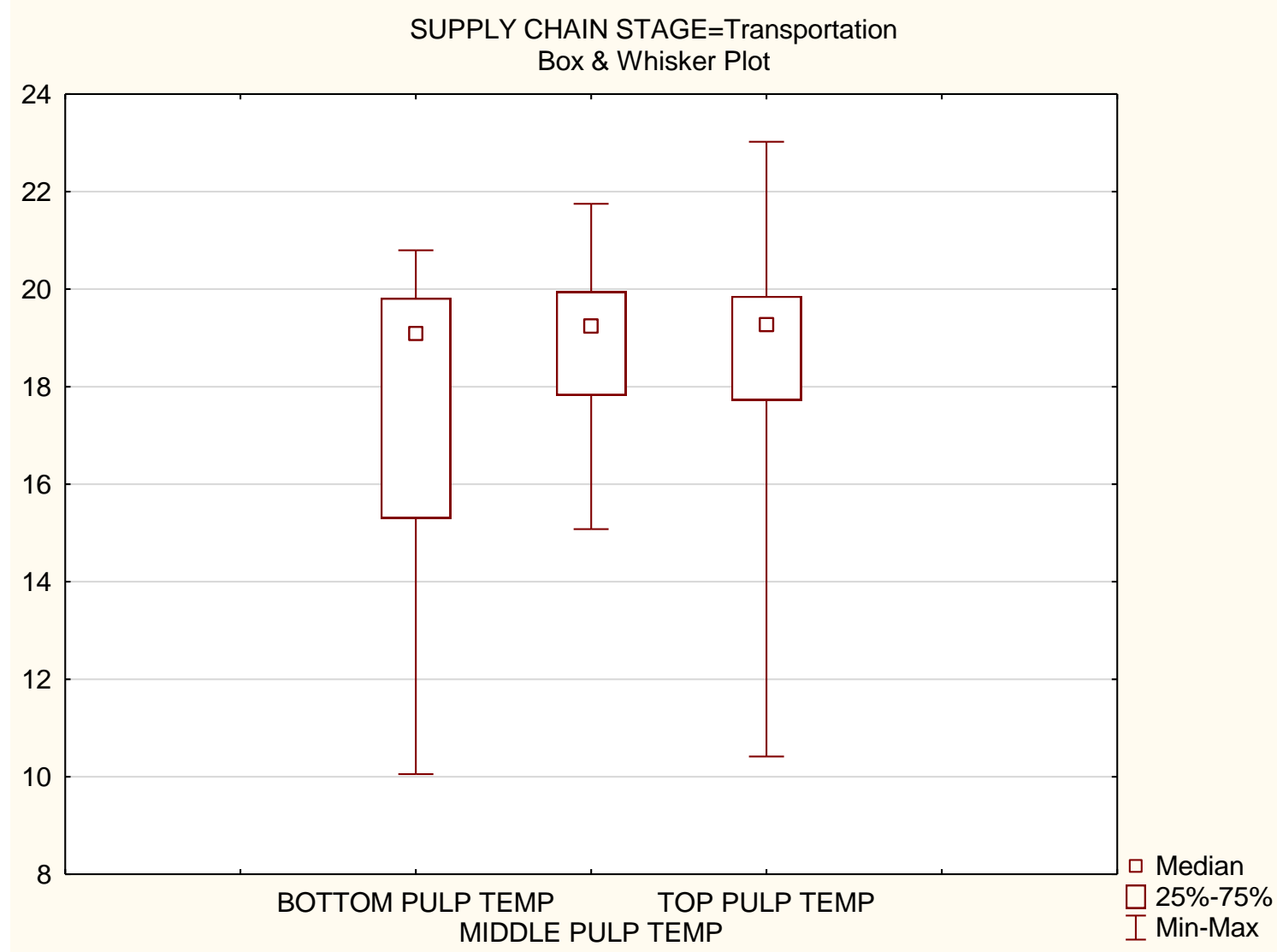

Figure 30: The difference in temperature at different positions at the transport stage

Figure 30 illustrates the Friedman test's finding that there are significant differences in temperature (ANOVA Chi Sqr. $(\mathrm{N}=191$, df = 2) = 37.83, p <0.001) during the transportation stage. The graph illustrates that the temperature at the bottom differs to that at the middle and at the top. The temperature at the bottom is lower than those of cartons placed at the middle and at the top. The temperatures at the middle and bottom do not differ significantly but the top positioned cartons show higher differences in temperature. 


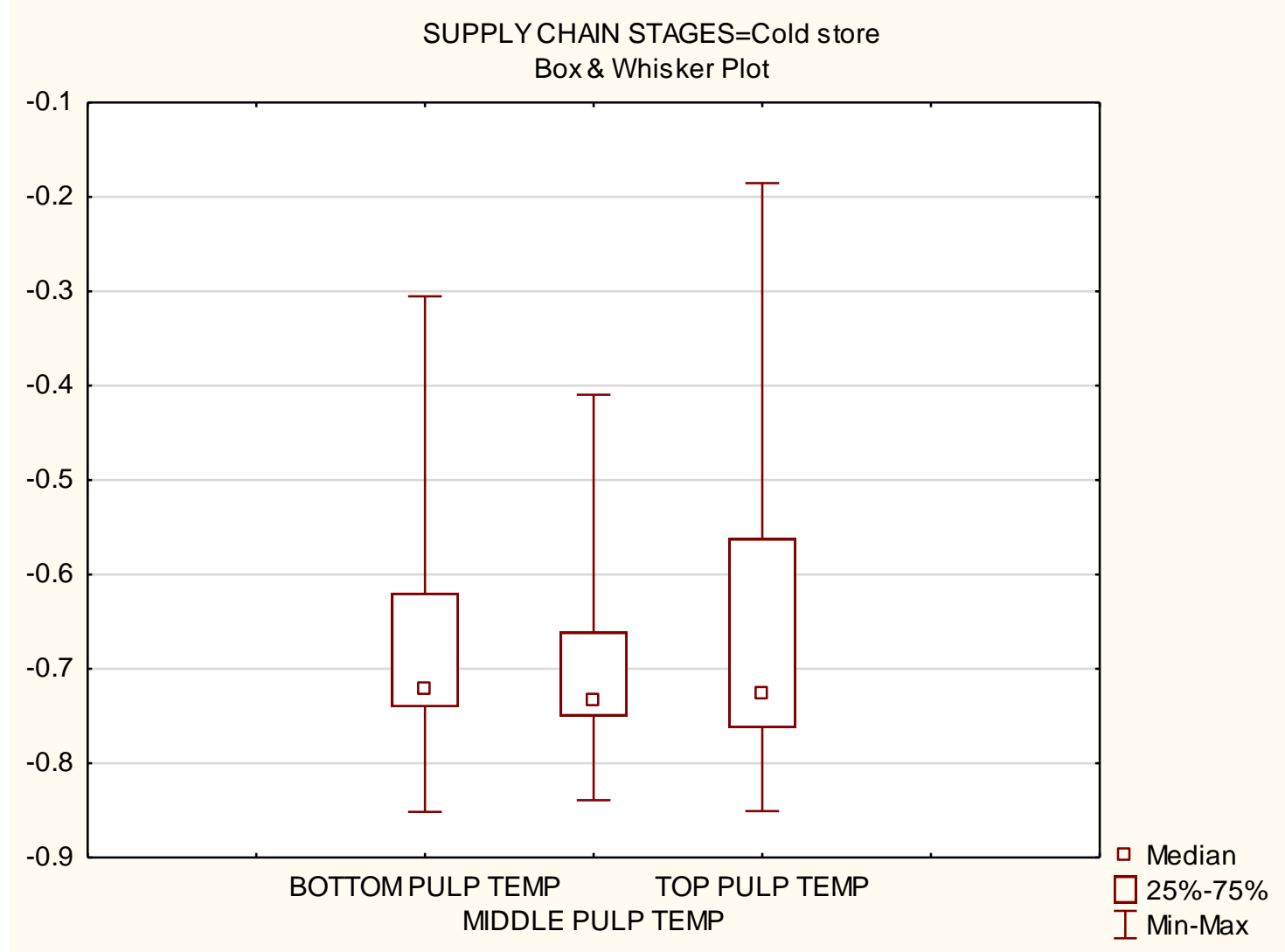

Figure 31: The difference in temperature at different positions at the cold store stage

Figure 31 illustrates the findings of the Friedman's test that there are differences in temperature at different positions during the cold storage phase (ANOVA Chi Sqr. $(\mathrm{N}=54$, df $=2)=10.25926$ $\mathrm{p}<0.001)$. The figure shows that the bottom positioned cartons shows a higher temperature than the top and middle positioned cartons. The median temperature of the bottom positioned cartons is higher than the median temperature of the cartons positioned in the middle and at the top. 


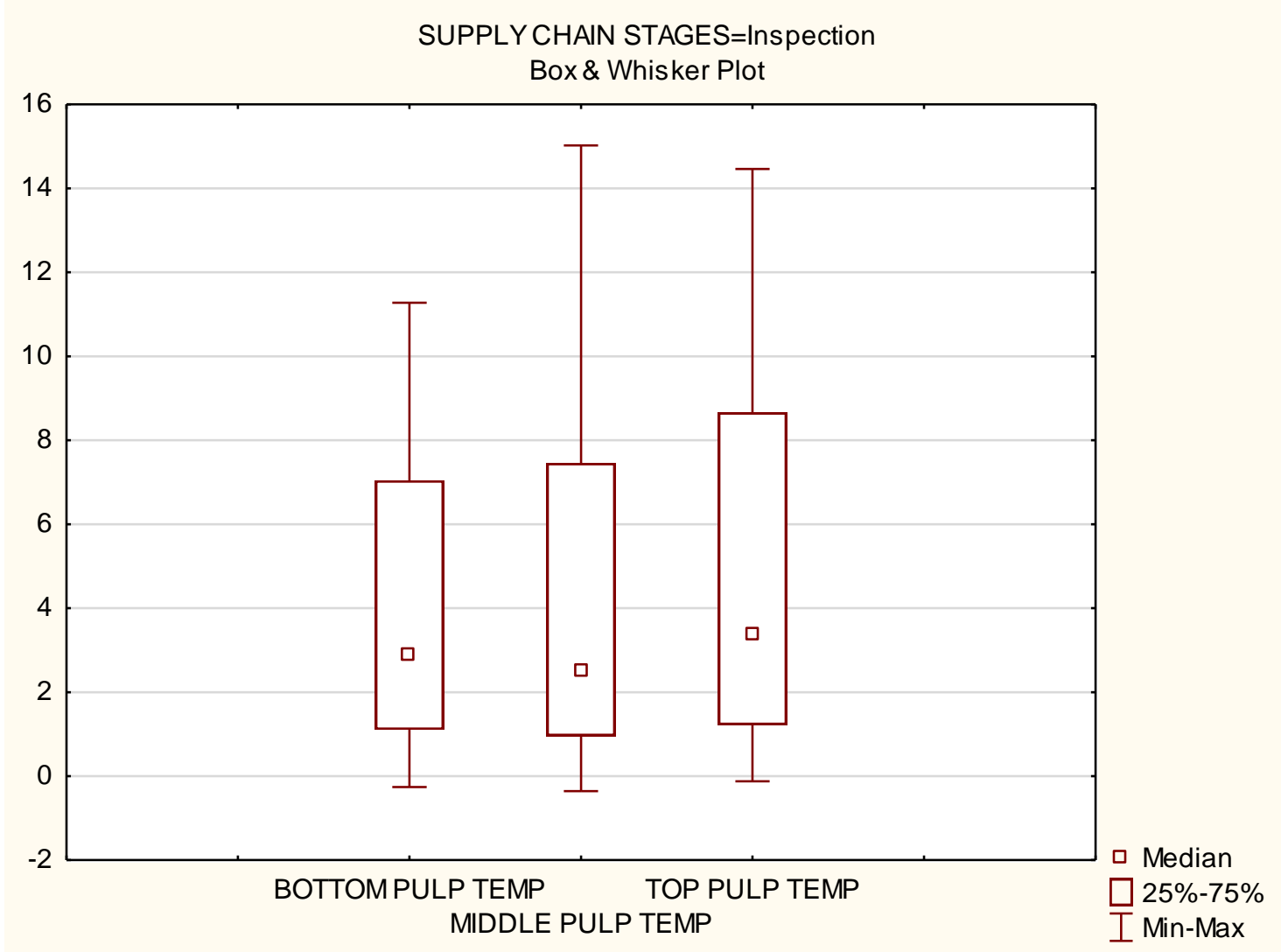

Figure 32: The difference in temperature at different positions at the inspection stage

Figure 32 illustrates the Friedman test's findings of the different temperature at different positions during the inspection phase (ANOVA Chi Sqr. $(\mathrm{N}=81, \mathrm{df}=2)=101.9506 \mathrm{p}<0.001)$. The figure shows that the top positioned cartons shows a higher temperature than the bottom and middle positioned cartons. The median temperature of the top positioned cartons is significantly higher than the median temperature of the cartons positioned in the middle and at the bottom. Figure 33 illustrates the differences in temperature at different positions at the cold sterilisation location stage. 


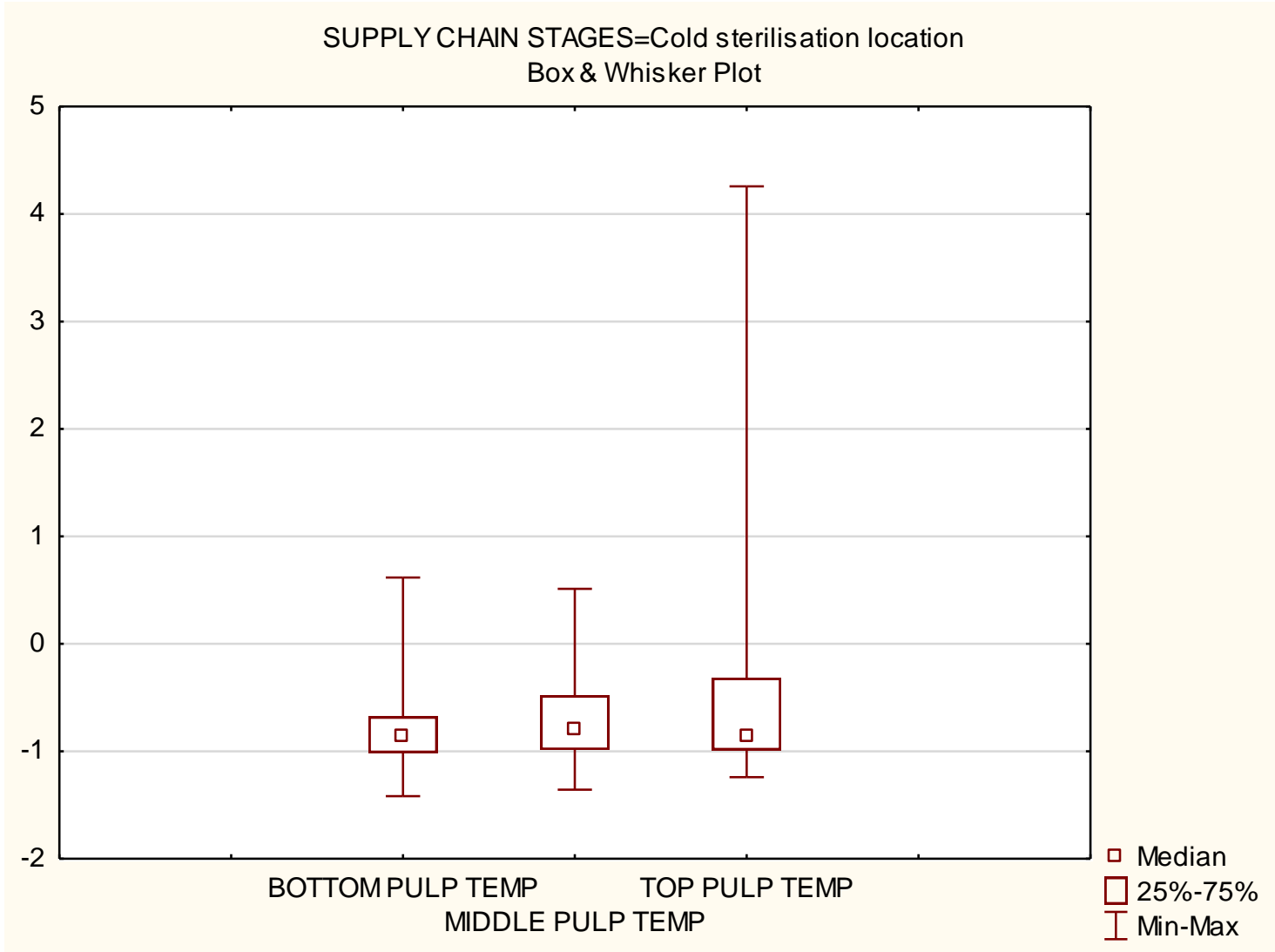

Figure 33: The difference in temperature at different positions at the cold sterilisation stage

Figure 33 illustrates the different temperature at different positions during the cold sterilisation location stage according to the Friedman's test (ANOVA Chi Sqr. $(\mathrm{N}=268$, df $=2)=192.1866$ $\mathrm{p}<0.001)$. The figure shows that the middle positioned cartons shows a higher temperature than the bottom and top positioned cartons. The median temperature of the bottom positioned cartons is significantly higher than the median temperature of the cartons positioned at the top but it does not differ significantly with the cartons positioned in the middle. 


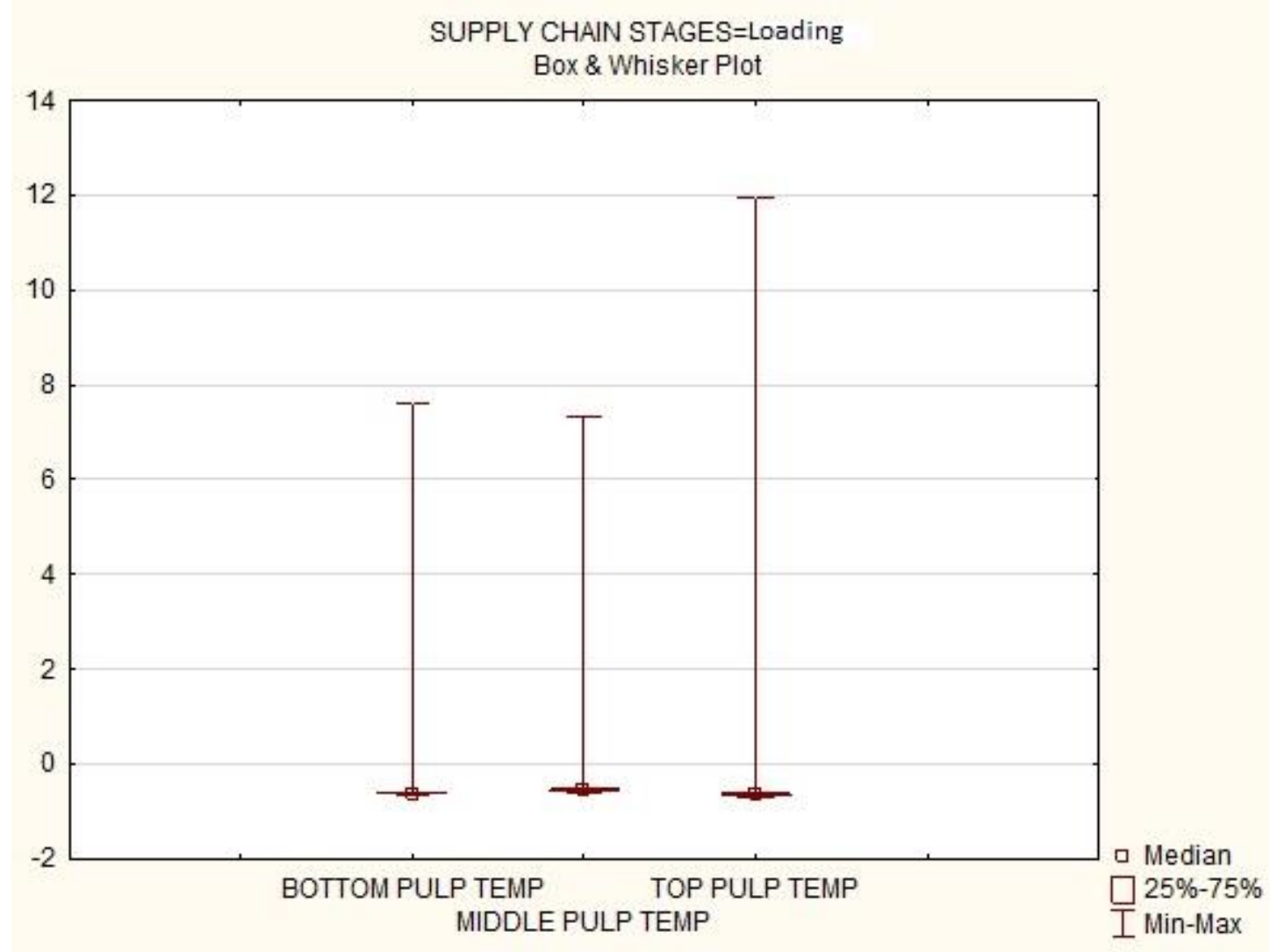

Figure 34: The difference in temperature at different positions at the loading stage

Figure 34 illustrates the findings of the Friedman's test that there are significant differences in temperature at different position during the loading stage (ANOVA Chi Sqr. $(\mathrm{N}=173, \mathrm{df}=2)=$ $315.3410 \mathrm{p}<0.001)$. The figure shows that during the loading stage top positioned carton shows a higher temperature than the middle and bottom positioned cartons. The bottom and middle positioned cartons differ slightly significantly compared to the top positioned cartons. 
Box \& Whisker Plot

Include cases: 577:1378

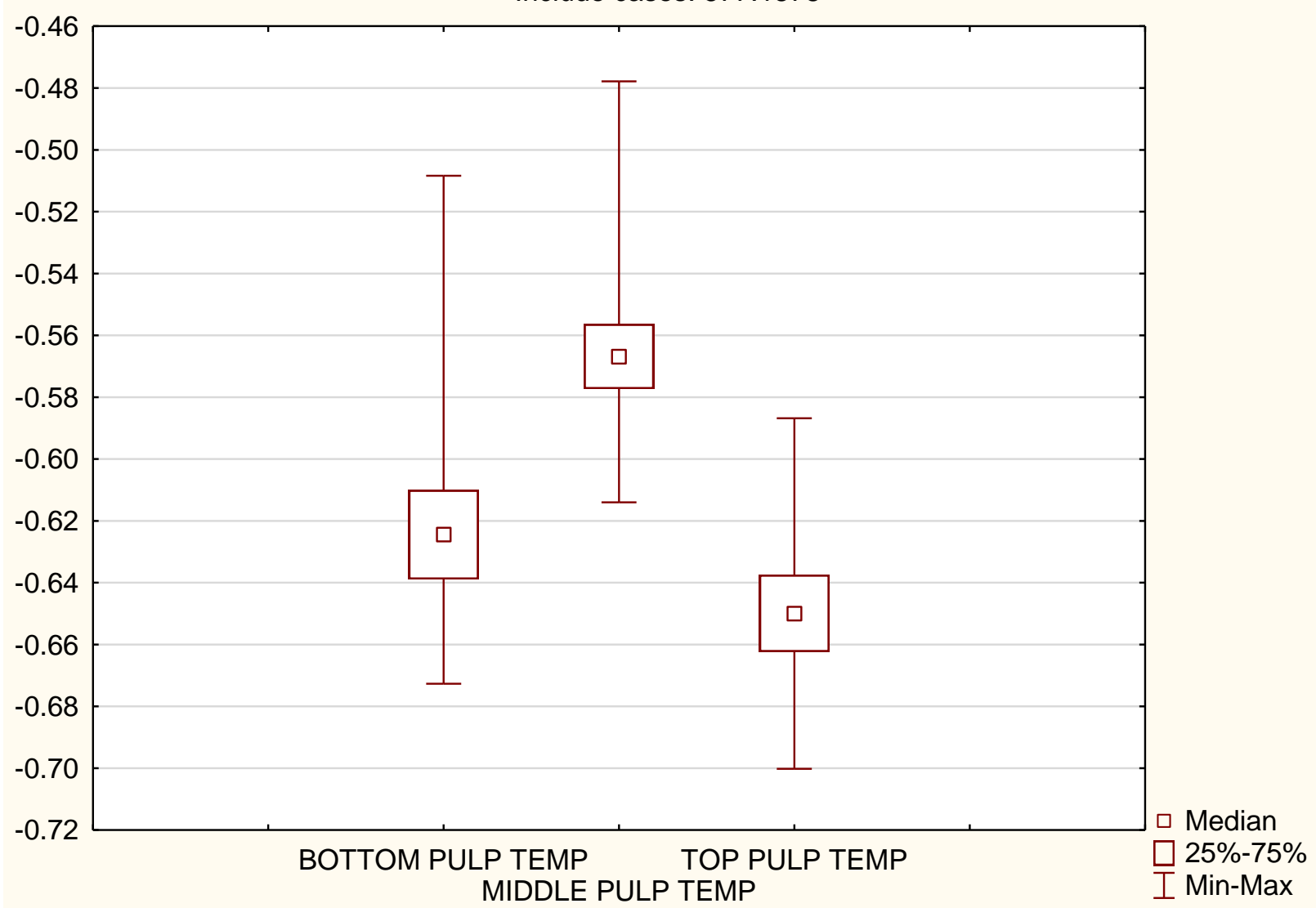

Figure 35: The difference in temperature at different positions at the shipment stage

Figure 35 illustrates the findings of the Friedman's test that there are significant differences in temperature at different positions for the shipping stage (ANOVA Chi Sqr. $(\mathrm{N}=960$, df $=2)=$ $1198.608 \mathrm{p}<0.001)$. The figure shows that the temperature of the middle positioned carton differs significantly from the bottom and the top position.

A summary of the descriptive statistics conducted while testing the hypothesis are shown in Table 18. The descriptive numerical statistics further prove that there are differences in temperature at different positions at each stage of the export cold chain. The means of the different positions show a difference in temperature. 
Table 18: Descriptive statistics for the different stages and position of iButtons $®$ in the export cold chain

\begin{tabular}{|c|c|c|c|c|c|c|c|c|}
\hline \multirow[b]{2}{*}{ Variable } & \multicolumn{8}{|c|}{$\begin{array}{l}\text { All Groups } \\
\text { Descriptive Statistics (SANTA LUCIA VESSEL in FIRST PART OF THE SC data rearranged.stw) }\end{array}$} \\
\hline & Valid N & Mean & Median & Minimum & Maximum & $\begin{array}{l}\text { Lower } \\
\text { Quartile }\end{array}$ & $\begin{array}{c}\text { Upper } \\
\text { Quartile }\end{array}$ & Std.Dev. \\
\hline BOTTOM PULP TEMP & 504 & 19.69580 & 19.94945 & 10.05436 & 24.41273 & 18.45345 & 23.09123 & 3.641175 \\
\hline MIDDLE PULP TEMP & 504 & 20.12415 & 19.99517 & 14.33967 & 24.62325 & 18.39413 & 23.03933 & 2.934709 \\
\hline TOP PULP TEMP & 504 & 19.73711 & 19.85940 & 10.41580 & 24.43700 & 18.22610 & 23.09240 & 3.504047 \\
\hline BOTTOM AMBIENT TEMP & 456 & 20.34876 & 19.97033 & 13.59400 & 24.50433 & 18.81267 & 23.23367 & 2.766509 \\
\hline MIDDLE AMBIENT TEMP & 456 & 20.33799 & 20.08467 & 13.34400 & 24.44133 & 18.89583 & 23.10767 & 2.778618 \\
\hline TOP AMBIENT TEMP & 456 & 20.43917 & 20.01390 & 13.90000 & 25.06800 & 18.80600 & 23.31740 & 2.808761 \\
\hline
\end{tabular}

\begin{tabular}{|l|r|r|r|r|r|r|r|r|}
\hline & \multicolumn{3}{|l|}{$\begin{array}{l}\text { All Groups } \\
\text { Descriptive Statistics (SANTA LUCIA in LAST PART OF THE SC DATA REARRANGED.stw) }\end{array}$} \\
\cline { 2 - 9 } & Valid N & \multicolumn{1}{|c|}{ Mean } & Median & Minimum & Maximum & $\begin{array}{c}\text { Lower } \\
\text { Quartile }\end{array}$ & $\begin{array}{c}\text { Upper } \\
\text { Quartile }\end{array}$ & $\begin{array}{c}\text { Std.Dev. } \\
\text { Variable }\end{array}$ \\
\hline BOTTOM PULP TEMP & 1536 & -0.074951 & -0.629231 & -1.41731 & 11.27592 & -0.653462 & -0.595538 & 1.852402 \\
\hline MIDDLE PULP TEMP & 1536 & -0.044546 & -0.566833 & -1.35758 & 15.02342 & -0.598333 & -0.540583 & 1.988320 \\
\hline TOP PULP TEMP & 1536 & 0.142827 & -0.650000 & -1.24000 & 14.46360 & -0.687400 & -0.612400 & 2.597643 \\
\hline BOTTOM AMBIENT TEMP & 1536 & -0.236072 & -0.778000 & -1.17600 & 11.42100 & -0.841000 & -0.736000 & 1.818118 \\
\hline MIDDLE AMBIENT TEMP & 1536 & 0.038055 & -0.416333 & -1.79867 & 15.36867 & -0.479000 & -0.374333 & 1.838048 \\
\hline TOP AMBIENT TEMP & 1536 & 0.224127 & -0.546400 & -1.32720 & 14.59020 & -0.609400 & -0.508800 & 2.599413 \\
\hline
\end{tabular}

The inferential statistics depicted in Figures 30 to 35 and the numerical descriptive statistics above in Table 18, prove that there is enough evidence to state that the null hypothesis of no differences among the position median temperatures is rejected. Therefore, there are significant differences in temperature among the different positions at each stage of the export cold chain conducted for the Santa Lucia Vessel.

\subsubsection{Regal Bay: Vessel four}

Another temperature trial was conducted in June. This temperature trial was conducted on navel oranges shipped on a reefer vessel called the Regal Bay. The aim of the trial was also to compare the pulp and ambient temperature, identify the occurrence of temperature spikes in the first phases and temperature breaks in the second phases of the export cold chain, in response to the research objectives. Table 19 depicts dates and days on which processes occurred until the port of destination. These dates are used as a point of reference to enable more accurate analysis.

Table 19: Temperature trial process for Regal Bay Vessel

\begin{tabular}{|l|c|c|}
\hline Export chain process & Date of process & Days \\
\hline Harvesting & 14 June & 1 \\
\hline Drenching & 15 June & 1 \\
\hline
\end{tabular}




\begin{tabular}{|l|c|c|}
\hline Degreening & 17 June & 3 \\
\hline Packing & 20 June & 3 \\
\hline Transportation & 22 June & 1 \\
\hline Cold store & 23 June & 2 \\
\hline Cold sterilisation location & 25 June & 3 \\
\hline Loading & 29 June & 4 \\
\hline Shipment & 02 July & 22 \\
\hline
\end{tabular}

Figure 36 depicts very few pulp and ambient temperature anomalies. A spike in temperature worth noting occurred when the fruit was re-probed by the researcher due to handling of iButtons® on 23 June, which resulted in an increase in temperature.

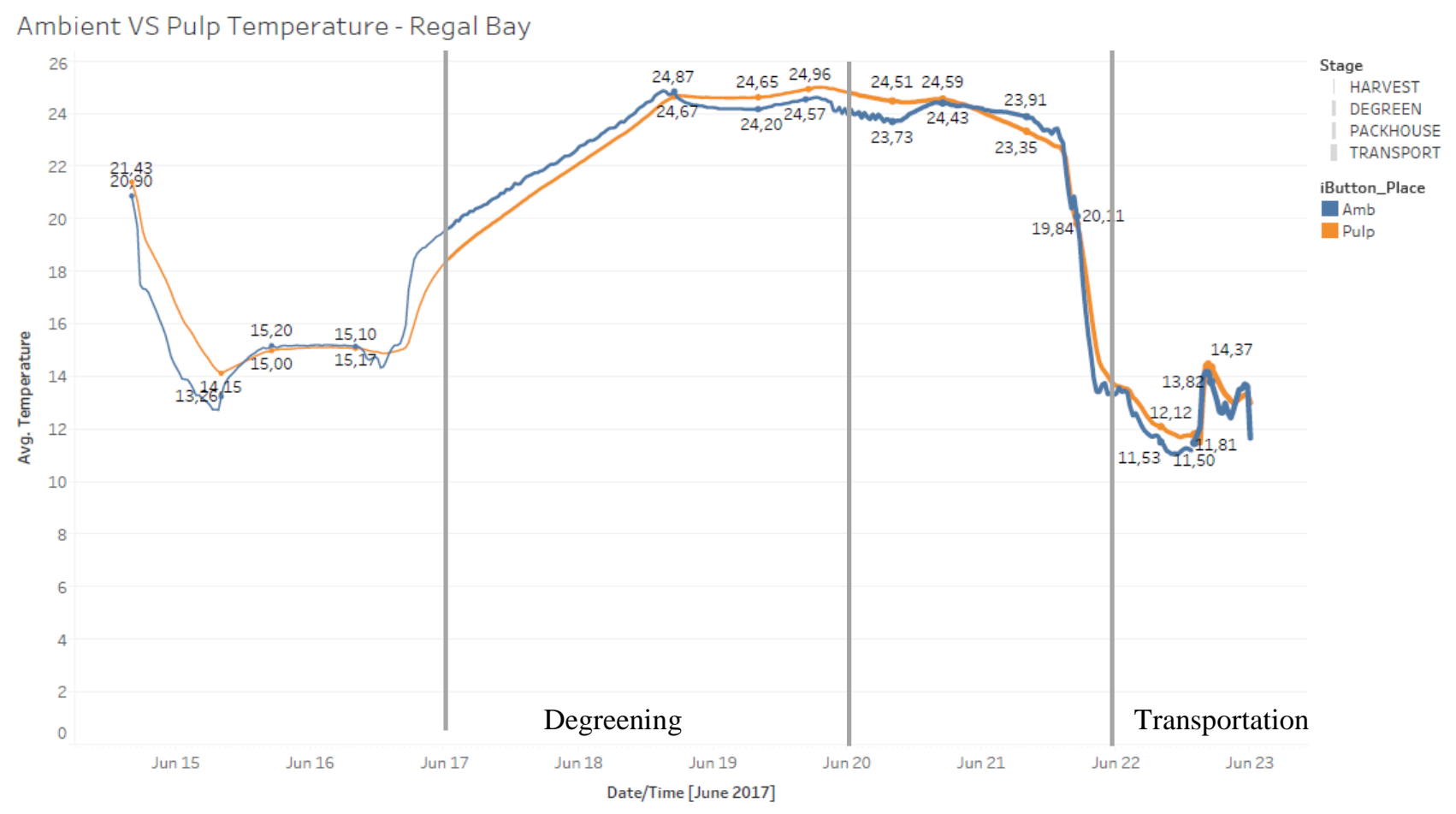

The trend of average of Temperature for Date/Time. Color shows details about iButton_Place. Size shows details about Stage. The view is filtered on Exclusions (Date/Time,iButton_Place,Stage), which keeps 801 members.

Figure 36: Pulp (56 iButtons $\left.{ }^{\circledR}\right)$ and ambient (14 iButtons $\left.{ }^{\circledR}\right)$ temperature for Regal Bay Vessel

For this temperature trial, the generic export cold chain processes were not followed precisely. For example, fruit was transported directly to the pack house instead of being left to dry after drenching. 
This explains the decrease in pulp temperature soon after harvest. The ambient temperature depicts a rapid decrease in temperature to $13.26^{\circ} \mathrm{C}$ and the pulp temperature decreases to $14.15^{\circ} \mathrm{C}$. The decrease in temperature may be caused by a decrease in outside temperature as fruit were being moved to the pack house. Figure 32 also depicts temperature rising gradually in the degreening room phase. There are no temperature spikes identified as the temperature is kept within the recommended range of 20$25^{\circ} \mathrm{C}$. The temperature drops during the pack house stages due to the removal of fruit from a set temperature of $20-25^{\circ} \mathrm{C}$ to a holding room set at $\pm 16^{\circ} \mathrm{C}$. The ambient and pulp temperature of the fruit shows a decrease in temperature during transportation to the cold store until arrival.

As conducted with the Santa Lucia Vessel, for the identification of the implications of temperature breaks in the second phase of the export cold chain, the researcher aimed to identify whether breaks occurred and whether they occurred when navel oranges were placed in cold storage or once the cold sterilisation protocols had begun. Figure 37 shows the second phase of the export cold chain on the Regal Bay vessel.

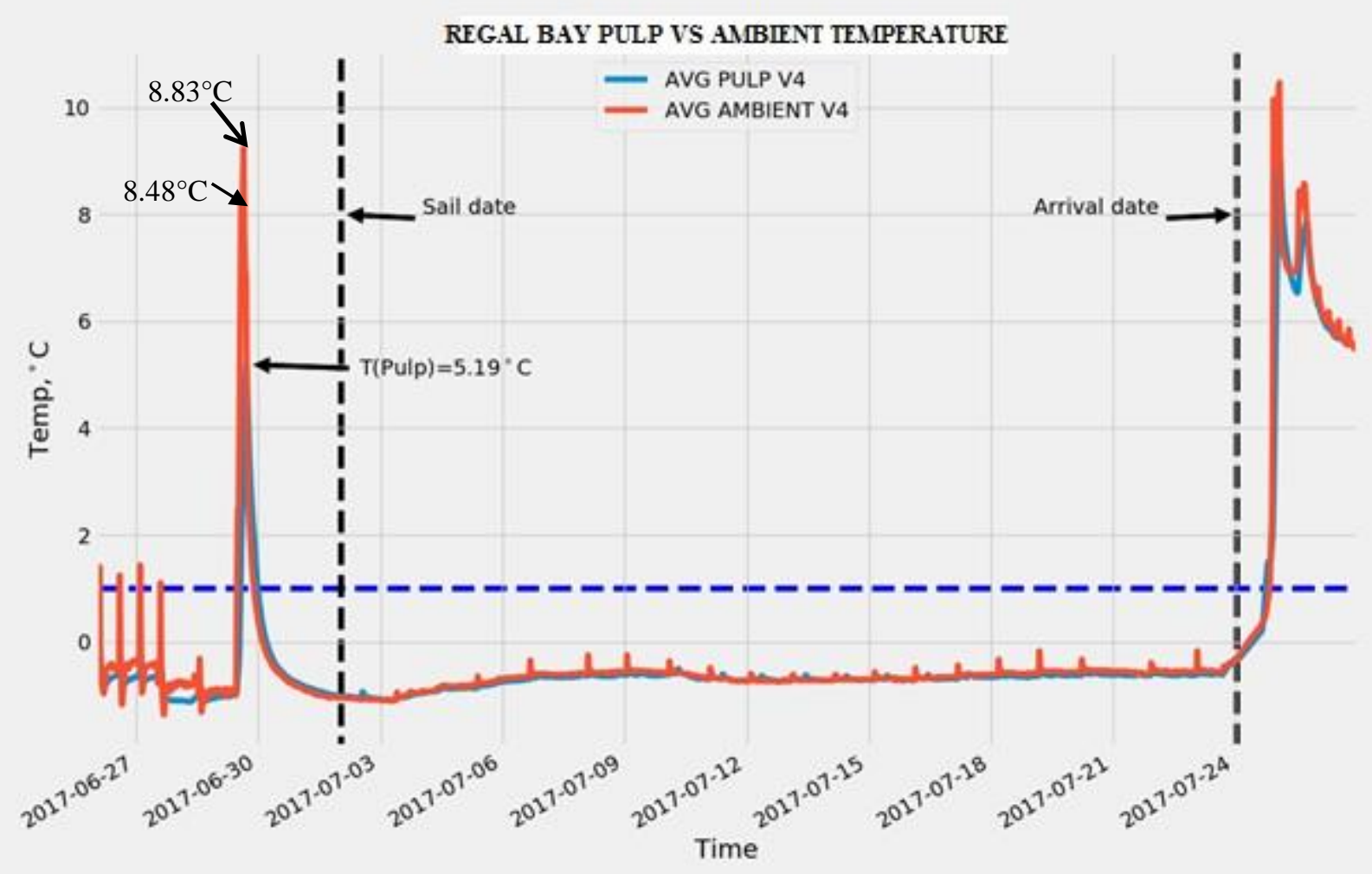

Figure 37: Pulp (56 iButtons ${ }^{\circledR}$ ) and ambient temperature (14 iButtons ${ }^{\circledR}$ ) of Regal Bay Vessel 
Figure 37 shows the pulp and ambient temperature for cartons staged on pallets as they move through the cold store until port of destination. The ambient temperature recorded in the pallets carrying the navel oranges prior to the sail date is at an alarming $8.48^{\circ} \mathrm{C}$. This is despite the fact that temperatures at the cold room are brought down to a set point of $4{ }^{\circ} \mathrm{C}$ prior to inspection and further dropped down to $-0.6^{\circ} \mathrm{C}$ in the cold sterilisation location the day before reefer vessel loading. Figure 37 depicts a temperature break before cold sterilisation protocols in the reefer vessel commences. The break goes up to $5.19^{\circ} \mathrm{C}$ for pulp and $8.83^{\circ} \mathrm{C}$ for ambient temperature. The temperature break in pulp lasts for approximately 9 hours before temperatures drop to below $0^{\circ} \mathrm{C}$. On the reefer sail date (02 July) temperatures are within cold sterilisation protocol, which varies between $-0.55^{\circ} \mathrm{C}$ to $0.0^{\circ} \mathrm{C}$.

Similar to Santa Lucia vessel, spatial variation analysis in the cold chain was conducted. This analysis was conducted for the last stages of the export cold chain (from the cold store to the port of destination). As depicted by Figure 38, for Regal Bay vessel, temperature breaks in the second phase of the export cold chain occur mostly at the top position, during the loading phase. The iButtons ${ }^{\circledR}$ placed on top cartons are shown by the green line (pulp temperature). The pulp temperature of top positioned cartons as depicted by the black arrow on 30 June, during the loading phase, was $6.1^{\circ} \mathrm{C}$. This means cartons placed on top of pallets during loading are likely to experience more temperature anomalies than those placed in the middle or bottom of the pallet. 
All Groups

Plot of selected variables (series)

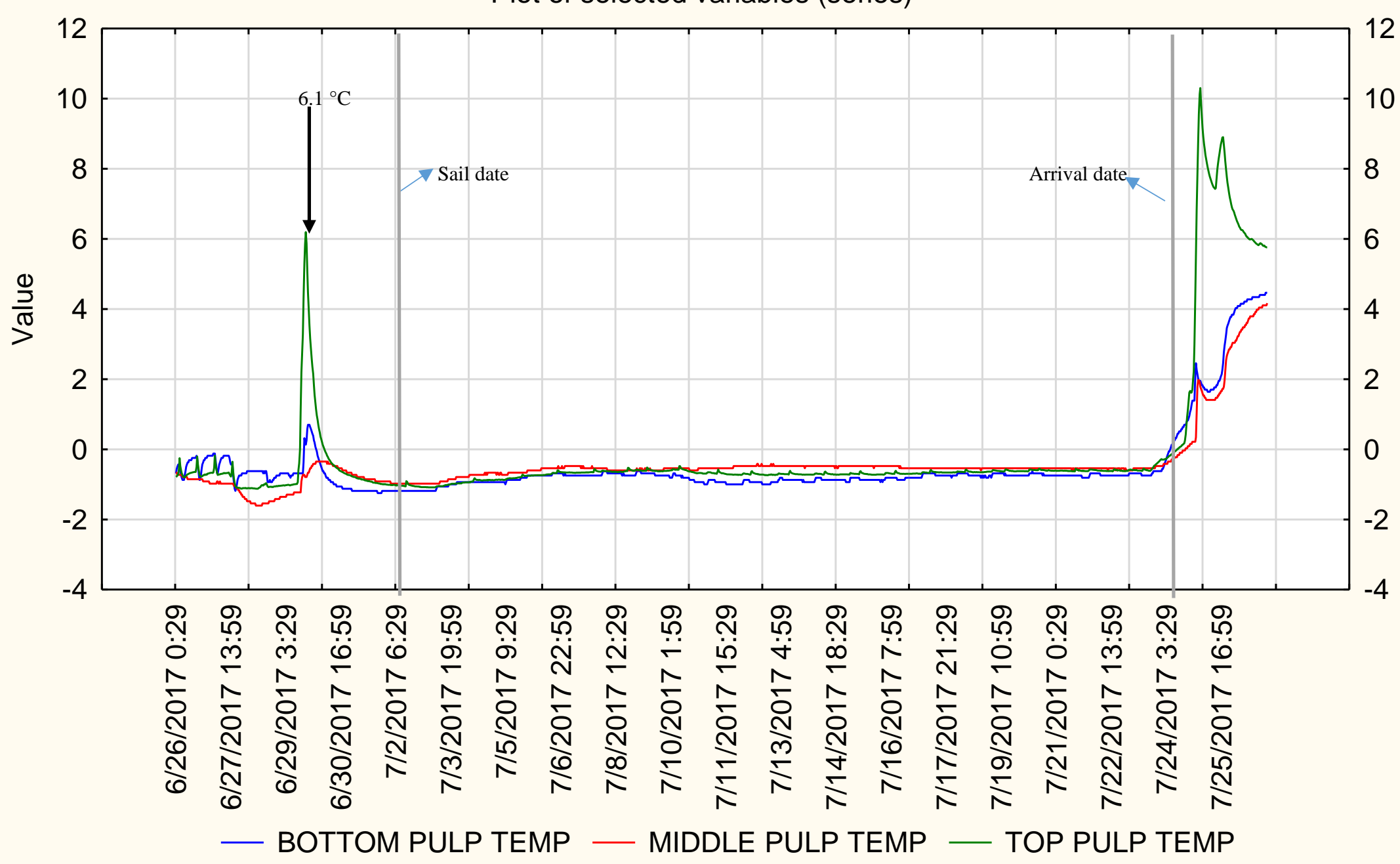

Figure 38: Average pulp (56 iButtons ${ }^{\circledR}$ ) temperature of iButtons position during shipment 
Similar to the Santa Lucia vessel, it is interesting to note that once the vessel sails the temperature in the top positioned cartons is surpassed by the middle positioned cartons. During sailing, the middle positioned cartons are more likely to experience temperature breaks. This may be due to the fact that the cooling system utilised in conventional vessels delivers cold air from the bottom and the top, hence middle positioned cartons possibly trap the warm air due to insufficient airflow in the middle. This is depicted in Figure 39 which illustrates the different temperatures of the different position of cartons.

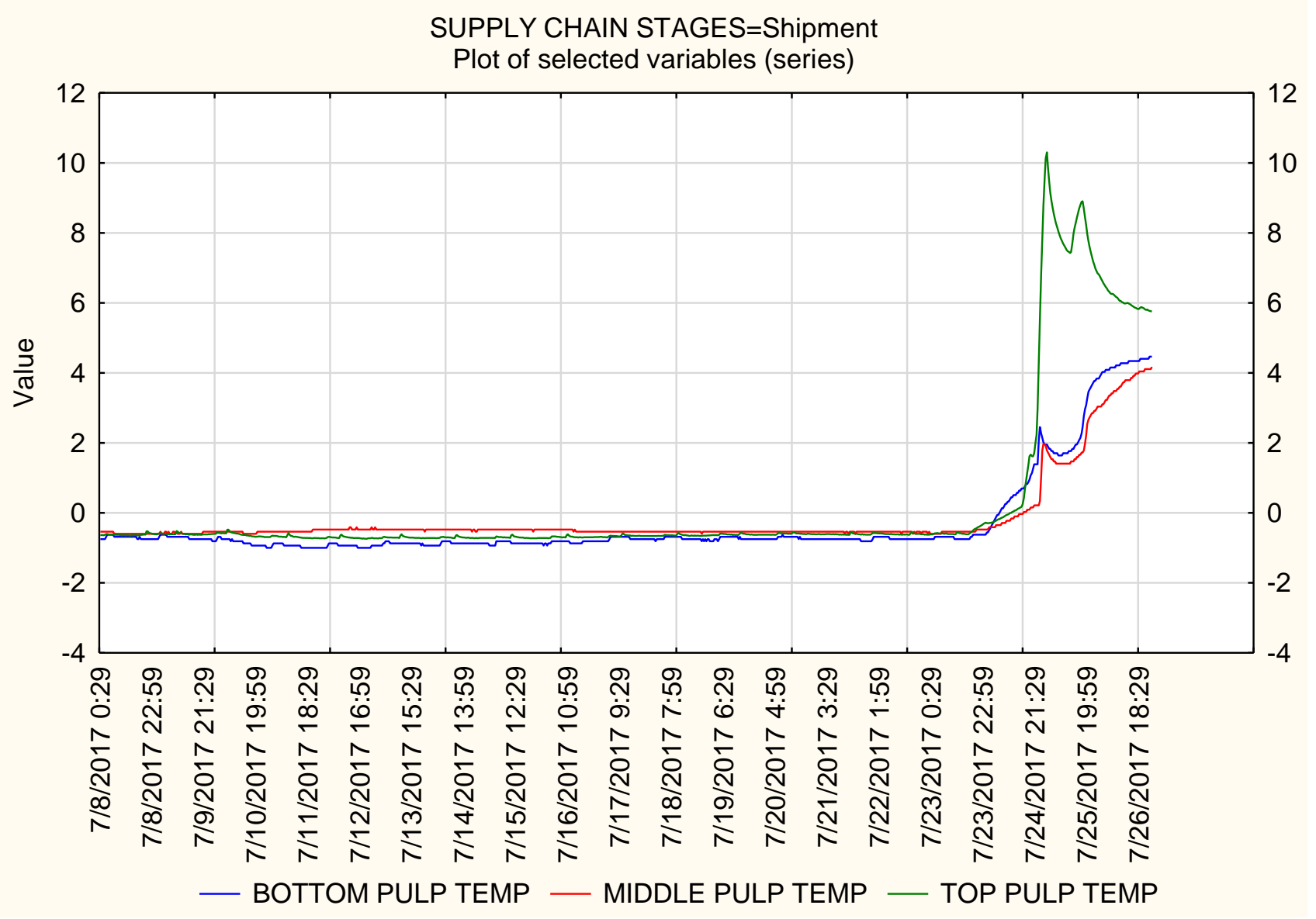

Figure 39: Cartons placed in the middle position during the sea leg for the Regal Bay vessel

Figure 39 illustrates that cartons placed in the middle position during the sea leg for the Regal Bay vessel have higher temperatures than the bottom and the top positioned cartons. The temperatures of the middle positioned cartons do not surpass the stipulated cold sterilisation treatment protocols, but the temperatures are appear to higher than the top and bottom positioned cartons. While, no fruit consignments were reported to be rejected upon arrival of the navel oranges at the port of destination, navel oranges that are packed into cartons placed on top and middle of the pallet are most likely to experience a steri-breach. Navel oranges packed at the top positions are more likely to experience temperature breaks during loading and those positioned in the middle are more likely to experience 
temperature breaks during the sea leg. The data was further analysed to identify how many times pulp temperature reaches $0.0^{\circ} \mathrm{C}$ for both vessels, which is a breach in cold sterilisation protocols.

Figure 40 indicates the times that pulp temperature increased to $0.0^{\circ} \mathrm{C}$ during the sea leg. Fifty-four percent $(54 \%)$ of the data showed that temperature ranged between -0.61 to $-0.8^{\circ} \mathrm{C}$ for the Santa Lucia vessel and $70 \%$ for Regal Bay vessel stayed within the same temperature range. Twelve percent of fruit maintained a pulp temperature of $-1{ }^{\circ} \mathrm{C}$ during both shipments. Only $0.001 \%$ (approximately 100 pallets) for both vessels reached a temperature of $0.0^{\circ} \mathrm{C}$. During the shipment, the temperature mostly ranged below the prescribed $-0.6^{\circ} \mathrm{C}$ for cold sterilisation protocols.

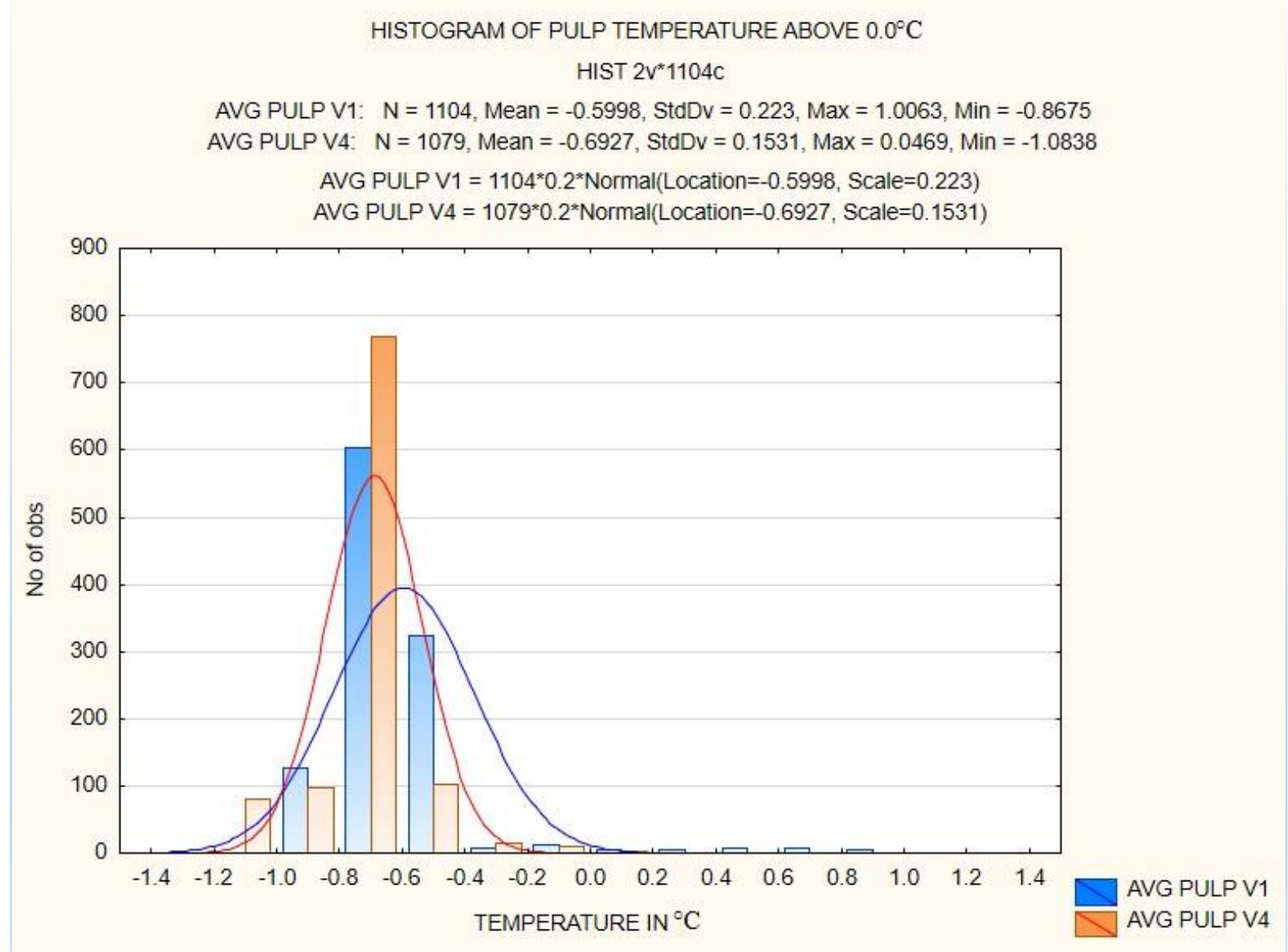

Figure 40: Histogram of pulp temperature above $0.0^{\circ} \mathrm{C}$

For the Regal Bay vessel, it is clear that temperature spikes occur during the transportation phase to the cold store. Temperature breaks are more likely to occur during loading of the reefer vessel as was also depicted for the Santa Lucia vessel. In addition, the top cartons are prone to more temperature variations than those placed on the bottom and middle position. 
Descriptive numerical statistics were conducted on the pulp and ambient temperature for the different stages of Regal Bay vessel. The measures of central tendency are discussed more in detail for each individual stage.

\subsubsection{Harvesting}

Table 20 illustrates the statistical summary of data collected at the harvesting stage. From the descriptive statistics, it is possible to conclude that the pulp and ambient temperature is $15.93^{\circ} \mathrm{C}$ and $15.62^{\circ} \mathrm{C}$ respectively. The median for pulp temperature is $15.11^{\circ} \mathrm{C}$ and for ambient temperature it is $15.19^{\circ} \mathrm{C}$. The descriptive numerical statistics show that the mean pulp temperature during harvesting is higher than the mean ambient temperature. This means that during the harvesting phase, the pulp of navel oranges is likely to record higher temperatures, which may be caused by exposure to evening weather temperatures.

Table 20: Descriptive statistics of the harvesting stage

\begin{tabular}{|c|c|c|c|c|c|c|c|}
\hline Variable & Mean & Median & $\begin{array}{l}\text { Standard } \\
\text { deviation }\end{array}$ & Maximum & Minimum & $\begin{array}{c}\text { Coefficient of } \\
\text { variation }\end{array}$ & $\begin{array}{c}\text { Number of } \\
\text { Observations }\end{array}$ \\
\hline $\begin{array}{l}\text { Pulp } \\
\text { Temperature } \\
\text { (56 iButtons }{ }^{\circledR} \text { ) }\end{array}$ & 15.932 & 15.113 & 1.623 & 22.321 & 15.156 & 2.555 & 120 \\
\hline $\begin{array}{l}\text { Ambient } \\
\text { Temperature } \\
\left(14 \text { iButtons }^{\circledR}\right)\end{array}$ & 15.6187 & 15.192 & 1.831 & 21.896 & 13.685 & 3.322 & 120 \\
\hline
\end{tabular}

\subsubsection{Degreening}

Table 21 illustrates the statistical summary of data collected at the degreening stage. From the descriptive statistics, it is possible to conclude that the pulp and ambient temperature is $22.92^{\circ} \mathrm{C}$ and $24.98^{\circ} \mathrm{C}$ respectively. The median for pulp temperature is $23.77^{\circ} \mathrm{C}$ and for ambient temperature, it is $24.24^{\circ} \mathrm{C}$. The descriptive numerical statistics show that the mean and median pulp and ambient temperature, both are kept within the acceptable temperature ranges required for the degreening of navel oranges.

Table 21: Descriptive statistics of the degreening stage

\begin{tabular}{|l|l|l|l|l|l|c|c|}
\hline Variable & Mean & Median & $\begin{array}{c}\text { Standard } \\
\text { deviation }\end{array}$ & Maximum & Minimum & $\begin{array}{c}\text { Coefficient of } \\
\text { variation }\end{array}$ & $\begin{array}{c}\text { Number of } \\
\text { Observations }\end{array}$ \\
\hline
\end{tabular}




\begin{tabular}{|l|c|c|c|c|c|c|c|}
\hline $\begin{array}{l}\text { Pulp } \\
\text { Temperature }\end{array}$ & 22.922 & 23.769 & 2.0462 & 25.320 & 18.5812 & 4.280 & 160 \\
\hline $\mathbf{5 6}$ iButtons $\left.^{\circledR}\right)$ & & & & & & & \\
\hline $\begin{array}{l}\text { Ambient } \\
\text { Temperature }\end{array}$ & 24.98 & 24.235 & 1.538 & 24.6300 & 19.680 & 2.4422 & 160 \\
$(\mathbf{1 4}$ iButtons & & & & & & & \\
\hline
\end{tabular}

\subsubsection{Pack house}

Table 22 illustrates the statistical summary of data collected at the pack house stage. From the descriptive statistics it is possible to conclude that pulp and ambient temperature is $20.45^{\circ} \mathrm{C}$ and $20.16^{\circ} \mathrm{C}$ respectively. The median for pulp temperature is $23.45^{\circ} \mathrm{C}$ and for ambient temperature it is $23.76^{\circ} \mathrm{C}$. According to the mean and median of both pulp and ambient temperatures, the temperature in the pack house is kept within an acceptable temperature range, which is between $18-25^{\circ} \mathrm{C}$. This proves that the pack house temperature is maintained at an ideal level.

Table 22: Descriptive statistics of the pack house stage

\begin{tabular}{|c|c|c|c|c|c|c|c|}
\hline Variable & Mean & Median & $\begin{array}{l}\text { Standard } \\
\text { deviation }\end{array}$ & Maximum & Minimum & $\begin{array}{c}\text { Coefficient of } \\
\text { variation }\end{array}$ & $\begin{array}{c}\text { Number of } \\
\text { Observations }\end{array}$ \\
\hline $\begin{array}{l}\text { Pulp } \\
\text { Temperature } \\
\left.\text { (56 iButtons }{ }^{\circledR}\right)\end{array}$ & 20.4458 & 23.447 & 5.088 & 24.817 & 11.703 & 5.0883 & 123 \\
\hline $\begin{array}{l}\text { Ambient } \\
\text { Temperature } \\
\left.\text { (14 iButtons }{ }^{\circledR}\right)\end{array}$ & 20.16292 & 23.759 & 5.322 & 24.446 & 11.06025 & 5.3225 & 123 \\
\hline
\end{tabular}

\subsubsection{Transportation}

Table 23 illustrates the statistical summary of data collected at the transport stage. From the descriptive statistics it is possible to conclude that pulp and ambient temperature is $13.26^{\circ} \mathrm{C}$ and $13.34^{\circ} \mathrm{C}$ respectively. The median for pulp temperature is $13.14^{\circ} \mathrm{C}$ and for ambient temperature it is $13.26^{\circ} \mathrm{C}$. The mean pulp temperature during transportation is marginally lower than the ambient temperature. The median pulp temperature is also lower than the median ambient temperature. The lower pulp mean and median temperatures may be due to the use of tautliner trucks used for 
transporting navel oranges as they serve the purpose of minimising direct sunlight and air flow on the fruit.

Table 23: Descriptive statistics of the transportation stage

\begin{tabular}{|c|c|c|c|c|c|c|c|}
\hline Variable & Mean & Median & $\begin{array}{l}\text { Standard } \\
\text { deviation }\end{array}$ & Maximum & Minimum & $\begin{array}{c}\text { Coefficient of } \\
\text { variation }\end{array}$ & $\begin{array}{c}\text { Number of } \\
\text { Observations }\end{array}$ \\
\hline $\begin{array}{l}\text { Pulp } \\
\text { Temperature } \\
\text { (56 iButtons }{ }^{\circledR} \text { ) }\end{array}$ & 13.263 & 13.139 & 0.803 & 14.632 & 11.53 & 0.6558 & 30 \\
\hline $\begin{array}{l}\text { Ambient } \\
\text { Temperature } \\
\text { (14 iButtons } ®)\end{array}$ & 13.336 & 13.263 & 0.819 & 14.322 & 11.49 & 0.669 & 30 \\
\hline
\end{tabular}

\subsubsection{Inspection}

Table 24 illustrates the statistical summary of data collected at the inspection stage. From the descriptive statistics, it is possible to conclude that pulp and ambient temperature is $11.26^{\circ} \mathrm{C}$ and $10.58^{\circ} \mathrm{C}$ respectively. The median for pulp temperature is $11.96^{\circ} \mathrm{C}$ and the ambient temperature is $10.53^{\circ} \mathrm{C}$. There is a decrease in the mean pulp and ambient temperature during the inspection phase. However, the pulp temperature is slightly higher than the ambient temperature, which is depicted by both the mean and the median. The ambient temperature may be lower due to set temperatures in the inspection room.

Table 24: Descriptive statistics of the inspection stage

\begin{tabular}{|l|c|c|c|c|c|c|c|}
\hline \multicolumn{1}{|c|}{ Variable } & Mean & Median & $\begin{array}{c}\text { Standard } \\
\text { deviation }\end{array}$ & Maximum & Minimum & $\begin{array}{c}\text { Coefficient of } \\
\text { variation }\end{array}$ & $\begin{array}{c}\text { Number of } \\
\text { Observations }\end{array}$ \\
\hline $\begin{array}{l}\text { Pulp } \\
\text { Temperature }\end{array}$ & 11.26 & 11.96 & 2.507 & 13.635 & 1.766 & 6.289 & 180 \\
\hline $\mathbf{5 6}$ iButtons@) & & & & & & & \\
\hline $\begin{array}{l}\text { Ambient } \\
\text { Temperature }\end{array}$ & 10.579 & 10.525 & 2.632 & 13.74 & 1.874 & 6.323 & 180 \\
\hline $\mathbf{( 1 4}$ iButtons@) & & & & & & \\
\hline
\end{tabular}

\subsubsection{6. $\quad$ Cold Storage}

Table 25 illustrates the statistical summary of data collected at the transport stage. From the descriptive statistics, it is possible to conclude that pulp and ambient temperature is $-0.814^{\circ} \mathrm{C}$ and $0.920^{\circ} \mathrm{C}$ respectively. The median for pulp temperature is $0.98^{\circ} \mathrm{C}$ and for ambient temperature it is 
$0.11^{\circ} \mathrm{C}$. Both the mean pulp and ambient temperature depict that the temperature at the cold store is kept below $-0.6^{\circ} \mathrm{C}$, which is the stipulated cold sterilisation treatment protocol temperature.

Table 25: Descriptive statistics of the cold storage stage

\begin{tabular}{|c|c|c|c|c|c|c|c|}
\hline Variable & Mean & Median & $\begin{array}{l}\text { Standard } \\
\text { deviation }\end{array}$ & Maximum & Minimum & $\begin{array}{c}\text { Coefficient of } \\
\text { variation }\end{array}$ & $\begin{array}{c}\text { Number of } \\
\text { Observations }\end{array}$ \\
\hline $\begin{array}{l}\text { Pulp } \\
\text { Temperature } \\
\left.\text { (56 iButtons }{ }^{\circledR}\right)\end{array}$ & -0.814 & 0.978 & 0.909 & 4.358 & -0.433 & 0.8277 & 200 \\
\hline $\begin{array}{l}\text { Ambient } \\
\text { Temperature } \\
\left.\text { (14 iButtons }{ }^{\circledR}\right)\end{array}$ & -0.920 & 0.114 & 0.918 & 4.562 & -0.548 & 0.831 & 200 \\
\hline
\end{tabular}

\subsubsection{7. $\quad$ Loading}

Table 26 illustrates the statistical summary of data collected at the transport stage. From the descriptive statistics, it is possible to conclude that pulp and ambient temperature is $0.91{ }^{\circ} \mathrm{C}$ and $0.98^{\circ} \mathrm{C}$ respectively. The median for pulp temperature is $0.90^{\circ} \mathrm{C}$ and for ambient temperature it is $0.94^{\circ} \mathrm{C}$. The mean and median pulp temperature shows that during the loading stage, there is a rise in temperature. Therefore, the statistics show that a temperature break is likely to occur as temperature rises from the set temperature prior to loading.

Table 26: Descriptive statistics of the loading stage

\begin{tabular}{|c|c|c|c|c|c|c|c|}
\hline Variable & Mean & Median & $\begin{array}{l}\text { Standard } \\
\text { deviation }\end{array}$ & Maximum & Minimum & $\begin{array}{c}\text { Coefficient of } \\
\text { variation }\end{array}$ & $\begin{array}{c}\text { Number of } \\
\text { Observations }\end{array}$ \\
\hline $\begin{array}{l}\text { Pulp } \\
\text { Temperature } \\
\text { (56 iButtons }{ }^{\circledR} \text { ) }\end{array}$ & 0.907 & 0.899 & 0.168 & 0.582 & -1.213 & 0.0284 & 180 \\
\hline $\begin{array}{l}\text { Ambient } \\
\text { Temperature } \\
\left.\text { (14 iButtons }{ }^{\circledR}\right)\end{array}$ & 0.977 & 0.936 & 0.2 & 0.782 & -1.58 & 0.058 & 180 \\
\hline
\end{tabular}




\subsubsection{Shipment}

Table 27 illustrates the statistical summary of data collected at the transport stage. From the descriptive statistics, it is possible to conclude that pulp and ambient temperature is $-0.57^{\circ} \mathrm{C}$ and $0.43^{\circ} \mathrm{C}$ respectively. The median for pulp temperature is $-0.47^{\circ} \mathrm{C}$ and for ambient temperature it is $0.32^{\circ} \mathrm{C}$. The descriptive numerical statistics show that the temperature is kept below the stipulated protocol temperature range for the duration of the shipment.

Table 27: Descriptive statistics of the shipment stage

\begin{tabular}{|c|c|c|c|c|c|c|c|}
\hline Variable & Mean & Median & $\begin{array}{l}\text { Standard } \\
\text { deviation }\end{array}$ & Maximum & Minimum & $\begin{array}{c}\text { Coefficient of } \\
\text { variation }\end{array}$ & $\begin{array}{c}\text { Number of } \\
\text { Observations }\end{array}$ \\
\hline $\begin{array}{l}\text { Pulp } \\
\text { Temperature } \\
\left.\text { (56 iButtons }{ }^{\circledR}\right)\end{array}$ & -0.565 & -0.473 & 0.135 & 0.102 & -1.051 & 0.018 & 200 \\
\hline $\begin{array}{l}\text { Ambient } \\
\text { Temperature } \\
\text { (14 iButtons } ®)\end{array}$ & -0.425 & -0.321 & 0.152 & -0.866 & -1.5 & 0.09 & 200 \\
\hline
\end{tabular}

\subsubsection{Inferential analysis of Regal Bay vessel}

Similar to the Santa Lucia vessel, the descriptive statistics conducted for the Regal Bay vessel assisted in validating the hypothesis of whether there are differences in temperature at different positions each stage of the export cold chain vessel. The harvesting, drenching, degreening and pack house phases were excluded in this analysis.

The hypothesis states:

$H_{0}:$ There are no differences in temperature at different positions at each stage of the export cold chain.

$H_{1}$ : There are differences in temperature at different positions at each stage of the export cold chain. As mentioned, the differences in positions refer to the different placement of iButtons ${ }^{\circledR}$ in cartons that were staged on pallets. The non-parametric Friedman test was used. The acceptance or the rejection of the null hypothesis is determined using the $\mathrm{p}$-value. If the calculated $\mathrm{p}$-value is low (P less than the selected significance level, $\alpha=0.05$ ) the null-hypothesis is rejected. The results are presented per export cold chain stage. 
Figure 41 depicts the differences in temperature at different positions at the transportation stages cold chain.

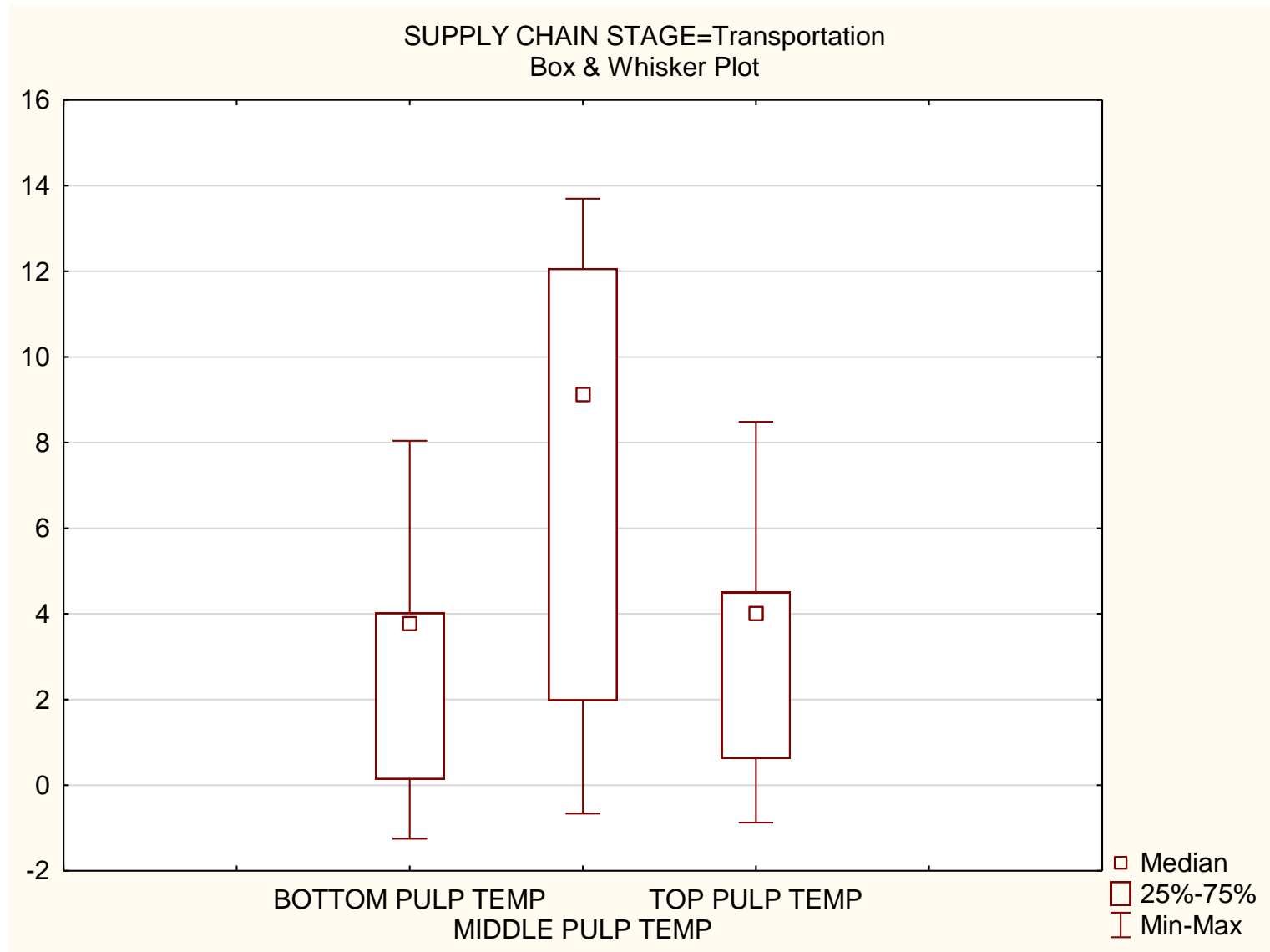

Figure 41: The difference in temperature at different positions at the transportation stage

Figure 41 illustrates the Friedman test's findings that there are significant differences in temperature (ANOVA Chi Sqr. $(\mathrm{N}=69$, df = 2) $=106.1159 \mathrm{p}<0.001)$ during the transportation stage. The graph illustrates that the temperature at the middle position differs from the top and bottom positioned. The temperatures at the bottom and top do not differ significantly. 


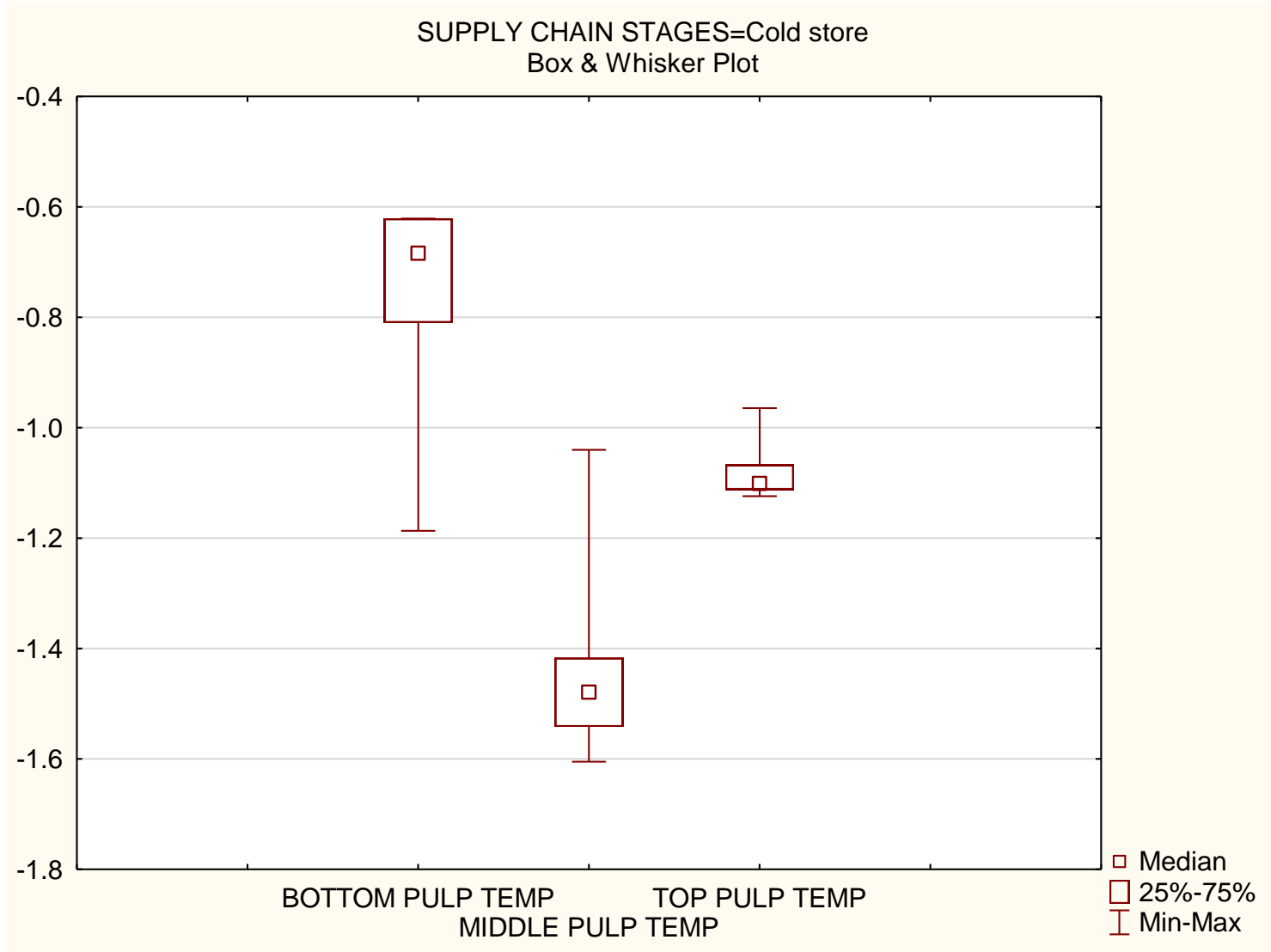

Figure 42: The difference in temperature at different positions at the cold store stage

Figure 42 illustrates the findings of the Friedman's test that there are differences in temperature at different positions during the cold store phase (ANOVA Chi Sqr. $(\mathrm{N}=54$, $\mathrm{df}=2)=10.25926$ $\mathrm{p}<0.001)$. The figure shows that the bottom positioned cartons shows a higher temperature than the middle and the top positioned cartons. The median temperature of the bottom positioned cartons is significantly higher than the median temperatures of the cartons positioned in the top and the middle. 


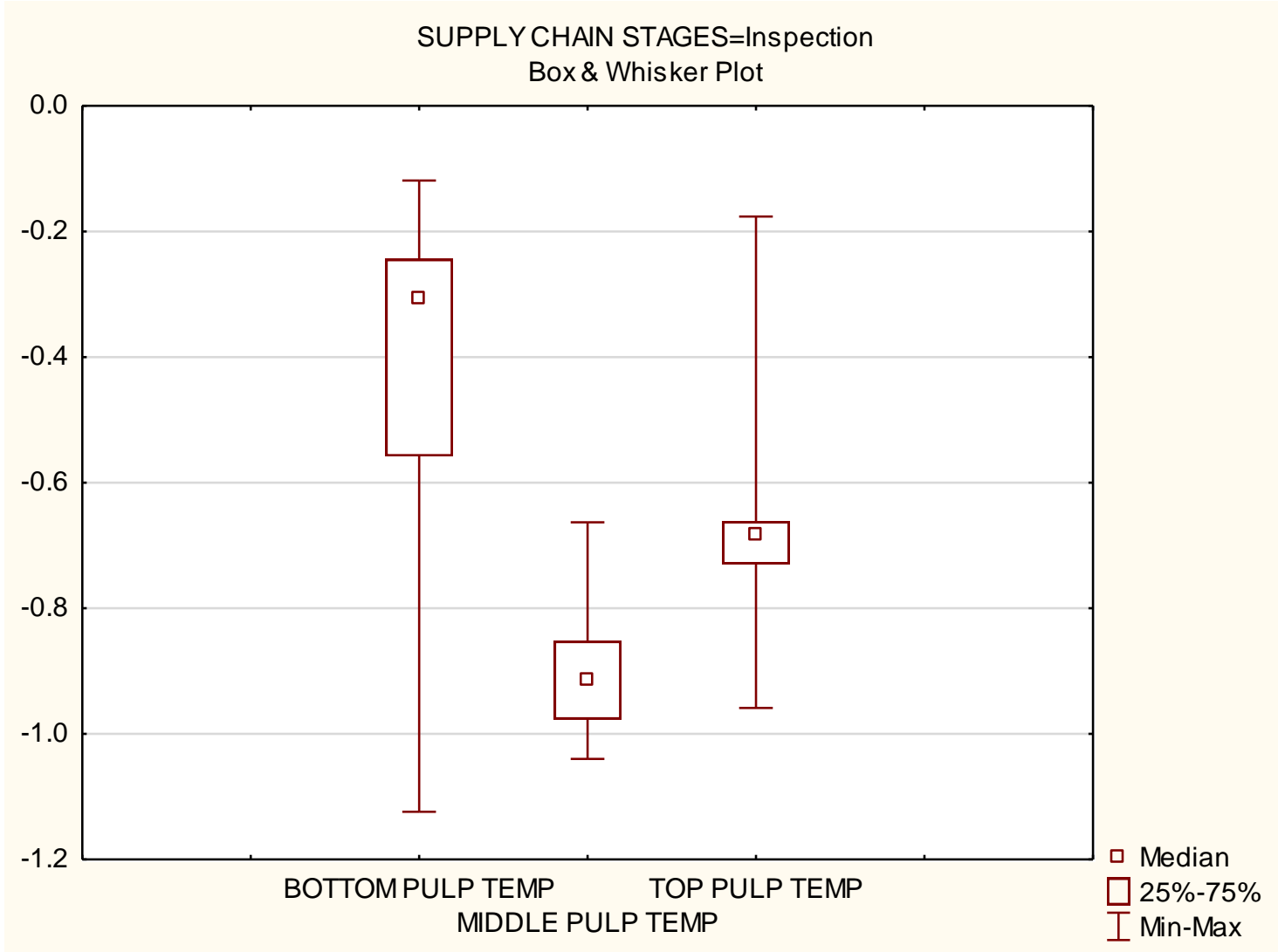

Figure 43: The difference in temperature at different positions at the inspection stage

Figure 43 illustrates the Friedman test's findings of the different temperature at different positions during the inspection phase (ANOVA Chi Sqr. $(\mathrm{N}=81, \mathrm{df}=2)=101.9506 \mathrm{p}<0.001)$. Figure depicts that during the inspection phase the bottom positioned cartons show higher differences in temperature than the top and middle positioned cartons. 


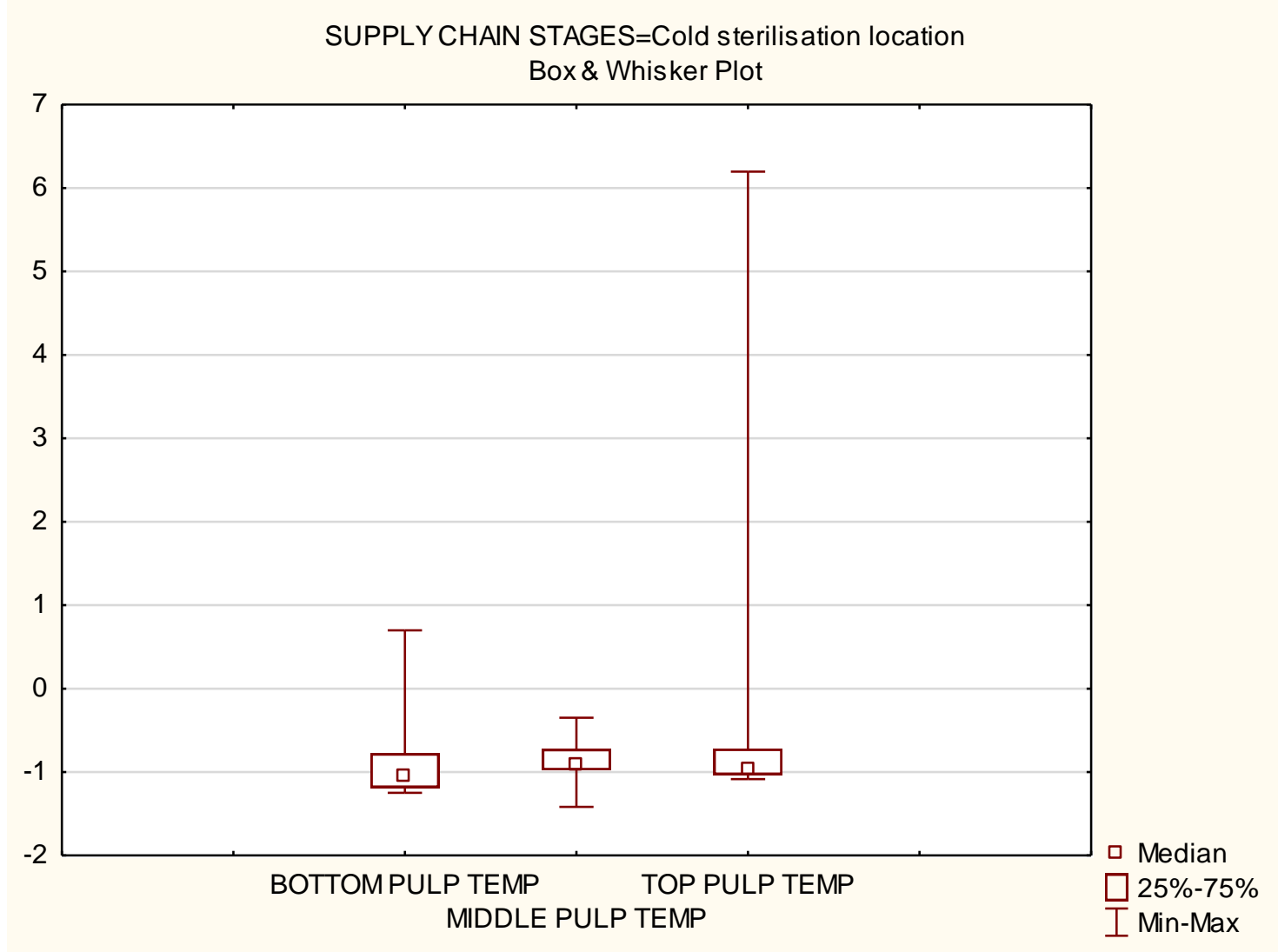

Figure 44: The difference in temperature at different positions at the cold sterilisation stage

Figure 44 shows the different temperature at different positions during the cold sterilisation location stage according to the Friedman's test (ANOVA Chi Sqr. $(\mathrm{N}=268, \mathrm{df}=2)=192.1866 \mathrm{p}<0.001$ ). The figure depicts that the middle positioned cartons show higher temperatures than the bottom and top positioned cartons but the difference is not highly significant. 


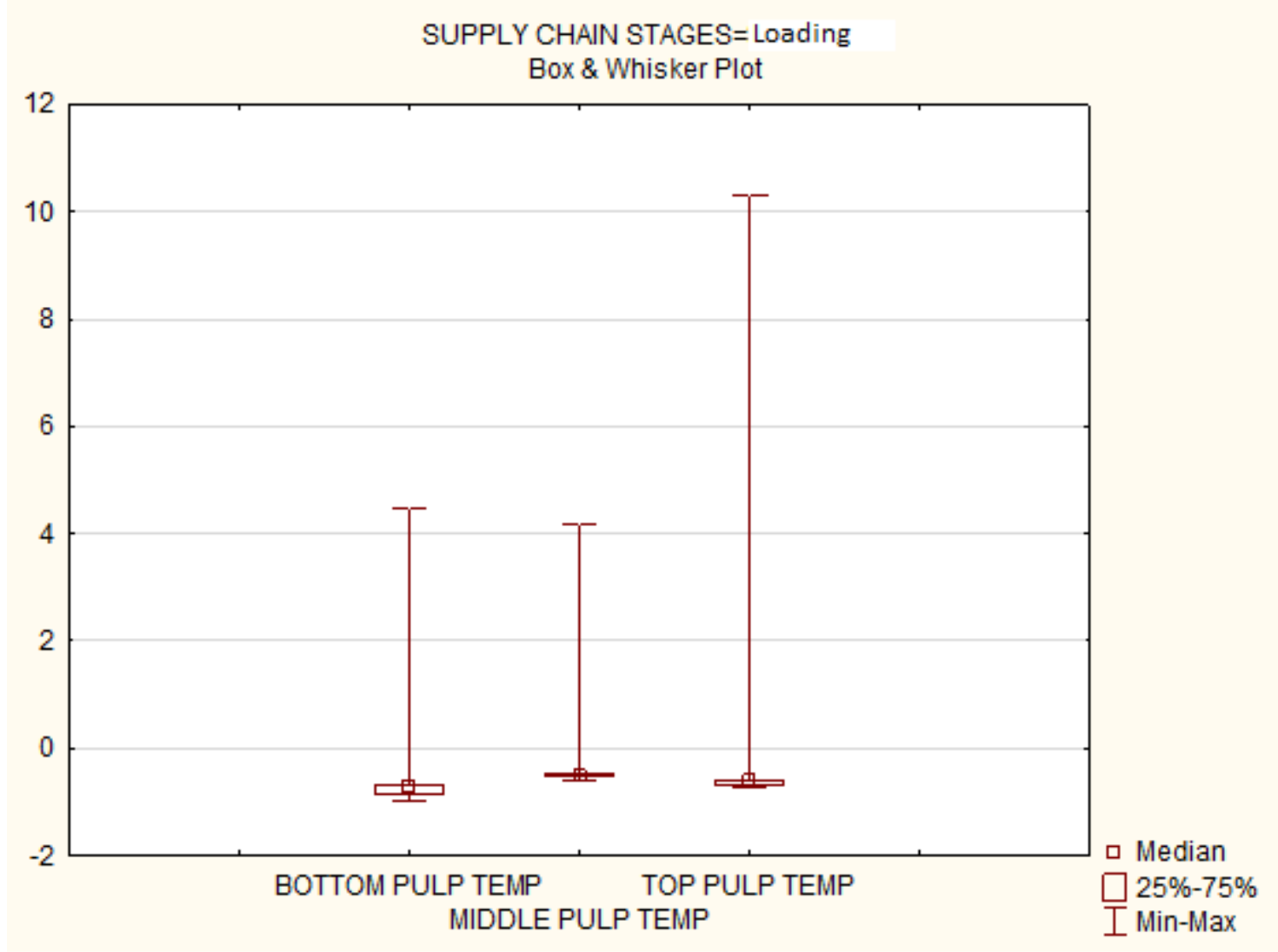

Figure 45: The difference in temperature at different positions at the shipment stage

Figure 45 illustrates the Friedman test's findings that there are significant differences in temperature (ANOVA Chi Sqr. $(\mathrm{N}=173, \mathrm{df}=2)=315.3410 \mathrm{p}<0.001)$ during the loading stage. The graph illustrates that the temperature at the top differs to that at the middle and at the bottom. The temperatures at the top differ slightly significantly from the middle positioned cartons. 
Box \& Whisker Plot

Include cases: $577: 1300$

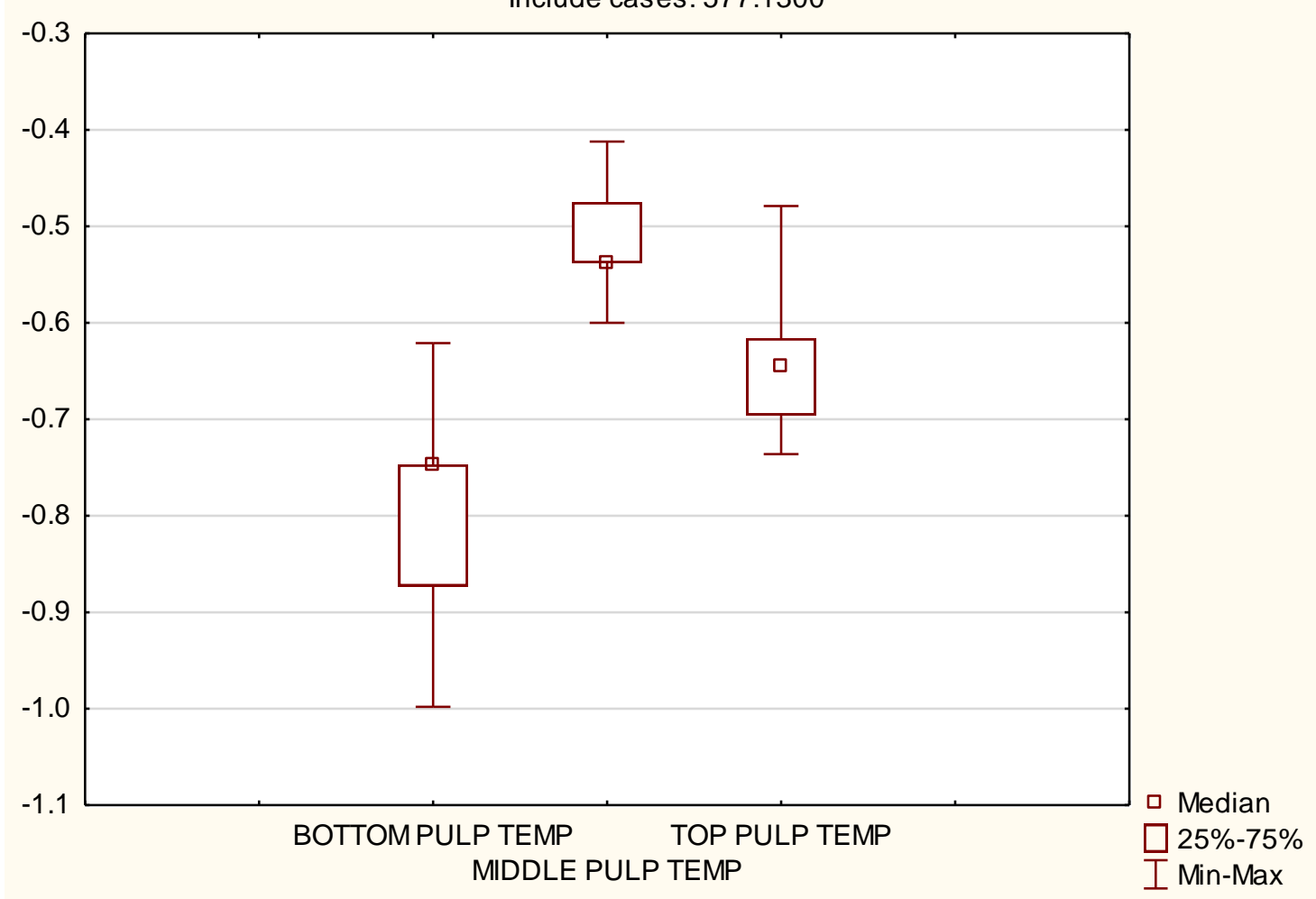

Figure 46: The difference in temperature at different positions at the shipment stage

Figure 46 illustrates the findings of the Friedman's test that there are significant differences in temperature at different positions for the shipping stage (ANOVA Chi Sqr. $(\mathrm{N}=960$, df $=2)=$ $1198.608 \mathrm{p}<0.00000)$. The figure shows that the temperature of middle positioned cartons differs significantly from the bottom and top positioned cartons.

A summary of the descriptive statistics conducted while testing the hypothesis are also shown in Table 28. The descriptive numerical statistics indicate that there are differences in temperature at different positions at each stage of the export cold chain. The means of the different positions show a difference in temperature.

Table 28: Descriptive statistics for the different stages and position of iButtons $®$ in the export cold chain

\begin{tabular}{|c|c|c|c|c|c|c|c|c|}
\hline \multirow[b]{2}{*}{ Variable } & \multicolumn{8}{|c|}{$\begin{array}{l}\text { All Groups } \\
\text { Descriptive Statistics (REGAL BAY VESSEL in FIRST PART OF THE SC data rearranged.stw) }\end{array}$} \\
\hline & Valid N & Mean & Median & Minimum & Maximum & $\begin{array}{l}\text { Lower } \\
\text { Quartile }\end{array}$ & $\begin{array}{l}\text { Upper } \\
\text { Quartile }\end{array}$ & Std.Dev. \\
\hline BOTTOM PULP TEMP & 549 & 16.28726 & $16.7520 \mathrm{C}$ & $-1.2500 \mathrm{C}$ & $28.1340 \mathrm{C}$ & $10.2990 C$ & $24.8850 \mathrm{C}$ & $8.75502 \varepsilon$ \\
\hline MIDDLE PULP TEMP & 549 & $17.1220 \bar{t}$ & $16.0140 \mathrm{C}$ & $-0.6630 \mathrm{C}$ & $26.9590 \mathrm{C}$ & $12.9460 \mathrm{C}$ & $24.7090 \mathrm{C}$ & $7.27663 \varepsilon$ \\
\hline TOP PULP TEMP & 549 & $15.5331 \Xi$ & 15.15155 & $-0.8730 \mathrm{C}$ & $27.2900 \mathrm{C}$ & $10.8571 \varepsilon$ & $23.1370 \mathrm{c}$ & 8.022787 \\
\hline MIDDLE AMBIENT TEMP & 549 & $16.0226 \varepsilon$ & $15.0570 \mathrm{C}$ & $-1.5030 \mathrm{C}$ & $25.1290 \mathrm{C}$ & $11.7990 \mathrm{C}$ & $24.0660 \mathrm{C}$ & $7.81939 \approx$ \\
\hline TOP AMBIENT TEMP & 549 & 15.80324 & 15.43467 & -0.96267 & 24.96967 & $11.1483 \AA$ & 23.75767 & $8.00207 \varepsilon$ \\
\hline
\end{tabular}




\begin{tabular}{l|l|l|l|l|r|r|r|r|}
\hline & \multicolumn{3}{|l|}{$\begin{array}{l}\text { All Groups } \\
\text { Descriptive Statistics (REGAL BAY VESSEL in LAST PART OF THE SC DATA REARRANGED.stw) }\end{array}$} \\
\cline { 2 - 9 } & Valid N & Mean & Median & Minimum & Maximum & \multicolumn{1}{l}{$\begin{array}{l}\text { Lower } \\
\text { Quartile }\end{array}$} & $\begin{array}{c}\text { Upper } \\
\text { Quartile }\end{array}$ & $\begin{array}{c}\text { Std.Dev. } \\
\text { Variable }\end{array}$ \\
\hline BOTTOM PULP TEMP & 1488 & -0.492353 & -0.747000 & -1.25000 & 4.46500 & -0.904000 & -0.684000 & 1.081131 \\
\hline MIDDLE PULP TEMP & 1488 & -0.423302 & -0.538000 & -1.60500 & 4.17000 & -0.726000 & -0.475000 & 0.911279 \\
\hline TOP PULP TEMP & 1488 & -0.102994 & -0.661545 & -1.12400 & 10.30318 & -0.730273 & -0.604545 & 2.041853 \\
\hline
\end{tabular}

Similar to the Santa Lucia vessel, Figures 39 to 42 and the numerical descriptive statistics show that there is enough evidence to fail to accept the null hypothesis. Therefore, the alternative hypothesis stated is accepted, which means there are differences temperature at the different positions at each stage of the export cold chain conducted for the Regal Bay vessel.

\subsubsection{Research Objective 3}

Analyse the impact of temperature breaks on the quality of navels.

To analyse the impact of temperature breaks on the quality of navel oranges, a hypothesis was formulated and tested. The structure that was followed for hypothesis testing is depicted in Figure 47.

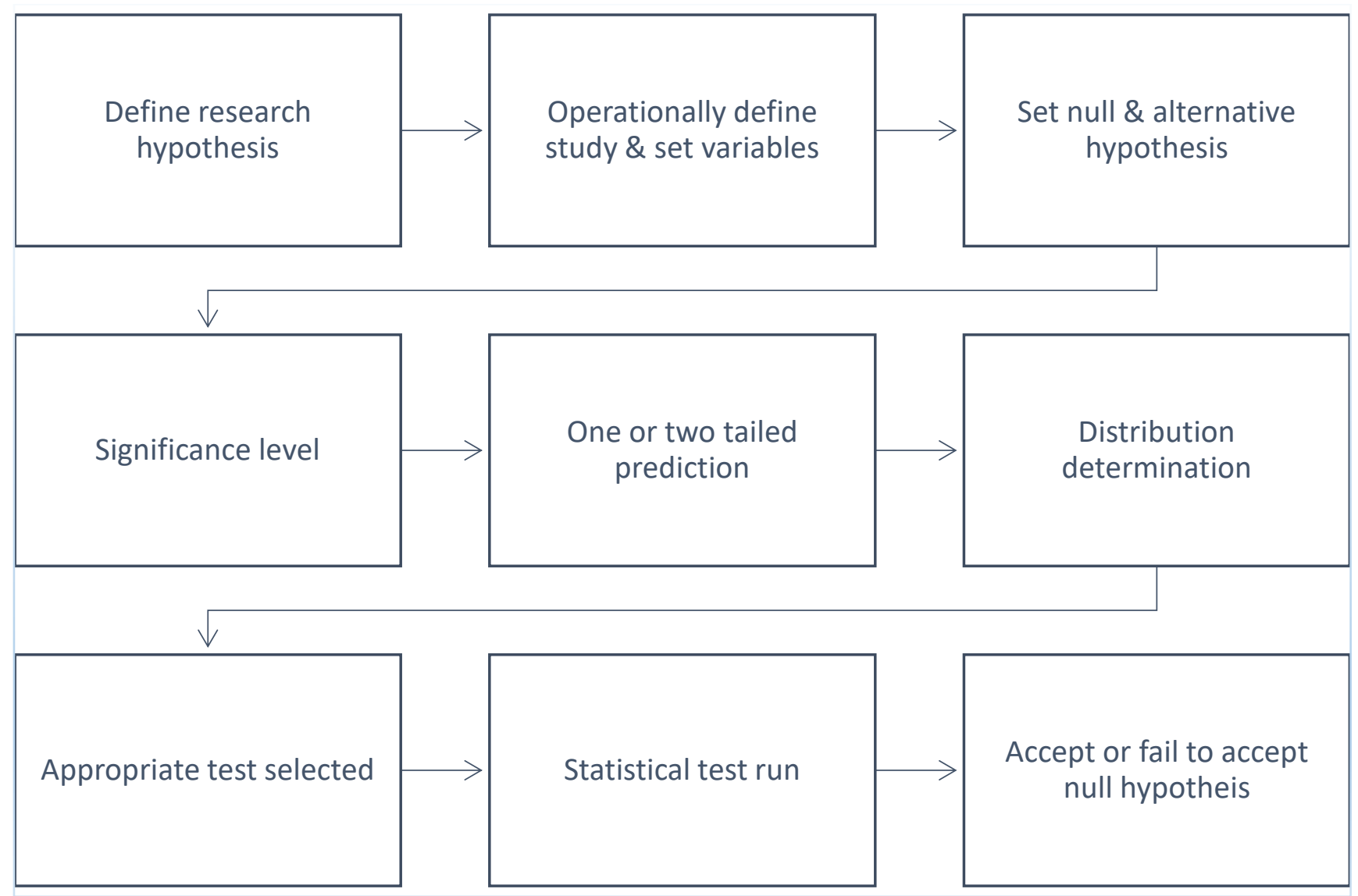

Figure 47: Structure of hypothesis testing 
The researcher had to measure whether temperature breaks in the export cold chain of navel oranges do occur and how many times they occur. The data analysed to measure whether temperature breaks did occur was collected through insertion of iButtons ${ }^{\circledR}$ into navel oranges during shipment. Since temperature breaks were measured from the cold store until the port of destination for the purpose of this study, the data analysed to test the hypothesis was data collected from the time cold sterilisation treatment protocols commence (the sea-leg).

After that was determined, the study had to be operationally defined, i.e. the study had to state which measure is to be tested and why. In this case, quality is measured, because it influences the market price of navel oranges shipped to the USA and it is the variable that diminishes if temperature controls are not within parameters. Fruit quality was ranked in percentages in accordance to fruit quality export standards and requirements as set out by the USDA (depicted in appendix 2). Quality is ranked in terms of percentages and those percentages are contrasted against quality tolerances, which stipulate the percentage that should not be surpassed by navel oranges to render them as of acceptable standard. The next step was to define the variables to be used for the hypothesis. Since the aim is to analyse the impact of temperature breaks on quality, the variables measured are temperature breaks (independent variable) and quality (dependant variable). The hypothesis formulated in response to the research objectives states:

\section{$H_{0}$ : There is no relation between temperature breaks and fruit quality.}

$H_{1}$ : There is a relation between temperature breaks and fruit quality.

To test the hypothesis, the researcher made use of the Kruskal-Wallis test. According to McDonald (2009), the Kruskal-Wallis test is best used if there is one measurement variable and one nominal variable. The test does not assume that the measurement variable is normally distributed. The measurement variable tested in the research claim was temperature breaks, whilst quality was the nominal variable. The Kruskal-Wallis test is also performed on ranked data. Quality can be ranked from lowest to highest. In addition, the Kruskal-Wallis test was conducted as it assumes that observations in a group come from a population with the same shape of distribution (McDonald, 2009).

The Kruskal-Wallis test was conducted through using the Statistical Package for Social Sciences (SPSS). The p-value of the test is used as an indicator if the researcher should reject or fail to reject the null hypothesis in favour of the alternative hypothesis (Nel, 2017). 
As mentioned in Chapter 1, Section 1.5, temperature is the main determinant of fruit quality and shelf life. The relationship between the two variables had to be determined through the occurrence of temperature breaks. The data that was analysed to test the hypothesis proved that during the sea leg, there were no observable temperature breaks that were recorded. This proves that cold sterilisation protocols are efficiently carried out, hence the analysis failed to reject the null hypothesis as there were no observable temperature breaks. This means the relation between temperature breaks and fruit quality could not be determined in this study.

To further analyse for temperature breaks that possibly occur in the export cold chain and their impact on fruit quality thereof, analysis was conducted on historical temperature data and fruit quality reports received from Company $\mathrm{X}$ and other export companies.

\subsection{Historic data on fruit quality}

Fruit quality reports of previous export seasons were received as historic data from Company X. The reports were analysed to further determine the link between temperature breaks and fruit quality. Fruit quality reports are documented results on factors affecting the quality of fruit. These factors are determined upon inspection by the import country. To determine whether the quality of fruit meets an acceptable standard, quality tolerances are stipulated by the country of import. Quality tolerances mean that there are limits (expressed in percentage) which fruit are not to surpass (Appendix 2). These quality tolerances pertain to quality factors such as oleocellosis, rind breakdown, peel colour, cold damage and granulation. During inspection, sample pallets are selected from each compartment and tested. If fruit is inspected and found to be defective, they may be rejected or accepted at a lower price, which may result in claims. Rejected cartons of fruit are referred to as non-compliant cases (Appendix 3).

For the year 2012-2013, an analysis on fruit quality was conducted from six reefer vessels. Shipment of navel oranges took place between the months of May and September. The total number of pallets inspected were 120. Each pallet had approximately 72 cartons. There was 24305 non-compliant cases (i.e. the number of navel oranges rejected in the total cartons sampled), which when calculated in terms of percentages gives a figure of $6 \%$. Figure 48 depicts the percentage of fruit rejected for all six vessels. 


\section{Percentage of non-compliant cases\%}

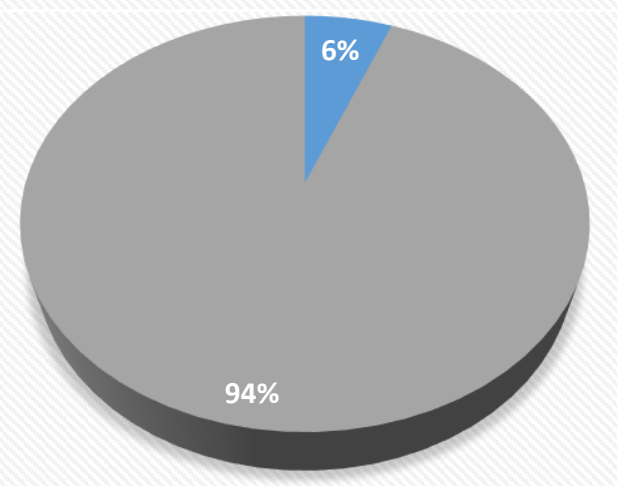

Non-compliant cases Compliant cases

Figure 48: A percentage of non-compliant cases in 2012/2013

Figure 48 shows that only $6 \%$ of the total fruit shipped did not meet the stipulated quality standards. The reason for the $6 \%$ rejection of navel oranges is depicted in Figure 49.

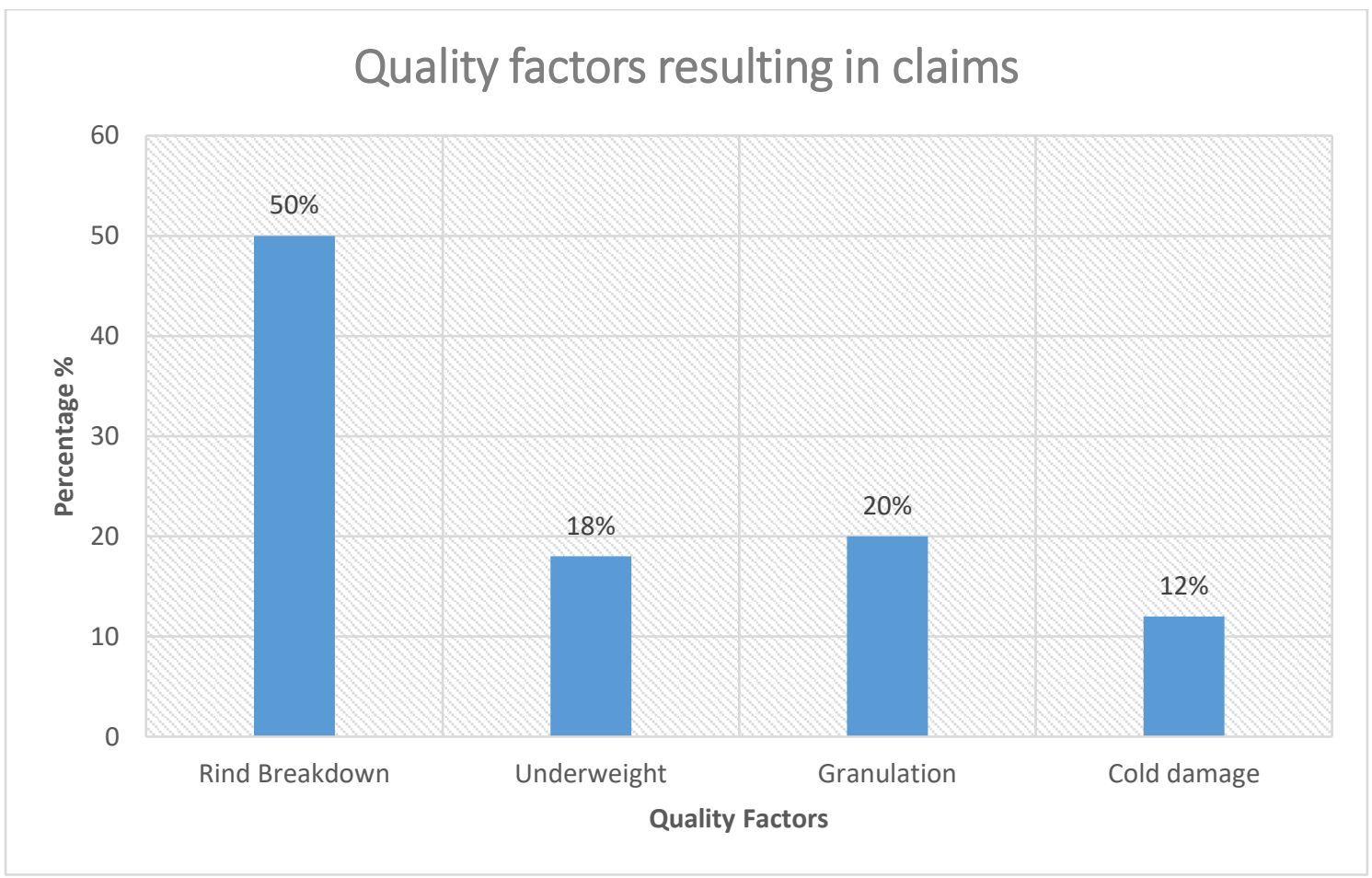

Figure 49: Factors resulting in fruit rejection in 2012/2013

The bar chart in Figure 49 depicts the percentage of different factors affecting quality. Rind breakdown is the most prevailing at $50 \%$. Eighteen percent of navel oranges were rejected due to being underweight, whilst $20 \%$ of fruit was rejected due to granulation. Twelve percent (12\%) of fruit was rejected due to cold damage. 
For the year 2014, analysis was conducted on reports for navel oranges shipped on three reefer vessels. There was a total of 29763 boxes inspected from the vessels. Claims were made on 2520 boxes meaning that 2520 boxes $(0.085 \%)$ of navel oranges were deemed to have poor quality fruit. The reason for the poor quality of fruits is depicted in Figure 50.

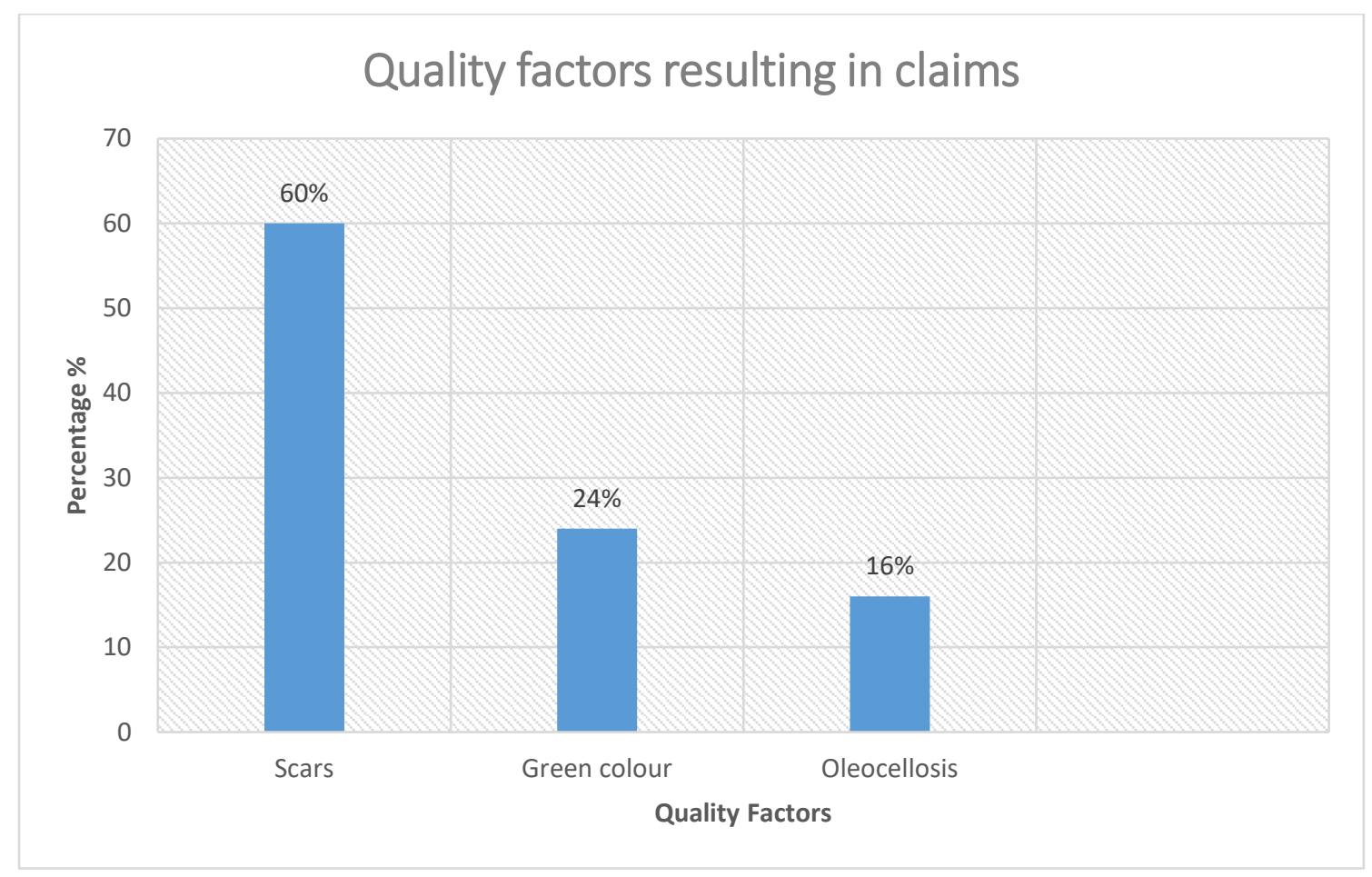

Figure 50: Factors resulting in fruit rejection in 2014

The bar chart in Figure 50 depicts that scars were the leading factor contributing to fruit being rejected upon inspection. Scar damage contributed 60\%, whilst the green colour which renders fruit unattractive contributed $24 \%$ and oleocellosis of navel oranges inspected in 2014 resulted in $16 \%$ of the fruit being rejected.

Quality reports were further analysed for the year 2016. A total of 74990 boxes were inspected for quality. A total of 1400 boxes $(0.019 \%)$ of navel oranges were reported to be of poor quality. The histogram in Figure 51 depicts the quality factors that contributed to the report of poor quality. 


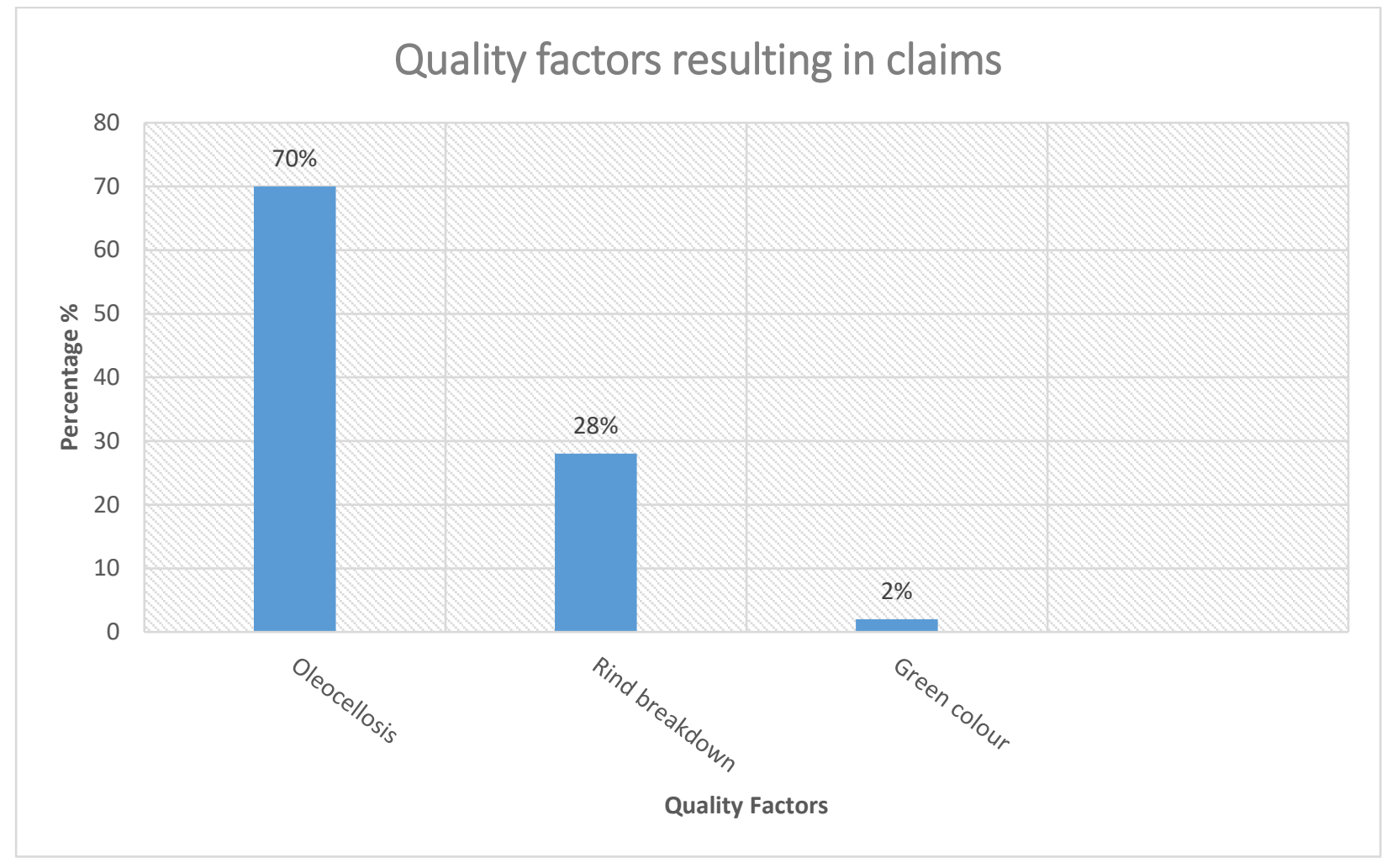

Figure 51: Quality factors resulting in claims in 2016

Figure 51 shows that oleocellosis was the major factor influencing the rejection of navel oranges in the 2016 at $70 \%$. Rind breakdown was reported at $28 \%$ and the green colour was reported to contribute only $2 \%$ of navel oranges being rejected.

For the year 2017, quality reports were analysed for navel oranges inspected from ten reefer vessels. Fruit was shipped to the USA in the months of June-August. A total of 85390 boxes were inspected from all ten reefer vessels. Only 4480 boxes $(0.05 \%)$ were rejected due to the navel oranges exceeding quality tolerance factors. The 4480 affected cases were due to quality factors depicted in the histogram in Figure 52. 


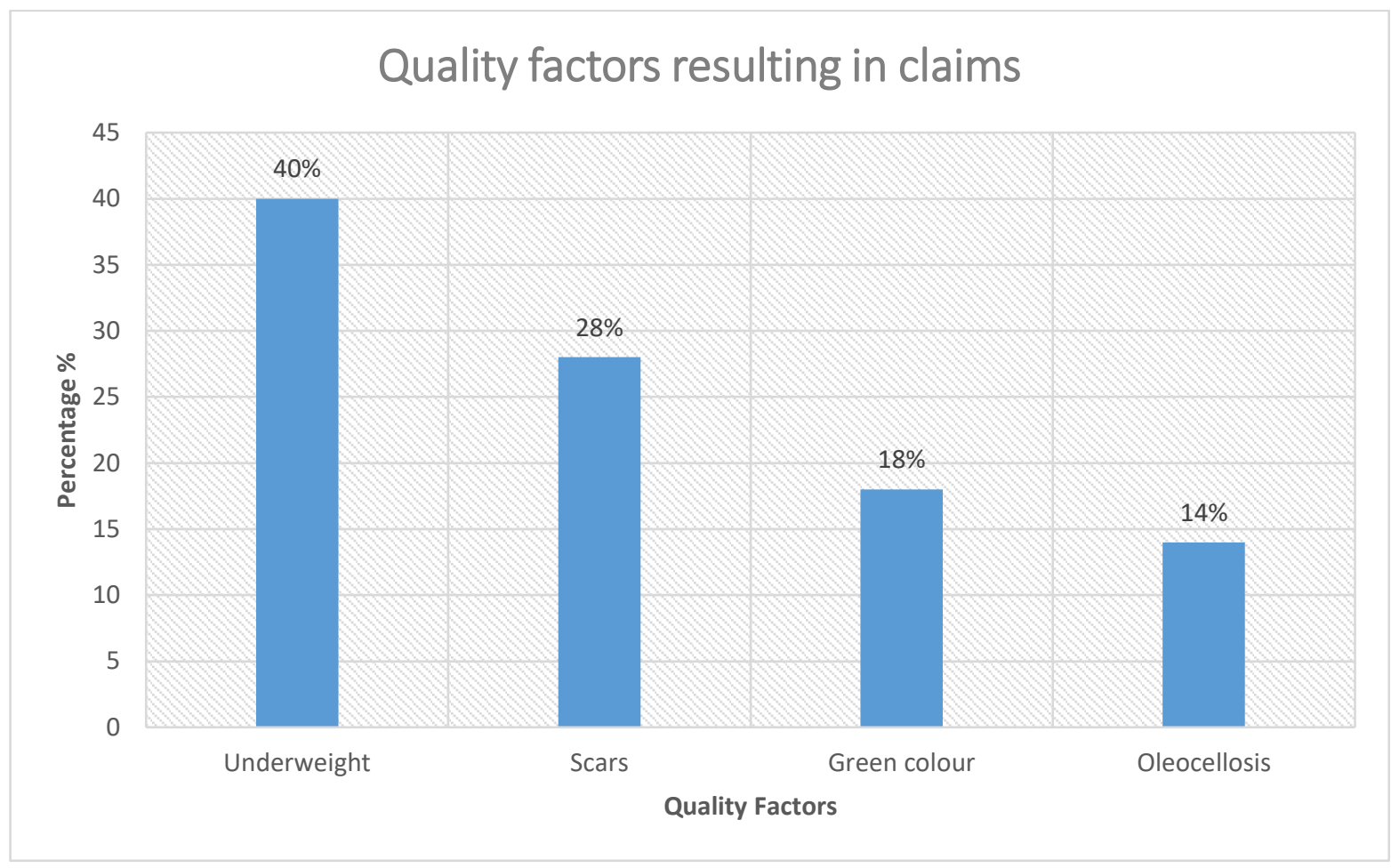

Figure 52: Quality factors resulting in claims in 2017

Fruit weight was the major factor that resulted in rejection of navel oranges during 2017. Forty percent (40\%) of the 4480 affected cases was deemed underweight, whilst $28 \%$ was rejected due to scars. Eighteen percent (18\%) was due to the fruit's green colour and oleocellosis contributed 14\% to navel oranges being rejected in 2017.

The quality reports analysed depict that navel oranges shipped to the USA are rejected as a result of poor quality. The percentage of fruit rejected could be considered as alarming. However, the percentage of rejections in the year 2014 dropped to below $0.1 \%$ in 2014 and remained below $0.1 \%$ in the years after.

In conclusion, to determine whether temperature breaks influence the quality of fruit the researcher analysed fruit quality reports that were received as historic data from Company $\mathrm{X}$. The fruit quality reports indicated the number of compliant cases and non-compliant cases, which is fruit that had been rejected due to poor quality. The reasons for the rejection of fruit were depicted in graphs. However, it should be noted that the fruit and the number of vessels recorded in the quality data reports were not noted to have undergone temperature breaks. Therefore, the fruit quality factors mentioned cannot be said to be related to temperature breaks. A discussion on how each factor contributes to fruit rejection and if these factors are a result of low temperatures and temperature breaks are discussed in Chapter 2, Section 2.8. 


\subsection{Historical temperature data analysis}

Secondary quantitative data also used for this analysis was received from exporting companies. These companies monitor the temperature of fruit from the cold store to final destination of the consignment. For the privacy of their data utilised, these external companies are identified as Cold chain 1 and 2 throughout the study. The historical data only contains the deep-sea leg of the export process.

\subsubsection{Cold Chain 1}

Cold chain 1 is an export organisation that provides cold chain management services. The data analysed is from 2012 to 2013 and from 2014 to 2017. The data analysed coincided with the data collection period of this study to enable better comparison. Temperature data supplied by Cold chain 1 was per vessel, per deck and per day from three vessels transporting navel oranges to the United States of America. The data was also analysed from once the decks and compartments on the reefer vessels were closed and cold treatment commenced until the port of destination. All decks on a reefer vessel are operated individually. For instance, Deck 4A may be closed on 29 May with cold sterilisation treatment commencing at 14:00, while Deck 3D may be closed on the same date with cold sterilisation commencing at 16:00. Therefore, the data was analysed from the day after all decks had been closed and cold sterilisation commenced. All consignments shipped under cold sterilisation protocols are on-board vessels for a period of 22 days at $-0.6^{\circ} \mathrm{C}$. Fruit pulp temperature was measured by at least 3 probes per deck or combined deck. For Cold chain 1, a temperature break for cold sterilisation protocols occurs when temperature exceeds $1.1^{\circ} \mathrm{C}$ as stipulated by the PPECB regulations. As mentioned, temperature readings are validated on special probes inserted into the fruit by the PPECB. Each probe must show that the temperature was kept below the stipulated specification for the required duration. For conventional vessels, 62 temperature probes are inserted into fruit per deck by PPECB and if any of these probes record a temperature beyond $1.1^{\circ} \mathrm{C}$, the temperature is nullified.

Figure 53 indicates the pulp temperature of iButtons ${ }^{\circledR}$ shipped in vessels A, B \& C. The graph shows that for the majority of the sea leg journey, temperature is kept below the threshold temperature until cold sterilisation protocols are completed. However, a temperature break did occur in vessel two. The temperature exceeded the steri-breach temperature of $0.0^{\circ} \mathrm{C}$, but not the threshold temperature of $1.1^{\circ} \mathrm{C}$. The temperature breaks are seen from 19-20 June (the rise indicated on 16 July is due to the fruit arriving in port and the offloading process starting). The rise in temperature above $0.0^{\circ} \mathrm{C}$ in vessel two means that Cold Chain 1's fruit consignment would need to be cooled down to $-0.6^{\circ} \mathrm{C}$ for at least three days to meet steri-protocols. It is evident in Figure 53 that this occurred. 


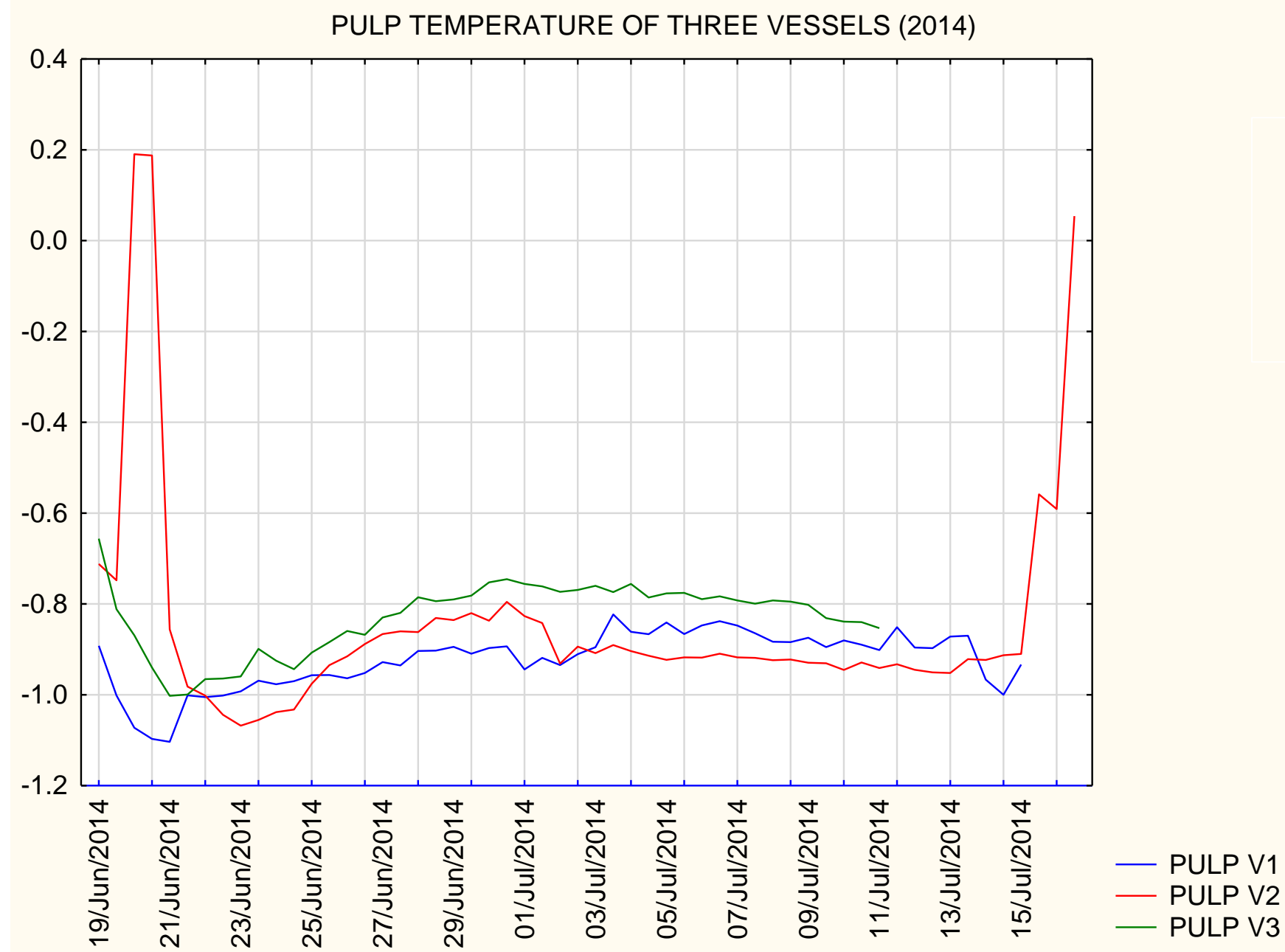

Figure 53: Pulp temperature for three vessels in 2014

Figure 54 depicts the pulp temperature of different decks on-board vessel A for the 2016/2017 season. Pulp temperature on-board vessel A was kept below $0.0^{\circ} \mathrm{C}$ for all decks utilised. Therefore, no cold sterilisation breach was experienced, which also means cold sterilisation failure was evaded.

Only one of the vessels utilised during the past export seasons experienced cold sterilisation protocol breach or failure. Cold chain 1 depicts a fairly optimally managed export cold chain with a decrease in temperature and a few spikes along the sea leg, which may be caused by certain factors, for example, the utilisation of old vessels, which may take a longer time to bring the temperature down to the stipulated protocol during shipment. In addition, the spikes in temperature may be due to the breakdown of insulation in the vessel, which leads to heat penetration. 


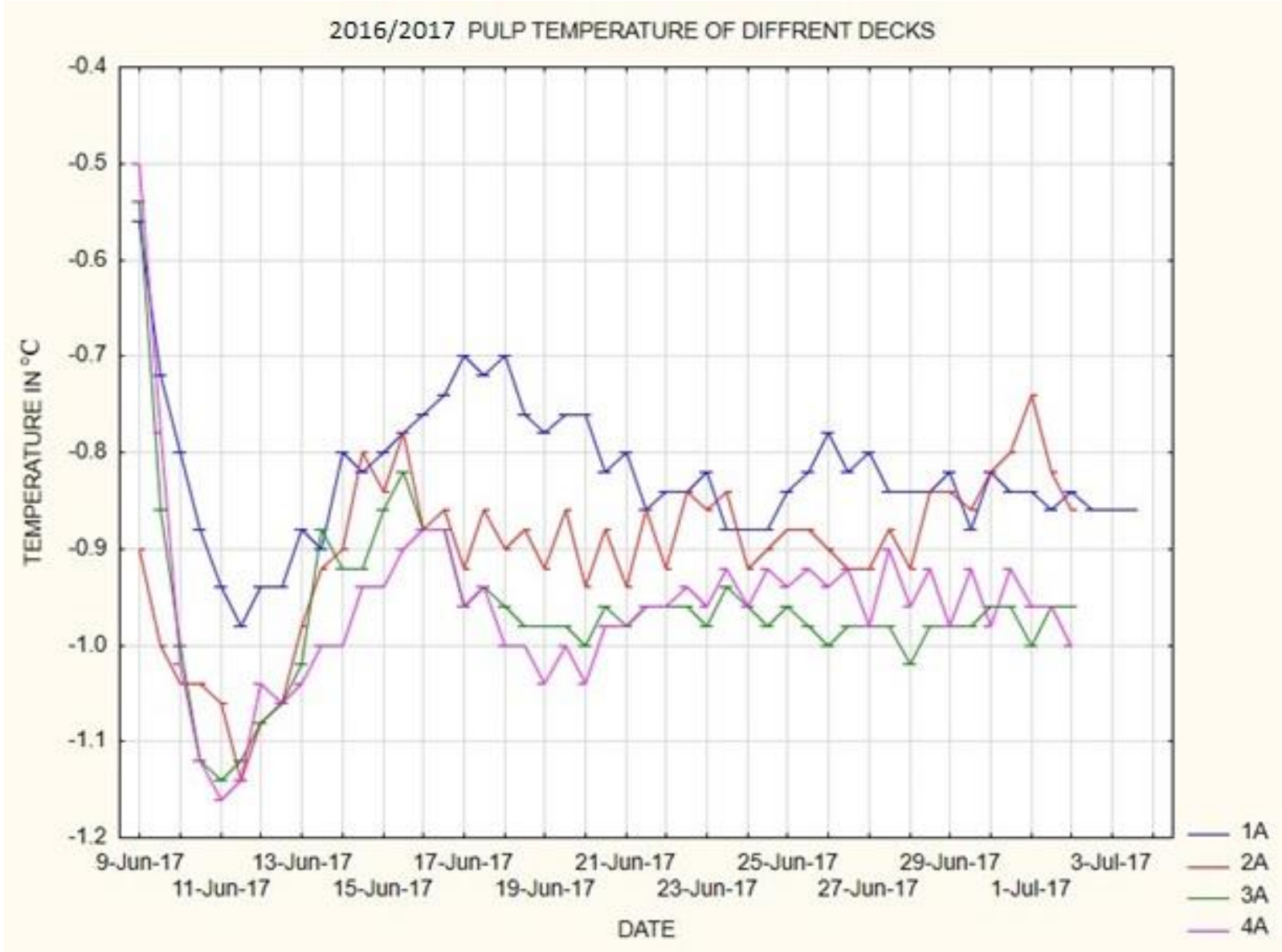

Figure 54: Pulp temperature of different decks in 2016/2017

\subsubsection{Cold chain 2}

Cold chain 2 is an export company that is a supplier of fresh fruit to global markets. The data analysed is from the export season of 2017. The data that was sourced from cold chain 2 corroborates the findings of the study as it was collected approximately at the same period as the data collection period of this particular study. The data analysed is from the sea leg of the export cold chain phase.

Figure 55 indicates the pulp temperature of one of the conventional vessels during shipment. 


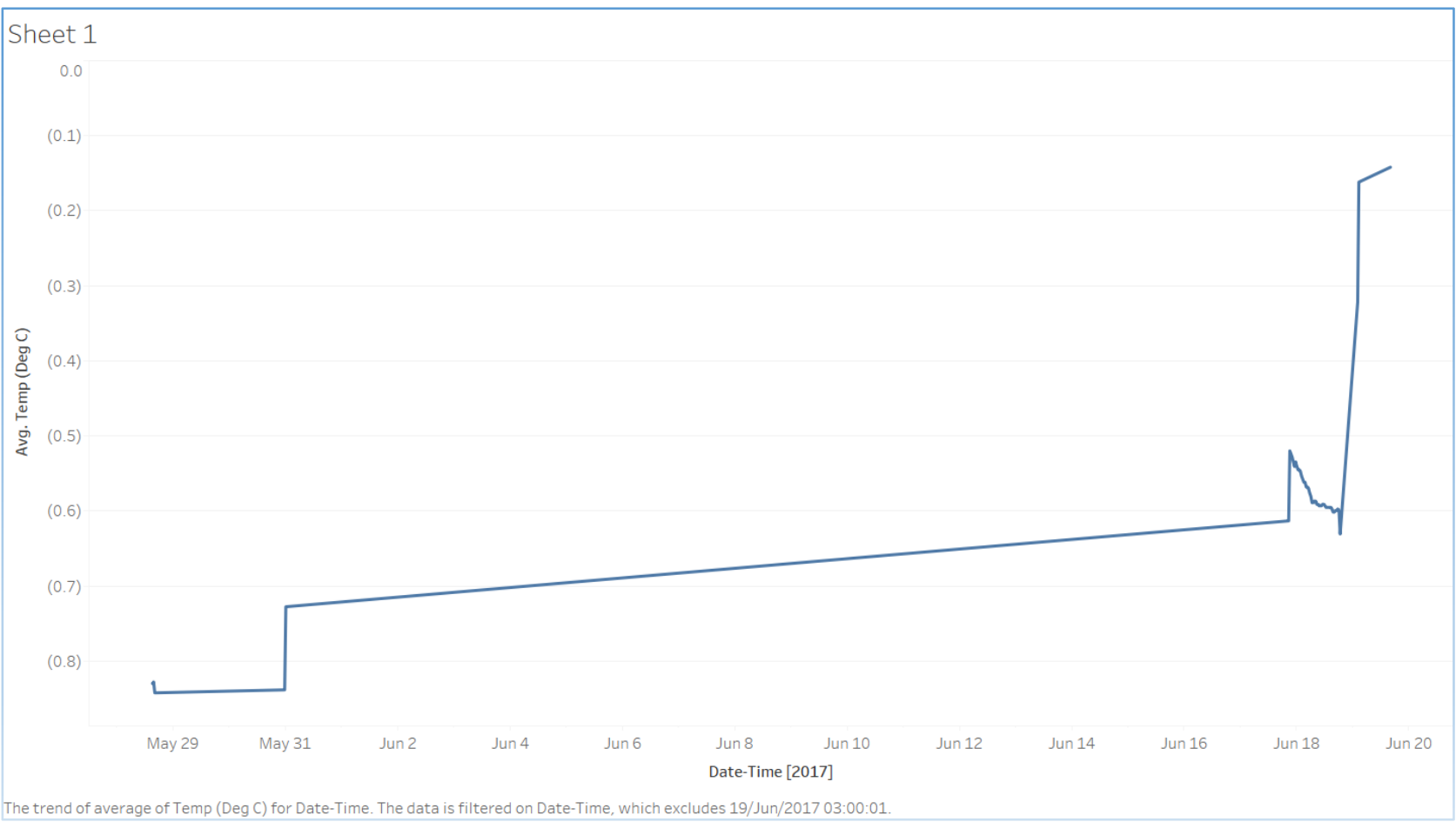

Figure 55: Pulp temperature of one of the reefer vessels

Figure 55 shows that temperature is kept below the threshold temperature until cold sterilisation protocols are completed, which proves the efficiency of the organisation's cold chain. The negative temperature values in Figure 55 are depicted using brackets.

Figure 56 illustrates the pulp temperature of two vessels (Figure 55 included) utilised by cold chain two (negative temperature values shown using brackets). The graph shows that the temperatures of the two vessels are within steri-protocols, further proving the efficiency of cold chain 2's export cold chain. 


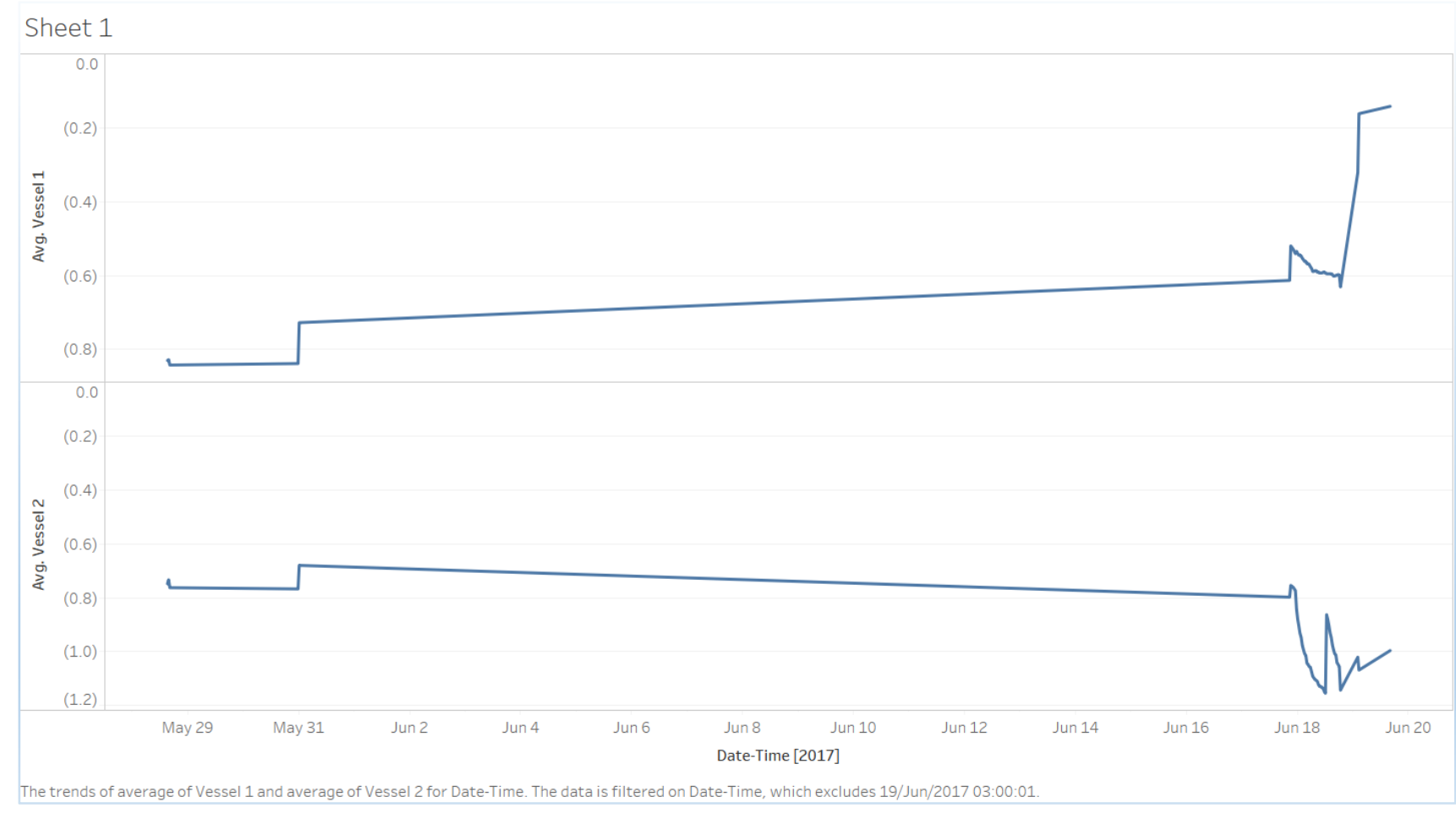

Figure 56: Pulp temperature of two vessels

\subsection{Conclusion}

The aim of the chapter was to present the graphical and numerical descriptive analysis of data collected. Inferential statistics were also presented. In addition, historic fruit quality and temperature data from 2012-2017 were analysed.

The data set from the Santa Lucia Vessel showed that temperature spikes were most evident during transportation of navel oranges from the pack house to the cold store. Temperature breaks mostly occurred during the inspection and loading phases of fruit. Similar to the Santa Lucia vessel, temperature spikes were mostly evident during the transportation phase for the Regal Bay vessel and temperature breaks were most prominent during the inspection and loading phases of navel oranges. The descriptive numerical statistics conducted for both vessels indicated that there are differences in the temperature profiles of the different export cold chain phases. The pulp and ambient temperature for the different phases of the export cold chain were mostly kept within the acceptable temperature ranges.

Inferential statistics were also conducted to test two hypotheses. The first hypothesis stated that there are no differences in temperature at different positions at each stage of the export cold chain. 
The nonparametric Friedman test used to test the hypothesis. For both vessels, it was found that there were differences in temperature at different positions at each stage of the export cold chain. The second hypothesis tested for the link between quality of fruit and temperature breaks. A KruskalWallis test was conducted and the analysis failed to reject the null hypothesis as there were no observable temperature breaks. This means the relation between temperature breaks and fruit quality could not be determined.

The historic temperature data analysed proved that cold sterilisation protocols are mostly kept within the stipulated temperature ranges. Cold chain 1 depicted a steri-breach (but not break) in one vessel. The historic fruit quality report data showed that a small percentage of fruit had been rejected due to different fruit quality factors.

In summary, it is clear that the export cold chain of navel oranges functions optimally. There are very few breaks in temperature in the cold store and sea leg phases, and not a large number of temperature spikes are depicted in the beginning stages of the cold chain. The export cold chain of navels oranges shipped to the US may owe its success largely to the fact that a consignment is rejected if cold sterilisation protocols are not adhered to, which in turn translates to loss of projected revenue. 


\section{Chapter 6: Interpretation of data analysis findings}

\subsection{Introduction}

This chapter interprets the data illustrated through graphs and tables in Chapter 5. Possible reasons for the data outcome are suggested.

\subsection{Main findings from data analysis}

Temperature data collected from two reefer vessels exporting navel oranges from the Port of Cape Town to Philadelphia in the United States of America were analysed. The analysis was divided into two parts: the first and the last phases of the export cold chain. Each temperature trial was linked to these phases to determine temperature spikes and breaks. For the purpose of this research study, temperature spikes were analysed from orchard until cold store and temperature breaks were analysed from cold store until the port of destination. Temperature spikes were defined as "any time temperature rises along the export cold chain". The definition of temperature breaks was differentiated between the export cold chain and steri-market protocols. Therefore, temperature breaks were defined as "any time temperature increases once the export cold chain process has begun." From the export port until the port of destination a temperature break is defined as " $a$ temperature deviation above $0.0^{\circ} \mathrm{C}$ or below $-1.5^{\circ} \mathrm{C}$ '. The latter definition takes into account sterimarket protocol requirements. Steri-market protocols stipulate that pulp temperature may vary between $-0.6^{\circ} \mathrm{C}$ to $0.0^{\circ} \mathrm{C}$, but if temperatures exceed $0.0^{\circ} \mathrm{C}$, it is considered a steri-breach and the cold treatment is extended so that temperature is brought back down to $-0.6^{\circ} \mathrm{C}$. If the temperature exceeds $1.1^{\circ} \mathrm{C}$, cold sterilisation treatment is nullified (PPECB, 2012). Therefore, for the purpose of this study's data analysis, a temperature break for steri protocols occurs when the pulp temperature of the navel oranges rises above $1.1^{\circ} \mathrm{C}$.

The Santa Lucia vessel trial indicated that temperature spikes were more prone during the drenching phase of the export cold chain. The temperature spikes started a few hours after the navel oranges were drenched and left to dry in an open area. These spikes continued until outside temperatures had dropped. The temperature spikes were not depicted after the fruit was removed from the drench area and sent to the pack line segment. Temperature spikes were also identified during the transportation phase of navel oranges to the pack house. Navel oranges are packed into cartons, then staged on pallets on the last day of pack house processes and immediately sent off to a cold store approximately 
two and a half hours away. For the Santa Lucia vessel trial, spikes were indicated soon after the researcher had re-probed fruit with iButtons ${ }^{\circledR}$ and the navel oranges were transported. The pulp temperature of fruit gradually increased until the truck arrived at the cold store. The temperature spike lasted for 5 hours before temperatures started decreasing.

In the last stages of the export cold chain, temperature breaks were most evident during the inspection and loading stages. During inspection, the samples of fruit pallets are placed in an unrefrigerated area. However, prior to inspection, the fruit pallets are placed into a cold room with a set point of $4^{\circ} \mathrm{C}$. The fruit has to maintain the temperature induced in the cold room. However, it was evident that both ambient and pulp temperature of fruit rise during inspection. The loading stage proved to constitute more temperature breaks. The temperature of navel oranges is brought down to $-0.6^{\circ} \mathrm{C}$ prior to loading. This temperature has to be maintained until all fruit pallets are loaded onto the reefer vessel. Once the temperature increases beyond $0.0^{\circ} \mathrm{C}$, it means there is a breach in steri-protocols and therefore fruit pallets have to be sent back into the cold room for an additional day(s) and the temperature has to be brought back down to $-0.6^{\circ} \mathrm{C}$. The loading phase for the Santa Lucia vessel trial proved that the temperature of navel oranges exceeded $0.0^{\circ} \mathrm{C}$ for periods longer than two hours on a number of occasions.

The higher positioned fruit in cartons staged on pallets were shown to be more likely to experience temperature breaks during vessel loading than those placed in the middle and the bottom. iButtons ${ }^{\circledR}$ inserted in fruit which were in the top of the pallet showed an increase in pulp temperature for longer than 3 hours. However, once the fruit had been loaded onto the vessel and during the sea leg, the middle positioned fruit depicted higher temperatures than those positioned at the bottom and at the top. Therefore, the analysis shows that the top and middle positioned fruit in cartons are more likely to be affected during the last stages of the export cold chain. It was also evident that there were breaks experienced in the export cold chain, but not after steri-market protocols had commenced.

The Regal Bay vessel trial also indicated that temperature spikes were more prone during the transportation phase. Both pulp and ambient temperature showed an increase during transportation of the fruit to the cold store. Temperature only started decreasing once fruit had been placed in the cold room.

The inspection phase during the temperature trial also depicted temperature breaks. Once the fruit was taken out of the cold room into the inspection location, temperature was not maintained. There was a rise in both pulp and ambient temperature and it started decreasing once fruit was taken back into the cold room. The loading stage also contributed to a number of temperature breaks. As 
mentioned, prior to loading, the temperature is brought down to $-0.6^{\circ} \mathrm{C}$ and has to be maintained until loading of the vessel is completed. Once temperatures rise higher than $0.0^{\circ} \mathrm{C}$, it means a breach in steri-protocols has occurred. During loading of the Regal Bay vessel, temperature breaks lasted for more than 9 hours.

Similar to the Santa Lucia vessel, spatial variation analysis in the cold chain was conducted. The positions in the pallet revealed that cartons placed on top during loading are more likely to experience fluctuations in temperature, thereby resulting in temperature breaks. For both vessels, during the loading stage of the cold chain, iButtons ${ }^{\circledR}$ inserted in fruit, which were in the top of the pallet showed an increase in pulp and ambient temperature for longer than 3 hours. Once the vessel had been loaded and the cold sterilisation treatment had begun in the sea leg, the middle positioned cartons experience higher fluctuations in temperature. It is important to note that no temperature breaks were experienced once the steri-market protocols had commenced, which proves the efficiency of the export cold chain during the sea leg.

\subsection{Findings from Historical data}

Historical data from two export companies was analysed. The analysis conducted was on temperature data collected once steri-market protocols had commenced, which is during the sea leg. A steri-breach was identified once pulp temperature rose above $0.0^{\circ} \mathrm{C}$ and temperature breaks were determined once pulp temperature surpassed $1.1^{\circ} \mathrm{C}$ as per PPECB regulations. The temperature data revealed that navel oranges shipped to the USA by the two export companies, termed Cold Chain 1 and Cold chain 2 were mostly kept within required protocol. Cold Chain 1 depicted a steri-breach in temperature in one vessel, but the temperature did not rise above $1.1^{\circ} \mathrm{C}$. No fruit pallets were reported to be rejected by the export company. Cold chain 2 showed that no temperature breaks occurred during the shipment of navel oranges. Overall, the temperature data analysed proved that temperature breaks in the cold sterilisation protocol procedure are mostly kept within stipulated temperature range, thus resulting in all fruit pallets shipped being accepted in the market. This means that the export cold chain of navel oranges to the USA is efficient.

The fruit quality reports analysed showed that a small percentage of fruit were rejected upon arrival at the end destination. The reasons for the rejection of the fruit cartons were mostly contributed by quality factors, which are not related to temperature breaks The quality factors were discussed more in depth to find the relation between temperature and temperature breaks in Chapter 2, Section 2.8. The fruit quality reports were also analysed to investigate the link between fruit quality and temperature breaks and to investigate the volume of fruit rejected due to breaks in temperature. 


\subsection{Findings from inferential statistics}

Inferential statistics were conducted to test the two hypotheses. The hypotheses related to fruit quality and temperature breaks and whether differences exist in temperature at different positions at each stage of the export cold chain of navel oranges.

For the first research hypothesis, the non-parametric Friedman test was used to test the hypothesis. The researcher tested for differences in temperature at different positions at each stage of the export cold chain to find out which position of cartons staged on pallets is much more likely to contribute to temperature breaks at the various stages of the export cold chain. The discussion of the findings and conclusions is discussed in more detail in the following section.

The Kruskal-Wallis test was conducted for the second research hypothesis to determine if a link between fruit quality and temperature breaks exists. The p-value of the test was used as an indicator if the researcher should reject or fail to reject the null hypothesis (P less than the selected significance level, $\alpha=0.05$ ). Since there were no observable temperature breaks in the data analysed, the analysis failed to reject the null hypothesis. This means the relation between temperature breaks and fruit quality could not be determined.

\subsection{Discussion of findings for the first research hypothesis}

The hypothesis tested for differences in temperature at the different stages of the export cold chain. The stages that were analysed in the hypothesis were the transportation, cold store, inspection, cold sterilisation location, loading and the shipment stage. The first four stages of the export cold chain were excluded as iButtons ${ }^{\circledR}$ were only probed into fruit at different positions in the cartons staged on pallets once pack house processes had been completed, before transportation of navel oranges to the cold store. The hypothesis was conducted for both the Santa Lucia and Regal Bay vessel data sets.

For Santa Lucia trail, during the transportation stage, the most likely position to contribute to temperature breaks are the top positioned cartons. The top positioned cartons showed higher differences in temperature. The top positioned fruit in cartons is much likely to be affected during transportation due to weather influences. For example, an increase in temperature. As much as taut liner trucks have a curtain that serves as insulation from heat, an increase in temperature could possibly warm up navel oranges that are placed on top cartons, more so if there is not enough air circulation. For the cold store stage, the bottom positioned cartons proved to be the most likely position to contribute to the occurrence of temperature breaks. Pallets of fruits are placed in a cold store where FAC is used to cool fruit after arrival from the exporter. Fruit is exposed to higher 
pressure on one side and cool air forced by the pressure picks up heat from the fruit. The bottom positioned cartons may show higher temperatures due to the cooling rate of the FAC system utilised, for instance, the amount of time it takes for the cool air to reach the bottom position of the pallets (air follows the easiest route). For the inspection stage, the top positioned cartons were revealed to be more likely to contribute to the occurrence of temperature breaks. During inspection, fruit cartons staged on pallets are placed in an unrefrigerated room (after being taken out of a cold room). The rise in temperature at the inspection room could be the reason why top positioned cartons are most likely affected as the inspection room is at ambient temperature. The cold sterilisation location stage, which is where fruit are placed after inspection, proved that the middle positioned cartons are more likely to contribute to temperature breaks. Similar to the cold store, FAC is used to cool down fruit to the required cold sterilisation treatment temperatures, the rate of the cooling system utilised may contribute to the higher temperatures depicted in the middle positioned cartons. The loading stage during the Santa Lucia vessel trial shown that top positioned cartons on pallets are much more likely to contribute to temperature breaks. This may be due to weather influences such as high winds which are one of the biggest concerns during loading at the Port of Cape Town, which also contribute to delays during loading. The shipment stage (sea leg) proved that the middle positioned cartons were most likely to contribute to the occurrence of temperature breaks. The cooling system used in conventional vessels delivers cold air from the bottom and the top. Since the cold air is delivered from the top and bottom, it might possibly push and trap warm air in the middle positioned cartons, hence the higher temperatures.

For the Regal Bay trial, during the transportation stage, the middle positioned carton showed higher differences in temperature than the middle and bottom positioned cartons. This may due to weather influences. For instance, an increase in temperature may result in warm air being trapped in the middle positioned cartons. For the cold store stage, the bottom positioned cartons proved to be the most likely position to contribute to the occurrence of temperature breaks. As mentioned, pallets of fruits are placed in a cold store where FAC is used to cool fruit. The fruit is exposed to higher pressure on one side and cool air forced by the pressure picks up heat from the fruit. The bottom positioned cartons may show higher temperatures due to the cooling rate of the FAC system utilised, for instance, the amount of time it takes for the cool air to reach the bottom position of the pallets (air follows the easiest route). For the inspection stage, the bottom positioned cartons were revealed to be more likely to contribute to the occurrence of temperature breaks. During inspection, pallets are placed in a room under ambient temperature. The rise in temperature at the inspection room could be the reason why bottom positioned cartons are most likely affected as the inspection room is at ambient temperature. 
The cold sterilisation location stage, which is where fruit are placed after inspection, proved that the middle positioned cartons are more likely to contribute to temperature breaks. FAC is used to cool down fruit to the required cold sterilisation treatment temperatures, the rate of the cooling system utilised may contribute to the higher temperatures depicted in the middle positioned cartons. For the Regal Bay vessel trial, during the loading stage, the top positioned cartons on pallets proved to have higher temperatures. This may be due to weather influences such as high winds which are one of the biggest concerns during loading at the Port of Cape Town, which also contribute to delays during loading or an increase in ambient temperature. The shipment stage (sea leg) proved that the middle positioned cartons were most likely to contribute to the occurrence of temperature breaks. The cooling system used in conventional vessels delivers cold air from the bottom and the top. Since the cold air is delivered from the top and bottom, it might possibly push and trap warm air in the middle positioned cartons, hence the higher temperatures.

The hypothesis proved that there are temperature variations at different positions at each stage of the export cold chain. For both vessels, the bottom positioned cartons proved to be the most likely to experience higher variations in temperature during the cold stage. For the cold sterilisation location, the middle positioned cartons proved to be the most likely to contribute to the occurrences of temperature breaks for both vessels. During loading, both vessels depicted that the top positioned cartons experience higher temperature variations and are likely to contribute to the occurrences of the temperature breaks. The findings concur with that of Figure 27 and 38 . For the shipment stage, both vessels proved that the middle positioned cartons are much more likely to contribute to the occurrences of temperature breaks as they show higher temperature.

\subsection{Possible explanations for the origin of spikes/breaks during drenching,} transportation, inspection and loading stages

As seen for the two vessels analysed, temperature mostly increased during the time fruit was left standing in an open area to dry, during transportation from the pack house to the cold store and during loading of vessels in preparation to export fruit to the final market. The questions as to why anomalies in temperature occur during these phases are answered from conclusions drawn during observations of the export cold chain. Possible explanations are suggested in the next section.

\subsubsection{Drenching outside an open area}

The researcher observed that fruit bins are drenched immediately after fruit has been harvested. Fruit are brought to the drench area by tractors and put in a wash system. After going through the wash 
system, fruit bins are stacked on top of each other for a maximum period of 24 hours to allow fruit to dry completely. The area in which navel oranges are drenched is an open space with no shelter provided. This means that navel oranges are exposed to different weather elements during that period. Plastic bins are used to store fruit in. Plastic bins are used as they are known to provide better ventilation, thus helping to prevent fruit from absorbing heat. In order for plastic bins to be more effective in preventing fruit from absorbing heat, they have to be lined with plastic liners. It was observed that plastic bins were used during the drenching process, but these plastic bins were not lined with plastic liners. This means that temperature spikes during the drenching stage of the cold chain are more likely.

\subsubsection{Delays during transportation}

Fruit is transported using trucks as road transportation is the preferred mode. Fruit is usually transported via trucks called tautliners, which have an insulated roof and plastic curtains on either side. The transportation phase is from the time trucks leave the pack house to deliver fruit at the cold store. The transportation of fruit from the pack house to the cold store indicated temperature spikes. The possible reasons why temperature increases during this phase may be due to delays in traffic and congestion at the port. The distance from the pack house in Citrusdal to the cold store at the Port of Cape Town is approximately $180 \mathrm{~km}$. This distance may be prolonged as road transportation is prone to congestion. The time that a truck leaves the pack house for the port also plays a role in the rise of temperature of fruit. For instance, for the first temperature trial, fruit were transported to the port at 15:30 p.m. The route used to transport fruit to the port is prone to traffic, especially during peak hours. Even though tautliner trucks are utilised, the delays experienced during transportation further contribute to the increase in temperature. In addition, the lower levels of air circulation in trucks and plastic curtains that are used to shield fruit from direct sunlight, could lead to fruit sweating. The longer the delays during the transportation phase, the higher the occurrences of temperature increases, which leads to temperature spikes.

Another reason for temperature increases during the transportation phase may be due to delays resulting from congestion at the port. Trucks have to offload their consignment at the port. Even though navel oranges are harvested in the winter season, the outside temperature still influences the pulp temperature of fruit, especially when trucks are lined up in queues to offload.

A study conducted by Haasbroek (2013) also found that temperature breaks occurred during transportation of fruit to the port and during the loading of the vessel. However, the fruit was exported using reefer containers. The different types of vessels are discussed in more detail in chapter 7 . 


\subsubsection{Delays during inspection}

Samples of fruit pallets are taken out of the cold store to a room where inspection of navel oranges takes place. The pallets of fruits are left to stand in an unrefrigerated room, while sample cartons are being inspected by USDA and DAFF officials. The rate at which inspection takes place depends on how fast officials can conduct the inspection. Temperature breaks may occur during the inspection phase due to the time that inspectors take to check all sample cartons. Temperature breaks may also be due to the fact that pallets of fruit are placed in an unrefrigerated room, which possibly contributes to a rise in temperature.

\subsubsection{Exposure to direct weather elements}

When a vessel is loaded at the Port of Cape Town, fruit pallets are brought out of the cold store and left to stand in an open area near the vessel. Even though pallets are not brought out in large numbers to try avoid breaks, the navel oranges are still exposed to weather conditions such as high winds, which are a big concern in the exportation industry. This may lead to a temperature break, which may lead to fruit being taken back for further pre-cooling, which will result in the fruit being placed back into cold storage, resulting in delays.

\subsection{Conclusion}

The chapter showed that the export cold chain of navel oranges to the USA is efficient. Temperature spikes mostly occur during drenching and transportation of fruit to the cold store. Temperature breaks were mostly evident during inspection and loading. The observations and analysis made, indicated that the export cold chain was well taken care of and that cold chain personnel were responsible for what happens during exportation processes. The areas that were observed to be well preserved were the harvesting, degreening, pack line, cold sterilisation location and the sea leg phases. The areas of the export cold chain where temperature spikes and breaks occurred could be improved further for a more efficient chain. The improvements that can be made to the areas that are lacking in the export cold chain are discussed in the next chapter. 


\section{Chapter 7: Conclusions and Recommendations}

\subsection{Introduction}

The citrus industry contributes substantially to the South African economy through the exportation of fresh navel oranges and other citrus fruits. The catalyst of this study was the fact that there is a growing concern in the citrus industry that there is substantial loss of income due to temperature breaks in the export cold chain. Therefore, the study aimed to identify whether there was an occurrence of temperature breaks in the navel oranges export cold chain. An occurrence of temperature breaks in the cold chain is theoretically known to have an unfavourable effect on the quality of fruit. Therefore, the study additionally aimed to determine if there is a link between fruit quality and temperature breaks. The objectives of the study were developed with the aim to provide an understanding on the export cold chain of navel oranges and the effects of temperature breaks. For the purpose of this study, temperature breaks were identified as "any time temperature increases once the export cold chain process has begun". The definition also had to take into account the cold sterilisation protocols. Therefore, for cold sterilisation protocols a temperature break was defined as “a temperature deviation above $0.0^{\circ} \mathrm{C}$ or below $-1.5^{\circ} \mathrm{C}$ ”. Steri-market protocols stipulate that pulp temperature may vary between $-0.6^{\circ} \mathrm{C}$ to $0.0^{\circ} \mathrm{C}$, but if temperatures exceed $0.0^{\circ} \mathrm{C}$, it is considered a steri-breach and the cold treatment is extended so that temperature is brought back down to $-0.6^{\circ} \mathrm{C}$. If the temperature exceeds $1.1^{\circ} \mathrm{C}$, cold sterilisation treatment is nullified (PPECB, 2012). The objectives of the study were to determine where along the export cold chain of navel oranges is temperature not optimally managed (if anywhere) and to analyse the impact of temperature breaks on the quality of navel oranges. For this purpose, it had to be identified whether temperature breaks do occur or not.

Secondary research was conducted for the purposes of analysing already existing literature. The literature reviewed the basis of a supply chain and the importance of the export cold chain. Temperature breaks, their effects and the importance of fruit quality were also explained. The cold sterilisation protocols along with their effects on navel oranges were discussed. The fresh fruit industry of South Africa and the roles played by cold chain organisations were explained. The literature review also examined international best practices conducted in export cold chains worldwide that could be adopted by the citrus industry of South Africa such as warm ambient loading of fruit, research programmes on citrus trees protection and training programmes for export cold chain personnel. The literature review ended off by exploring previous studies reviewed, which showed 
that temperature breaks do occur due to operational concerns, lack of infrastructure, general lack of knowledge and capacity around the industry. The studies reviewed also revealed that a majority of the breaks occurred in the transportation, storage and port segments.

Qualitative research was conducted, between the months of April and June, through making observations in the various stages of the export cold chain, namely; citrus farms, pack houses, cold stores and the Multipurpose Terminal at the Port of Cape Town. The observations of the navel oranges export cold chain made it clear that protocols were to a large extent followed and role players in the citrus industry understood the importance of maintaining the chain.

Quantitative data was collected during the same period through the use of temperature monitors known as iButtons ${ }^{\circledR}$. iButtons ${ }^{\circledR}$ were probed inside the fruit and some placed amongst the fruit inside cartons. This enabled the researcher to measure temperature as navel oranges moved along the export cold chain until the port of destination. The temperature monitors measured pulp and ambient temperature of navel oranges. Unfortunately, due to poor communication between the exporter and the USDA officials, only $49 \%$ of iButtons ${ }^{\circledR}$ were retrieved by USDA officials, but valuable information was gathered which enabled the data analysis of the study. The data gathered indicated that conventional vessels are able to maintain set temperature; hence there is hardly any temperature breaks recorded in deep-sea leg of the export cold chain.

This chapter presents the conclusions derived from the findings of the study. The conclusions are presented based on the research questions and objectives of the study, to reflect on whether the objectives were achieved and research questions were answered. This chapter also gives recommendations and identifies opportunities for future research.

\subsection{Did the study meet the objectives?}

The primary objective of the study was to identify whether temperature breaks occur along the export cold chain of navel oranges from the Citrusdal region in the Western Cape, South Africa to Philadelphia in the United States of America. Several temperature breaks were identified along the export cold chain during the analysis of data collected in the different phases of the chain. Temperature data analysed was from two conventional vessels exported through the Port of Cape Town.

Temperature breaks were identified during the transportation, drenching, inspection and loading segments. The possible reasons of why temperature is not optimally managed in these stages of the 
export cold chain were discussed in Chapter 6. Therefore, the second objective of the study was also met.

The third objective was to analyse the impact of temperature breaks on the quality of navel oranges. Firstly, it had to be determined whether temperature breaks have an impact on the quality of fruit. This was done through hypothesis testing. Since there were no observable temperature breaks in the data analysed, the analysis failed to reject the null hypothesis. This means the relation between temperature breaks and fruit quality could not be determined.

The factors related to fruit quality were discussed in Chapter 6, which provided possible explanations as to why the quality of fruit may deteriorate. Therefore, all three objectives that the study aimed to address were met.

\subsection{Did the study answer the research questions?}

The main research question that the study aimed to answer is where along the export cold chain of navel oranges were temperature profiles not optimally managed? It was evident from the analysis and observations undertaken that the transportation segment from the pack house to the cold store was not optimally managed. The other stages along the export cold chain where optimal management of the export cold chain is lacking were the drenching, loading and inspection phases. Temperature breaks were also evident during the loading of the two reefer vessels that were analysed in the study. Thus, the study showed that temperature breaks do occur in the different stages of the export cold chain.

The sub-research questions of the study aimed at answering what causes temperature breaks in the cold chain?; how can temperature breaks be minimised?; what impact do these breaks have on the quality of navel oranges? and which best practices can be undertaken to ensure the effective management of temperature along the export cold chain stages? The results of the study showed that the main determinant of temperature breaks was due to exposure to weather elements, for instance, exposure to direct sunlight and high winds during drenching, transportation and loading. Another cause for temperature breaks was the rise in ambient temperature, which affected the pulp temperature of fruit, causing a rise in temperature that resulted in temperature breaks. In addition, during the fruit drenching stages bin liners were not utilised when navel oranges were placed inside bins and left to dry. This could also be noted as a possible contributor to the cause of quality problems since bin liners minimise the level of oleocellosis. The export season also proved to be an abnormal season in terms of weather patterns. This led to difficulties with navel oranges at the start of the cold chain as effects 
of the drought and heat waves experienced in the Citrusdal region resulted in the navel oranges bursting open and dropping from the tree and thus no longer being viable for export.

The question of whether temperature breaks have an effect on fruit quality was answered through the testing of a hypothesis formulated for the study. The Kruskal-Wallis test employed proved that there were no (significant) links between fruit quality and temperature breaks. However, there are factors which influence the quality of fruit, which may be related to low temperatures.

From the results derived during data analysis, it was clear that there is room for improvement in terms of optimal management of the export cold chain. To respond to the last two sub-research questions, the study explored good cold chain best practice guides developed in previous studies undertaken. The aim of the practices developed is to assist the fresh fruit industry in minimising cold chain breaks.

\subsubsection{Exploration of good cold chain practice guides developed in previous studies}

Haasbroek (2013) and Freiboth (2012) developed good cold chain best practice guides to assist in minimising cold chain break incidences and identify areas in the cold chain, which could further be improved. Suggestions were made for each individual stages of the export cold chain. The cold chain best practice guides developed in the previous studies can be adapted and applied in the export cold chain of navel oranges. In the guide developed by Freiboth (2012), a differentiation between unavoidable and avoidable breaks is made. Therefore, the aim is to avoid the breaks that can be avoided and to minimise the occurrences of those that cannot be avoided. Leaving fruit to stand for more than 24 hours after drenching is an example of an avoidable break. For the navel orange cold chain, an example of an unavoidable temperature break is the loading of vessels, which could be minimised through efficient operations.

Both guides suggest that it is crucial for a cold chain to be maintained from the point of harvest as quality starts deteriorating soon after the fruit is harvested from the tree. Fruit has to be harvested during cool hours once the pulp temperature of fruit has decreased after being exposed to the day's heat. Navel oranges are picked at any time of the day as long as it is determined that the fruit is dry. However, picking navel oranges when temperatures are high has been known to increase the Vapour Pressure Deficit (VPD) levels and the occurrence of oleocellosis. Therefore, picking navel oranges once the pulp temperature of fruit has cooled down could help minimise the occurrence of temperature breaks as such incidences can be avoided.

Once navel oranges have been harvested, it is important that they are removed from the orchard into a shaded area. As much as citrus fruits are non-climacteric, meaning the rate of respiration is lower, 
holding them for a long time under high temperatures after harvesting leads to decay producing organisms and fruit may also undergo changes that may render them unattractive. Hence, moving fruit to a sufficiently shaded area would help avoid temperature breaks and also preserve fruit quality. According to the good cold chain best practice guides developed, pack houses tend to be warmer than necessary. Pack house temperatures should be maintained between $18-25^{\circ} \mathrm{C}$. There should be sufficient air cooling systems and temperature monitors placed to continually monitor the temperature. Pack houses utilised for packing navel oranges have fairly shaded areas where fruit is placed before and after degreening. In order to minimise the incidences of exposure to direct sunlight, the areas where fruit is placed before pack line processes start should be fully shaded. Minimising the exposure to direct sunlight minimises the chances of temperature breaks.

The port segment, which proved to have the most temperature breaks, is also addressed in the good cold chain best practice guides. Although it addresses concerns that arise in the container terminal at the Port of Cape Town, some of the suggestions on improvements that can be made can be applied in the Multipurpose Terminal and during the loading of conventional vessels. For instance, fruit should be pre-cooled to optimum temperature before loading. If fruit is not properly cooled, there are higher chances that temperature breaks will occur.

Staging of pallets is another recommended solution. Before pallets are taken out for loading, they could be staged per conventional vessel compartment; this would reduce the amount of time pallets stand outside during loading.

As mentioned, a study conducted by Haasbroek in 2013 found similar results of temperature breaks during the transportation and loading segment. Although, the study conducted by Haasbroek was on fruit shipped through reefer containers. Looking into the different vessels that can be used could help minimise the occurrence of temperature breaks. For instance, conventional vessels are vessels that have compartments in which fruit pallets can be stacked. Conventional vessels carry loads up to 5000 pallets and each deck is individually operated. Conventional vessels can carry loads in their compartments and on-board the deck. The advantages of conventional vessels are its abilities to carry larger loads and have each compartment individually operated, which minimises the chances of income losses. However, container vessels have gained more prominence over the years. Container vessels carry their loads in truck-size intermodal containers, a system known as containerisation. Container vessels carry less loads than conventional vessels, which means they are easier to load. Container vessels require an external power supply for its operation. The disadvantage of container 
vessels is that once the door has been shut after loading, breaking the seal almost guarantees a temperature break (Simpson,2017).

The good cold chain best practices that were developed in previous studies proved to be crucial in putting forth recommendations on the avoidance and minimising of temperature breaks. These best practices can be undertaken to further ensure continued success of the navel orange export cold chain. Therefore, this discussion responded to the last two sub-research questions that this study aimed to answer. It is clear that temperature breaks are to a large extent minimised by role players in the citrus industry. For example, after harvesting, citrus fruits are placed under a shaded area, fruit is cooled to optimum temperature before loading and pallets are staged before loading in reefer vessels.

\subsection{Recommendations}

This section presents possible implications observed during the research study and recommendations that can be implemented to improve the export cold chain of navel oranges.

\section{- $\quad$ Implication 1}

During the drenching phase of the export cold chain, it was observed that navel oranges were left to dry in an open area, with direct exposure to outside weather elements. The analysis conducted proved that the drenching phase was prone to temperature spikes. From the observations made, the export cold chain of navel oranges is likely to experience temperature breaks during this stage as abnormal weather patterns due to global warming such as excessive heat and drought have to be taken into account.

\section{- $\quad$ Recommendation 1}

Since abnormal weather patterns were observed during the course of the year, it would highly be recommended that during drenching, fruit be left to dry under a shaded area. The aim of drenching is to remove field heat, which could lead to moisture loss. If fruit are left to stand in an unshaded area, moisture loss that mostly occurs on the rind of the fruit could be accelerated, thus affecting the quality of navel oranges.

\section{- $\quad$ Implication 2}

The analysis of the study showed that the inspection phase contributed to temperature breaks. Both temperature datasets showed that the inspection phase had breaks in temperature that lasted for longer than two hours. From the analysis and observations made, it appears that temperature breaks will 
continue to occur during the inspection phase of the export cold chain due to factors such placing pallets in unrefrigerated rooms.

- $\quad$ Recommendation 2

The room/area in which pallets are placed once they are taken for inspection is unrefrigerated. Pallets are taken out of a cold room with a set point of $4^{\circ} \mathrm{C}$. An efficient export cold chain has to depict a step down approach, which means that once cooling is applied, there should be no interruptions as this contributes to high chances of temperature breaks occurring. It is recommended that the inspection area be set at the same temperature as pack houses $\left(18^{\circ} \mathrm{C}-25^{\circ} \mathrm{C}\right)$ to avoid a steep rise in temperature while fruit pallets await inspection.

The inspection rate also depends on how fast officials can carry on their duties. During observation of the export cold chain, it was witnessed that only a handful of officials carry out the inspection process. The rate of inspection would possibly be higher if more officials were assigned for inspection of fruit.

\section{- Implication 3}

The study explored the effects of applying sub-zero temperatures during the shipment of fruit. Subzero temperatures are known to cause chilling injury. The link between temperature and the quality of fruit was determined. Fruit quality reports were further analysed to determine the link between the two. According to the fruit reports analysed, cold damage was found to affect fruit, although not by a high percentage. However, the analysis undertaken suggests that chilling injury will continue to occur, which may possibly lead to fruit rejection.

- $\quad$ Recommendation 3

Alternative methods can be used to eradicate pests, which are of phytosanitary concern. Some of the alternative methods that can be applied to reduce the occurrence of chilling injury and still eliminate phytosanitary pests are male annihilation and the sterile insect technique. Male annihilation involves using lures to attract the males of the fruit fly population. This leads to a lower population of male fruit fly species left to fertilise the female population resulting in a gradual decrease of the fruit fly population. Sterile Insect Technique could be used to eliminate FCM. The technique involves massrearing and sterilisation of insects using radiation. The sterile insects are then released, which results in a decline in FCM population. Therefore, it is recommended that these methods be taken into account for the navel orange export cold chain. 


\subsection{Future research studies}

The study addressed the issue of temperature breaks in the export cold chain of navel oranges that are destined to the United States of America, under cold sterilisation protocols. Although the study addressed a range of issues relating to the topic, there still is room for future research studies that can be undertaken. As mentioned, cold sterilisation is known to contribute towards the occurrence of chilling injury, future studies can be conducted on the warm ambient loading of fruit, which is still being explored as an alternative and how that can affect or contribute to the projected income of sterimarkets such as the USA.

A similar research study could be undertaken, which would include temperature data being collected in the pack line phase of the export cold chain. Temperature monitors could be inserted and fruit handled with extra care to eliminate the high risk of temperature monitors falling out.

A study on the export cold chain of navel oranges can be conducted focusing on the collection of temperature data from the point of harvest until the completion of cold store processes. It would be interesting to collect temperature data until the cold store as it is evident that from the sea leg, temperature is kept within required protocols as there are hardly any occurrences of temperature breaks. Measuring temperature from the orchard until the cold store would help reduce the risk of losing temperature monitoring devices, as the researcher would be able to collect the devices themselves rather than relying on USDA officials to return the temperature monitoring devices after they are collected in the USA. Research that focuses on only the measuring temperature from the orchard until the cold store would provide the citrus industry with information that could possibly help to reduce the incidence of temperature spikes and breaks in the initial stages of the cold chain.

It would be interesting to expand the study from only focusing on navel oranges to include all citrus varieties exported from the Western Cape to the USA. In addition, the study could be expanded to include citrus varieties produced in other regions in South Africa as well as citrus fruits that are exported to other steri-markets across the globe. 


\section{Bibliography}

Ahmad M S \& Siddiqui M W. 2015. Postharvest quality assurance of fruits: Practical approaches for developing countries. Springer. Link

Anon., 2017. SA navel export from Eastern Cape possibly 50\% down. Zestfruit, 25 April 2017. Available: http://www.zestfruit.co.za/2017/04/25/sa-navel-exports-from-eastern-capepossibly-50-down/. Date of access: 28 July 2017

Arah, I K., Harrison, A., Kumah E K., \& Ofori, H., 2015. Preharvest and postharvest factors affecting quality and shelf life of harvested tomatoes: A mini review. International Journal of Agronomy. Available: http:// doi:10.1155/2015/478041

Arpaia, M L., 2015. Citrus degreening. Postharvest Technology Center. Available: http://postharvest.ucdavis.edu. Date of access: 20 October 2017

Barth, M M., \& Weston, L A., 1997. Preharvest factors affecting postharvest quality of vegetable. HortScience Journal, 32(5): 812-816

Becker, B R., \& Fricke, B A., 1996. Transpiration and Respiration of Fruits and Vegetables. Science et technique du froid. Available: http://aims.fao.org/serials/c_091fa86

Beukes, H T., 2011. The development of generic simulation model of citrus packing lines. Final year project. Stellenbosch: Stellenbosch University [Online]. Available: http://hdl.handle.net/10019.1/18140

Boyette, M., Wilson, L., \& Estes, E., 2014. Design of room cooling facilities: Structural \& energy requirements. The North Carolina Agricultural Extension Service.

Bryman, B., \& Bell, E. 2045. Business research methods. Oxford University Press

Burns, N., \& Grove, S K., 2003. Understanding nursing research. Philadelphia, PA: W B Saunders Cannon, H.M. (2004). Redesigning the principalship in Catholic Schools. Unpublished Doctoral Thesis. Australia Catholic University.

Chadwick, J., 2009. The South African citrus industry. Post-harvest series learner guide. Citrus Academy. Available: http:// citrusacademy.org.za/learning-tools/learning-media/audiovisual-learning. Date of access: 17 March 2017

Citrus Growers Association of Southern Africa. 2016. 2016 Annual Report. South Africa: Citrus Growers Association

Council of Supply Chain Management Professionals. 2017. Supply chain Definitions. Available: http:// cscmp.org 
Cronje, P., 2017. Research assignment, E-mail to G Khumalo, [Online], 11 May. Available Email:20408463@sun.ac.za

Cronje, P., 2017. Personal Interview. 26 June 2017.

Defraeye T., Cronje P., Verboven P., Opara U L., \& Nicolai B. 2015. Exploring ambient loading of citrus fruit into reefer containers for cooling during marine transport using computational fluid dynamics. Postharvest Biology and Technology, 108: 91-101.

Defraeye T., Nicolai B., Kirkman W., Moore S., van Niekerk S., Verboven P., \& Cronje P. 2016. Integral performance evaluation of the fresh-produce cold chain: A case study for ambient loading of citrus in refrigerated containers. Postharvest Biology and Technology, 112:113.

Department of Agriculture, Forestry and Fisheries. 2015. A profile of the South African citrus market value chain. Available:http://www.nda.agric.za/doaDev/sideMenu/Marketing/Annual\%20Publicatio ns/Commodity\%20Profiles/FRUITS\%20AND\%20VEGETABLES/Citrus\%20market\% 20value\%20chain\%202015.pdf. Date of access: 11 March 2017

Dodd, M., n.d. Cold chain review. Post-harvest series learner guide. Citrus Academy. Available: http:// citrusacademy.org.za/learning-tools/learning-media/audio-visual-learning. Date of access: 17 March 2017

Dreistadt, S.H., 2012. Integrated pest management. Technology and Engineering Journal, 3: 156162

Dwarakish, G S., \& Salim, A M., 2015. Review on the Role of Ports in the Development of a Nation. Aquatic Procedia, 4: 295-301.

Ehlers, J., 2016. Post-harvest rind pitting studies on 'Valencia' orange. Published Master's Thesis. Stellenbosch: Stellenbosch University [Online]. Available: http://scholar.sun.ac.za/handle/10019.1/98751

Eisehardt, K M., 1989. Building theories from case study research. Academy of Management Review, 14(4):532-550

Fisher, M J., \& Marshall, A P., 2009. Understanding descriptive statistics. Australian Critical Care, 22(2):93-97 
Freiboth, H. W., 2012. Best practice operational procedures for the South African fruit export cold chain from the pack house to the vessel. Published Master's Thesis. Stellenbosch: Stellenbosch University [Online].

Freiboth, H.W., Goedhals- Gerber, L.L., Van Dyk, F.E. \& Dodd, M.C., 2013. Investigating temperature breaks in the summer fruit export cold chain: A case study. Journal of Transport and Supply Chain Management 7(1), Available: http://dx.doi. org/10.4102/jtscm.v7i1.99

Fresh Fruit Trade SA. 2017. Department of Agriculture, Forestry \& Fisheries. Available: http://www.nda.agric.za/doaDev/sideMenu/internationalTrade/docs/tradeFacilitation/fts a-latestjj.pdf

Fresh Produce Terminals. 2017. Available: http://Fresh Produce Terminals. Cape Town.

Fundira, T., 2004. A transaction cost analysis of the fruit supply chain in South Africa: a case study approach. Published Master's Thesis. Stellenbosch: Stellenbosch University [Online]. Available: http://hdl.handle.net/10019.1/49864

Geisel, P M., \& Unruh, C L., 2003. Frost protection and other subtropicals. University of California. Available: http://anrcatalog.ucdavis.edu.

Goedhals-Gerber, L.L., 2016. The composite supply chain efficiency model: a case study of the Sishen-Saldanha supply chain. Journal of Transport and Supply Chain Management, 10: $1-13$

Goedhals-Gerber, L. L., Stander, C. \& Van Dyk, F. E., 2017. Maintaining cold chain integrity: Temperature breaks within fruit reefer containers in the Cape Town container terminal, South African Business Review, 21: 362-384

Goedhals-Gerber, L.L., Haasbroek, L., Freiboth, H. \& Van Dyk, F.E., 2015. An analysis of the influence of logistics activities on the export cold chain of temperature sensitive fruit through the Port of Cape Town. Journal of Transport and Supply Chain Management 9(1), Available: http://dx.doi. org/10.4102/jtscm.v9i1.201

Goedhals, L.L., 2003. Fruit export from South Africa after deregulation-changes required to the infrastructure and supply chain. Published Master's Thesis. Stellenbosch: Stellenbosch University [Online].

Goble. T., 2009. Investigation of entomopathogenic fungi for control of false codling moth, Thaumatotibia leucotreta, Mediterranean frui fly, Ceratitis capitate and Natal fruit fly, 
C.rosa in South African citrus. Published Master's Thesis. Rhodes: Rhodes University. Available: http://hdl.handle.net/10962/d1005409

Haasbroek, L M., 2013. An analysis of temperature breaks in the summer fruit export cold chain from pack house to vessel. Published Master's Thesis. Stellenbosch: Stellenbosch University [Online]. Available: http://hdl.handle.net/10019.1/85676

Hagenmaier, R D., \& Baker, R A., 2004. Quality of fresh and processed foods. Boston: Springer

Hattingh, V., Le Roux, H., \& Schutte, G C., 2000. Citrus Black Spot: Pest risk assessment document for the review of current phytosanitary regulations pertaining to the export of fresh citrus from the Republic of South Africa to the EU, Report. Submitted to the Agriculture Commission of the European Communities by the South African National Department of Agriculture, Directorate Plant Health and Quality.

Heilbron, S., 2016. Inspections-PPECB. Module 33. Citrus Academy [Online], Available: http://www.citrusacademy.org.za/learning/learning/audio-visual-learning/citruspostharvest-series/citrus varieties. Date of access: 12 June 2017.

Henning, B., 2018. Personal Interview. 09 February 2018.

Hewett, E., 2006. An overview of preharvest factors influencing postharvest quality of horticultural products. Journal of Postharvest Technology and Innovation, 1(1):4-15

Hordjik, J., 2013. Studies to reduce the incidence of chilling injury in Navel orange fruit. Published Master's Thesis. Stellenbosch: Stellenbosch University [Online]. Available: http://scholar.sun.ac.za/handle/10019.1/80254

Jackman, R L., Yada, R Y., Parkin, K L., \& Stanley, D W., 1998. Chilling injury: A review of quality aspects. Journal of Food Quality, 11(4):253-278

Jobling, J., 2009. Correct cool chain management is essential for all fruit and vegetables. Sydney Postharvest Laboratory Information Sheet [Online]. Available: http// postharvest.com.au. Date of access: 23 June 2017

Ketchen, D J., \& Hult, G T M., 2006. Bridging organization theory and supply chain management: The case of best value supply chains. Journal of Operations Management, 25: 573-580.

Khumalo, N P., 2006. Factors affecting post-storage quality of 'nules clementine' mandarin fruith with special reference to rind breakdown. Published Master's Thesis. Stellenbosch. Stellenbosch University [Online]. 
King, N., 2014. Spain is the Mediterranean orange producer most dependent on exports. Fresh Plaza, 28 November. Available: http://www.freshplaza.com/article/131506/Spain-is-theMediterranean-orange-producer-most-dependent-on-exports. Date of access: 28 July 2017

Kothari, C R., 2004. Research methodology: Methods and techniques. New Delhi: New Age International.

Ladaniya, M S., 2008. Citrus Fruit Biology, Technology and Evaluation. Academic Press.

Lee, A., 2016. Citrus Varieties. Module 3. Citrus Academy [Online], Available: http://www.citrusacademy.org.za/learning/learning/audio-visual-learning/citruspostharvest-series/citrus varieties. Date of access: 22 May 2017

Lesar, K., 2017.Packhouse process flow: Module 15. Citrus Academy [Online], Available: http://www.citrusacademy.org.za/learning-tools/learning/audio-visual-learning/citruspostharvest-series. Date of access: 22 May 2017

Liphadzi, K., 2015. SA fruit industry: trends and prospects. CGA Citrus Summit. Limpopo. (1112 March)

Liphadzi, K., 2017. Overview of the South African fruit industry. Fruit South Africa [Online]. Available: $\quad$ http://www.fruitsa.co.za/wp-content/uploads/2017/07/Fruit-IndustryOverview-.pdf. Date of access: 05 February 2018

Lu, S., Gu, Y., \& Predko, R., 2015. How to assess risks in weak links in cold chain distribution process? Published Master's Thesis. Linneuniversitetet. Sweden. Available: http:// lnu.diva-portal.org/smash/record.jsf?pid=diva2:873192.

Mabatha, N., 2012. The cascade of physiological events leading to chilling injury: The effect of post-harvest hot water and molybdenum applications to lemon (Citrus Limon) fruit. Published Doctoral Thesis. Pietermaritzburg: University of Kwazulu Natal

Mafuwane, B M., 2011. The contribution of instructional leadership to learner performance. Published Doctoral Thesis. Pretoria: University of Pretoria.

Malan A P., Knoetze R., \& Moore S D. 2011. Isolation and identification of entomopathogenic nematodes from citrus orchards in South Africa and their biocontrol potential against false codling moth. Journal of Invertebrate Pathology, 108: 115-125. 
Marques, R., Falivene, S., Creek, A., \& Spohr, L., 2015. Assessing variability in navel orange fruit maturity. Department of Primary Industries: NSW Government. Available: http:// https://www.dpi.nsw.gov.au/agriculture/horticulture/citrus/citrusconnect/2015_08_citrusconnect_articles/assessing-variability-in-navel-orange-fruitmaturity

Mashabela T E. 2007. Measuring the relative competitiveness of global deciduous fruit supply chains: South Africa versus Chile. Published Master's Thesis. Stellenbosch. Stellenbosch University [Online].

Matare T E. 2012. Postharvest losses and changes in physico-chemical properties of fruit (peaches, pears and oranges) at retail and during post-purchase storage. Published Master's Thesis. Stellenbosch. Available: http://hdl.handle.net/10019.1/71974

Mathaba N. 2012. The cascade of physiological events leading to chilling injury: The effect of post-harvest hot water and molybdenum applications to lemon (citrus limon) fruit. Published Doctoral dissertation. University of Kwa-Zulu Natal.

Mayuoni, L., Tietel, Z., Patil, B S., \& Porat, R., 2011. Does ethylene degreening affect internal quality of citrus fruit? Postharvest Biology and Technology 62(1):50-58

McGlashan J., Cronje P., \& Defraeye T. 2017. Guidelines for pre-cooling of citrus fruits for intransit cold treatment in containers. Citrus Research International.

McGlasson, W.B., Scott, K.J., \& Mendoza, Jr D.B., 1979. The refrigerated storage of tropical and subtropical products. International. Journal of. Refrigeration. 2: 199-206.

Mditshwa, A., 2012. The potential of post-harvest potassium silicate dips to mitigate chilling injury on citrus fruits. Published Master's Thesis. Pietermaritzburg: University of KwaZulu-Natal.

Montanari R. 2008. Cold chain tracking: a managerial perspective. Trends in Food Science \& Technology, 19: 425-431. Available: http:// doi:10.1016/j.tifs.2008.03.009

Muller, C., 2016. Drenching. Module 16. Citrus Academy [Online], Available: http://www.citrusacademy.org.za/learning/learning/audio-visual-learning/citruspostharvest-series/drenching. Date of access: 19 May 2017 
Negi S. \& Anand N. 2015. Cold Chain: A Weak Link in the Fruits and Vegetables Supply Chain in India. IUP Journal of Supply Chain Management, 12(1): 48-62. Available: http://web.b.ebscohost.com.ez.sun.ac.za

Nel D. 2017. Data analysis, Email to G Khumalo [Online], 18 September 2017. Available, Email: 20408463@sun.ac.za

Ndou P. 2012. The competitiveness of the South African citrus industry in the face of the changing global health and environmental standards. Published doctoral dissertation. Alice: Seals.

Ntshangase T., Phaleng L. \&Potelwa Y. 2016. South African fruit trade flow. National Agricultural Marketing Council. [Electronic], (22) Available: http://www.namc.co.za/upload/South-African-Fruit-Trade-Flow-June2016-Issue-22.pdf

Ortmann F G. 2005. Modelling the South African fresh fruit export supply chain. Published Master's Thesis. Stellenbosch. Stellenbosch University [Online].

Oxford Dictionary: Oxford living dictionaries [Online]. [n.d.]. Available: https://en.oxforddictionaries.com/definition/temperature. Date of access: 24 November 2017.

Polit, D F., Beck, C T., \& Hungler, B P., 2001. Essentials of nursing research- methods, appraisal and utilisation. Philadelphia: Lippincott

Porat, R., 2008. Degreening of citrus fruits.Tree and Forestry and Biotechnology (2): 71-76

Potelwa, Y., Moobi M. \& Ntombela S. 2014. South African fruit trade flow. National Agricultural Marketing Council. [Electronic], (15) Available: http://www.namc.co.za/upload/SouthAfrican-Fruit-Trade-Flow-September-2014-Issue-15.pdf

Potelwa, Y. 2016. Beautiful country, beautiful fruit. South African Fruit Trade Flow. Issue 6.

Potgieter, L., 2016. Risk profile of port congestion: Cape Town Container Terminal case study. Unpublished Master's Thesis. Stellenbosch. Stellenbosch University.

PPECB. 2013. PPECB Blue Book. Available: http://PPECB.com

PPECB. 2017. PPECB online. Available: http:// PPECB.com

Rodrigue J P \& Notteboom T. 2013. The cold chain and its logistics. The Geography of Transport Systems. Available: https://people.hofstra.edu/geotrans/eng/ch5en/appl5en/ch5a5en.html Ross, D. F., 1998. Competing through supply chain management. Boston: Springer Link 
Roxburgh K. 2017. Research assignment, E-mail to G Khumalo, [Online], 20 Mar. Available Email:20408463@sun.ac.za

Saunt J. 2000. Citrus varieties of the world. Sinclair International Limited. Norwich, England.

Scwardt, T A., 2007. The SAGE dictionary of qualitative inquiry. University of Illinois.

Sinha, R., 2017. Granulation: A major threat in citrus production. Biotech Article, 17 February 2017. Available: http://www.bioarticles.com/Granulation-a-major-threat-in-citrus. Date of access: 28 November 2017

South African Maritime Authority. 2014. Ports of South Africa. South African Maritime Authority online. Available: http:// samsa.org.za. Date of access: 22 June 2017.

Spreen, T H., 2010. Projections of world production and consumption of citrus to 2010. FAO corporate document repository. China/FAO symposium. Available: http://www.fao.org/docrep/003/x6732e/x6732e02.htm

Stander, O P J., 2013. Fruit split and fruit studies on citrus. Published Master's Thesis. Stellenbosch. Stellenbosch University [Online]. Available: http://hdl.handle.net/10019/7933

Stander, C., 2014. The handling of fruit reefer containers in the Cape Town container terminal. Published Master's Thesis. Stellenbosch. Stellenbosch University [Online].

Stotter R L. 2009. Spatial and temporal distribution of False Codling Moth across landscapes in the Citrusdal area (Western Cape Province, South Africa). Published Master's Thesis. Stellenbosch. Stellenbosch University [Online].

Strano, M C., Altieri, G., Admane, N., Genovese, F., \& Di Renzo G C., 2017. Advance in Citrus Postharvest Management: Diseases, Cold Storage and Quality Evaluation, Citrus Pathology, Dr. Harsimran Gill (Ed.), InTech, DOI: 10.5772/66518. Available from: https://www.intechopen.com/books/citrus-pathology/advance-in-citrus-postharvestmanagement-diseases-cold-storage-and-quality-evaluation

Terblanche J S., Addison P., Nyamukondiwa C., \& Manrakhan A. 2012. Factors influencing the distribution of Medfly and Natal fly in South Africa: current research status. SA Fruit Journal, 24 May. 
Thompson, J. F., Rumsey, F. G., Kasmire, R. F. \& Crisosto, C. H., 2008. Commercial Cooling of Fruits, Vegetables, and Flowers. Revised ed. Oakland: University of California Agriculture and Natural Resources.

Transnet National Ports Authority. 2017. Transnet National Ports Authority online. Available: http:// transnetnationalportsauthority.net

Truter M. 2010. Epidemiology of citrus black spot disease in South Africa and its impact on phytosanitary trade restrictions. Published doctoral thesis. Pretoria: University of Pretoria.

Umeh, V C., Olaniyan, A A., Ker, J., \& Andir, J., 2004. Development of citrus fruit fly control strategies for small-holders in Nigeria. Fruits, International Journal of Tropical \& subtropical Horticulture, 59(4):265-274

United States International Trade Commission. 2006. Conditions of competition for certain oranges and lemons in the U.S. fresh market. Washington DC. USITC publication.

Valverde C. 2016. Spain's citrus report. USDA Foreign Agricultural Service. Gain Report.

Van Niekerk, N. 2017. Research assignment, E-mail to G Khumalo, [Online], 15 June 2017. Available E-mail: 20408463@sun.ac.za

Wacker, C O., 2016. Supply management and procurement at a South African FMCG company: A practical example of developing a decision support tool for managing direct material cost. Published Master's Thesis. Stellenbosch. Stellenbosch University [Online].

Wegner, T., 2012. Applied business statistics, $3^{\text {rd }}$ Edition. Juta Academic.

Zikmund, W.G. and Babin, B.J. 2010. Exploring Marketing Research, $10^{\text {th }}$ Edition. SouthWestern Cengage Learning 


\section{Appendices}

1. The export cold chain process
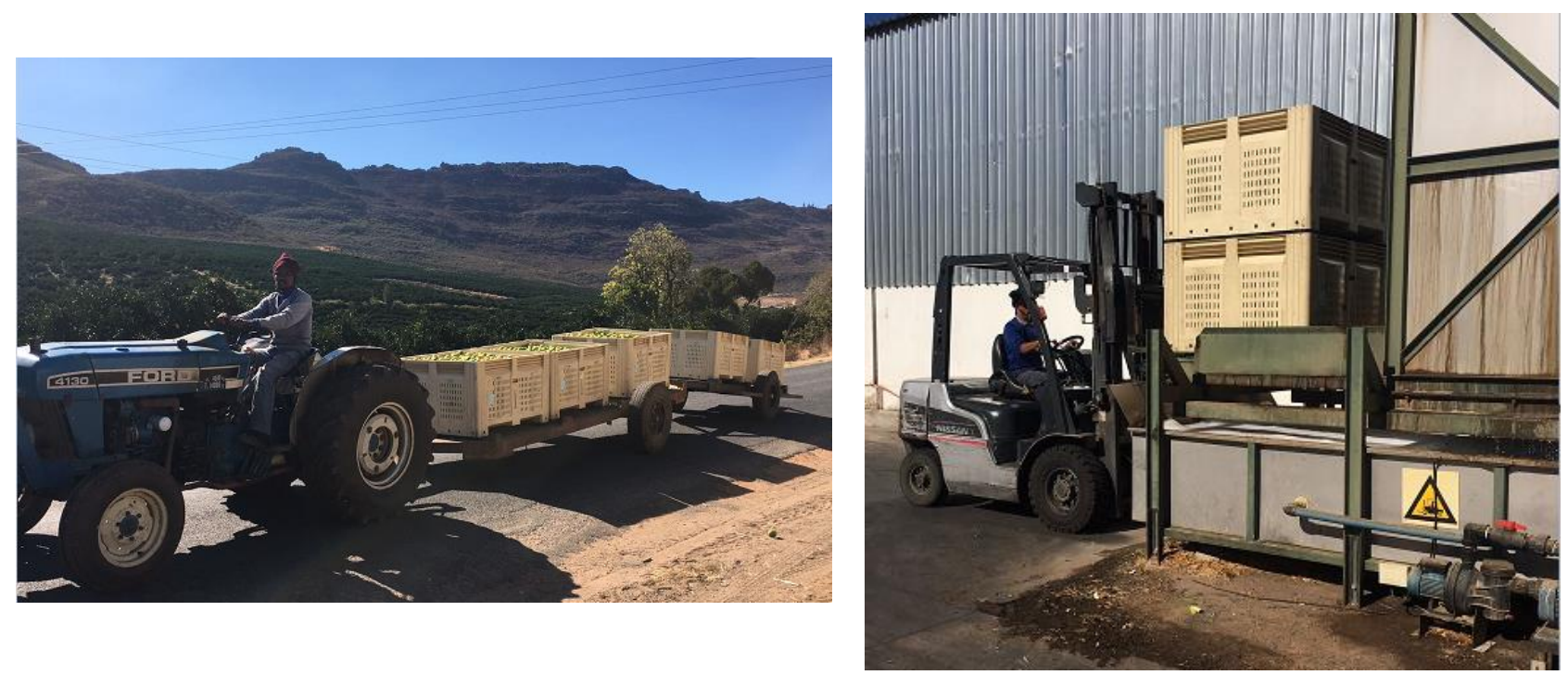

Tractors after harvesting

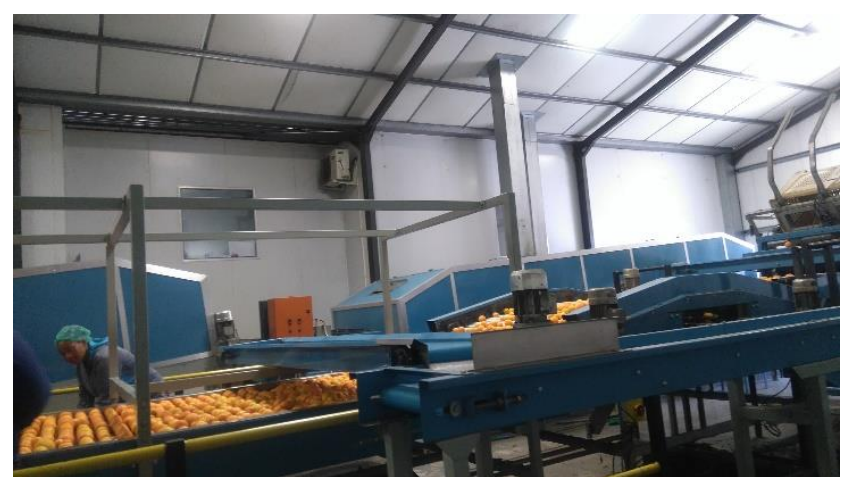

Pack line segment

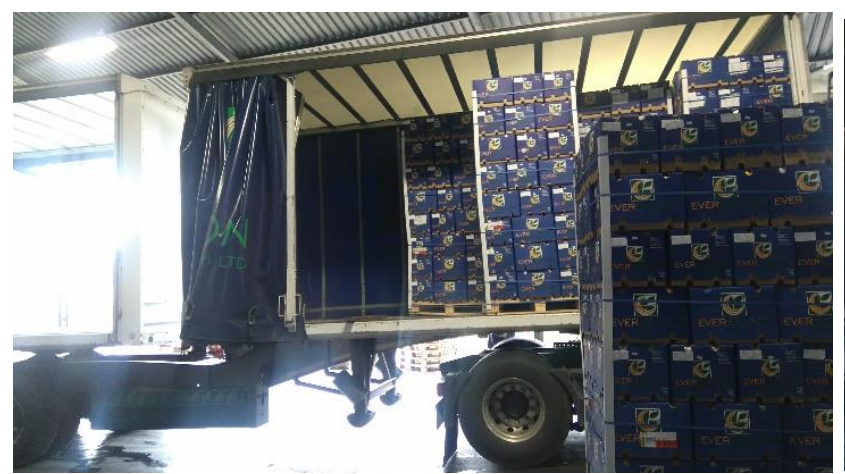

Transportation
The drenching process

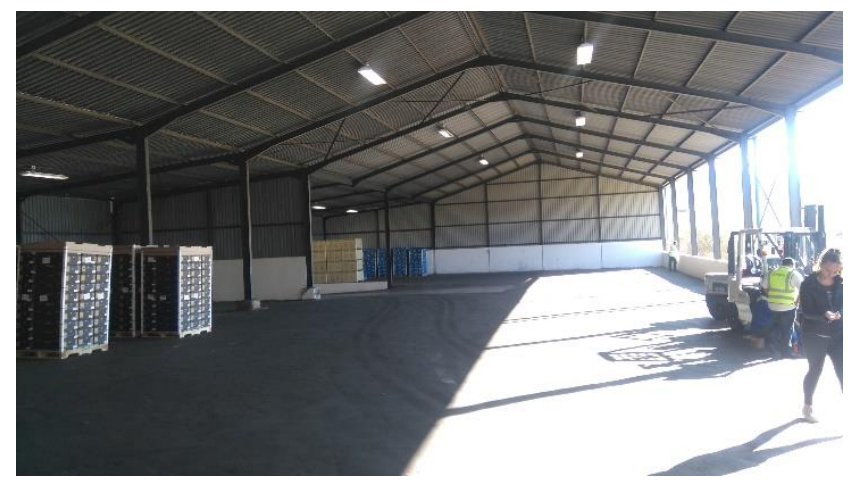

Palletisation

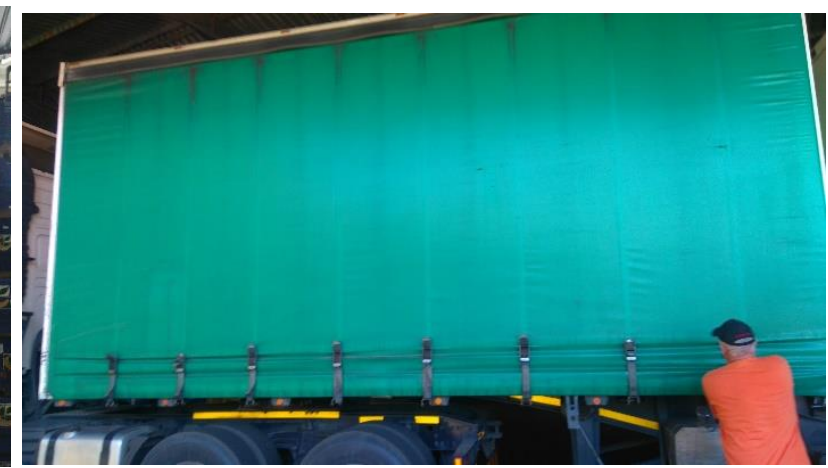

Tautliner truck 


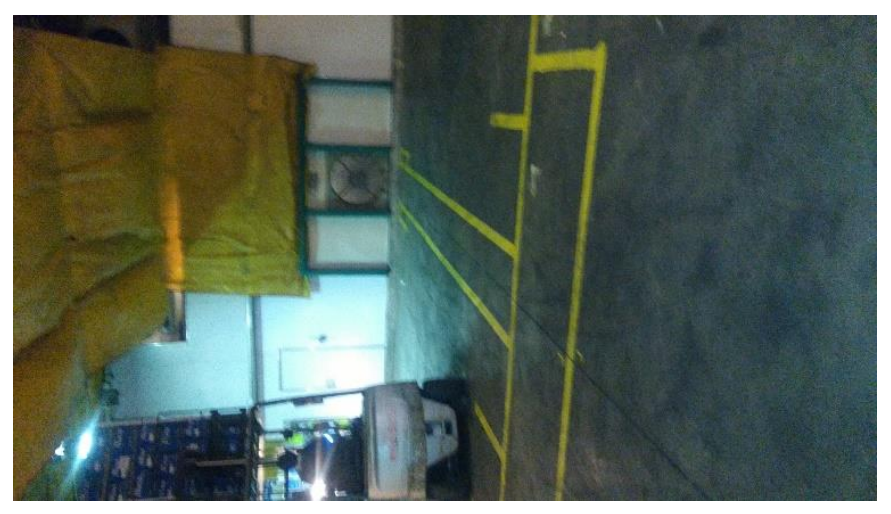

\section{Cold storage}

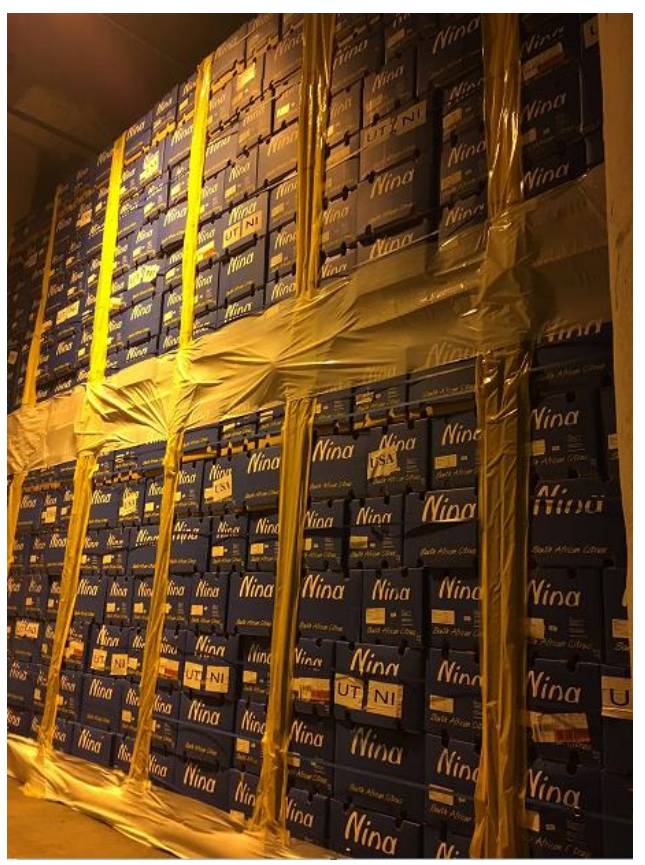

Cold storage

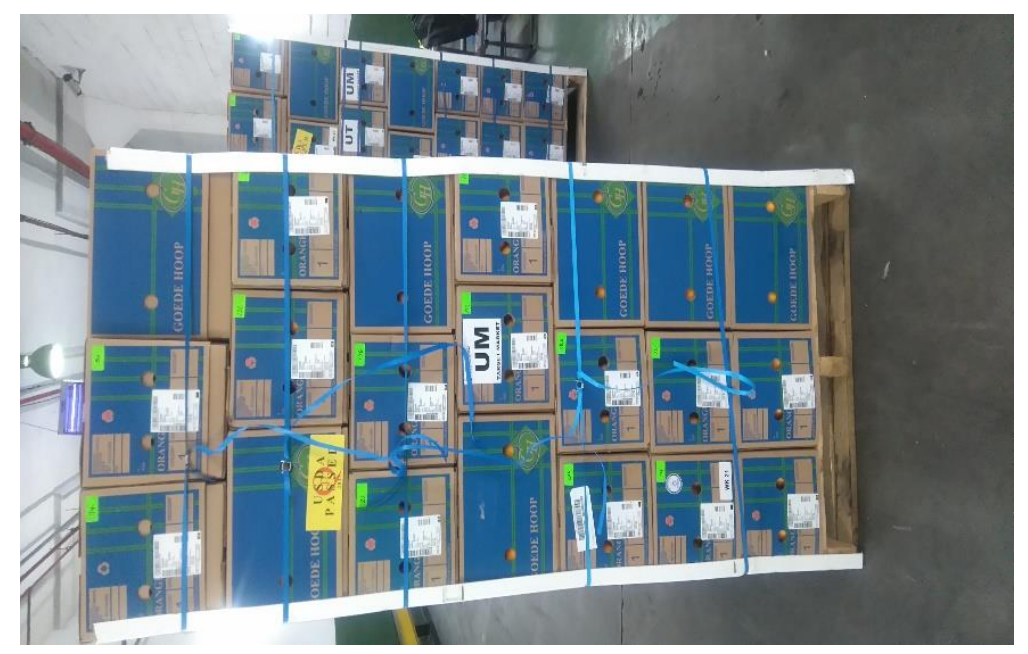

Inspection

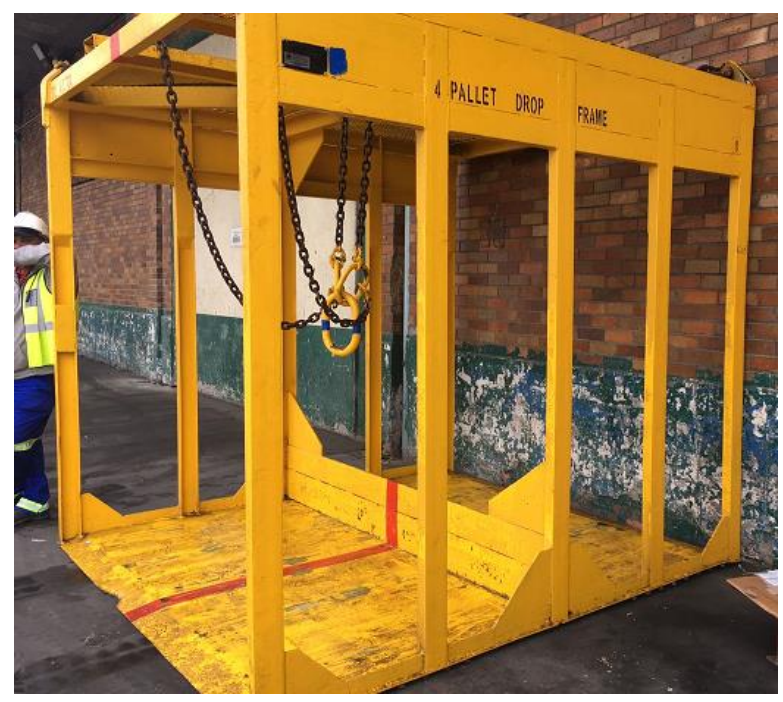

Stevedore pallet loader

Forklift during loading 


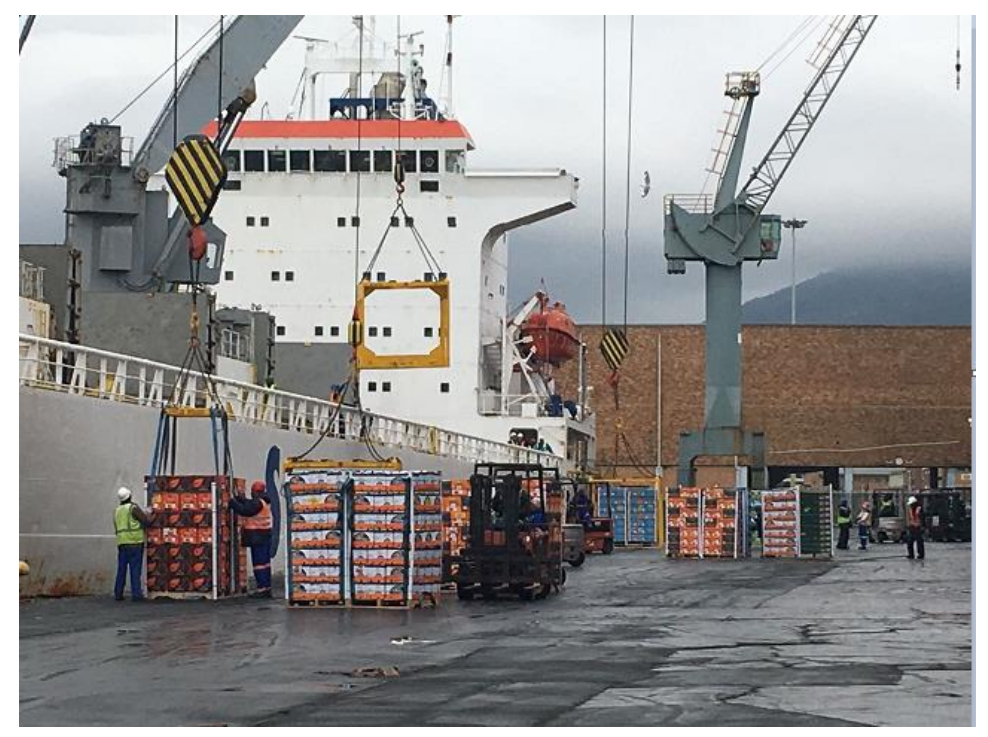

Loading of conventional vessel 
2. $\quad$ Fruit Quality Tolerances

\section{EXPORT STANDARDS AND REQUIREMENTS: PART 4: CITRUS (USA)}

Page 159

1999-15

\begin{tabular}{|c|c|c|}
\hline \multicolumn{3}{|c|}{$\begin{array}{l}\text { Citrus type: Oranges } \\
\text { Cultivar: Navels and Navelates }\end{array}$} \\
\hline No. & Quality Factor & Class 1 \\
\hline 1 & Decay & $1,5 \%$ \\
\hline 2 & Factors that may cause decay. & \\
\hline 2(a) & Major injuries & \\
\hline (i) & First inspection & $1 \%$ \\
\hline (ii) & Second/fruit age inspection & $2 \%$ \\
\hline (iii) & Water saturation & $2 \%$ \\
\hline 2(b) & Minor injuries & $4 \%$ \\
\hline 2(c) & Skin weakness & $2 \%$ \\
\hline 2(d) & 2(a) and 1 collectively & $3 \%$ \\
\hline $2(e)$ & $2(a, b, c)$ and 1 & $5 \%$ \\
\hline 3 & Greening disease & $2.5 \%$ \\
\hline 4 & Superficial black fungus growth & $2.5 \%$ \\
\hline 5 & Granulation & \\
\hline 5(a) & Major granulation & $2 \%$ \\
\hline $5(b)$ & Minor granulation & $50 \%$ \\
\hline 6 & Scale & $4 \%$ \\
\hline 7 (a) & $\begin{array}{l}\text { Blemishes, dirty fruit, wilt, shriveling, skin defects, malformation, } \\
\text { bruises, underdeveloped or out of season, overripeness, hailmarks } \\
\text { and foreign matter }\end{array}$ & $4 \%$ \# \\
\hline 7 (b) & $\begin{array}{l}\text { Oleocellosis and progressive defects including but not limited } \\
\text { to stem end browning, rind pitting, rind breakdown and } \\
\text { anthracnose }\end{array}$ & $5 \%$ \\
\hline 8 & Long stems & $4 \%$ \\
\hline 11 & Absence of buttons & $20 \%$ \\
\hline 12(a) & Container and packing requirements & $10 \%$ \\
\hline 12 (b) & Incorrectly sealed flaps (excluding loose flaps) & $5 \%$ \\
\hline 12 (c) & Loose flaps & Not allowed \\
\hline 13(a) & Minimum diameter (too small) & $10 \%$ \\
\hline 13(b) & Lack of uniformity in size in the same container & $10 \%$ \\
\hline 14 & Deviations from prescribed marking requirements & $0 \%$ \\
\hline 15 & Unpunched out ventilation holes & $4 \%$ \\
\hline 16(a) & $\begin{array}{l}\text { Deviations not specified in inems } 1 \text { to } 7 \text { of this table collectively. that } \\
\text { affect the exterior appearance of the fruit }\end{array}$ & $10 \%$ \\
\hline 16(b) & 16(a), 1-7 Collectively, excluding 5 (b) & $10 \%$ \\
\hline 17 & internal quality & \\
\hline 17.1 & Minimum juice content & $46 \%$ \\
\hline 17.2 & "Brix: Acid Ratio & $9.1: 1$ \\
\hline 17.3 & Minimum acid\% & 0.75 \\
\hline 17.4 & Maximum acid\% & $1.5^{*}$ \\
\hline 17.5 & "Brix & $10^{\circ} \mathrm{B}$ \\
\hline 17.6 & Limit for Seed Content & 0 \\
\hline 18 & Minimum colour\$ & \\
\hline 18.1 & Set no. 34 & $\begin{array}{c}\text { print no. } 2 \text { with a } 10 \% \\
\text { tolerance to print no. } 3 \\
\text { only" }\end{array}$ \\
\hline
\end{tabular}


3. Fruit quality trouble reports and rejected fruit

\begin{tabular}{|c|c|}
\hline \multicolumn{2}{|c|}{ NON - COMPLANT PRODUCT REPORT - VESSEL } \\
\hline Exponter. & Company $X$ \\
\hline Labet: & OS \\
\hline Grower: & 'R1011 \\
\hline Product (Species, Variety, Size): & Oranges, Navels, 64, 72, 88 \\
\hline Package Type: & $A 15 C$ \\
\hline Inspection Temperature: & $31-32 \mathrm{~F}$ \\
\hline Arriving Vessel Name / Number. & \#531-\# 221480 Amazonas \\
\hline Date of Vessel Arrival: & 72512 \\
\hline Date of Inspection: & 727712 \\
\hline Date of NC Report & 73012 \\
\hline Number of Cases of Non-Complant Product & 3780 \\
\hline Number of Samples Inspected: & 13 \\
\hline Palet Numbers of Non-Complant Product & See Pallet ID \\
\hline Insurance Claim Required? & No \\
\hline Reason for Non-Complant & Undersize, Underweight \\
\hline Code: & UNDERSIZE, UNDERWEIGHT \\
\hline Notes: & $\begin{array}{l}\text { Undersize: } 22-40 \% \\
\text { Underweight: } 12.8-14.8 \mathrm{Kg} \\
\text { Soft Fruit: Up to } 13 \% \\
\text { Cold Damage:Up to } 11 \%\end{array}$ \\
\hline Production Number: & Q6840 \\
\hline Digtals (YNN): & Y \\
\hline File Number (assigned by QC Department): & USC_LM_001 \\
\hline Verfied: & Gore Vidal. \\
\hline
\end{tabular}




\begin{tabular}{|c|c|}
\hline \multicolumn{2}{|c|}{ NON - COMPLIANT PRODUCT REPORT - VESSEL } \\
\hline Exponter: & Company $X$ \\
\hline Label: & OS \\
\hline Grower: & A0094 \\
\hline Product (Species, Variety, Size): & Oranges, Navels, 40, 48, 56, 64, 72, 88 \\
\hline Package Type: & $A \bar{C} C$ \\
\hline Inspection Temperature: & $31-32 \mathrm{~F}$ \\
\hline Arriving Vessel Name / Number. & \#523-\# 221328 MSC Carla \\
\hline Date of Vessel Arrival: & Eา912 \\
\hline Date of inspecion: & Q2012 \\
\hline Date of NC Report & 7,0212 \\
\hline Number of Cases of Non-Compliant Product. & 1520 \\
\hline Number of Samples Inspected: & 18 \\
\hline Pallet Numbers of Non-Compliant Product & See Pallet ID \\
\hline Insurance Claim Required? & No \\
\hline Reason for Non-Complant. & Green Color \\
\hline Code: & GREEN \\
\hline Notes: & \\
\hline Producton Number: & Q66138 \\
\hline Digtals $(\mathrm{Y} / \mathrm{N})$ : & $\mathrm{Y}$ \\
\hline Fle Number (assigned by $\propto$ C Deparment): & USC_CA_001 \\
\hline Vertied: & Gore Vid \\
\hline
\end{tabular}



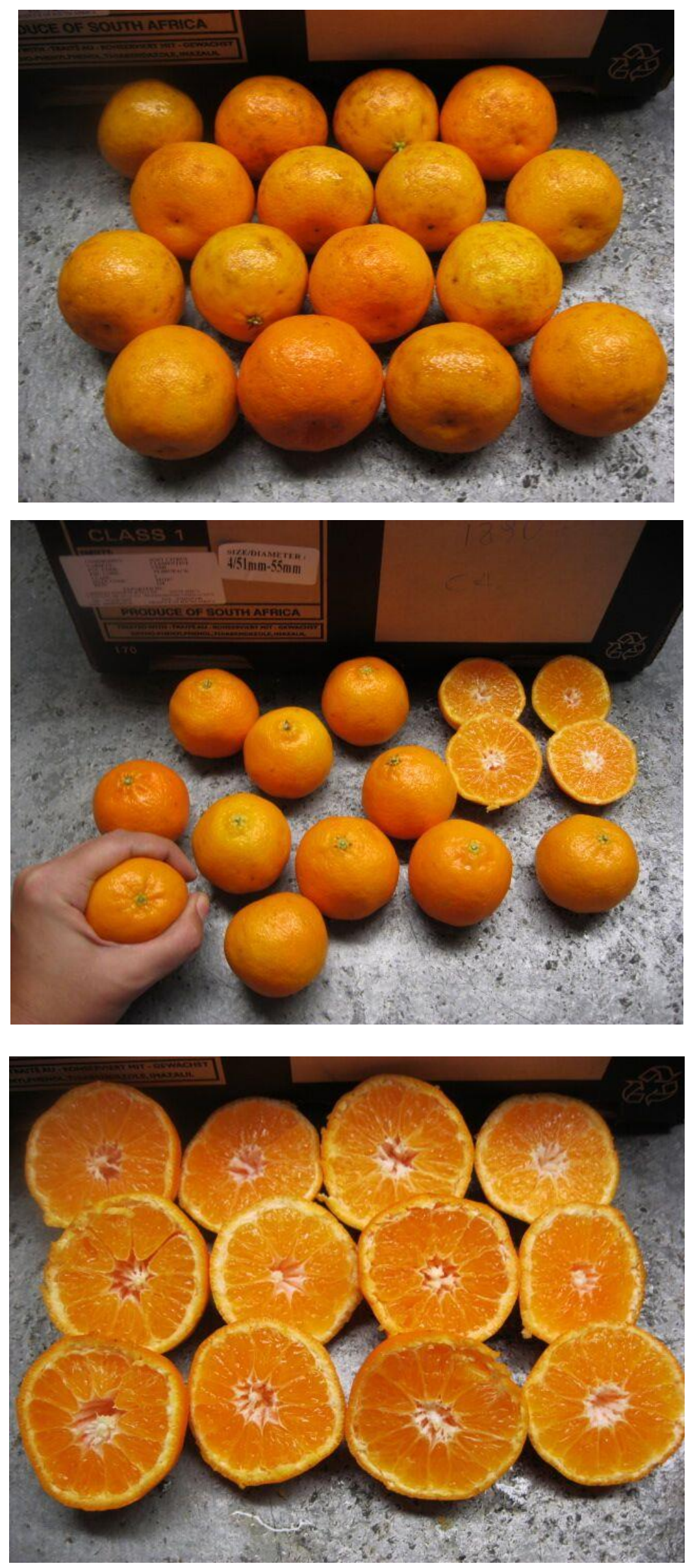


\section{Loading scheduling and processes}

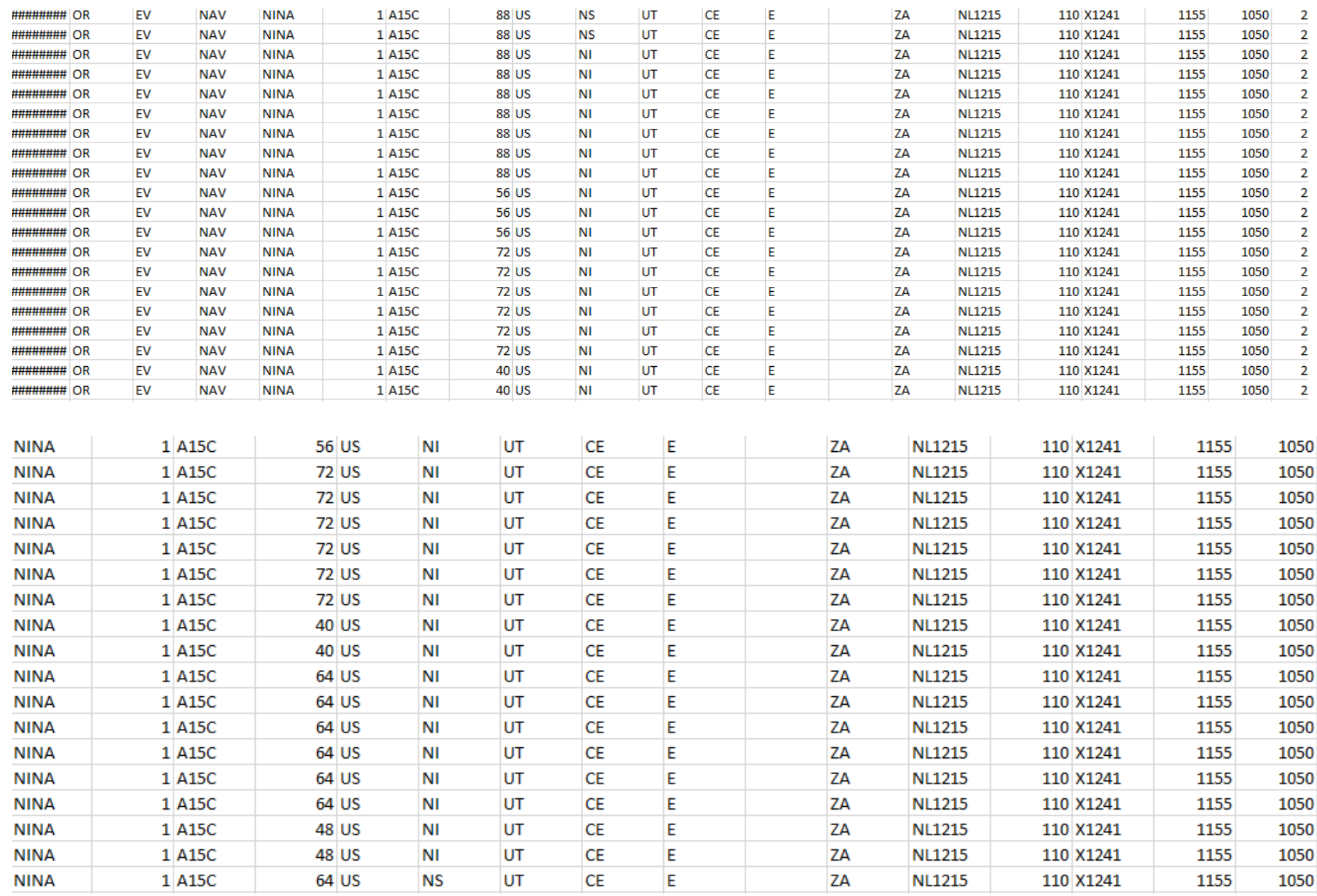




\section{PPECB yellow card}

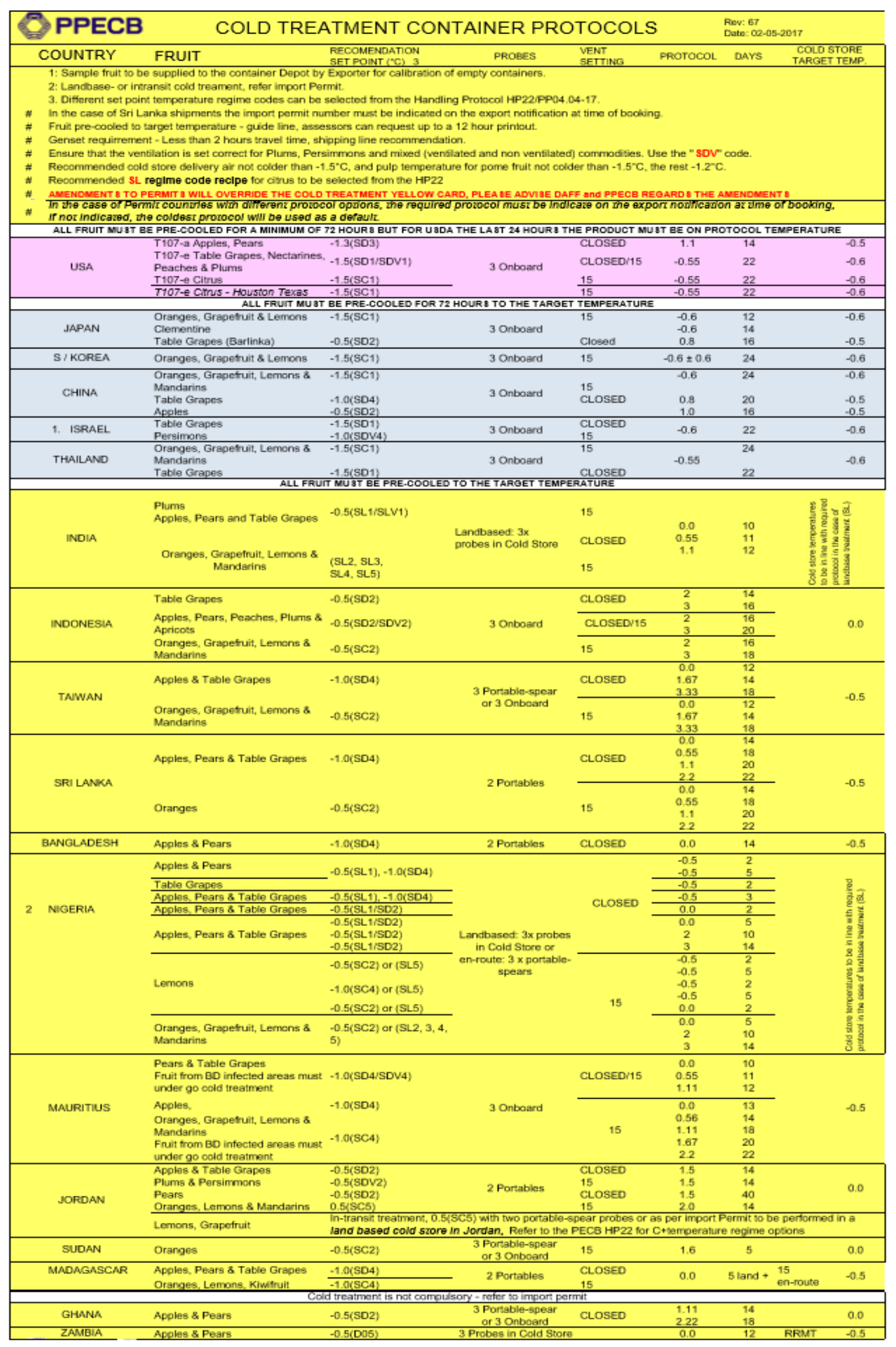

